\title{
PROPRIEDADES FÍSICO-HÍDRICO-MECÂNICAS DE UM LATOSSOLO ROXO, SOB DIFERENTES SISTEMAS DE USO E MANEJO
}

\author{
VILSON ANTONIO KLEIN
}

Engenheiro Agronômo

Orientador: Prof. Dr. PAULO LEONEL LIBARDI

Tese apresentada à Escola Superior de Agricultura "Luiz de Queiroz", Universidade de São Paulo, para obtenção do título de Doutor em Agronomia. Área de Concentração: Solos e Nutrição de Plantas.

P I R A C I C A B A

Estado de São Paulo - Brasil

Dezembro - 1998 
Dados Internacionais de Catalogação na Publicação (CIP) DIVISĀo DE BIBLIOTECA E DOCUMENTAÇĀO - Campus "Luiz de Queiroz"/USP

Klein, Vilson Antonio

Propriedades fisico-hídrico-mecânicas de um latossolo roxo, sob diferentes sistemas de uso e manejo / Vilson Antonio Klein. - Piracicaba, 1998.

$150 \mathrm{p}$.

Tese (doutorado) - Escola Superior de Agricultura Luiz de Queiroz, 1998. Bibliografia.

1. Condutividade hidráulica do solo 2. Compactaçao do solo 3. Densidade do solo 4. Física do solo 5. Infiltração 6. Porosidade do solo 7. Resistència a penetração I. Titulo 
A memória do meu pai, Osvino Klein, um grande homem,

OFEREÇO.

Com minha mãe Elma Cecilia e meus irmãos Maria Hilária, Ivo Aloísio, Imelda Maria, Otávio José, Terezinha Maria, Celso Inácio, Neiva Maria e Ivania Maria,

COMPARTILHO.

À minha querida esposa Ciloe Maria pela compreensão, apoio e amor em todos os momentos e aos meus filhos Karen e Arthur fonte de inspiração,

DEDICO. 


\section{AGRADECIMENTOS}

À Deus pela vida e saúde.

À Universidade de Passo Fundo, pela oportunidade de realização deste curso.

À Escola Superior de Agricultura "Luiz de Queiroz" pelo curso e pelo acolhida.

À CAPES, através do Plano Institucional de Capacitação Docente e Técnica (PICDT), pela bolsa de estudos concedida.

Ao Professor Dr. Paulo Leonel Libardi, verdadeiro orientador em todas as etapas do curso, pela amizade e convívio.

À Prefeitura Municipal de Guaíra - SP pelo apoio durante as atividades de campo, com a cessão da infra-estrutura do CEPAR, imprescindível para a realização deste trabalho.

Ao Maurício Sakai, um dos proprietários da Fazenda Lagoa do Fogão, pela permissão de uso da área e por todo apoio sem os quais este trabalho não poderia ter sido realizado.

Aos Professores Sérgio de Oliveira Moraes, Klaus Reichardt, Quirijn de Jong Van Lier e Álvaro Pires da Silva da ESALQ pelo prazer do convívio e pelas contribuições a este trabalho.

Ao Professor Dr. Walter Boller, da Faculdade de Agronomia e Medicina Veterinária da Universidade de Passo Fundo, meu procurador, por todo apoio. 
Ao Professor Orêncio Vilar e ao técnico de Laboratório Zé Luiz, do Departamento de Geotecnia da Escola de Engenharia de São Carlos pela oportunidade da utilização do Laboratório de Mecânica de solos e pelo auxilio prestado.

Ao Dr. Antonio Melhem Saad pelo apoio no início este trabalho.

Aos colegas de Pós Graduação Cassio Tormena, Claudio Marciano, Cláudia Teixeira, Fernando Cintra, Luciana Gomes de Castro, Luis Timm e Pablo Ghiberto pelas contribuições e pelo prazer do convívio.

Aos funcionários Luis Fernando Novello e Francisco Bernardo Dias do laboratório de Física e Meteorologia da ESALQ, pelo competente auxilio prestado em inúmeras fases.

Aos funcionários Vladimir e Luciano do Laboratório de Física de Solos do Departamento de Ciência do Solo da ESALQ pelo apoio.

A Bibliotecária Eliana Sabino, da divisão de referência, da Biblioteca Central da ESALQ, pela revisão das referências bibliográficas.

Aos funcionários Gilmar, César e Hélio do Departamento de Engenharia Rural da ESALQ por todo o auxilio.

Aos funcionários Airton, Álvaro, Fátima, Ronaldo e Silvana do setor de empréstimo da Biblioteca Central da ESALQ pelo eficiente atendimento.

Aos vizinhos e grandes amigos Edivaldo e Nancy, por tudo.

Aos amigos Ricardo Fietz, Remi Dambroz, Luiz Araújo, Maurício Teixeira, Marcos Montoya e Ronaldo Bulhões e suas familias pela amizade. 


\section{SUMÁRIO}

Página

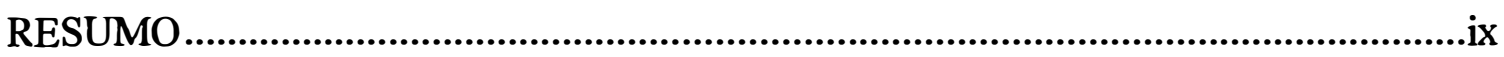

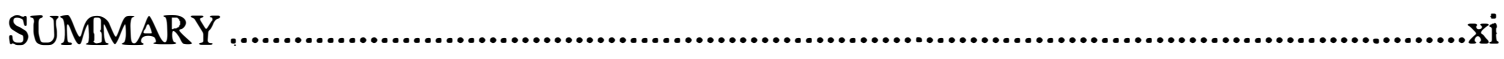

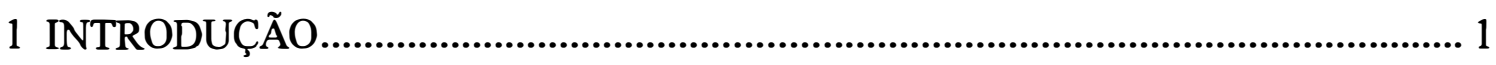

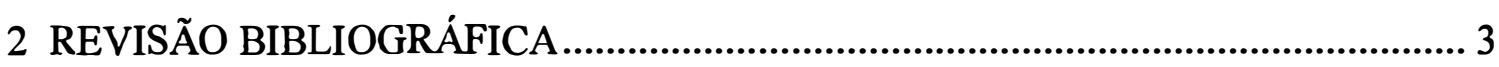

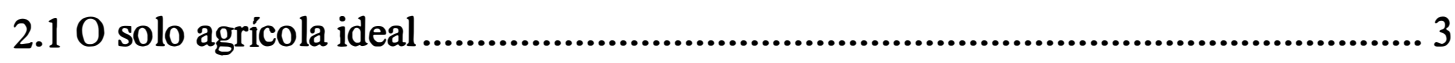

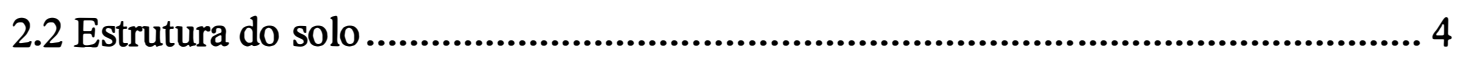

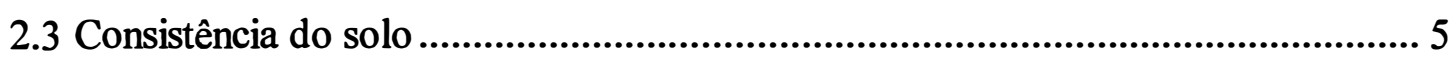

2.4 Densidade do solo ........................................................................................ 7

2.4.1 Alterações na densidade do solo.................................................................. 7

2.4.2 Compactabilidade do solo ........................................................................... 9

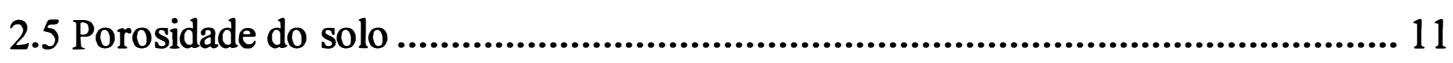

2.5.1 Porosidade de aeração .......................................................................... 13

2.6 Resistência do solo à penetração......................................................................... 14

2.7 Infiltração da água no solo........................................................................... 15

2.8 Condutividade hidráulica do solo .................................................................. 18

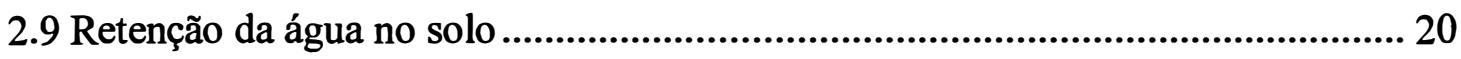

2.10 Água no solo disponível as culturas ................................................................. 22 


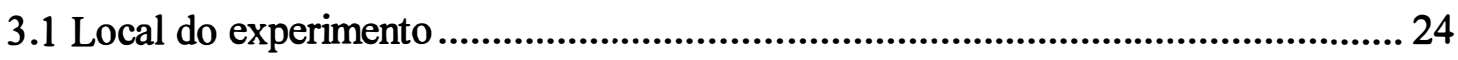

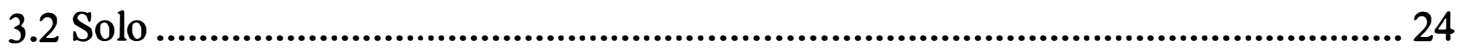

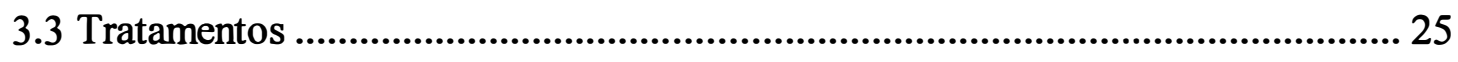

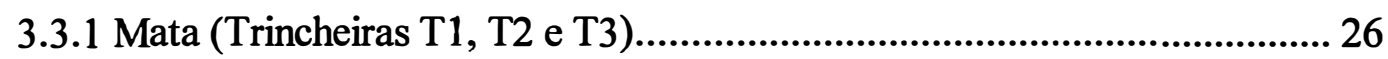

3.3.2 Sequeiro (Trincheiras T4, T5 e T6) ........................................................... 26

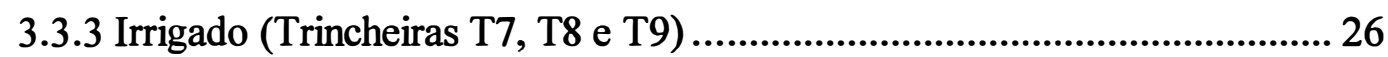

3.4 Coleta das amostras de solo com estrutura preservada ......................................... 26

3.5 Coleta de amostras de solo com estrutura alterada .............................................. 27

3.6 Densidade do solo e de sólidos ........................................................................ 27

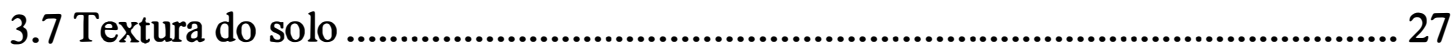

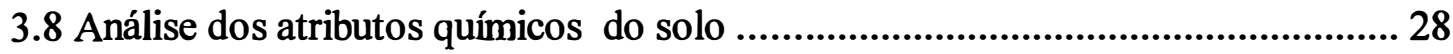

3.9 Consistência do solo ......................................................................................... 28

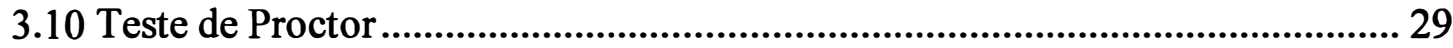

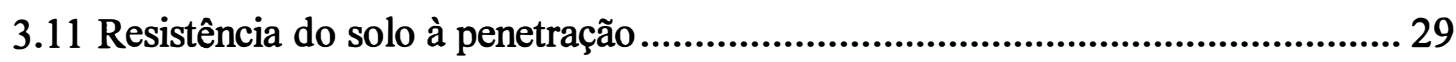

3.12 Determinação da retenção de água em amostras com estrutura preservada....... 31

3.13 Determinação da retenção de água em amostras com estrutura não preservada 32

3.14 Porosidade do solo ............................................................................................ 32

3.15 Capacidade de infiltração de água no solo .......................................................... 32

3.16 Condutividade hidráulica do solo saturado .......................................................... 33

3.17 Construção, teste e instalação dos tensiômetros ................................................... 35

3.18 Determinação da condutividade hidráulica do solo não saturado no campo ....... 36

3.19 Determinação da condutividade hidraúlica do solo não saturado, em laboratório, de amostras com estrutura indeformada............................................................... 40

3.20 Armazenagem de água no solo........................................................................... 44

3.21 Água disponível as plantas............................................................................. 44

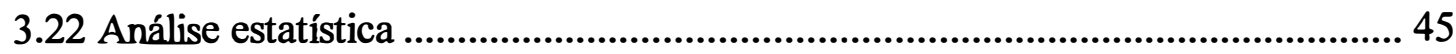

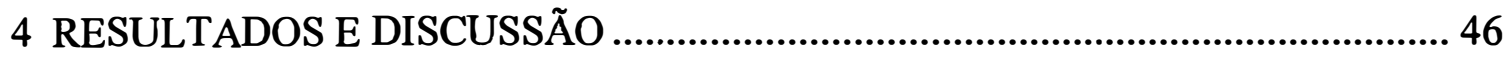




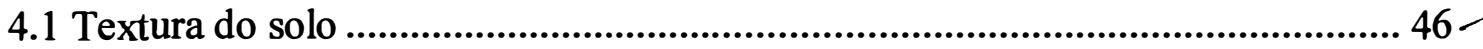

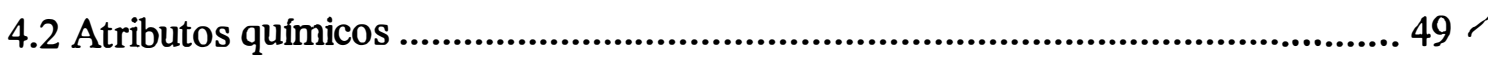

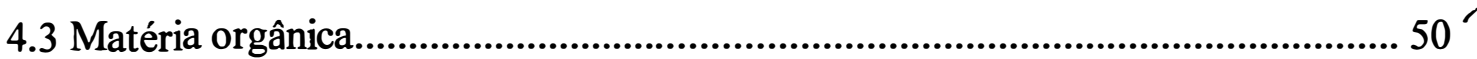

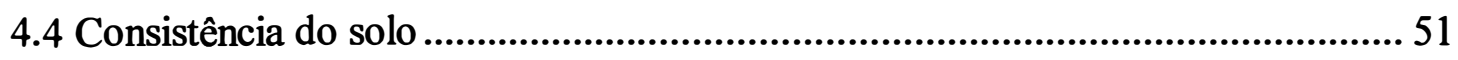

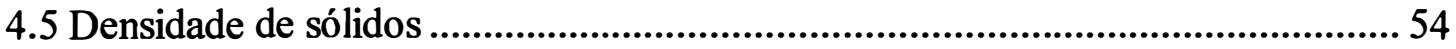

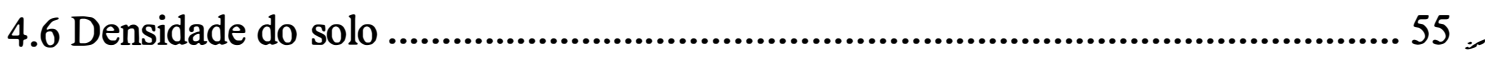

4.7 Máxima compactabilidade do solo ................................................................... 56

4.8 Resistência do solo à penetração......................................................................... 59 -

4.9 Curvas de retenção da água no solo com estrutura preservada .............................. 63

4.10 Curvas de retenção da água no solo com estrutura alterada ................................. 66

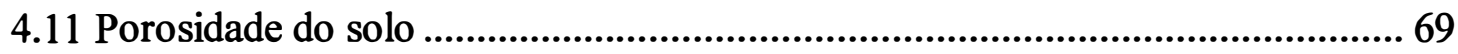

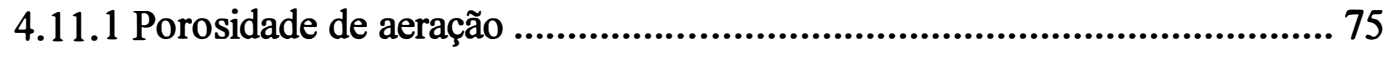

4.12 Infiltração da água no solo ................................................................................. 77

4.13 Condutividade hidráulica do solo saturado ........................................................ 80

4.14 Redistribuição da água no solo.......................................................................... 83

4.15 Condutividade hidráulica do solo não saturado ................................................... 85

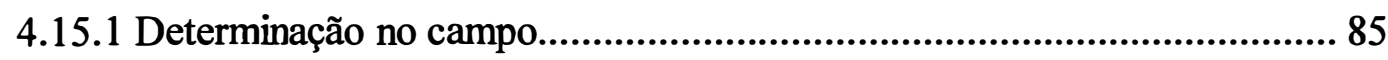

4.15.2 Determinação em laboratório …………………................................... 92

4.15.3 Análise conjunta de $\mathrm{K}(\theta)$ realizada no campo e em laboratório ................. 96

4.16 Armazenagem de água no solo e disponibilidade as culturas..............................100

4.16.1 Capacidade de campo ............................................................................100

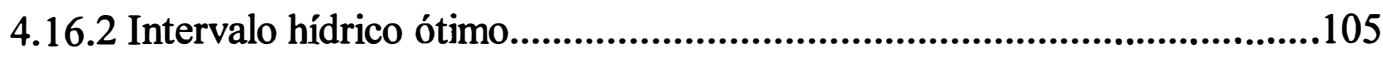

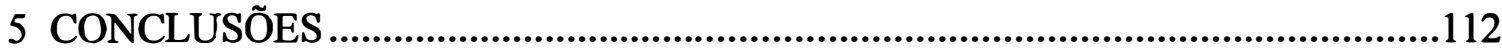

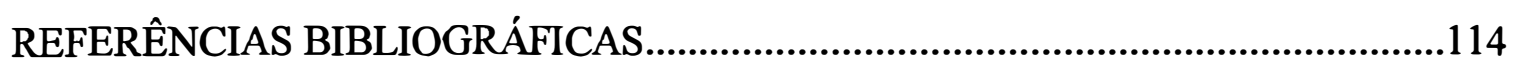

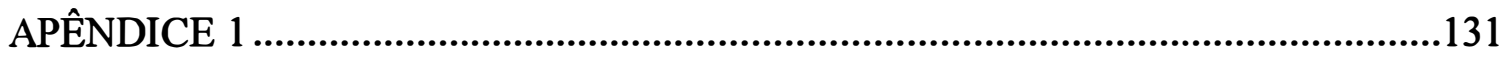

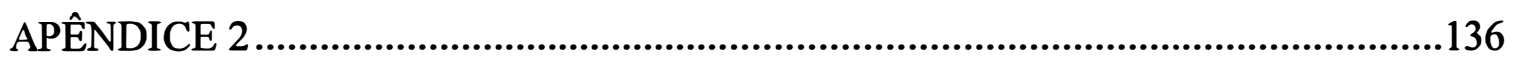

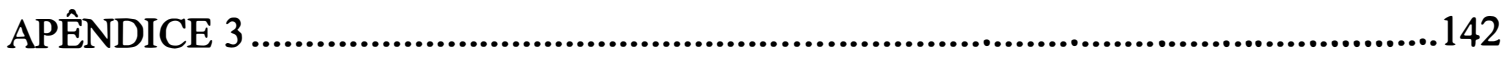




\title{
PROPRIEDADES FÍSICO-HÍDRICO-MECÂNICAS DE UM LATOSSOLO ROXO, SOB DIFERENTES SISTEMAS DE USO E MANEJO
}

\author{
Autor : VILSON ANTONIO KLEIN \\ Orientador: Prof. Dr. PAULO LEONEL LIBARDI
}

\section{RESUMO}

O solo, um dos principais suportes da produção agrícola, é afetado pela ação do homem através das práticas agrícolas de preparo do solo e manejo das culturas. Esta ação altera a estrutura ocasionando alterações nas propriedades físico-hídrico-mecânicas do solo. O objetivo deste trabalho foi avaliar as alterações nas propriedades físicas (densidade dos sólidos e do solo, porosidade e distribuição do diâmetro dos poros), hídricas (infiltração da água, condutividade hidráulica do solo saturado e não saturado, armazenagem de água no solo e disponibilidade às culturas) e mecânicas (resistência do solo à penetração, consistência e compactabilidade do solo), de um Latossolo Roxo ácrico (Typic Acrorthox) do município de Guaira, região nordeste do Estado de São Paulo, comparando os manejos plantio direto sequeiro e plantio direto irrigado em relação a mata, solo que se encontra na condição natural. Os resultados demonstraram que a estrutura do solo foi afetada pelos manejos até a profundidade de $0,4 \mathrm{~m}$, com maior intensidade no solo sob plantio direto irrigado, acarretando aumento significativo de densidade com conseqüente redução na porosidade, alteração na distribuição do diâmetro dos poros, aumento da resistência a penetração, diminuição da condutividade hidráulica do solo saturado e não saturado, redução na taxa de infiltração da água no solo e alteração nos limites de plasticidade. No entanto o aumento da densidade até o limite de $1,1 \mathrm{Mg} \mathrm{m}^{-3}$, aumentou a retenção de água no solo e a disponibilidade desta às plantas. Já 
densidade superior a 1,2 $\mathrm{Mg} \mathrm{m}^{-3}$ acarretou deficiência de aeração no solo. O movimento da água no solo não saturado também foi afetado pelo aumento da densidade, especificamente pela alteração na distribuição do diâmetro dos poros demonstrando ainda gue o solo na condição natural apresenta duas fases distintas, uma próxima a saturação e outra a partir da tensão de $40 \mathrm{kPa}$, sendo que as equações de $\mathrm{K}(\boldsymbol{\theta})$ não podem ser extrapoladas para fora da faixa de umidade em que elas foram obtidas. Os manejos de solo adotados tem proporcionado ao solo um índice de estabilidade estrutural superior ao da mata, fazendo com que este solo se encontre na condição friável antes de atingir a - capacidade de campoé no entanto nesta umidade que ocorre a máxima compactabilidade deste solo. Conclui-se que o manejo do solo sob sistema plantio direto em um Latossolo Roxo, provoca alterações significativas nas propriedades fisico-hídrico-mecânicas, no entanto desde que a densidade do solo seja mantida em torno de $1,1 \mathrm{Mg} \mathrm{m}^{-3}$ a maioria das alterações é benéfica ao crescimento e desenvolvimento das plantas. 


\title{
PHYSICO-HYDRIC-MECHANICAL PROPERTIES OF UN OXISOL, UNDER DIFFERENT USE AND MANAGEMENT SYSTEMS
}

\author{
Author: VILSON ANTONIO KLEIN \\ Adviser: Prof. Dr. PAULO LEONEL LIBARDI
}

\section{SUMMARY}

The soil, one of the main supports of the agricultural yield, is affected by the management practices of the field soil-plant systems. These practices modify the soil structure and, consequently, its physic-hydraulic-mechanical properties. The objective of this work was to assess the changes of physical (particle density, bulk density, porosity and pore diameter distribution), hydric (water infiltration, hydraulic conductivity, water storage and available water) and mechanical (resistance to penetration, consistency and compactability) properties of an oxisol (Typic Acrorthox) of the county of Guaira (SP), Brazil $\left(20^{\circ} 27^{\prime} \mathrm{S}, 48^{\circ} 18^{\prime} \mathrm{W}, 518 \mathrm{~m}\right)$, under different managements: no-tillage-nonirrigated and no-tillage-irrigated, in comparison with the natural forestry. According to the results, soil structure was affected by managements till the depth of $0.4 \mathrm{~m}$ (with higher intensity in the soil under no-tillage-irrigated treatment), leading to a significant increase of soil bulk density and, consequently, decrease of soil porosity, changing of pore diameter distribution, increase of soil resistance to penetration, decrease of soil hydraulic conductivity function, that is, the $\mathrm{K}(\theta)$ function, $\theta$ being the volumetric soil water content, decrease of the rate of infiltration and changing of the limits of plasticity. The increase of soil bulk density till the limit of $1.1 \mathrm{Mg} \mathrm{m}^{-3}$ increased the soil water retention and the water availability to the plants. However values greater than $1.2 \mathrm{Mg} \mathrm{m}^{-3}$ 
caused aeration deficiency to the plant roots. Soil water movement, under unsaturation condition, was also affected by the bulk density increase, specifically by changing the pore diameter distribution, showing that the soil, under the natural condition, has two distinct phases, one just near the saturation and other from the water tension of $40 \mathrm{kPa}$ on, during the redistribution process of the instantaneous profile method to determine the $K(\theta)$ function. Values of $\mathrm{K}(\theta)$ for this soil have shown that they cannot be extrapolated to water ranges out of those they were measured. The used soil managements have given to the soil a structural stability index greater than that of the forestry one. As a result, this soil reaches the friable condition in a soil water content value smaller than the field capacity, in this soil water content, however, occurred the maximum compactability of this soil. In conclusion, the no-tillage management, in this type of soil, provokes significant changes on its physico-hydric-mechanical properties but, if the soil bulk density is keeped around the value of $1.1 \mathrm{Mg} \mathrm{m}^{-3}$, the majority of the changes is of benefit to the growing of plants. 


\section{INTRODUÇÃO}

A produção de alimentos continua sendo um dos grandes desafios da humanidade. Tecnologias cada vez mais modemas tem sido adotadas para obter esta produção em quantidade e qualidade suficiente para a população do planeta. A ação do homem no sistema solo-água-atmosfera-planta para a produção destes alimentos tende a ocasionar alterações, muitas vezes positivas, como melhoria das condições de desenvolvimento e proteção das plantas, outras vezes negativas como a degradação do solo e a poluição do ambiente e dos recursos hídricos.

O solo é um dos principais suportes da produção agrícola, sendo seu comportamento regido por um complexo conjunto de fatores físicos, químicos e biológicos, submetidos à ação do clima, que interagem e tendem ao equilibrio. $\mathrm{O}$ homem, através das práticas agrícolas interfere neste sistema, alterando-o, afetando as propriedades fisico-hidrico-mecânicas do solo.

As alterações que ocorrem na estrutura do solo, evidenciando-se por modificações nos valores de densidade, afetam a resistência do solo à penetração, a porosidade total, distribuição do diâmetro dos poros e na porosidade de aeração, a armazenagem e disponibilidade de água as plantas, a dinâmica da água na superficie e no perfil do solo, bem como a consistência e a máxima compactabilidade do solo.

Sistemas conservacionistas de manejo do solo têm sido adotados em grande escala em determinadas regiões do País. Entre eles o que mais se destaca é o sistema de plantio direto, no qual a semeadura e feita sem preparo prévio, reduzindo consideravelmente os custos de produção e os efeitos negativos da erosão hídrica do 
solo. Essa prática de manejo conservacionista do solo ocasiona mudanças significativas nas propriedades do solo.

O objetivo geral deste trabalho foi estudar as alterações nas propriedades físico-hídricas e mecânicas de um Latossolo Roxo de Guaira -SP, submetido a diferentes sistemas de uso e manejo do solo.

A luz do conhecimento, de que toda ação antrópica altera o ambiente, a hipótese que se formula é de que, o uso e manejo do solo para fins agrícolas, em cultivos sucessivos, após vários anos, mesmo sob sistemas conservacionistas como o plantio direto, proporciona alterações na estrutura do solo afetando, consequentemente, as propriedades físico-hídrico-mecânicas de um Latossolo Roxo em relação à condição natural (mata).

Para verficar a hipótese os objetivos específicos foram estudar as alterações nas propriedades físicas (densidade dos sólidos e do solo, porosidade e distribuição do diâmetro dos poros), hídricas (infiltração da água, condutividade hidráulica do solo saturado e não saturado, armazenagem de água no solo e disponibilidade às culturas) e mecânicas (resistência do solo à penetração, consistência e compactabilidade do solo), comparando os manejos plantio direto sequeiro e plantio direto irrigado em relação a mata, solo da qual serviu de referência como condição natural. 


\section{REVISÃO BIBLIOGRÁFICA}

\subsection{O solo agrícola ideal}

O solo considerado ideal para agricultura deve ser bem drenado, possuir um volume adequado de poros de transmissão e de drenagem de água e não ser severamente ácido ou alcalino; as raizes não devem possuir impedimentos físicos ou químicos e devem ser supridas de nutrientes livres de elementos tóxicos; é aconselhável, mas não essencial, que o solo contenha um moderado teor de matéria orgânica; a porosidade deve ser estável aos efeitos da precipitação pluvial e à mecanização. Deve ainda apresentar um regime térmico do solo e um volume e dimensão dos poros adequados para a entrada, movimento e retenção de ar e água para atender as necessidades das culturas (Hillel, 1980 e Greenland, 1981).

Esta definição de solo é muito complexa e raras vezes encontra-se solos, atendendo a todos os itens, na natureza. Solos de floresta, muitas vezes, apresentam elevada acidez, baixa disponibilidade de nutrientes, camadas de impedimento, coesas ou adensadas, no entanto ocorre uma adaptação das plantas a estas condições, desenvolvendo-se normalmente, mas a longo prazo. Como na agricultura os resultados precisam ser imediatos, busca-se ao máximo obter as condições favoráveis ao desenvolvimento das plantas dentro de uma viabilidade econômica da exploração agrícola. 


\subsection{Estrutura do solo}

A estrutura do solo de acordo com Brewer \& Sleeman (1960), é a condição física do material do solo expressa pela dimensão, forma e arranjo das partículas sólidas e poros a elas associados, incluindo partículas primánias e as originadas pela união delas. Uma definição muito simples é a de se referir à estrutura do solo como o arranjo das partículas e a aglomeração destas, formando agregados maiores. Segundo Reichardt (1987) a estrutura ao contrário da textura pode ser modificada por práticas agrícolas, podendo ser melhorada ou degradada. Rezende (1997) destaca que a presença de uma rede ideal de poros, com ampla variação dos diâmetros, é um fator chave na fertilidade do solo, pois afeta as relações entre drenagem, teor de água disponível para as plantas, absorção de nutrientes, penetração de raízes, aeração, temperatura, afetando a produtividade das culturas.

A matriz ou esqueleto do solo é composta por sólidos minerais e orgânicos, podendo ser descrita através da análise granulométrica, a qual permite classificar os componentes sólidos em classes de acordo com os seus diâmetros, normalmente em argila, silte e areia (Kiehl, 1979 e Lemos \& Santos, 1984). Em solos argilosos predominam as partículas minerais coloidais, sendo a argila, a matéria orgânica, o calcário e os sesquióxidos de ferro e alumínio agentes cimentantes agregando as demais partículas.

Latossolos possuem uma microagregação muito acentuada. Neste sentido, embora possam ter elevado teor de argila a sua microagregação lhe confere um comportamento parecido com um solo arenoso. Esta microagregação, segundo El-Swaify (1980), ocorre muito mais em função do tipo de argila com cargas negativas (caulinita) combinadas a sesquióxidos de ferro (goethita e hematita) e de alumínio (gibsita), do que em função da presença de material orgânico.

Erickson, citado por Ellies et al. (1993), ressalta que a avaliação dos efeitos das alterações na estrutura do solo sobre as culturas são dificeis, pois mesmo com aumento da densidade as culturas mantêm rendimentos aceitáveis. Destaca ainda que a 
compactação altera a distribuição dos poros, mas no entanto o seu efeito sobre o crescimento vegetal depende também das condições meteorológicas vigentes. Por outro lado, Silva \& Kay (1996) trabalhando com o conceito de intervalo hídrico ótimo, obtiveram boa correlação entre este parâmetro , as condições climáticas e a produtividade das culturas. Portanto, esta metodologia se apresenta como uma boa alternativa para estudar o efeito das alterações na estrutura do solo sobre as plantas.

\subsection{Consistência do solo}

- A consistência do solo descreve a resposta do solo a ação das forças externas que tendem a deformá-lo, sendo que estas forças podem ocasionar fluxo, fratura ou compressão do solo (Forsythe, 1975). Um solo pode ter vários estados de consistência segundo a sua umidade, sendo os valores de umidade nos pontos de transição denominados de limites. Define-se como índice de plasticidade o intervalo do conteúdo de águà no qual o solo apresenta entre o límite líquido, condição a partir da qual o solo se comporta como fluído e o limite plástico condição de umidade, abaixo da qual o solo se apresenta friável.

Neste contexto, Salire \& Woodhead (1994) afirmam que o estudo da friabilidade dos solos pode ser utilizado para avaliar os efeitos dos preparos do solo, sendo afetada pela seqüência de cultivos e que a incorporação de resíduos é particularmente interessante.

A magnitude dos limites está relacionada com a natureza da argila, pelo teor de matéria orgânica e cátions trocáveis. Niggemann citado por Ellies \& Mac Donald (1985) destaca ainda que as forças de coesão são de natureza eletrostática, efeito cimentante dos agregados e tensão superficial na interface ar-solo-água. A forma dos grãos de argila é tão importante quanto a sua dimensão, podendo em função da sua estrutura cristalina ter forma lamelar, escamosa , filiforme ou outras. As caulinitas, predominantes nos 
Latossolos, tem forma de placas hexagonais, por isso menos plásticas (Vargas, 1978), predominam na composição do Latossolo Roxo (Moura Filho \& Buol, 1972).

Ellies \& Gayoso (1986) trabalhando com solos de origem vulcânica no sul do Chile, destacam que o limite líquido foi profundamente influenciado pelo teor de carbono do solo e o limite plástico pela capacidade de troca de cátions e teor de carbono, enquanto que o índice de plasticidade foi afetado somente pelo teor de argila.

Para o manejo do solo a umidade em que este se encontra é muito importante. A condição de umidade do solo, na qual ele pode ser trabalhado é a friável (Dalla Rosa, 1981 e Silveira, 1988), pois se estiver muito seco, apresenta alta coesão, exigindo maior potência das máquinas agrícolas e maior número de operações para obter um leito de semeadura adequado em função da excessiva formação de torrões. Por outro lado se o solo estiver muito úmido além de problemas de sustentação e capacidade de tração dos tratores, ocorrerão danos a estrutura, pois filmes de água estarão dispostos ao redor das partículas, funcionando como lubrificante, favorecendo a desagregação pela pressão exercida pelas máquinas e implementos agrícolas, compactando-o.

A determinação da umidade em que os solos adquirem características friáveis é muito importante, uma vez que com estes é possível definir as faixas de umidade em que poderão ser feitos preparos sem afetar a estrutura do solo. Ellies \& Mac Donald (1985) reapresentam a proposta do índice de estabilidade da estrutura para solos argilosos, como um quociente entre a umidade no limite plástico e a capacidade de campo. Um quociente maior que um, indica uma boa estabilidade estrutural.

Poucos estudos foram realizados sobre este assunto no Brasil. Atualmente alguns trabalhos tem sido apresentados como o de Figueiredo et al. (1998) que obtiveram valores de limite plástico em torno de $0,32 \mathrm{~kg} \mathrm{~kg}^{-1}$ em Latossolo Roxo da região de Lavras - MG, observou ainda que a umidade ótima de compactação está a $90 \%$ do limite plástico, dentro da faixa de friabilidade do solo. É nessa condição de solo friável que se recomenda a realização das operações motomecanizadas em função da mínima coesão 
entre as partículas do solo e da menor adesão do solo às ferramentas de preparo e semeadura ( Ashburner \& Sims, 1984).

A pegajosidade do solo, segundo Kiehl (1979), é aquela em que as películas de água que revestem as partículas sólidas não mais se atraem, sendo este o estado de aderência, sendo esta a atração entre superficies líquida e sólida. Destaca ainda que solos argilosos com grande número de partículas coloidais tendo películas de água com elevadas tensões superficiais, possuem maior força de adesão que solos arenosos.

\subsection{Densidade do solo}

A densidade do solo, definida como o quociente de sua massa de sólidos por seu volume é afetada por cultivos que alteram a estrutura e por conseqüência o arranjo e volume dos poros. Estas alterações afetam propriedades fisico-hídricas importantes como a porosidade de aeração, a retenção de água no solo, a disponibilidade de água as plantas e a resistência do solo à penetração.

Segundo Beltrame \& Taylor (1980), as causas das alterações na densidade dos solos são naturais, dificeis de serem definidas e avaliadas, agindo lentamente no solo, como por exemplo a eluviação de argilas e as forças mecânicas originadas da pressão causada pelos rodados das máquinas agrícolas e pela própria ação de implementos sobre o solo. Afirmam ainda, que esta pressão é originária das forças de tração e do próprio peso do trator e implementos. $\mathrm{O}$ tráfego excessivo realizado indiscriminadamente sob diferentes condições de umidade do solo é o principal responsável pela compactação.

\subsubsection{Alterações na densidade do solo}

A compactação do solo induz, como conseqüência, a redução do espaço poroso, principalmente macroporos, o que afeta as propriedades físico-hídricas. Grohmann \& Queiroz Neto (1966) observaram, em laboratório, a redução pela metade 
do volume de macroporos de um Latossolo Roxo, enquanto a porosidade total foi reduzida em $20 \%$. Silva et al. (1986) observaram a transformação de macroporos em microporos devido a compactação. Hillel (1970) afirma que para o bom desenvolvimento das plantas estas necessitam no mínimo entre, 6 a $20 \%$ de macroporos, dependendo do tipo de solo.

\# Raghavan et al. (1977b) afirmam que 50\% da compactação do solo pode ser atribuída a tensões geradas pela patinagem das rodas de tração das máquinas agrícolas. Destacam ainda que o máximo efeito de compactação ocorre com patinagens entre 15 e $25 \%$. A taxa usual de patinagem é $20 \%$, portanto condição em que ocorre a máxima compactação.

A camada do solo onde veículos leves ocasionam a máxima compactação do solo é a superficial $(0,0-0,3 \mathrm{~m})$, enquanto que equipamentos pesados tendem a compactar o solo em camadas mais profundas, de 0,3 a $0,6 \mathrm{~m}$ (Raghavan et al. ,1990). No último caso o problema é bem mais sério, pois para eliminar este, será necessária uma subsolagem profundà, com custos mais elevados do que preparos convencionais a profundidades menores.

Como solução para o problema da compactação, efetua-se o preparo do solo, buscando otimizar as condições até uma profundidade conveniente para a boa germinação das sementes e desenvolvimento das culturas. Segundo Gupta \& Larson (1982); Baryeh (1986) e Castro (1989), o preparo do solo pode ser definido como uma manipulação física, química ou biológica do solo e seus objetivos são proporcionar: temperatura, aeração e umidade adequadas, incorporação de restos culturais e fertilizantes, controle de plantas daninhas, minimização da erosão do solo, aumento da capacidade de infiltração e da armazenagem de água, aquecimento e secagem do ambiente das sementes e minimização de prejuízos decorrentes de ataques de pragas e moléstias. 
A condução das operações de preparo de forma inadequada, ocasiona sérios problemas de conservação do solo. Wünsche \& Denardin (1980) afirmam que solos preparados comumente apresentam menor estabilidade dos agregados, aumento de densidade, alterações no espaço poroso e redução na condutividade hidráulica e gasosa.

As práticas culturais afetam a estrutura do solo, alterando a densidade e, em conseqüência, a porosidade, a distribuição do tamanho dos poros e a resistência à penetração. Inúmeros trabalhos, avaliando a densidade do solo, em diferentes manejos, concluem que de modo geral o plantio direto apresenta densidade do solo mais elevada (Woorhees \& Lindstrom, 1983; Sidiras et al., 1984; Vieira, 1985 e Klein \& Boller, 1995). Kertzmann (1996) ainda ressalta que o plantio direto em áreas irrigadas, situação em que a umidade do solo é mantida mais elevada os problemas de compactação são acentuados.. Por outro lado, a ação de insetos e a decomposição das raízes das plantas origina uma estrutura do solo benéfica para o desenvolvimento das plantas, mesmo com densidades mais elevadas, em função da formação de canais ou macroporos por onde as raízes podem se desenvolver (Stirzaker et al., 1996).

\subsubsection{Compactabilidade do solo}

Para Bueno \& Vilar (1998) a compactação é entendida como ação mecânica por meio da qual se impõe ao solo uma redução de seu índice de vazios, como conseqüência ocorrendo um acréscimo da resistência ao cisalhamento e a redução da compressibilidade e da permeabilidade.

A primeira contribuição significativa ao estudo da compactação foi dada por Ralph Proctor, em 1933, o qual empresta o seu nome até hoje ao mais conhecido teste de compactação. O teste determina a relação existente entre a densidade, umidade e energia de compactação de um solo com estrutura alterada, sendo o ponto em que se obtém a máxima densidade denominado de umidade ótima de compactação para um dado nível de energia aplicada (Bueno \& Vilar, 1998). 
${ }^{\star} \mathrm{O}$ fenômeno da compactação pode ser explicado, levando em conta a grande influência que a água intersticial exerce sobre os solos. No parte da curva de Proctor, tendo um solo baixa umidade, a água dos seus vazios está sob efeito capilar, nesta situação as tensões de capilaridade tendem a aglutinar o solo mediante a coesão entre suas partículas constituintes, impedindo o rearranjo destas. A medida que aumenta o teor de água, ela em forma de água livre, absorve parte considerável da energia de compactação aplicada (Bueno \& Vilar, 1998).

No entanto, como o teste de Proctor foi desenvolvido em função das necessidades da Engenharia Civil, especificamente na mecânica de solos, a sua utilização para fins de estudo da dinâmica dos solos agrícolas tem sido bastante discutível. Testes alternativos como o proposto por Bruce (1955) e mais recentemente por Hâkansson (1990) tem sido propostos. A utilização de consolidômetros para estudar níveis de adensamento em função da energia de compactação aplicada vem sendo adotada no Brasil e seus resultados apresentados em congressos recentes (Zanette et al., 1998; Silva et al., 1998 e Figueiredo et al., 1998).

A importância das definições acima está em se determinar a faixa de umidade do solo a campo em que as condições de compactabilidade não sejam máximas. Akram \& Kemper (1979) afirmam que a máxima densidade de um solo franco arenoso, em amostras compactadas em laboratório, independente do nível de energia aplicada geralmente ocorre em valores de umidade próximos à capacidade de campo.

Em condições de campo a energia de compactação aplicada pelos rodados das máquinas agrícolas, dificilmente irá atingir os níveis de $560 \mathrm{kPa}$ adotados no teste de Proctor normal. Hâkansson (1990) utilizou como valor médio de energia imposta pelas máquinas agrícolas a superfície do solo, $200 \mathrm{kPa}$. Neste sentido Bruce (1955) e Bueno \& Vilar (1998) destacaram que a utilização do teste de compactação com energia diferenciada, reduz obviamente a densidade máxima, obedecendo no entanto a mesma saturação relativa que a do teste proctor normal, ocorrendo com isto, em função da maior porosidade um aumento na umidade ótima de compactação. 
Por outro lado Raghavan et al. (1977a) e Novak et al. (1992) comprovaram em condições de campo, efetuando compactação do solo com tráfego de tratores sobre a superficie com diferentes níveis de umidade, que a máxima compactação ocorre na mesma umidade daquela do teste de Proctor. Destacam ainda, concordando com Doneen et al. (1952) de que é na primeira passada que ocorre o maior efeito sobre a compactação do solo.

\subsection{Porosidade do solo}

A porosidade é a fração volumétrica do solo ocupada com ar e água, representando o local onde circulam a solução (água e nutrientes) e o ar, sendo portanto o espaço em que ocorrem os processos dinâmicos do ar e solução do solo (Hillel, 1970). A distribuição dos diâmetros dos poros condicionam o comportamento físico-hídrico. $\mathrm{O}$ estudo da porosidade é, portanto, uma das metodologias indicadas para caracterizar e quantificar as propriedades fisico-hídricas do solo ( Guerif, 1987).

A distribuição do diâmetro dos poros no solo tem um papel preponderante nesse contexto. Inúmeras classificações do diâmetro de poros são citadas na literatura, sendo que uma forma mais simplificada separa os poros em duas classes: macroporos com diâmetro $>0,06 \mathrm{~mm}$ e microporos $<0,06 \mathrm{~mm}$ como a proposta por Kiehl (1979), enquanto Richards (1965) e ESTADOS UNIDOS (1972) classificam em macroporos os poros com diâmetro $>0,05 \mathrm{~mm}$ e microporos os com diâmetro < que $0,05 \mathrm{~mm}$.

Vários autores incluem nesta classificação os mesoporos como uma classe intermediária. Há, no entanto, uma variação muito grande na definição dos limites de diâmetro entre uma classe e outra. Assim Luxmoore (1981) define como limite para macroporos o diâmetro de $1 \mathrm{~mm}$, enquanto Koorevaar et al. (1983) utilizam o diâmetro de $0,1 \mathrm{~mm}$. Outras classificações mais detalhadas, como a de Brewer citada por Campos (1971) subdividem os poros em até oito classes de diâmetro, adotando classificações como criptoporos para poros com diâmetro menor que $0,0002 \mathrm{~mm}$. 
Através de exames microscópicos em lâminas délgadas de Latossolo Roxo, Tognon (1991) e Curmi et al. (1994) relatam que o espaço poroso é constituído por dois tipos de poros: um resultante do arranjamento dos microagregados formando o espaço porose intra-agregado, contínuo, irregular e policôncavo e que ocupa um volume importante do solo (diâmetro $<0,0002 \mathrm{~mm}$ ) ; e outro, formado por canais e cavidades com dimensões maiores ( diâmetro > 0,0002 mm), denominados de poros interagregados (micro e macroporos). Destacam ainda que os manejos de solo afetaram. apenas os poros interagregados, enquanto os poros dentro dos agregados não sofreram quaisquer alterações em função da sua grande estabilidade.

Segundo Baver et al. (1972), a infiltração, redistribuição rápida da água e a aeração ocorre principalmente através dos macroporos. Nesses poros de maior diâmetro, o efeito da força da gravidade é o componente principal que rege o movimento da água. Bouma (1991) concluiu que as implicações dos fluxos preferenciais de solutos pelos macroporos são de fundamental importância para a qualidade do ambiente. Estudou a influência da macroporosidade na qualidade do ambiente, propondo metodologias para: a) caracterizar a macroporosidade nos seus aspectos morfológicos e fisicos; b) estudar os efeitos dos macroporos no movimento de solutos, c) estudar fluxos de solução nos macroporos.

Por outro lado, os canais também denominado de bioporos, originados por insetos podem incrementar a lixiviaçao de nutrientes ou pesticidas em profundidade, para fora do alcance das raízes, como destacam Francis et al. (1988) e Trojan \& Linden (1992).

Curmi et al. (1994) relatam que a condutividade hidráulica do solo saturado foi negativamente afetada pela ausência de poros tubulares biológicos, como consequaência da compactação ou pelo uso de pesticidas. $O$ estudo foi feito em um Latossolo roxo, utilizando a técnica de análise de imagens de lâminas delgadas, relacionando a distribuição do tamanho dos poros com algumas propriedades hidráulicas deste solo. 
Os microporos são definidos também como poros de armazenamento de água às plantas, enquanto criptoporos são aqueles poros onde a água pode permanecer retida com energia muito baixa, sendo portanto indisponivel às plantas; é a água que o solo retém quando se encontra no ponto de murcha permanente (1500 kPa).

\subsubsection{Porosidade de aeração}

A porosidade de aeração é a razão entre o volume de ar e o volume do solo, sendo esta portanto afetada pela umidade. $\mathrm{O}$ ar ocupa o espaço poroso do solo não ocupado pela água. Para um solo seco, todo o espaço vazio (porosidade total) é ocupado por ar. A exigência das plantas para a aeração do solo, isto é, porosidade livre de água necessária para o pleno desenvolvimento varia entre espécies e solos e os efeitos da deficiência de difusão de oxigênio no solo sobre as plantas são bastante estudados e descritos por Sojka (1992). Erickson (1982) em revisão detalhada a respeito do assunto, cita vários autores e concluiu que para a maioria das culturas o valor mínimo de espaço poroso livre de água deve ser ao redor de $0,10 \mathrm{~m}^{3} \mathrm{~m}^{-3}$. Sabe-se, no entanto, que estes valores são apenas uma referência, pois a taxa de difusão gasosa no solo depende da profundidade e densidade do sistema radicular, temperatura do solo, tortuosidade do espaço poroso, entre outros.

O uso e manejo do solo alteram a densidade do solo, alterando conseqüentemente a porosidade total e de aeração. Neste sentido, Tormena et al. (1998a) estudando as alterações na porosidade de aeração em plantio direto, observaram que o tráfego de máquinas reduziu esta a valores próximos de zero. Observaram ainda que, com o decorrer do tempo, mesmo sem mobilizar o solo, houve aumento da porosidade total e de aeração, o que os autores atribuem a ação do sistema radicular da cultura da aveia preta implantada nesta área com a finalidade de adubação verde. 


\subsection{Resistência do solo à penetração}

A resistência do solo à penetração é uma das propriedades físicas do solo que influencia diretamente o crescimento das raízes e da parte aérea das plantas (Letey, 1985 e Weaich et al., 1992). Vários autores utilizam a resistência do solo à penetração para a avaliação dos efeitos dos sistemas de manejo do solo sobre o ambiente radicular (Benghough \& Mullins, 1990 e Tormena \& Roloff, 1996).

Os níveis críticos de resistência à penetração para o crescimento das plantas variam com o tipo de solo e com a espécie cultivada (Taylor et al., 1966 e Materechera et al., 1991). Num Latossolo Roxo, Petter (1990), verificou que a resistência de 2,8 MPa foi limitante ao crescimento radicular da cultura da soja. Taylor \& Gardner (1963); Taylor et al. (1966) e Nesmith (1987) adotaram o valor de 2 MPa como o valor de resistência crítica para a penetração das raízes.

A penetrometria é considerada um método apropriado para avaliar a resistência. à penetração de raízes no solo (Benghough \& Mullins, 1990). Idealmente, a quantificação da resistência real encontrada pelas raízes deveria ser feita por métodos diretos (Stolzy \& Barley, 1968), mas as dificuldades práticas têm levado os pesquisadores a utilizar o

penetrômetro. A facilidade e rapidez na obtenção dos resultados, além da possibilidade de um maior número de repetições, são as principais vantagens do uso do penetrômetro. No entanto, a dependência com relação ao conteúdo de água e à densidade do solo, dificulta a interpretação dos resultados (Cassel et al. 1978). Além disso, os penetrômetros utilizados no campo apresentam problemas operacionais relacionados com a dificuldade em manter uma velocidade de penetração constante (Camargo, 1983 e Balastreire, 1987) e com a variação do contéudo de água no solo nas diversas camadas (Chancellor, 1977). Outra limitação refere-se ao fato de que estes equipamentos não permitem a obtenção da resistência sob baixos conteúdos de água no solo.

Vários autores recomendaram que a resistência seja medida em umidades próximas à capacidade de campo (Bauder et al.,1981; Mata, 1988 e Henderson, 1989) situação em que se consegue uma boa correlação entre densidade do solo, resistência à 
penetração e crescimento radicular. Petter (1990) concluiu que com a umidade do solo equivalente à tensão $10 \mathrm{kPa}$, a densidade do solo de $1,4 \mathrm{Mg} \mathrm{m}^{-3}$ não foi limitante ao desenvolvimento radicular da soja. No entanto, o período em que o solo permanece na capacidade de campo é pequeno, de modo que a resistência do solo à penetração pode rapidamente variar de níveis não impeditivos para impeditivos com a secagem do solo. Perini et al. (1998) observaram que na densidade de $1,4 \mathrm{Mg} \mathrm{m}^{-3}$, sem controle de umidade, não houve penetração de raízes da cultura da soja, conduzida em minilisímetros.

Quando se compara a resistência do solo à penetração em diferentes manejos, a presença ou ausência de diferenças entre os sistemas podem ser confundidas com as influências destes sobre o conteúdo de água do solo (Chancellor, 1977). Por isso, é importante que a determinação da resistência à penetração seja feita com o controle da umidade do solo, o que permite evidenciar os efeitos dos sistemas de manejo sobre a estrutura do solo.

Com relação ao tamanho do cone utilizado nos penetrômetros, Schaffer et al. (1969) e Koolen \& Kuipers (1983) destacam que a força por unidade de área, necessária para promover a penetração dos cones no solo, não varia muito com o seu diâmetro, quando estes são constituídos do mesmo metal e ângulo de $30^{\circ}$. Por outro lado, autores como Cassel (1982) relatam diferenças significativas nos valores de resistência à penetração quando se altera o diâmetro do cone. Isto pode ocorrer em função de outros fatores como a textura, a estrutura e a rugosidade da superfície das partículas do solo, que podem afetar a resistência em função do tamanho do cone.

\subsection{Infiltração da água no solo}

A infiltração é o processo da penetração de água no sentido vertical descendente. A capacidade de infiltração de água no solo é afetada pelo tempo, umidade inicial, porosidade e textura, condutividade hidráulica entre outros. Com o transcorrer do 
tempo a capacidade de infiltração vai diminuindo tendendo para uma taxa constante de infiltração, que será igual a máxima condutividade hidráulica da camada limitante.

A taxa de infiltração é fortemente afetada pelas características da camada superficial do solo, como restos culturais ou cultura implantada, rugosidade superficial características da porosidade e pela umidade inicial. Vieira (1985) relata que a capacidade de infiltração é dependente de três fatores: a estabilidade de agregados, a cobertura do solo e a macroporosidade. Avaliando algumas combinações desses fatores, o autor observou que, em alguns casos, houve maior infiltração no plantio direto e em outros em sistema convencional de preparo. Isto pode ocorrer em função da grande variação da quantidade e qualidade dos restos culturais sobre a superficie do solo e da variação do volume de macroporos, que ocorre nos diferentes sistemas de exploração agrícola dentro do plantio direto.

Em trabalho conduzido por Kertzmann (1996), utilizando os cilindros duplos de Muntz, a taxa constante de infiltração em mata foi de $1396 \mathrm{~mm} \mathrm{~h}^{-1}$, enquanto que na área cultivada com sistema plantio direto por 15 anos, $63 \mathrm{~mm} \mathrm{~h}^{-1}$. Estes resultados demonstram que houve uma drástica redução na velocidade de infiltração, em mais de 20 vezes, em função do manejo e cultivo adotados. Lal (1955) e Larson (1964) também constataram redução significativa na infiltração de água no solo em decorrência da intensificação de operações mecanizadas, em relação à condição natural.

Edwards (1982) demonstrou, em um bom trabalho sobre a previsão dos efeitos do preparo do solo sobre a infiltração de água, que em áreas com sistema plantio direto, a capacidade de infiltração de água é maior do que em sistemas convencionais de preparo. Atribuiu estes resultados à ação da mesofauna sobre o solo abrindo os megaporos biológicos, os quais propiciam um rápido fluxo de água, bem como a função da palha (restos culturais) sobre a superficie que evita o impacto direto da gota da água da chuva ou da irrigação sobre a superfície do solo e o encrostamento desta, reduzindo assim a infiltração. 
Kladivko et al. (1986), estudaram o efeito da ação das minhocas sobre a capacidade de infiltração de água no solo, e concluíram que a ação delas tem uma influência importante sobre a redução do encrostamento superficial e que em áreas com plantio direto a presença das minhocas é bem mais acentuada, e que os canais por elas criados interferem positivamente na infiltração da água. Por outro lado, Ehlers (1975), ressalta que a grande maioria dos canais não contribui significativamente com a infiltração de água por não estarem conectados com a superficie, concordando com Ela et al. (1992) que ainda destacam que mesmo os canais conectados com a superficie apresentam em volta deles um microrrelevo, originado pelas minhocas o que dificulta a entrada de água neles.

Neste sentido, Edwards (1982) afirma que, em se tratando do manejo da infiltração da água no solo, as operações de preparo podem ser omitidas, por destruírem a conexão dos macroporos com a superfície.

Por outro lado, Beven \& Germann (1981) destacam que a eficiência da infiltração da água no solo através dos macroporos ou canais biológicos é altamente influenciada pelo sistema de microporos circunvizinho. Esta afirmativa ressalta a importância da determinação da condutividade hidráulica do solo saturado e não saturado em profundidade, pois após o sistema de macroporos estar "saturado" o que comandará o fluxo descendente de água no solo, e o conseqüente "esvaziamento" destes poros ou canais será a condutividade do sistema de poros ao redor deles.

A utilização de implementos de preparo do solo, como subsoladores ou escarificadores, segundo Cassel (1979) aumentam significativamente a capacidade de infiltração de água no solo, enquanto que Mukhtar et al. (1985) destacam o incremento na capacidade de infiltração que uma escarificação pode ocasionar em áreas com plantio direto.

Por outro lado, Azooz \& Arshad (1996) afirmam que solos com muito tempo sob plantio direto, geralmente têm incrementada a taxa de infiltração de água no solo 
próxima e na capacidade de campo, mas não durante a fase próxima a saturação, isto ocorre em função do maior número de macroporos ou canais biológicos.

\subsection{Condutividade hidráulica do solo}

Revisões detalhadas sobre o assunto podem ser vistas em Libardi (1978) e Pauletto (1986) por exemplo. De lá para cá muitos outros trabalhos foram desenvolvidos. Para citar alguns considere-se o de Ellies et al. (1997) que descreve a funcionalidade dosistema poroso, englobando propriedades tais como: quantidade, tamanho, morfologia , continuidade e orientação dos poros. Libardi (1995) define todas estas propriedades dos poros, como sendo a "geometria porosa dos solos".

A condutividade hidráulica, segundo Vieira (1985), tem sido muito pouco estudada, dentro de diferentes preparos e manejo de solos, cita, no entanto, que em literatura estrangeira são relatados casos de maiores valores deste parâmetro sob condição de saturação em plantio direto, principalmente devido a continuidade e rigidez dos poros, apesar destes se apresentarem em menor volume neste sistema.

"Sauer et al. (1990) estudando as propriedades hidráulicas do solo, com o uso de permeâmetro de disco (Perroux \& White, 1988), submetido a diferentes manejos (plantio direto e convencional) concluem que um dos parâmetros mais importantes que condiciona a condutividade hidráulica é a qualidade dos poros e não o volume de macroporos, pois em solos preparados, normalmente se tem maior volume de macroporos, no entanto a condutividade hidráulica do solo saturado é menor do que em solos sob plantio direto."

"Estudos sobre o fluxo da água no solo não saturada, situação mais comum em solos agrícolas, no Brasil ainda são escassos, assumindo no entanto um papel fundamental no entendimento da dinâmica da água no solo, durante os processos de infiltração, redistribuição e suprimento de água as culturas." 
A condutividade hidráulica do solo não saturado, $K(\theta>\theta$ s) traduz o fluxo de água através do solo em função da sua umidade. A contribuição que este fluxo pode representar para a região onde estão as raízes das plantas é ainda mais importante e foi estudado por Jong Van Lier \& Libardi (1997) que observaram que uma raiz individual de uma planta de arroz, é capaz de retirar água do solo de uma distância de mais de 0,1 m, no intervalo de alguns dias. Estes resultados concordam com Hulugalle \& Willatt (1983) que destacam que em condições de baixa densidade de raízes deve-se utilizar condutividade hidráulica crítica ao invés de umidade crítica ao desenvolvimento das plantas.

Sharma \& Uehara (1968) destacam que a condutividade hidráulica, para Latossolos, decresce rapidamente, quando pequenas tensões são aplicadas. Próximo à saturação a condutividade foi de aproximadamente $150 \mathrm{~mm} \mathrm{~h}^{-1}$, com $10 \mathrm{kPa}$ de tensão foi reduzida para $0,1 \mathrm{~mm} \mathrm{~h}^{-1}$. Othmer et al. (1991) atribuem isto a agregação deste solo, que proporciana uma distribuição bimodal dos diâmetro dos poros, sendo classificados em interagregados e intra-agregados, sendo que os primeiros são rapidamente esvaziados fazendo decrescer rapidamente a condutividade e os segundos mais lentamente proporcionando uma condutividade menor.

O comportamento da condutividade hidráulica, em solos com estrutura microagregada próximo a saturação é diferente de outros solos argilosos (Radulovich et al., 1992 e Chen et al., 1993). Na faixa de umidade de domínio dos macroporos (poros interagregados) a função $K(\theta)$ não linear, enquanto que na faixa de umidade abaixo da capacidade de campo (poros intra-agregados) o potencial mátrico passa a governar, valendo para esta condição a clássica teoria, baseada na equação de Richards.

Freire (1979) trabalhando com condutividade hidráulica do solo não saturado de um Latossolo roxo, constatou que os valores de condutividade foram proporcionais a porosidade total do solo na faixa de umidade de 0,30 a $0,42 \mathrm{~m}^{3} \mathrm{~m}^{-3}$.

Em estudos das mudanças nas características do solo sob diferentes manejos, Blevins et al. (1984) concluíram que a condutividade hidráulica do solo não saturado, em 
uma faixa de baixas tensões, foi maior para solos sob plantio direto do que em solos arados. "Em contraposição, Roth et al. (1988) estudando os parâmetros fisico-hídricos do solo em diferentes manejos constataram que em potenciais abaixo de $20 \mathrm{kPa}$ o plantio direto apresentou menores valores de condutividade hidráulica do que manejo convencional enquanto que acima deste potencial mátrico apresentou valores superiores, o que segundo os autores é muito importante no contexto da determinação de água disponivel as plantas." Esta aparente contradição pode ser explicada em função da variação de manejos adotados dentro do plantio direto, uns com maior atividade biológica no solo, outros utilizando culturas com sistema radicular mais agressivo e profundo e a própria variação das características do solo.

Neste sentido, a generalização de resultados de pesquisa para um determinado sistema de manejo do solo, sem uma amplo detalhamento de todas as práticas adotadas, bem como a caracterização das propriedades fisico-hídricas envolvidas, é muito impreciso e pouco científico, pois cada situação poderá ser distinta.

\subsection{Retenção da água no solo}

O solo, o reservatório de água para as plantas, é afetado pelo manejo e práticas culturais alterando a dinâmica e a retenção de água nos seus poros. Esta retenção de água na matriz do solo é governada por duas forças principais: as forças capilares e as forças de adsorção, as quais denomina de forças mátricas que dá origem ao termo potencial mátrico da água no solo. Destaca ainda que um gráfico relacionando a umidade do solo com o potencial mátrico, denomina-se de curva de retenção da água no solo.

Muitos fatores afetam a retenção da água no solo, sendo o principal deles a textura, pois ela determina a área de contato entre as partículas sólidas e a água, determinando em boa parte a distribuição do diâmetro dos poros (Reichardt, 1987). Arruda et al. (1987) tentaram efetuar uma correlação entre textura do solo e água 
disponível. Conclui afirmando que a obtenção da capacidade de campo e do ponto de murcha permanente, baseado somente da textura pode levar a conclusões enganosas.

A estrutura, por determinar o arranjo das partículas e por conseqüência a distribuição dos diâmetro dos poros, juntamente com o tipo e quantidade de argila e o teor de matéria orgânica do solo afetam em muito a disponibilidade de água as culturas. A interação entre estes fatores é bastante complexa e muito dificil de ser prevista. Neste contexto o estudo da distribuição dos diâmetros dos poros do solo é muito importante. Bouma et al. (1977), afirmam que nos microporos, em função do diâmetro muito reduzido, a água circula lentamente devido à ação das forças capilares. Os microporos são portanto os responsáveis pela retenção e redistribuição da água no solo.

Kertzmann (1996) afirma ainda que a água retida dentro dos microagregados de um Latossolo roxo pode ser extraída do solo apenas com tensões muito elevadas, devido ao diminuto diâmetro dos poros, o que a toma praticamente indisponível para as plantas; no entanto, trata-se de um teor de água sempre presente no solo, conferindo-lhe uma umidade permanente, mesmo que reduzida. Essa umidade tem papel importante na condutividade hidráulica e térmica do solo.

A compactação do solo afeta principalmente os poros interagregados. Diversos estudos demonstram que esta compactação pode não afetar significativamente a retenção de água no solo, o mesmo não ocorre com a água disponível para as plantas, pois, em função da diminuição da macroporosidade e aumento da microporosidade, ocorre um aumento da tensão com que esta água está retida nos poros (Baumer \& Bakermans, 1973).

Tognon (1991) e Kertzmann (1996) relatam que na região de Guaira-SP, com a intensificação do cultivo, principalmente em áreas irrigadas, o volume de macroporos foi drasticamente diminuído, ficando o espaço poroso reduzido e os poros mais irregulares. 


\subsection{0 Água no solo disponivel as culturas}

O conceito de água disponível (AD), como aquela contida no solo entre a capacidade de campo e o ponto de murcha permanente é indispensável para o correto manejo da água e orientação de projetos de irrigação. $\mathrm{O}$ critério é controvertido mas se usado com bom senso é de grande utilidade no entendimento da dinâmica da água e sua disponibilidade as culturas. A grande dificuldade é estabelecer critérios para definição da umidade na qual o solo se encontra na capacidade de campo e no ponto de murchamento permanente.

Neste sentido, Reichardt (1988) fez uma detalhada revisão sobre "capacidade de campo" citando trabalho pioneiro de Veihmeyer \& Hendrickson (1949) que definem a "capacidade de campo como a quantidade de água retida pelo solo, depois que o excesso tenha drenado e a taxa de movimento descendente tenha decrescido acentuadamente, o que geralmente ocorre dois a três dias depois de uma chuva ou irrigação em solos permeáveis de estrutura e textura uniformes".

Por outro lado Faria \& Caramori (1986), trabalhando em um Latossolo Roxo distrófico, utilizaram como parâmetro para definir a umidade volumétrica para capacidade de campo, quando a variação $\mathrm{d} \theta / \mathrm{dt}$ era inferior a $0,0025 \mathrm{dia}^{-1}$. Obtiveram valores de potencial mátrico em torno de $8 \mathrm{kPa}$, no entanto, o tempo para atingir estes valores variou de 5 a 7 dias, tempos superiores aos observados por Veihmeyer \& Hendrickson (1949).

O conceito da umidade de murchamento permanente como umidade limite para absorção de água também é controvertido. Sykes (1969) ressalta que a utilização indistinta da umidade na tensão de $1500 \mathrm{kPa}$, não é correto, pois encontrou valores de PMP de $700 \mathrm{kPa}$ para girassol (Helianthus annuus L.) e $3900 \mathrm{kPa}$ para capim trigo intermediário ( Agropyron intermedium Host.). "Destaca ainda que o principal fator que determina a murcha permanente das plantas é a taxa de movimento de água através do solo até as raízes como também comprovaram Jong Van Lier \& Libardi (1997) para a cultura do arroz." 
Por outro lado, em determinadas situações, nem toda a água retida entre a capacidade de campo e o ponto de murchamento permanente é disponível às plantas. Neste sentido Letey (1985) introduziu o conceito de faixa de umidade não limitante, definida por Orellana et al. (1997) como intervalo hídrico ótimo (IHO), como sendo a faixa de umidade do solo cujos limites são definidos considerando-se além da capacidade de campo e o ponto de murchamento permanente, a resistência à penetração e a porosidade de aeração do solo.

Diversos autores têm trabalhado com o conceito de intervalo hídrico ótimo sendo que Silva \& Kay (1997) observaram que o IHO era negativamente afetado pelo aumento da densidade e teor de argila dos solos. Tormena et al. (1998b) trabalhando em Latossolo Roxo, observaram que o IHO foi positivamente afetado pelo aumento da densidade até uma densidade crítica, diminuindo após.

Em outro trabalho, Silva \& Kay (1996) observaram alta correlação entre a redução na produtividade de milho e a frequiência de dias em que a umidade do solo ficou fora do IHO. Isto segundo os autores justifica mais estudos, em diferentes condições de clima e solo, comparando a produtividade das culturas com o IHO. 


\section{MATERIAL E MÉTODOS}

\subsection{Local do experimento}

A área onde foram realizadas as atividades de campo está localizada na Fazenda Lagoa do Fogão, de propriedade de Nelson e Maurício Sakai no Município de Guaira-SP. As coordenadas geográficas aproximadas no local do experimento são $20^{\circ}$ $27^{\prime}$ de latitude Sul e $48^{\circ} 18^{\prime}$ de longitude Oeste, sendo a altitude aproximada de $518 \mathrm{~m}$ em relação ao nível do mar, a temperatura média é de $24^{\circ} \mathrm{C}$ e a precipitação pluvial anual é de $1300 \mathrm{~mm}$, com uma estação seca de maio a setembro, caracterizando o tipo climático Aw de acordo com o Sistema Koeppen (Setzer, 1946).

A escolha do local ocorreu pelo fato desta região, norte do Estado de São Paulo, ser a mais expressiva em área irrigada por aspersão, existindo atualmente em torno de 212 pivôs centrais. Nesta região, as culturas predominantes são o milho, o feijão e a soja, as quais alcançam elevadas produtividades devido à irrigação, bem como pela elevada quantidade de insumos utilizados, sendo a sua principal característica a elevada intensidade de cultivo ( 5 safras em 2 anos).

\subsection{Solo}

O solo da área estudada é um Latossolo Roxo ácrico (Typic Acrorthox), A moderado, textura argilosa, sendo profundo, argiloso e bem drenado em função da sua 
microagregação e posição na paisagem. Este tipo de solo ocupa $85 \%$ da superfície do Município de Guaira (Tognon, 1991 e IPT, 1995).

\subsection{Tratamentos}

Para avaliação das propriedades físico-hídrico-mecânicas do solo foram selecionados três sistemas de uso e manejo, situados em áreas adjacentes, e os locais das determinações definidos em função de facilidade de acesso, uma vez que havia culturas implantadas nas áreas. $\mathrm{O}$ croqui da área bem como a localização das trincheiras, onde foram coletadas as amostras e próximas às quais realizadas as determinações no campo, está apresentado na figura 1.

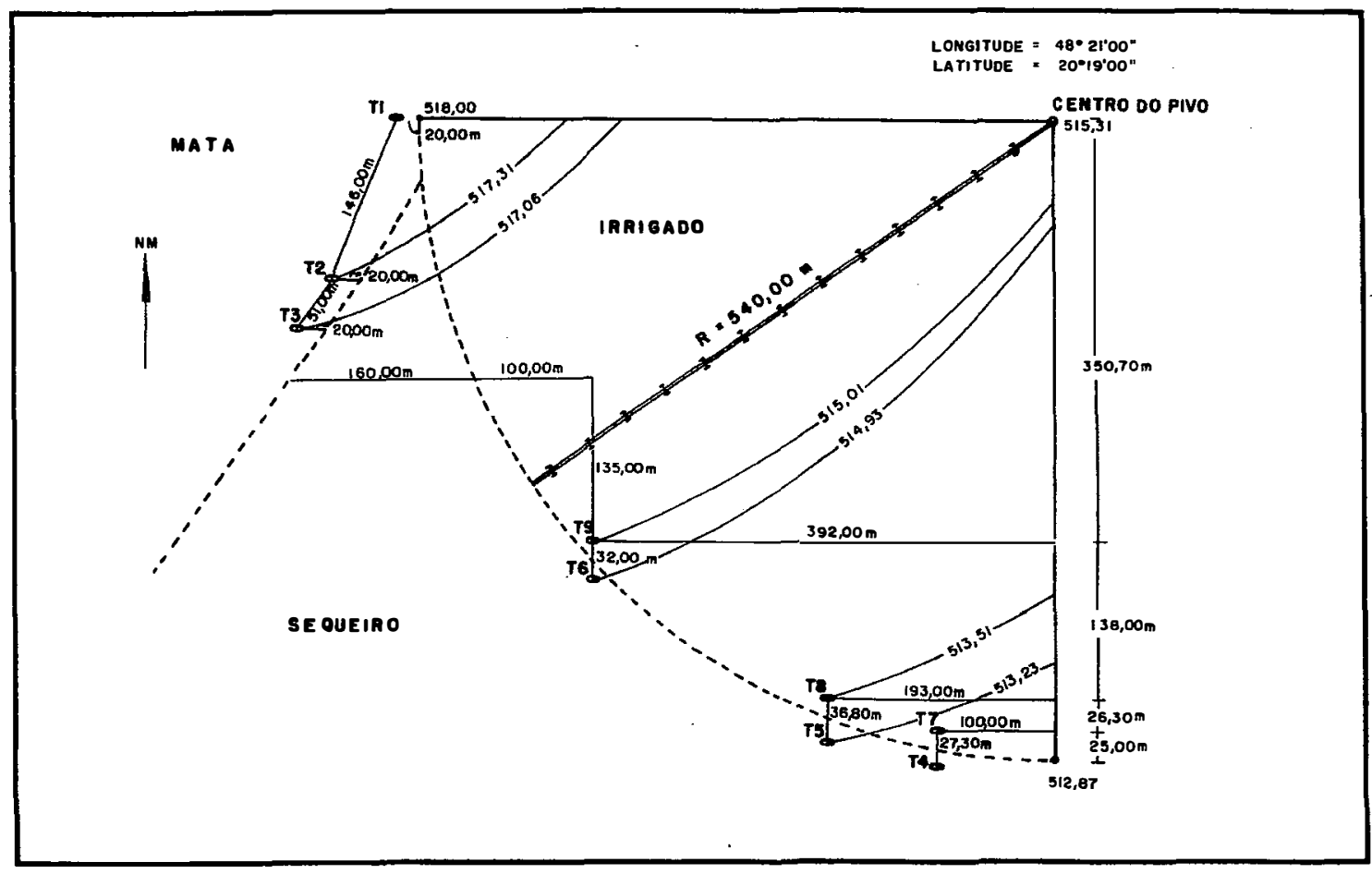

Figura 1 -Croqui da área onde foram realizadas as atividades de campo, ( $T$ : trincheira). 


\subsubsection{Mata (Trincheiras T1, T2 e T3)}

Representado pela mata secundária. $O$ solo sob esta vegetação, não sofreu quaisquer tipo de manejo. As propriedades físico-hídrico-mecânicas deste solo serão consideradas como referência para comparação com os outros sistemas. Denominado simplesmente de "Mata".

\subsubsection{Sequeiro (Trincheiras T4, T5 e T6)}

Área desmatada em 1959 e desde então cultivada com duas culturas anuais, uma no período chuvoso e outra na de safrinha. No período 1959-1991 o solo da área foi manejado no sistema convencional de preparo, com utilização de implementos de discos (arados e grades). A partir de então passou a ser manejada de forma conservacionista, intercalando plantio direto e preparo reduzido. Denominado de "Sequeiro".

\subsubsection{Irrigado (Trincheiras T7, T8 e T9)}

Área desmatada em 1981 para instalação de sistema de irrigação por pivô central, sendo cultivada desde então com culturas anuais em sistema de manejo conservacionista, com plantio direto intercalado com aração profunda, quando da instalação da cultura do tomate (aração profunda em 1990 e 1992). Denominado de "Irrigado".

\subsection{Coleta das amostras de solo com estrutura preservada}

Para cada tratamento, foram abertas 3 trincheiras para a coleta das amostras ao longo de todo o perfil $(0,036 ; 0,1: 0,2 ; 0,3 ; 0,4 ; 0,5 ; 0,6 ; 0,7 ; 0,8 ; 0,9$ e $1 \mathrm{~m})$ utilizando amostrador do tipo "Uhland". Anéis de alumínio com dimensões aproximadas de $73 \mathrm{~mm}$ diâmetro e $72 \mathrm{~mm}$ altura $\left(0,00030 \mathrm{~m}^{3}\right)$ foram utilizados, para determinação da densidade 
do solo, condutividade hidráulica do solo saturado e da resistência à penetração. Para a determinação da retenção de água no solo, utilizou-se conjuntos de 3 anéis, com altura de 23,9 mm, coletadas nas mesmas profundidades. A amostragem foi feita de tal maneira que o plano horizontal que divide o anel em duas partes iguais ficasse na profundidade de coleta. Todas as amostras foram envoltas em folha de alumínio, mergulhadas em parafina derretida e mantidas em geladeira até o momento da análise.

\subsection{Coleta de amostras de solo com estrutura alterada}

Amostras em profundidade $(0,012 ; 0,036 ; 0,06 ; 0,1: 0,2 ; 0,3 ; 0,4 ; 0,5 ; 0,6$;

0,$7 ; 0,8 ; 0,9 \mathrm{e} 1 \mathrm{~m}$ ) foram retiradas em cada trincheira. Estas foram secas ao ar e peneiradas por peneira com malha de $2 \mathrm{~mm}$. Utilizou-se esta terra fina seca ao ar para determinar a textura, densidade de sólidos, teor de argila dispersa em água, limite plástico, líquido e de pegajosidade e para as análise dos atributos químicos.

\subsection{Densidade do solo e de sólidos}

Com as amostras com estrutura indeformada determinou-se a densidade do solo nas diferentes camadas. A densidade de sólidos foi determinada pelo método do balão volumétrico (EMBRAPA, 1997), utilizando-se álcool etilico para a medição do volume de $20 \mathrm{~g}$ de solo.

\subsection{Textura do solo}

Efetuou-se a análise granulométrica seguindo rotina do Laboratório de Física de Solos da ESALQ, baseada na metodologia descrita por Gee \& Bauder (1986), utlizando como dispersantes solução aquosa de hexametafosfato de sódio puro $\left(6 \mathrm{~kg} \mathrm{~m}^{3}\right)$ e de hidróxido de sódio $\left(4 \mathrm{~kg} \mathrm{~m}^{-3}\right)$ e densímetro de Bouyoucos para as leituras. A 
primeira leitura foi feita $40 \mathrm{~s}$ após 18 horas de agitação para determinação da areia total e a segunda 2 horas após para determinação da argila, sendo a fração silte determinada por diferença. A separação da fração areia foi feita for lavagem e peneiramento em peneira com malha de $0,053 \mathrm{~mm}$.

Após secas em estufa efetuou-se a separação das frações areia, através de peneiramento em muito grossa $(>1 \mathrm{~mm})$, grossa $(0,5-1,0 \mathrm{~mm})$, média $(0,25-0,5 \mathrm{~mm})$, fina $(0,105-0,25 \mathrm{~mm})$ e muito fina $(<0,105 \mathrm{~mm})$. Determinou-se também o teor de argila dispersa em água, utilizando-se somente água destilada como meio dispersor e efetuandose a leitura com o densímetro duas horas após a agitação. Analisaram-se 3 amostras por profundidade, em 13 profundidades, para os três manejos.

\subsection{Análise dos atributos químicos do solo}

Amostras do terra, 3 repetições por profundidade e manejo foram submetidas a análise dos atributos químicos quais sejam: $\mathrm{pH}$, matéria orgânica, fósforo, potássio, cálcio, magnésio, hidrogênio + alumínio, saturação por bases, capacidade de troca de cátions e saturação por bases para verificar possível efeito destas sobre as propriedades do estudadas.

\subsection{Consistência do solo}

Efetuou-se a determinação dos limites de liquidez, de plasticidade e de pegajosidade , seguindo metodologia descrita em Sowers (1965); EMBRAPA (1997) e Nogueira (1998). O teste foi feito com amostras coletadas nas profundidades 0,$01 ; 0,03$; 0,$05 ; 0,1 ; 0,2 ; 0,3 ; 0,4$ e $0,5 \mathrm{~m}$, secas ao ar, peneiradas em peneira com malha de $0,42 \mathrm{~mm}$ e umedecidas com 3 dias de antecedência. 


\subsection{Teste de Proctor}

O teste de Proctor normal com $560 \mathrm{kPa}$, sem reuso de material, foi realizado seguindo metodologia descrita por Nogueira (1998). Para tal, finalidade amostras compostas de terra para duas camadas $(0,00-0,45 \mathrm{~m}$ e $0,45-0,95 \mathrm{~m})$ nos três tratamentos foram peneiradas em peneira com $4,8 \mathrm{~mm}$ de malha.

Os resultados de densidade do solo em função da umidade gravimétrica do solo foram ajustados, minimizando a soma dos quadrados dos desvios, obtendo-se uma equação polinomial de $2^{\circ}$ grau.

\subsection{Resistência do solo à penetração}

Determinou-se a resistência à penetração, nas amostras com estrutura indeformada, de $73 \mathrm{~mm}$ de diâmetro e $73 \mathrm{~mm}$ de altura, coletadas nas profundidades 0,$035 ; 0,1 ; 0,2 ; 0,3 ; 0,4 ; 0,5 ; 0,6 ; 0,7 ; 0,8 ; 0,9$ e $1 \mathrm{~m}$. Estas amostras foram submetidas a diferentes tensões $(8,50,100,300$ e $500 \mathrm{kPa})$ através da utilização de funis e câmaras de placa porosa, para obter diferentes níveis bem como uniformidade de umidade em toda a amostra.

Como o objetivo era determinar qual a umidade em que a resistência a penetração se tornava limitante $(2 \mathrm{MPa})$, determinou-se inicialmente a resistência nas tensões de 8, 100 e $500 \mathrm{kPa}$. Após, conforme os resultados, intercalaram-se tensões abaixo da tensão em que haviam ocorrido valores acima de $2 \mathrm{Mpa}$. No solo da mata efetuou-se as determinações em três potenciais por falta de amostras.

A resistência do solo à penetração foi determinada em laboratório, utilizandose um penetrômetro eletrônico (figura 2) desenvolvido no Laboratório de Física de Solos do Departamento de Ciência do Solo da ESALQ/USP, baseado naquele descrito por Bradford (1986). É equipado com atuador linear-Electrak 2000 e célula de carga (10 kgf), acoplada, por meio de uma interface, a um microcomputador, que utiliza 
software AQDXy (Lynx). Com isto obtém-se uma velocidade constante de penetração de $0,1667 \mathrm{~mm} \mathrm{~s}^{-1}$, num cone com $4 \mathrm{~mm}$ de diâmetro da base $\left(12,56 \mathrm{~mm}^{2}\right)$ e semi-ângulo de $30^{\circ}$, coletando um dado a cada segundo. A resistência à penetração foi obtida pelo quociente da força aplicada ao cone, medida pela célula de carga pela área da base do cone $\left(\mathrm{N} \mathrm{m}^{-2}=\mathrm{Pa}\right) . \mathrm{O}$ perfil de resistência foi reconstituido a partir dos valores médios da resistência das amostras. Para o cálculo da média utilizou-se em torno de 400 valores centrais de cada amostra.

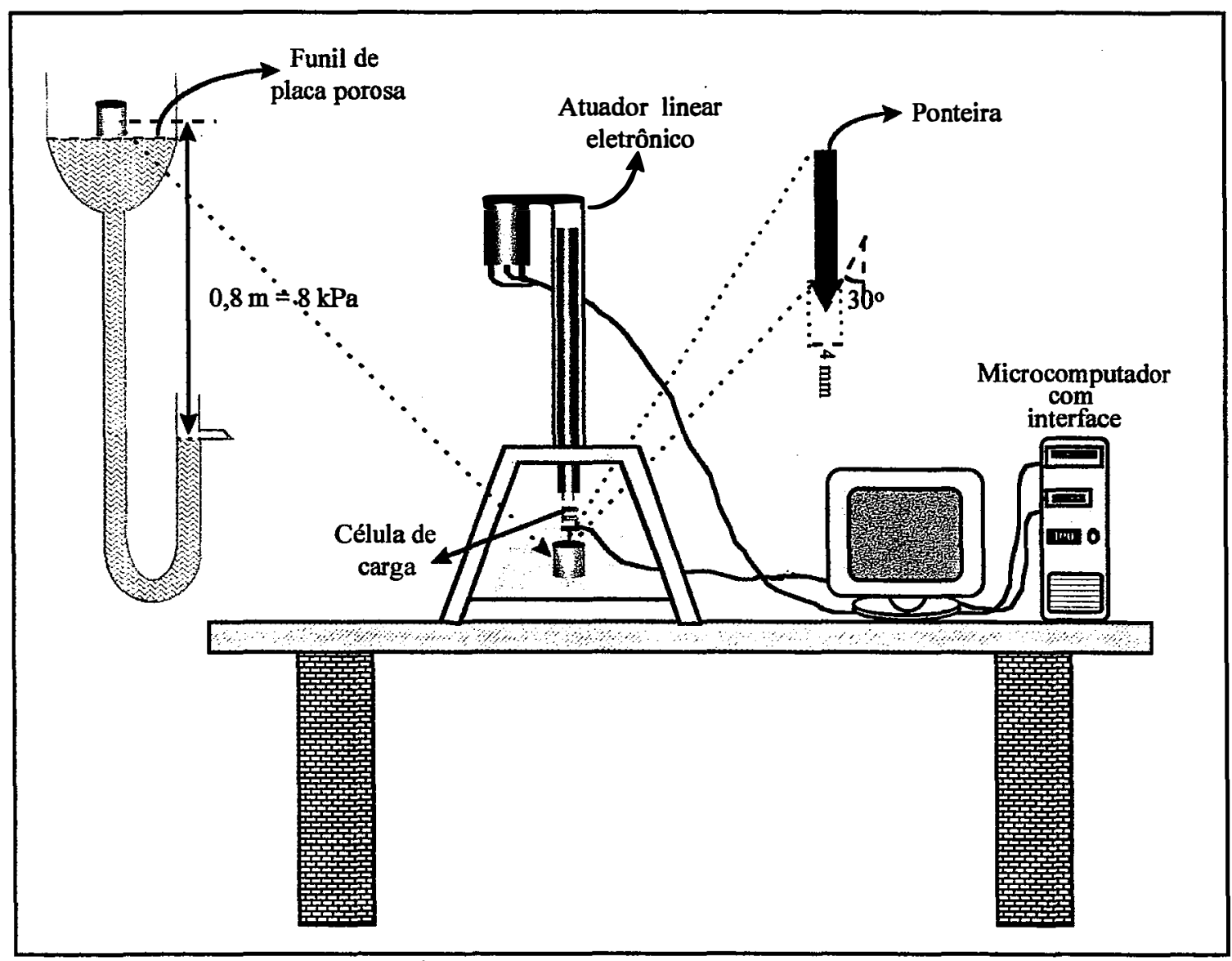

Figura 2 - Esquema do penetrômetro eletrônico utilizado para as determinações de resistência do solo à penetração. 


\subsection{Determinação da retenção de água em amostras com estrutura preservada}

Utilizaram-se as amostras compostas por 3 anéis. Após a separação, o volume do solo era ajustado ao volume do anel, retirando-se o excesso. Acoplava-se na parte inferior um paninho (tecido sintético) com um atilho e eram colocadas para saturar, acrescentando-se água lentamente, deixando saturar por um período de 24 horas.

Utilizaram-se funis de placa porosa para determinação da retenção de água nas amostras do solo para as tensões 0,$5 ; 1 ; 2 ; 3 ; 5 ; 8 ; 10$ e $15 \mathrm{kPa}$ e câmaras de pressão de Richards para as tensões $30 ; 50 ; 100 ; 300 ; 500$ e $1500 \mathrm{kPa}$.

Nos funis de placa porosa as amostras eram deixadas até que era atingido o equilíbrio, o que normalmente ocorria 72 horas após terem sido colocadas. Nas câmaras de pressão de Richards as amostras eram deixadas até cessar completamente o fluxo de água para fora da placa.

Após cessada a saída de água das amostras, retirava-se o paninho, colocava-se a amostra com o anel em uma latinha, pesava-se e colocava-se na estufa $\left(105^{\circ} \mathrm{C}\right.$ durante 24 horas) a fim de obter a massa de solo seco . Cada ponto da curva de retenção foi feito utilizando-se amostras diferentes, com isto obteve-se maior agilidade nesta determinação, pois vários pontos (tensões) podem ser determinados simultaneamente, além de amenizar o efeito da variabilidade espacial que se sabe que existe nesta característica do solo.

Ajustou-se os pontos experimentais à equação de Van Genuchten (1980) minimizando a soma dos quadrados dos desvios, utilizando o software SWRC (Dourado Neto et al., 1990), obtendo assim os parâmetros empíricos de ajuste, $\alpha, \mathrm{m}$ e n, fixando-se $\theta$ s no valor correspondente à porosidade total. 


\subsection{Determinação da retenção de água em amostras com estrutura não preservada}

Anéis com dimensões $73 \mathrm{~mm}$ diâmetro e $24 \mathrm{~mm}$ de altura, com paninho na parte inferior foram preenchidos com terra peneirada em peneira com malha $2 \mathrm{~mm}$ (tfsa) das diferentes camadas e tratamentos. Foram saturadas com água destilada e submetidas a tensões, seguindo a mesma metodologia descrita acima. Duas sub-amostras foram utilizadas altemadamente, tanto nos pontos de baixa como de alta tensão, para determinação da capacidade de retenção da água.

\subsection{Porosidade do solo}

Para determinação da porosidade total do solo nas diferentes camadas, utilizou-se a relação existente entre a densidade dos sólidos e a densidade do solo.

A porosidade foi classificada em função do diâmetro dos poros, que foi obtido a partir da curva característica de água no solo. Para esta classificação chamou-se de "macroporos" poros com diâmetro maior que 0,05 mm (que perdem a água em tensões menores que $6 \mathrm{kPa}$ ), "microporos" aqueles com diâmetro entre 0,05 e 0,0002 mm (que são esvaziados a tensões entre 6 e $1500 \mathrm{kPa}$ ) e "criptoporos", poros com diâmetro menor que $0,0002 \mathrm{~mm}$ (que perdem a água apenas para tensões maiores que $1500 \mathrm{kPa}$ ).

\subsection{Capacidade de infiltração de água no solo}

Para a determinação da capacidade de infiltração de água no solo, utilizaram-se cilindros concêntricos, sendo o central equipado com bóia para manter o nível de água constante, conforme descrito por Bouwer (1986). Efetuou-se esta determinação em 3 profundidades (superficie, 0,2 e 0,5 $\mathrm{m}$ de profundidade), instalando-se sempre os cilindros no mesmo local, por proporcionar maior facilidade de instalação e economia de 
água em função da mais rápida estabilização da taxa de infiltração. A lâmina foi mantida constante até a obtenção da taxa constante de infiltração.

Efetuaram-se 3 determinações por profundidade para cada manejo, com exceção da mata, onde não se fez nenhuma determinação por problemas operacionais como dificuldade de suprimento de água e por já existirem informações de outros autores sobre esta propriedade do solo nesta área.

Os dados experimentais foram ajustados a equação de Kostiakov, a qual embora empírica, se ajusta bem para curtos intervalos de tempo, para uma grande quantidade de solos.

\subsection{Condutividade hidráulica do solo saturado}

Determinou-se a condutividade hidráulica do solo saturado, conforme metodologia proposta por Klute \& Dirksen (1986), a qual propõe fluxo ascendente com pequeno gradiente para amostras com alta condutividade. Utilizando-se as amostras de $0,00030 \mathrm{~m}^{3}$ (73 mm diâmetro e $72 \mathrm{~mm}$ altura) determinou-se a condutividade do solo saturado em laboratório, acoplando a amostra em um dispositivo (figura 3), no qual se promovia fluxo ascendente de água e o nível era mantido constante através da utilização de dois frascos de Mariotte.

Um frasco (A) com o nível da água posicionado na parte inferior da amostra, utilizado para saturar a amostra e outro (B) para efetuar a determinação propriamente dita, com nível de água posicionado acima da superficie da amostra, sendo que se efetuava medições da vazão até esta se tornar constante, quando então se efetuava a determinação propriamente dita coletando água em proveta graduada, durante 20 minutos.

A partir da vazão calculou-se o fluxo (equação 1) e pela equação de DarcyBuckingham (equação 2) o cálculo da condutividade hidráulica. 


$$
q=\frac{d Q}{A d t}
$$

onde:

$\mathrm{q}=$ fluxo $\left(\mathrm{mm} \mathrm{h}^{-1}\right)$

$\mathrm{dQ}=\operatorname{Vazão}\left(\mathrm{mm}^{3}\right)$

$\mathrm{dt}=$ tempo $(\mathrm{h})$

$A=$ Seção da superficie da amostra $\left(\mathrm{mm}^{2}\right)$

$$
q=-K \frac{d \phi t}{d z}
$$

onde:

$\mathrm{q}=$ fluxo $\left(\mathrm{mm} \mathrm{h}^{-1}\right)$

$\mathrm{K}=$ condutividade hidráulica do solo $\left(\mathrm{mm} \mathrm{h}^{-1}\right)$

$\mathrm{d} \phi \mathrm{t}=$ diferença de potencial total $(\mathrm{mm})$

$\mathrm{dz}=$ altura da amostra (mm)

a qual aplicada para o cálculo da condutividade do solo saturado, do esquema utilizado (figura 3) fica:

$$
K o=\frac{q}{\frac{\Delta \phi t}{\Delta z}}=\frac{q}{\frac{\phi t(A)-\phi t(B)}{L}}=\frac{q}{\frac{163 m m-90 m m}{73 m m}}=\mathrm{q}
$$




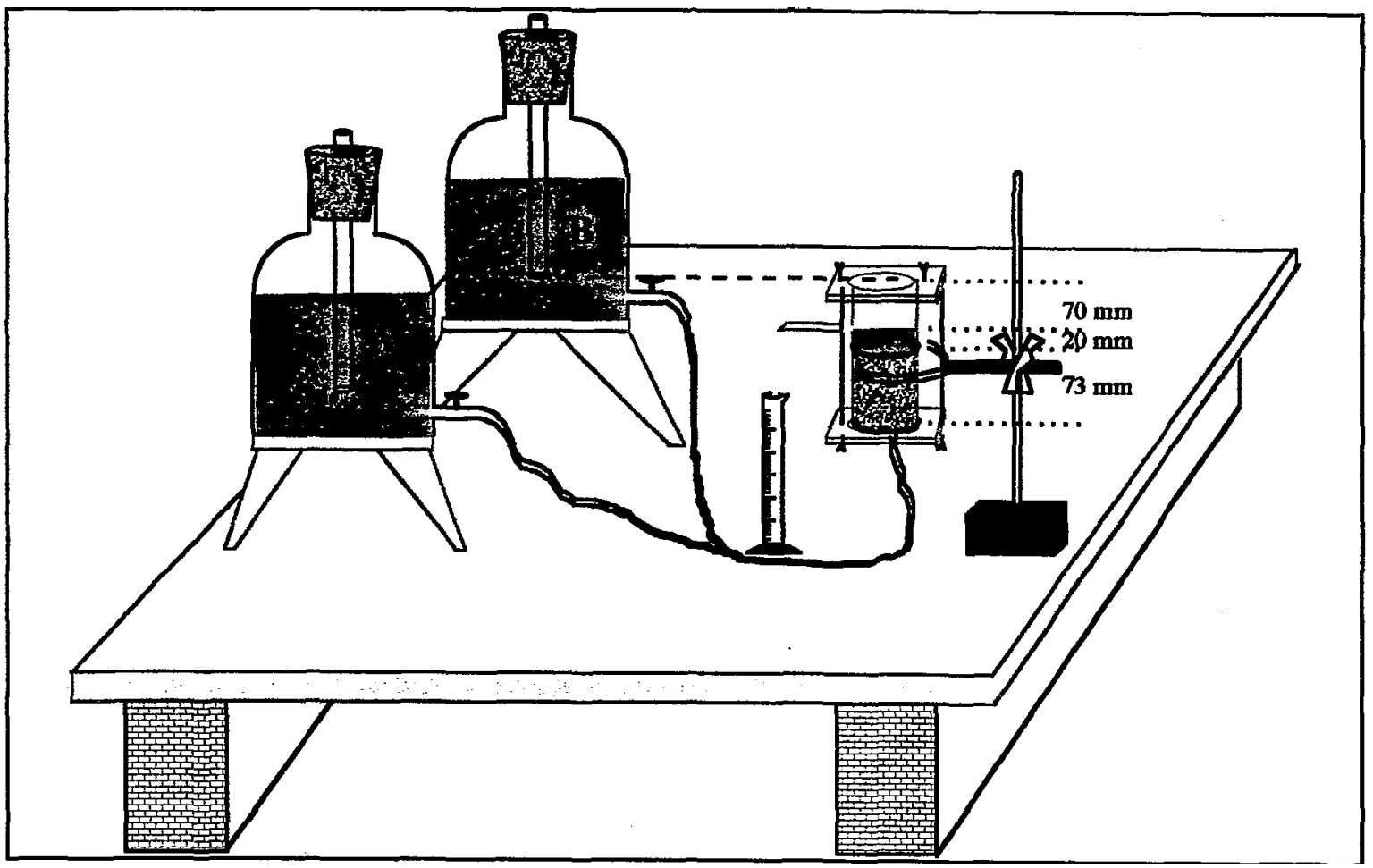

Figura 3 - Sistema utilizado para determinação da condutividade hidráulica do solo saturado em laboratório.

\subsection{Construção, teste e instalação dos tensiômetros}

Os tensiômetros com manômetro de mercúrio, utilizados para a medida do potencial mátrico no campo, foram construídos no Laboratório do Departamento de Física e Meteorologia da ESALQ/USP. Antes da construção as cápsulas porosas foram submetidas aos testes de condutância e pressão de borbulhamento, selecionando-se as que apresentavam condutância maior que $1.10^{-5} \mathrm{~cm}^{2} \mathrm{~s}^{-1}$, seguindo recomendação de Cassel \& Klute (1986) e pressão de borbulhamento superior a $100 \mathrm{kPa}$. Após terminada a construção dos tensiômetros efetuou-se novamente o teste de pressão de borbulhamento para verificar possíveis vazamentos seguindo metodologia proposta por Libardi (1997).

Para determinação da condutividade hidráulica do solo não saturado, 9 baterias (3 em cada tratamento) de 10 tensiômetros foram instaladas no campo. As cápsulas 
porosas dos tensiômetros foram instaladas no perfil a profundidades de $0,1 \mathrm{em} 0,1 \mathrm{~m}$ até $1 \mathrm{~m}$. A instalação foi feita com um mês de antecedência, a fim de avaliar o correto funcionamento dos tensiômetros antes do início dos ensaios. $\mathrm{O}$ procedimento consistiu em mantê-los cheios de água e fechados (figura 4A) até uma semana antes da instalação do experimento quando então o espaguete era conectado e o manômetro de mercúrio ativado (figura 4B).

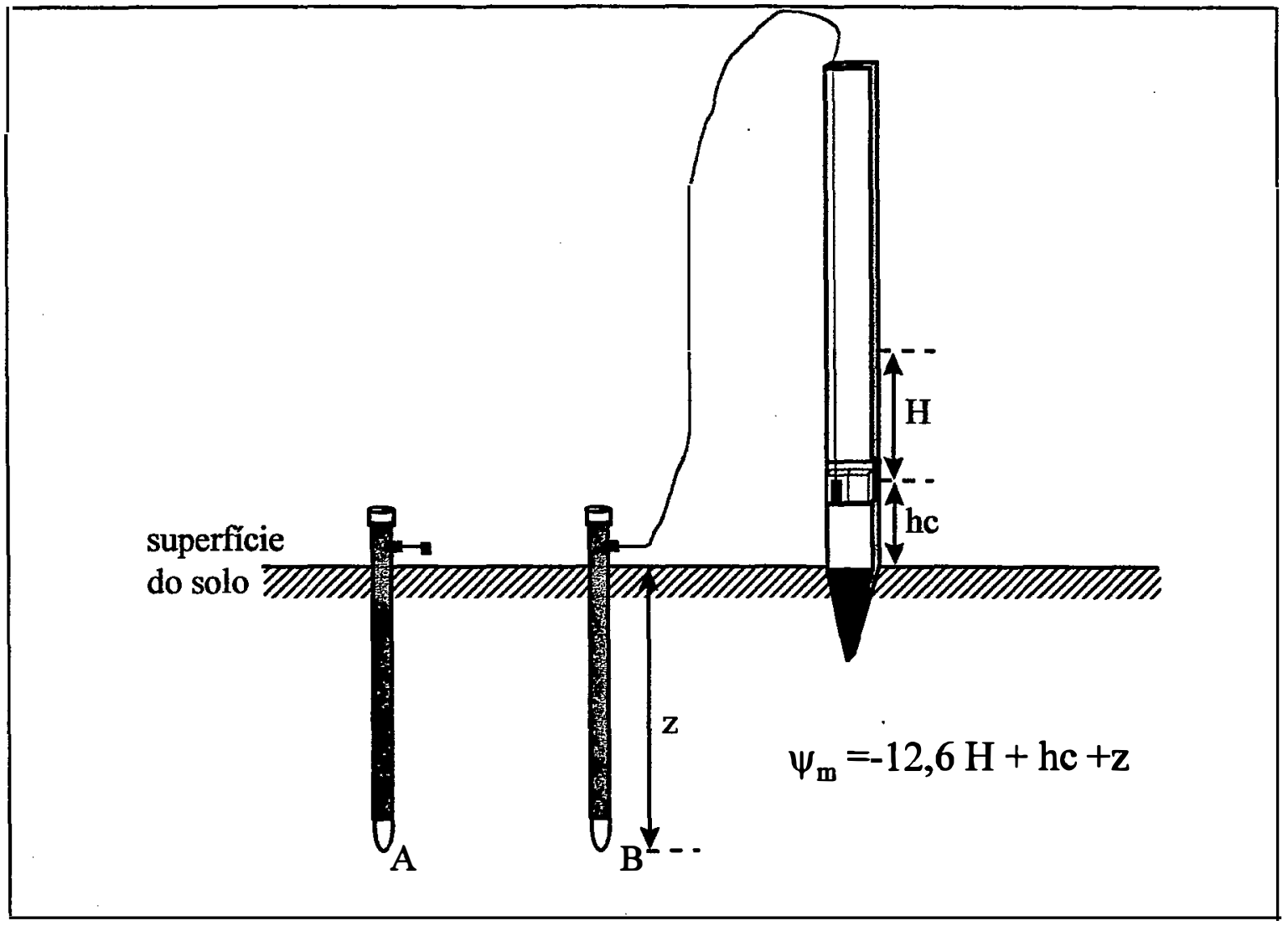

Figura 4 - Esquema da instalação dos tensiômetros a campo

\subsection{Determinação da condutividade hidráulica do solo não saturado no campo}

Utilizou-se o método do perfil instantâneo proposto por Hillel et al. (1972) Para delimitar as parcelas, utilizaram-se folhas de flandre de $0,5 \mathrm{~mm}$ de espessura, $0,5 \mathrm{~m}$ de altura e $15,7 \mathrm{~m}$ de comprimento. Unindo as extremidades por meio de parafusos e 
vedação de borracha, obteve-se um círculo com $5 \mathrm{~m}$ de diâmetro, 19,60 $\mathrm{m}^{2}$ de área inundada, conforme pode ser observado na figura 5 .

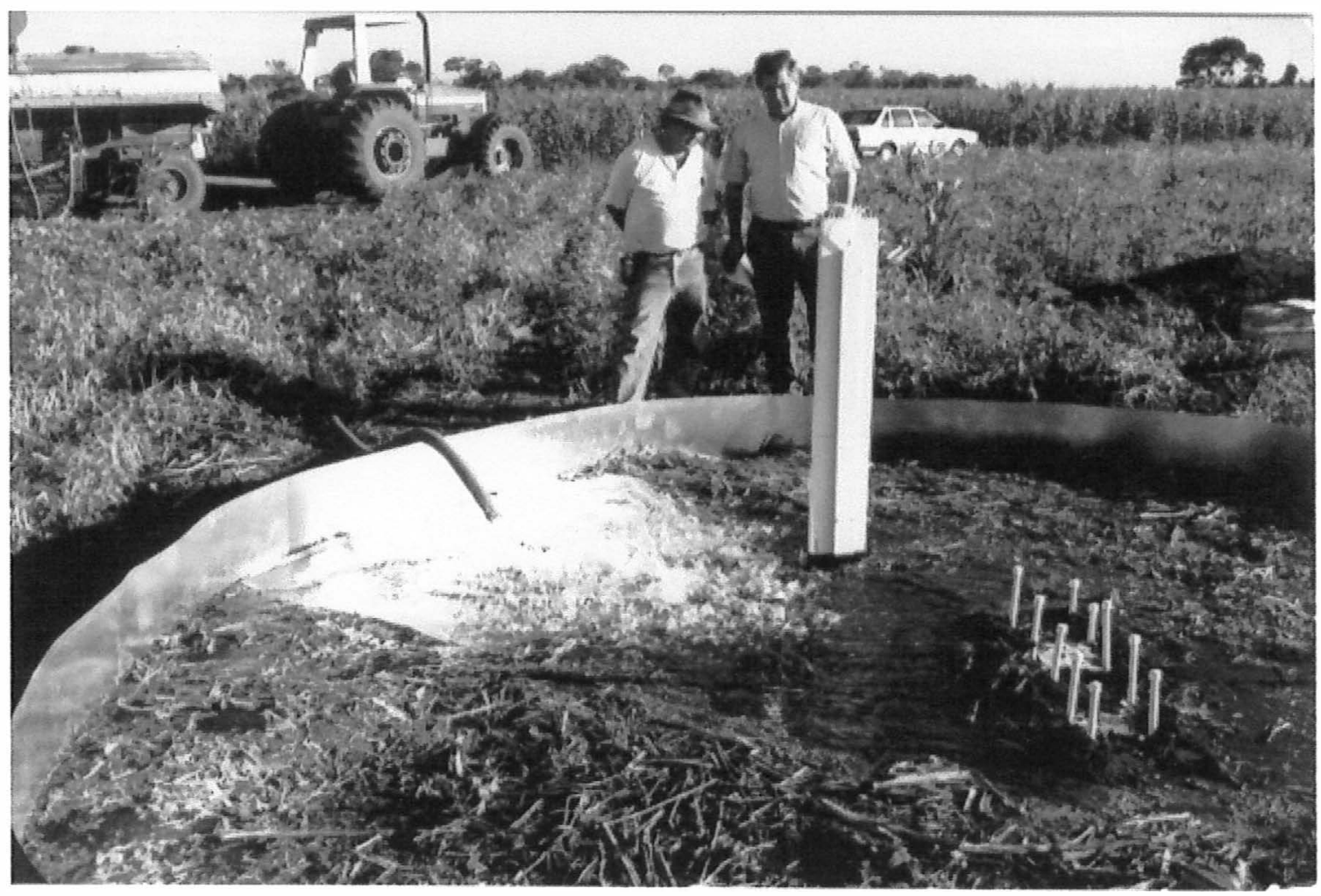

Figura 5 - Detalhe da instalação dos tensiômetros, manômetro e delimitação da área no início do processo de inundação.

Abriu-se um sulco em forma circular, 0,2 $\mathrm{m}$ de profundidade, onde foi introduzida a folha de flandre. Após fechado o sulco iniciou-se a inundação das parcelas, utilizando-se em torno de $10 \mathrm{~m}^{3}$ de água. Cessada a infiltração, para evitar evaporação de água, cobriu-se a parcela com duas lonas de plástico, e com folhas de isopor junto aos tensiômetros (figura 6).

No $\mathrm{t}=0$ de redistribuição de água iniciaram-se as leituras diárias dos tensiômetros sempre na primeira hora da manhã, antes do sol esquentar o plástico ou a água dos tensiômetros e dos espaguete o que pode acarretar erros nas determinações. As leituras foram efetuadas, durante um período de aproximadamente 30 dias. 


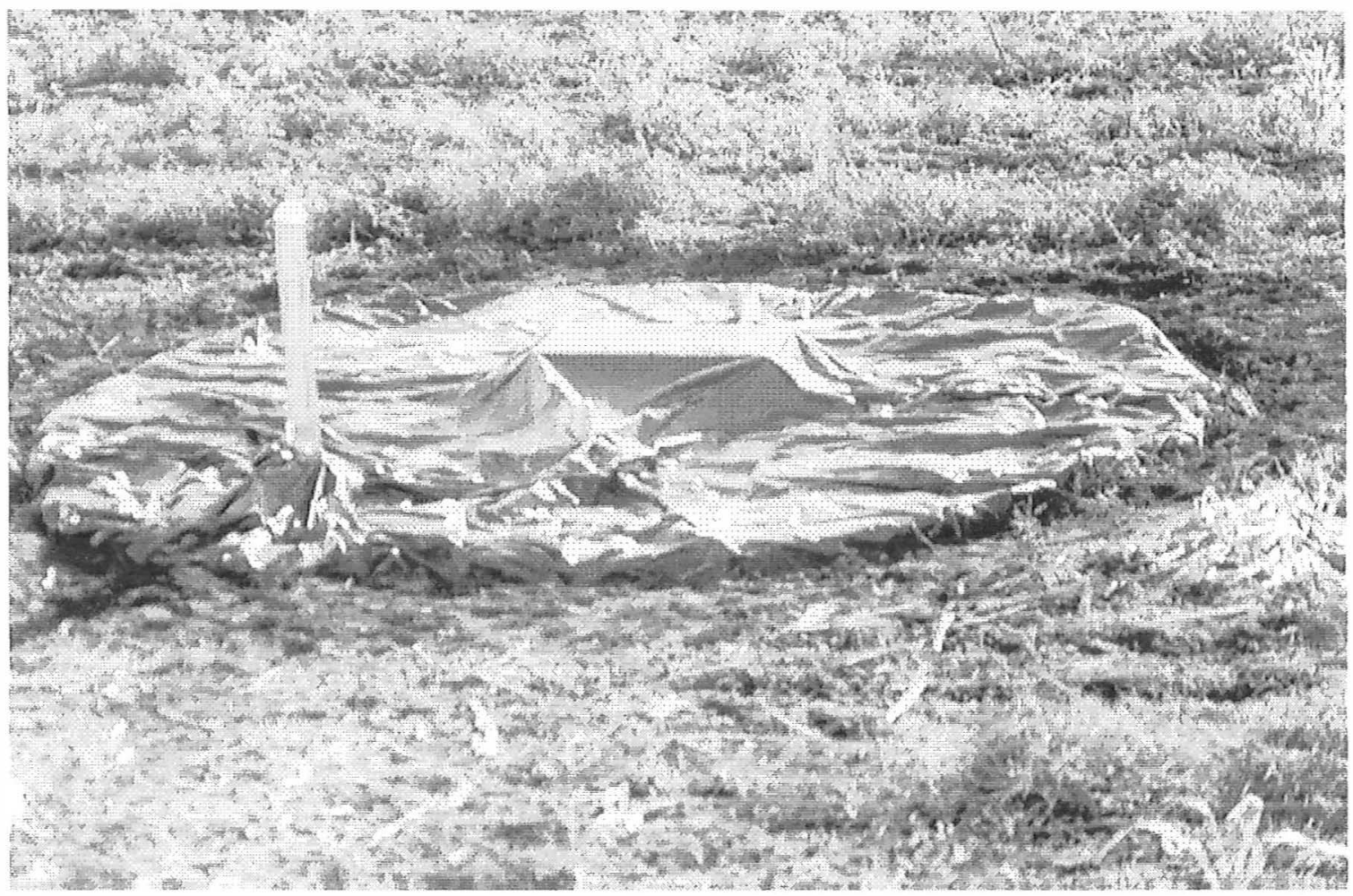

Figura 6 - Detalhe da parcela coberta com lona plástica para evitar evaporação.

Com os valores de potencial mátrico obtidos através das leituras dos tensiômetros e as curvas de retenção, gráficos de armazenagem da água no solo em função do tempo para cada profundidade e manejo foram confeccionados e os dados ajustados a uma equação do tipo potencial.

$$
\mathrm{h}_{\mathrm{z}}=\mathrm{at} \mathrm{t}^{\mathrm{b}}
$$

onde:

$\mathrm{h}_{\mathrm{z}}=$ armazenagem de água no solo $(\mathrm{mm})$ até a profundidade $\mathrm{z}(\mathrm{m})$

$\mathrm{t}=$ tempo(h)

$\mathrm{a}\left(\mathrm{mm} \mathrm{h}^{\mathrm{b}}\right)$ e b são os parâmetros empíricos 
Derivando-se a equação 4 com relação ao tempo obtém-se a equação 5 para cálculo do fluxo (q) de água em cada profundidade e tempo.

$$
\frac{d H z}{d t}=\mathrm{q}=a b^{\mathrm{b}-1}
$$

Para o cálculo do gradiente de potencial total obtidos através dos tensiômetros, foram utilizados os valores de potencial total logo acima e logo abaixo da profundidade em questão (equação 6), razão pela qual não foi possível calcular a condutividade na primeira e última profundidades.

$$
\operatorname{grad} \phi \mathrm{t}\left(Z_{\mathrm{i}}\right)=\frac{\phi t\left(Z_{i-1}\right)-\phi t\left(Z_{i+1}\right)}{Z_{i-1}-Z_{i+1}}
$$

Calculou-se a condutividade hidráulica do solo não saturado, através da equação 7.

$$
K(\theta)=\frac{q}{\operatorname{grad} \phi t}
$$

Para a obtenção de uma relação entre $\mathrm{K}$ e $\theta$ procurou-se ajustar os valores de $\mathrm{K}(\theta)\left(\mathrm{mm} \mathrm{h}^{-1}\right)$ em função de $\theta\left(\mathrm{m}^{3} \mathrm{~m}^{-3}\right)$, para cada profundidade e manejo de solo (equação 8).

$$
\ln \mathrm{K}=\mathrm{a} \theta+\mathrm{b}
$$

onde:

$\mathrm{K}=$ condutividade hidráulica $\left(\mathrm{mm} \mathrm{h}^{-1}\right)$

$\theta=$ umidade volumétrica do solo $\left(\mathrm{m}^{3} \mathrm{~m}^{-3}\right)$

$\mathrm{a}$ e $\mathrm{b}=$ parâmetros empíricos 
3.19 Determinação da condutividade hidraúlica do solo não saturado, em laboratório, de amostras com estrutura in deformada

Para determinar a condutividade hidráulica do solo não saturado em laboratório, amostras de solo com estrutura indeformada foram coletadas utilizando tubos de PVC (polivinil-cloreto) de $1,15 \mathrm{~m}$ comprimento e $0,2 \mathrm{~m}$ de diâmetro e de espessura de parede de 4,5 $\mathrm{mm}$. Na parte inferior do tubo acoplou-se um anel de metal, em forma de bisel, o qual possuía diâmetro interno $2 \mathrm{~mm}$ menor que o do tubo (figura 7).

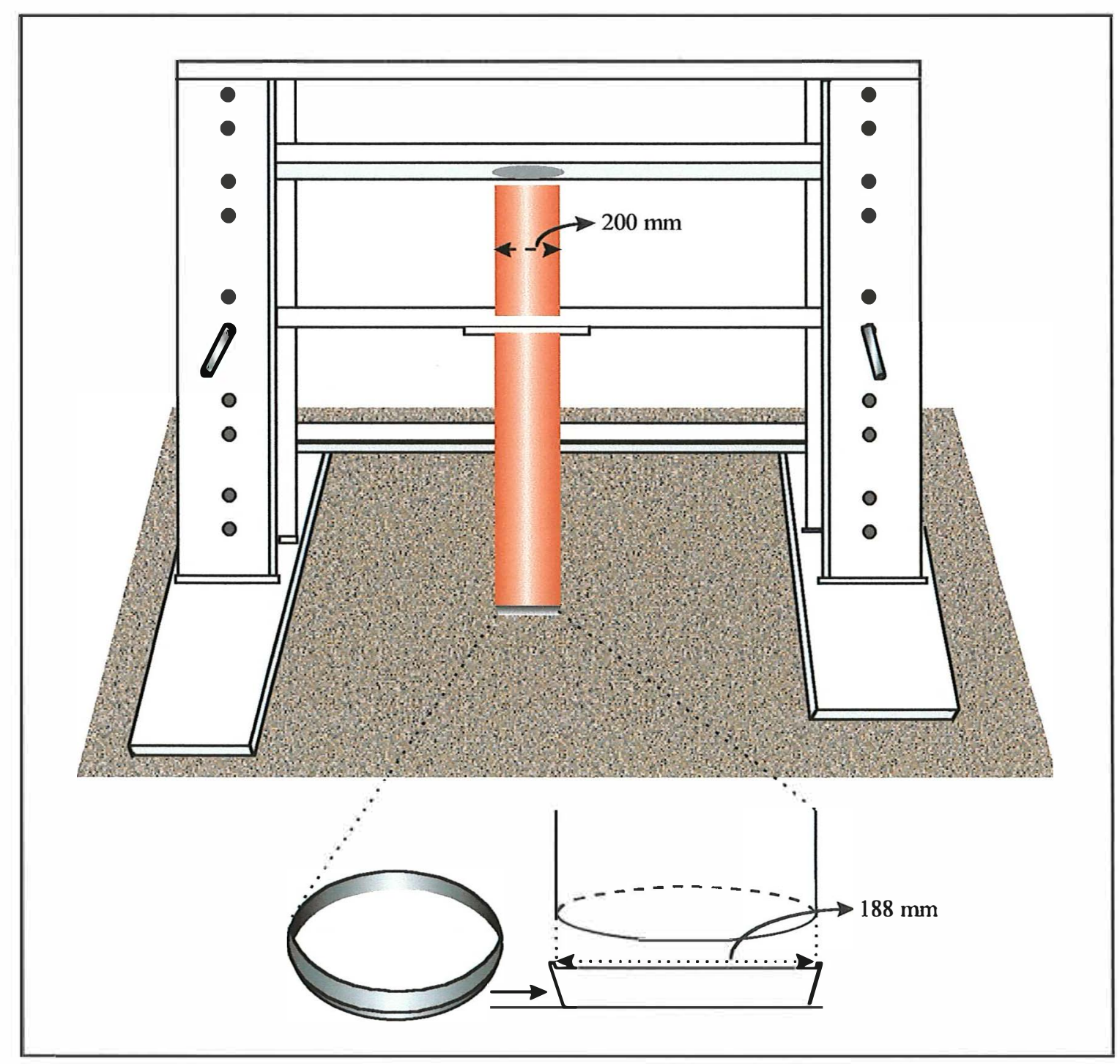

Figura 7 - Dispositivo utilizado para retirar amostra de solo. 
Utilizando-se uma estrutura de madeira, ancorada ao solo por meio de estacas de ferro e arames, a qual serviu de apoio a um macaco hidráulico com capacidade de 20 $\mathrm{kN}$, introduziu-se o tubo no solo, ao lado da trincheira. Conforme o tubo entrava no solo, cavava-se em volta para diminuir a resistência à penetração (figura 8).

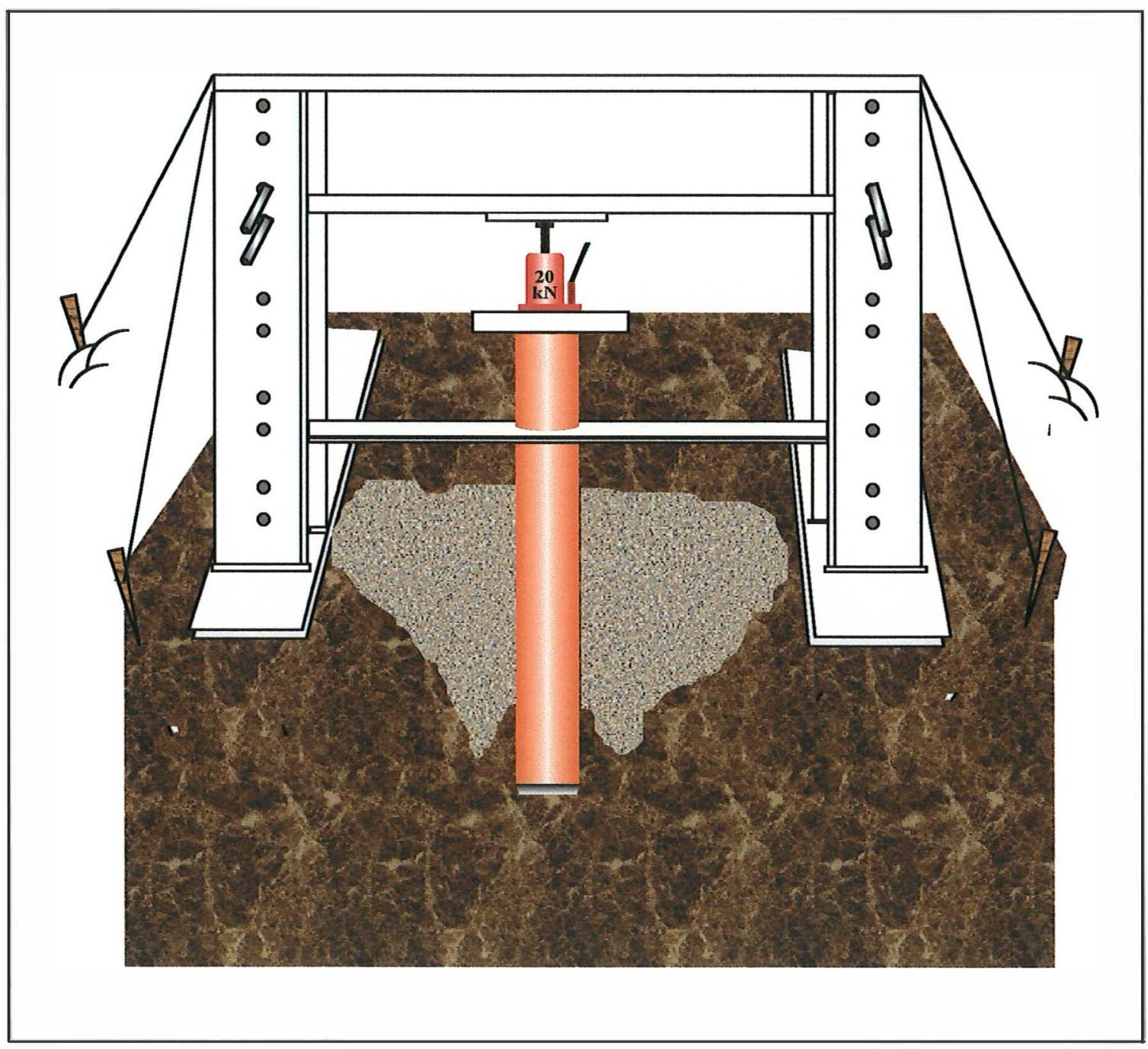

Figura 8 - Detalhe do procedimento da retirada da amostra de solo. 
Terminada a penetração, fechava-se o tubo nas duas extremidades com discos e varões de metal, sendo transportado com todo cuidado na vertical até o laboratório. Da parte inferior da coluna retirou-se uma camada com $50 \mathrm{~mm}$ de solo para colocação de uma manta de bidin e uma camada com $45 \mathrm{~mm}$ de pedrisco com o objetivo de proporcionar um fluxo unidirecional de água junto ao aplicador de água que foi acoplado na parte inferior da coluna, utilizado para a saturação do solo da coluna de baixo para cima e medida a vazão quando do estabelecimento do fluxo de cima para baixo.

A coluna foi instrumentada com tensiômetros cujas cápsulas porosas foram instaladas, de $0,1 \mathrm{em} 0,1 \mathrm{~m}$ a partir da superficie, em ângulo de $45^{\circ}$ e posicionada no centro da coluna. Estas foram conectadas a manômetros de água por meio de espaguetes (figura 9).

Para determinar a condutividade hidráulica, promovia-se diferentes fluxos descendentes de água através da coluna, o que era conseguido com um sistema de gotejamento na superficie do solo. Esperava-se ocorrer fluxo estacionário, o qual era medido, com uma proveta, em um dispositivo de nível constante, conectado ao aplicador de água da parte inferior da coluna.

Quando ocorria o fluxo estacionário efetuava-se as leituras do potencial total nos manômetros dos tensiômetros e calculava-se a condutividade, através da equação 7 .

Para determinação do gradiente de potencial total na profundidade em questão, utilizava-se a leitura de potencial dos tensiômetros imediatamente acima e abaixo.

Após terminadas as medições, cortava-se a coluna de PVC, e com um amostrador, coletava-se de dentro das colunas, 3 amostras com estrutura indeformada por meio de anéis de $50 \mathrm{~mm}$ de diâmetro e $50 \mathrm{~mm}$ de altura. Com estas amostras determinava -se a densidade do solo e a retenção de água no solo até a tensão de $10 \mathrm{kPa}$, através da utilização de funis de placa porosa, para obtenção do $\theta$ correspondente ao potencial mátrico, indicado pelos tensiômetros. 


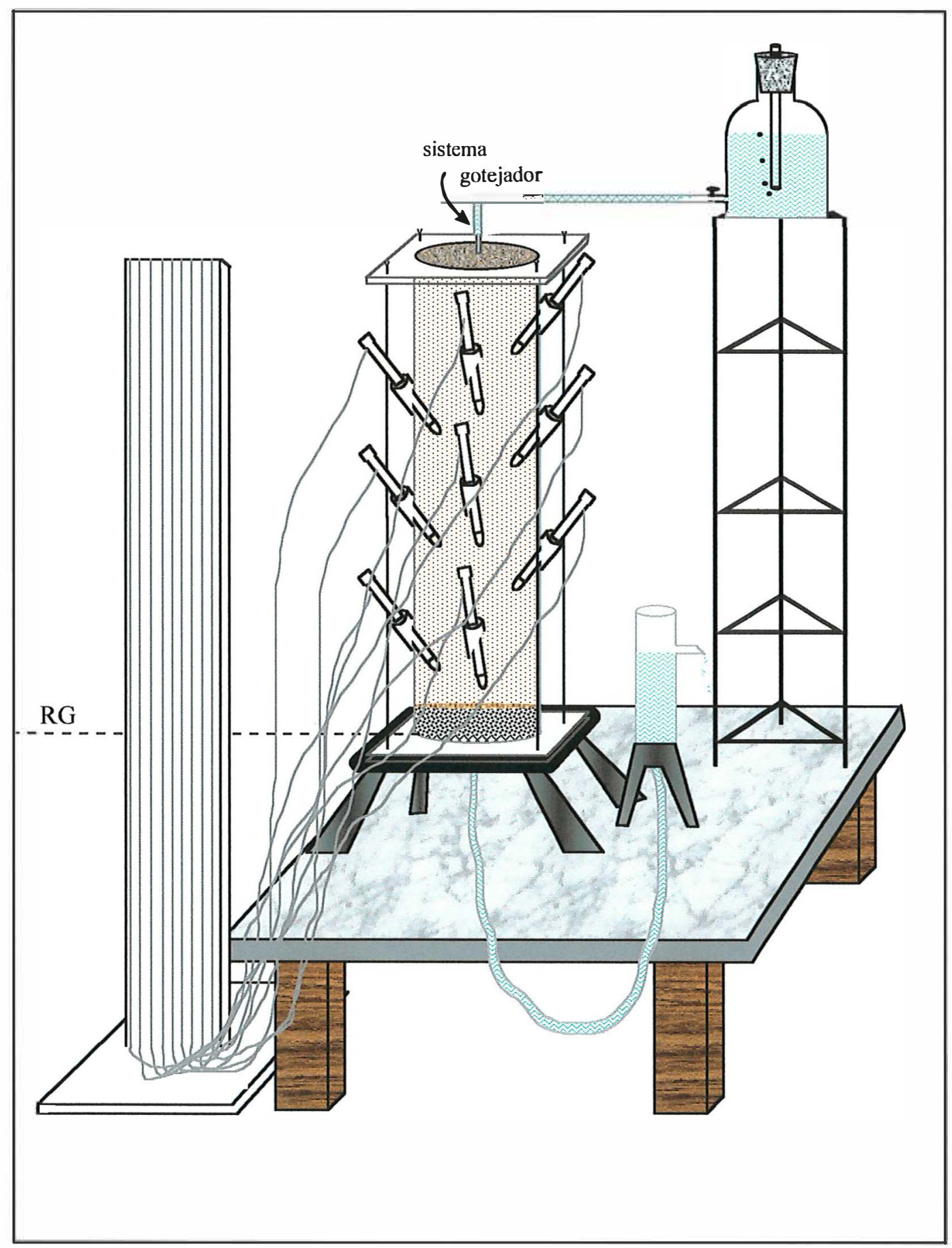

Figura 9 - Coluna de solo instrumentada com tensiômetros para determinação do $K(\theta)$ 


\subsection{Armazenagem de água no solo}

Como os tempos de leitura nos tensiômetros, após $t=0$, não foram os mesmos efetuou-se a interpolação dos potenciais mátricos em função do tempo, no sentido de uniformizar tempos de leitura e possibilitar o calculo da média do potencial mátrico para os diferentes manejos e profundidades.

Com os potenciais mátricos médios, utilizando-se os parâmetros da equação de ajuste da curva característica de retenção de água no solo, calculava-se os valores da umidade volumétrica do solo. A armazenagem de água no solo foi calculada utilizando-se a regra do trapézio.

\subsection{1 Água disponível as plantas}

Para o cálculo da água disponível, utilizou-se metodologia proposta por Letey (1985) que propõe utilizar, além dos valores da capacidade de campo e do ponto de

murcha permanente, os valores limitantes da resistência do solo à penetração e da porosidade de aeração.

Para o cálculo do IHO inseriu-se linhas de tendência aos dados experimentais das propriedades, em função densidade do solo, sendo que a umidade da capacidade de campo e a porosidade de aeração foram definidas como limitante na parte úmida do intervalo e a umidade no ponto de murcha permanente e da resistência a penetração limitante na parte seca $\mathrm{O}$ menor intervalo entre esses valores limitantes é definido como o IHO.

Neste sentido utilizou-se para capacidade de campo os valores de umidade correspondente a $8 \mathrm{kPa}(\cong 48$ horas drenagem), para ponto de murcha permanente os valores de umidade correspondentes a $1500 \mathrm{kPa}$, para resistência limite do solo à penetração o valor de $2 \mathrm{MPa}$ (Taylor \& Gardner, 1963; Taylor et al., 1966 e Nesmith, 
1987) e para porosidade limite de aeração o valor de $0,10 \mathrm{~m}^{3} \mathrm{~m}^{-3}$ (Erickson, $1982 \mathrm{e}$ Sojka, 1992).

\subsection{Análise estatística}

Para as propriedades e atributos do solo, que se tinha três repetições por manejo e profundidade, adotou-se o delineamento experimental denominado "Grupos de experimentos em blocos casualizados" assumindo-se para os grupos os três manejos de solo e os blocos as profundidades com 3 repetições.

Estes dados foram submetidos a análise da variância e quando esta era significativa ao teste de Duncan, ao nível de $5 \%$ de probabilidade para comparação das médias entre grupos (manejos) e entre blocos (profundidades). 


\section{RESULTADOS E DISCUSSÃO}

\subsection{Textura do solo}

A composição granulométrica do perfil do solo nos três manejos onde se efetuou o experimento está apresentada na figura 10, demonstrando diferenças significativas principalmente para as frações argila e areia em profundidade e entre os manejos, conforme está apresentado na análise estatística comparativa das médias no apêndice 1.1 a 1.8 .

Em relação à argila do solo, a mata apresentou os maiores valores em todas as profundidades, enquanto que a do irrigado os menores, ficando o sequeiro numa condição intermediária. Até $1 \mathrm{~m}$ de profundidade, com exceção da profundidade $0,6 \mathrm{~m}, \mathrm{a}$ mata apresentou valores significativamente maiores de argila que o sequeiro e o irrigado. Neste sentido Moura Filho \& Buol (1972) não encontraram evidências de translocação de argila em profundidade para este tipo de solo e como neste trabalho não foi detectada nenhuma camada com acúmulo de argila e a possibilidade desta ter sido translocada a profundidade maior do que $1 \mathrm{~m}$ é pequena, deduz-se que ou o solo nos diferentes manejos é distinto na sua composição granulométrica ou houve problemas na determinação, especificamente na fase de dispersão. A outra possibilidade é de esta argila, dispersa em água, tenha sido carreada para fora destas áreas junto com a enxurrada provocada por precipitações ou por irrigação com lâmina excessiva, hipótese pouco provável em função da pouca declividade da área e elevada capacidade de infiltração de água no solo. 


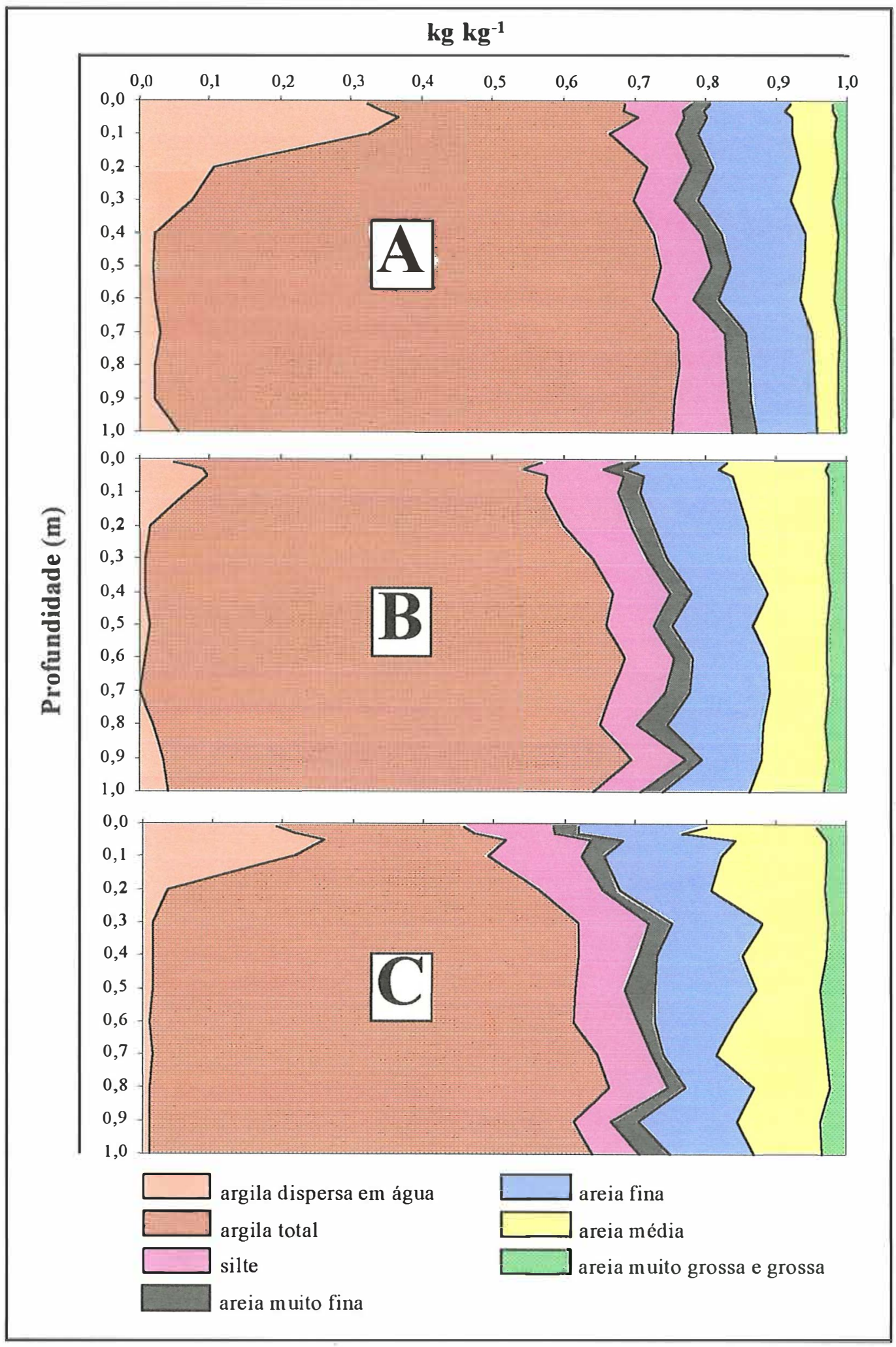

Figura 10 - Composição ganulométrica do perfil de solo da mata (A), do sequeiro (B) e do irrigado (C). 
A segunda hipótese é também destacada por Kertzmann (1996), que afirma que nem toda a argila do solo, especificamente em Latossolos, é dispersa, mesmo com a utilização de dispersantes químicos, pois verificações feitas com auxílio de lupa das frações de silte e areia revelaram a presença de argila ligada a estes grãos. Análises de raio-X (IPT, 1994) também demonstraram picos importantes de caulinita na fração mais grosseira do solo, indicando, segundo Kertzmann (1996), a dificuldade em dispersar e quantificar corretamente a argila nestes solos.

Neste sentido, a validade da metodologia de determinação da granulometria para solos com microagregação muito intensa é problemática, concordando com ElSwaify (1980) que questiona a aplicabilidade dos métodos desenvolvidos para determinação da granulometria de solos temperados, quando aplicados em Oxisóis, em função da grande estabilidade estrutural dos seus microagregados. Cita trabalhos em que os microagregados somente foram totalmente dispersos com a utilização de tratamento com ultra-som.

Uma hipótese que poderia ser levantada é que o solo da área irrigada, em função do plantio direto apresentaria maiores teores de matéria orgânica o que teria aumentado a agregação, dificultando a dispersão. Hipótese rejeitada pelos dados apresentados na tabela 1 , que demonstram não haver diferença significativa entre teores de matéria orgânica até $0,2 \mathrm{~m}$ de profundidade entre os manejos e abaixo desta a mata apresentou valores iguais ou maiores de matéria orgânica e de argila, o que concorda com El-Swaify (1980) que afirma que a remoção do carbono orgânico através do método da digestão pouco afetou a dispersão dos microagregados.

Diferenças significativas para a argila dispersa em água foram observadas, sendo esta maior junto a superficie, onde a mata apresentou os maiores valores e o sequeiro o menor, sendo que o sistema de manejo irrigado apresentou valores intermediários mais próximo dos apresentados pela mata.

Os maiores valores encontrados junto a superficie, segundo Moura Filho \& Buol (1972) podem ser atribuídas aos ciclos de umedecimento e secagem mais 
freqüentes. Destacam ainda que a argila dispersa em água é aquela com maior superficie específica, isto é "argila mais fina", não encontrando diferenças de composição minerológica entre a argila dispersa e a estável.

\subsection{Atributos químicos}

A condição química do solo nos diferentes manejos está apresentada no apêndice 2.1 a 2.9, onde se observa os maiores valores de saturação por bases e soma das bases (apêndice 2.1 e 2.2) para os sistemas sequeiro e irrigado. Em função disto, os microagregados nas áreas de sequeiro e irrigado podem ter ficado mais estáveis, a tal ponto de não se dispersarem e passarem por areia.

Em relação à saturação do solo por bases a $\mathrm{pH} 7$, observa-se a diferença significativa dos solos cultivados em relação a mata, inclusive com mudanças significativas até $1 \mathrm{~m}$ de profundidade, indicando uma efetiva lixiviação destas bases em profundidade.

A soma de bases teve o mesmo comportamento que a saturação por bases, no entanto em maior escala, sendo que os valores na superficie foram 5 vezes maior no irrigado do que na mata em função da grande quantidade de insumos (gesso, adubo e calcário) aplicados neste sistema de cultivo sob plantio direto. O sistema de sequeiro assume uma condição intermediária entre a mata e irrigado, uma vez que a intensidade de cultivo e aplicação de insumos e feita em menor escala. Esta análise demonstrou também a ocorrência de lixiviação de bases em profundidade, sendo que a $1 \mathrm{~m}$ de profundidade o sequeiro apresentava uma soma de bases 3 vezes maior que a mata enquanto o irrigado 6 vezes.

O fósforo, nutriente pouco móvel, não apresentou diferenças significativas em profundidade maior que $0,2 \mathrm{~m}$, sendo que no sistema irrigado a concentração chega a ser 6 vezes superior do que na mata, em função da elevadas doses de adubos utilizados nesta área. Como este nutriente é fundamental para o desenvolvimento da planta, e este está 
concentrado nesta camada superficial, é esta a camada de maior importância em termos do estudo das propriedades físico-hídrico-mecânicas do solo.

\subsection{Matéria orgânica}

Quanto ao teor de matéria orgânica não houve diferença significativa entre os manejos até a profundidade de $0,2 \mathrm{~m}$, indicando a matéria orgânica no solo atinge um equilíbrio, e que este depende muito mais das características do solo e clima do que do volume de restos culturais ou adubos orgânicos introduzidos no sistema (tabela 1).

Tabela 1- Teor de matéria orgânica do solo, em profundidade, para diferentes manejos, média de 3 repetições

\begin{tabular}{|c|c|c|c|c|c|c|c|c|c|}
\hline \multirow{3}{*}{$\begin{array}{c}\text { Prof(m) } \\
0,01\end{array}$} & \multirow{2}{*}{\multicolumn{3}{|c|}{ Mata }} & \multirow{2}{*}{\multicolumn{3}{|c|}{$\frac{\text { Sequeiro }}{\mathrm{g} \mathrm{dm}^{-3}}$}} & \multicolumn{3}{|c|}{ Irrigado } \\
\hline & & & & & & & & & \\
\hline & $\overline{\mathrm{A}}$ & 42,33 & $a$ & $\bar{A}$ & 38,33 & $a$ & $\bar{A}$ & 40,33 & $\mathrm{a}$ \\
\hline 0,03 & A & 37,00 & $\mathrm{ab}$ & A & 35,67 & a & A & 35,00 & b \\
\hline 0,05 & A & 35,33 & bc & A & 36,00 & $\mathbf{a}$ & A & 30,33 & c \\
\hline 0,10 & A & 30,67 & cd & A & 30,00 & b & A & 28,00 & c \\
\hline 0,20 & A & 23,00 & ef & $\mathrm{A}$ & 26,33 & bc & $\mathrm{A}$ & 23,33 & $\mathrm{~d}$ \\
\hline 0,30 & A & 25,33 & de & $A B$ & 22,00 & $\mathrm{~cd}$ & B & 18,67 & $\mathrm{e}$ \\
\hline 0,40 & A & 23,33 & e & B & 20,00 & de & B & 19,00 & e \\
\hline 0,50 & A & 21,00 & efg & $\mathrm{A}$ & 18,33 & def & A & 17,00 & ef \\
\hline 0,60 & A & 17,00 & fg & A & 16,67 & def & A & 16,33 & ef \\
\hline 0,70 & A & 17,00 & $\mathrm{fg}$ & A & 15,67 & ef & A & 14,67 & fg \\
\hline 0,80 & A & 16,33 & $\mathrm{~g}$ & A & 16,67 & def & A & 15,33 & efg \\
\hline 0,90 & A & 16,67 & g & B & 12,67 & $\mathbf{f}$ & B & 12,33 & $\mathrm{~g}$ \\
\hline 1,00 & A & 15,33 & $\mathrm{~g}$ & $\mathrm{AB}$ & 14,67 & ef & B & 12,33 & g \\
\hline Média & A & 24,64 & & B & 23,30 & & C & 21,74 & \\
\hline CV $(\%)$ manejos & & 13,49 & & & 13,25 & & & 9,46 & \\
\hline CV(\%)geral & & 11,76 & & & & & & & \\
\hline
\end{tabular}

Médias seguidas pelas mesmas letras minúsculas, nas colunas, e antecedidas pelas mesmas letras maiúsculas, nas linhas não diferem significativamente entre si, ao nível de $5 \%$, pelo teste de Duncan.

Ao contrário do que afirma Sanchez (1976) de que um dos efeitos do cultivo intensivo é a redução do teor de matéria orgânica no solo, os dados obtidos neste trabalho não confirmam esta afirmação, pois em ambas as áreas, sequeiro e irrigado, não 
se observaram diferenças significativas. O manejo adotado nas áreas, provavelmente em função do plantio direto, manteve os mesmos níveis de matéria orgânica no solo que na sua condição natural.

No sistema irrigado sob plantio direto o retorno de matéria seca ao solo é bastante elevado, provavelmente superior ao da mata. No entanto, como as condições de umidade são mais favoráveis à atividade microbiana e a taxa de decomposição anual de carbono é superior, estabilizando com um mesmo nível de carbono no solo.

\subsection{Consistência do solo}

A consistência do solo analisada através dos seus limites plástico, líquido e pegajoso, bem como através dos índices de plasticidade e de estabilidade da estrutura do solo, (tabela 2) apresentou modificações em função dos manejos adotados.

Para o limite plástico esta modificação foi positiva, uma vez que tanto o manejo de sequeiro como o irrigado, principalmente na camada superficial, elevou a umidade para este limite. Nesta condição a umidade do solo na capacidade de campo (48 horas drenagem) a condição de friabilidade é atingida mais rapidamente, podendo este solo cultivado antes do que o solo da mata.

A partir destes dados, uma vez determinada a umidade na qual o solo atinge o limite plástico, isto é, a umidade na qual se toma friável, ou através das leituras dos tensiômetros à campo ou pela curva de retenção a água no solo, poder-se-ía facilmente monitorar as condições de trafegabilidade conforme destaca Earl (1996). 
Tabela 2 - Valores de umidade gravimétrica para o limite plástico (LP), limite líquido(LL), limite de pegajosidade (PEG), índice de plasticidade (IP) e de estabilidade da estrutura do solo(IEE) para os manejos em profundidade

\begin{tabular}{|c|c|c|c|c|c|c|c|c|}
\hline \multicolumn{9}{|c|}{ Profundidade (m) } \\
\hline & 0,01 & 0,03 & 0,05 & 0,1 & 0,2 & 0,3 & 0,4 & 0,5 \\
\hline \multicolumn{9}{|c|}{ u $\left(\mathrm{kg}_{\mathrm{kg}} \mathrm{kg}^{-1}\right)$} \\
\hline \multicolumn{9}{|c|}{ Mata } \\
\hline $48 h$ & 0,374 & 0,356 & 0,367 & 0,333 & 0,354 & 0,346 & 0,350 & 0,364 \\
\hline LP & 0,335 & 0,322 & 0,308 & 0,309 & 0,298 & 0,309 & 0,316 & 0,324 \\
\hline LL & 0,443 & 0,454 & 0,410 & 0,420 & 0,432 & 0,410 & 0,415 & 0,427 \\
\hline IP & 10,80 & 13,19 & 10,14 & 11,03 & 13,34 & 10,07 & 9,89 & 10,23 \\
\hline PEG & 0,535 & 0,527 & 0,462 & 0,486 & 0,484 & 0,485 & 0,489 & 0,493 \\
\hline IEE & 0,89 & 0,90 & 0,84 & 0,93 & 0,84 & 0,89 & 0,91 & 0,89 \\
\hline \multicolumn{9}{|c|}{ Sequeiro } \\
\hline $48 h$ & 0,325 & 0,354 & 0,371 & 0,321 & 0,321 & 0,322 & 0,330 & 0,331 \\
\hline LP & 0,339 & 0,352 & 0,317 & 0,336 & 0,323 & 0,337 & 0,328 & 0,327 \\
\hline LL & 0,386 & 0,379 & 0,388 & 0,379 & 0,386 & 0,381 & 0,427 & 0,397 \\
\hline IP & 4,735 & 2,687 & 7,049 & 4,332 & 6,221 & 4,447 & 9,955 & 7,002 \\
\hline PEG & 0,434 & 0,454 & 0,464 & 0,436 & 0,427 & 0,449 & 0,483 & 0,452 \\
\hline IEE & 1,04 & 0,99 & 0,86 & 1,04 & 1,00 & 1,02 & 0,98 & 0,98 \\
\hline \multicolumn{9}{|c|}{ Irrigado } \\
\hline $48 \mathrm{~h}$ & 0,363 & 0,313 & 0,328 & 0,337 & 0,321 & 0,354 & 0,371 & 0,364 \\
\hline LP & 0,371 & 0,374 & 0,354 & 0,350 & 0,303 & 0,318 & 0,327 & 0,337 \\
\hline LL & 0,426 & 0,408 & 0,405 & 0,391 & 0,381 & 0,408 & 0,386 & 0,399 \\
\hline IP & 5,51 & 3,34 & 5,11 & 4,11 & 7,82 & 9,89 & 5,89 & 6,20 \\
\hline PEG & 0,44 & 0,44 & 0,404 & 0,416 & 0,394 & 0,47 & 0,438 & 0,489 \\
\hline IEE & 1,02 & 1,19 & 1,08 & 1,04 & 0,95 & 0,90 & 0,88 & 0,93 \\
\hline
\end{tabular}


Em relação ao índice de estabilidade da estrutura do solo, o qual poderia ser considerado ideal, é que os valores de umidade no limite plástico e capacidade de campo fossem muito semelhantes, pois nesta situação já seria possivel o preparo sem ocasionar danos a estrutura, o solo já estando friável. Observando-se os valores deste índice na tabela 16, constata-se que tanto o solo sob plantio irrigado como de sequeiro apresentaram vários índices maiores que 1, indicando boa estabilidade da estrutura, pois antes mesmo deste atingir a umidade de capacidade de campo, já se encontra na condição de friabilidade. Esta é uma constatação muito interessante, principalmente para o sistema de plantio direto, pois é justamente esta camada de solo que é mobilizada durante a semeadura, indicando que poder-se-ía iniciar a semeadura nesta tratamento antes do que nas outras condições de manejo. Isto, sem considerar o aumento na retenção de água e diminuição da evaporação pelos restos culturais.

Em relação à consistência, os valores de umidade para o limite plástico e líquido, obtidos por Petter (1990) foram de 0,27 e $0,44 \mathrm{~kg} \mathrm{~kg}^{-1}$, respectivamente, em um solo classificado como Haplorthox. Figueiredo et al. (1998) obtiveram valores para limite plástico em torno de $0,32 \mathrm{~kg} \mathrm{~kg}^{-1}$ em Latossolo Roxo da região de Lavras - MG, sendo bastante semelhantes aos encontrados neste trabalho.

Uma questão relacionada a metodologia utilizada nestas determinações merece ser analisada. É o fato de a terra utilizada ser peneirada em peneira com malha $0,42 \mathrm{~mm}$, como preconiza o método. O solo da mata, como demonstraram as curvas de retenção com estrutura alterada ( $\mathrm{tfsa}=$ malha $2 \mathrm{~mm}$ ) apresentou um comportamento distinto, com agregados maiores. Em função do peneiramento esta estrutura foi destruída, sendo portanto questionável a utilização desta metodologia para estudar o solo agrícola em condições de campo, onde principalmente, como neste estudo, a mata ou solo sob plantio direto apresentam inúmeros fragmentos de vegetais que estarão afetando esta umidade por estarem absorvendo água.

Os teores de matéria orgânica do solo não explicam as alterações dos limites de consistência do solo, uma vez que a mata apresentou em todas as camadas estudadas 
valores superiores aos outros manejos. Soane et al. (1972), Emerson (1995) e Ball et al. (1996) destacam que é mais importante a qualidade do que quantidade de matéria orgânica na alteração da plasticidade do solo, indicando que a fração de carboidratos e polissacarídeos são os mais importantes.

O limite plástico parâmetro importante para estimar a capacidade de suporte do solo, foi superior para a mata. Neste caso o solo da mata, com maior umidade, ofereceria melhores condições de trafegabilidade às máquinas, principalmente na superficie em função da sua maior agregação e maior teor de argila.

O limite de pegajosidade também foi afetado pelo manejo, sendo superior na mata, principalmente na camada superficial. Esta também é uma informação importante, pois este solo poderia ser trabalhado com maior umidade, sem ocorrer aderência de solo aos rodados das máquinas e aos órgãos ativos dos implementos.

\subsection{Densidade de sólidos}

Observa-se que a densidade de sólidos os valores tanto para o solo de mata como de sequeiro não variaram significativamente em profundidade, enquanto que o irrigado apresentou menores valores na superficie e maiores em profundidade (tabela 3 ).

Comparando os tratamentos observa-se valores maiores para o sequeiro, somente na camada bem superficial $(0,01 \mathrm{~m})$ enquanto que nas outras profundidades, apesar de ocorrerem diferenças significativas não se observou um comportamento diferencial claro e definido. 
Tabela 3- Densidade dos sólidos, em profundidade, para diferentes manejos, média de 3 repetições

\begin{tabular}{|c|c|c|c|c|c|c|c|}
\hline \multirow[t]{2}{*}{$\operatorname{Prof}(m)$} & \multicolumn{2}{|r|}{ Mata } & \multirow{2}{*}{\multicolumn{2}{|c|}{$\begin{array}{c}\text { Sequeiro } \\
M g m^{-3}\end{array}$}} & \multicolumn{3}{|c|}{ Irrigado } \\
\hline & & & & & & & \\
\hline 0,01 & B & $2,56 \mathrm{~ns}$ & A & $2,84 \mathrm{~ns}$ & B & 2,42 & e \\
\hline 0,03 & A & 2,69 & A & 2,69 & A & 2,55 & cde \\
\hline 0,05 & A & 2,65 & A & 2,70 & A & 2,62 & abcd \\
\hline 0,10 & A & 2,64 & $\mathrm{AB}$ & 2,71 & B & 2,58 & cd \\
\hline 0,20 & A & 2,59 & A & 2,84 & A & 2,71 & ab \\
\hline 0,30 & B & 2,60 & $\mathrm{AB}$ & 2,77 & A & 2,64 & abc \\
\hline 0,40 & A & 2,65 & A & 2,76 & A & 2,66 & abc \\
\hline 0,50 & A & 2,65 & A & 2,71 & A & 2,74 & $\mathrm{a}$ \\
\hline 0,60 & $\mathrm{AB}$ & 2,57 & A & 2,75 & B & 2,50 & de \\
\hline 0,70 & B & 2,64 & A & 2,83 & B & 2,60 & abcd \\
\hline 0,80 & A & 2,55 & A & 2,94 & A & 2,72 & $a b$ \\
\hline 0,90 & A & 2,57 & A & 2,72 & A & 2,73 & a \\
\hline 1,00 & A & 2,71 & A & 2,75 & A & 2,69 & $a b$ \\
\hline Média & $\mathrm{B}$ & 2,61 & A & 2,76 & $\mathrm{~B}$ & 2,62 & \\
\hline$C V(\%)$ trata & & 3,61 & & 6,27 & & 2,90 & \\
\hline$C V(\%)$ gera & & 4,60 & & & & & \\
\hline
\end{tabular}

Médias seguidas pelas mesmas letras minúsculas, nas colunas, e antecedidas pelas mesmas letras maiúsculas, nas linhas não diferem significativamente entre si, ao nível de $5 \%$, pelo teste de Duncan.

\subsection{Densidade do solo}

A densidade do solo da mata apresentou diferença significativa, no perfil apenas na camada superficial $(0,03 \mathrm{~m})$ certamente pela influência da liteira (tabela 4$)$, indicando a homogeneidade desta característica do solo na sua condição natural, sem camadas de impedimento ou de acúmulo de argila.

A área de sequeiro e irrigado tiveram a sua estrutura modificada, com alterações significativas na densidade até a profundidade de $0,4 \mathrm{~m}$. Abaixo de $0,4 \mathrm{~m}$ não se detectaram alterações, com exceção da profundidade $0,7 \mathrm{~m}$, em relação a mata. Esses resultados concordam com os relatados por Tognon (1991), Curmi et al. (1994) e Kertzmann (1996) em trabalhos realizados no mesmo tipo de solo e na mesma região de Guaira - SP 
Os valores da densidade do solo foram significativamente superiores até a profundidade de $0,4 \mathrm{~m}$ para o sistema plantio direto irrigado, o que corrobora com o citado por Kertzmann (1996). Por outro lado Derpsch et al. (1986) e Silveira et al.(1997) afirmam que em plantio direto a compactação seria mais superficial, até $0,2 \mathrm{~m}$. Estes resultados são preocupantes pois indicam que o efeito do tráfego de máquinas sobre a superficie do solo está afetando a estrutura em profundidade (Taylor \& Gill , 1984) e uma possível solução para eliminar este efeito no futuro poderia ser uma subsolagem profunda com custos elevados, conforme destaca Raghavan et al. (1990).

Tabela 4 - Densidade do solo, em profundidade, para diferentes manejos, média de 3 repetições

\begin{tabular}{|c|c|c|c|c|c|c|c|c|c|}
\hline \multirow[t]{2}{*}{ Prof(m) } & \multicolumn{3}{|c|}{ Mata } & \multirow{2}{*}{\multicolumn{3}{|c|}{$\frac{\text { Sequeiro }}{M_{\mathrm{gg}} \mathrm{m}^{-3}}$}} & \multicolumn{3}{|c|}{ Irrigado } \\
\hline & & & & & & & & & \\
\hline 0,03 & $\bar{B}$ & 0,924 & $\mathrm{~b}$ & $\overline{\mathrm{AB}}$ & 1,068 & cd & $\mathrm{A}$ & 1,213 & bc \\
\hline 0,10 & B & 0,986 & $a b$ & A & 1,212 & a & A & 1,299 & $\mathrm{a}$ \\
\hline 0,20 & $\mathrm{C}$ & 1,025 & $\mathrm{a}$ & B & 1,076 & $a b$ & A & 1,255 & $a b$ \\
\hline 0,30 & $\mathrm{C}$ & 1,014 & a & B & 1,185 & $\mathrm{~b}$ & A & 1,228 & $a b c$ \\
\hline 0,40 & $\mathrm{C}$ & 1,016 & a & B & 1,146 & c & A & 1,161 & cd \\
\hline 0,50 & A & 1,027 & a & A & 1,077 & c & A & 1,104 & de \\
\hline 0,60 & A & 1,023 & a & A & 1,039 & cde & A & 1,051 & ef \\
\hline 0,70 & B & 1,002 & a & B & 1,014 & de & A & 1,058 & ef \\
\hline 0,80 & A & 1,007 & a & A & 1,018 & cde & A & 1,022 & ef \\
\hline 0,90 & $\mathrm{~A}$ & 1,027 & a & A & 0,983 & e & A & 1,019 & $\mathrm{f}$ \\
\hline 1,00 & $\mathrm{~A}$ & 0,996 & a & A & 1,006 & $\mathrm{e}$ & A & 0,999 & f \\
\hline Média & $\mathrm{C}$ & 1,004 & & B & 1,078 & & $\mathrm{~A}$ & 1,128 & \\
\hline$C V(\%)$ trate & entos & 3,92 & & & 2,90 & & & 3,99 & \\
\hline CV(\%)geral & & 3,67 & & & & & & & \\
\hline
\end{tabular}

Médias seguidas pelas mesmas letras minúsculas, nas colunas, e antecedidas pelas mesmas letras maiúsculas, nas linhas não diferem significativamente entre si, ao nível de $5 \%$, pelo teste de Duncan.

\subsection{Máxima compactabilidade do solo}

Os valores de umidade ótima de compactação, densidade máxima, equações e coeficiente de determinação(tabela 5) e as curvas ajustadas aos dados experimentais de compactação do solo (figura 11) demonstram um bom ajuste, pois algumas 
determinações (pontos) foram repetidos com umidades intermediárias entre pontos em que a tendência não ficava clara bem como próximo da umidade ótima de compactação.

Tabela 5 - Umidade ótima(UOt) para compactação e densidade máxima do solo em profundidade para os diferentes manejos

\begin{tabular}{|c|c|c|c|c|c|}
\hline Manejo & prof. (m) & $\begin{array}{c}U O t \\
u\left(k g k g^{-1}\right)\end{array}$ & $\begin{array}{l}\text { Ds máx. } \\
\left(M g m^{-3}\right)\end{array}$ & equação & $r^{2}$ \\
\hline \multirow[t]{2}{*}{ Mata } & $0,00-0,45$ & 0,307 & 1,492 & Ds $=91,617 u^{2}+56,375 u-7,179$ & 0,96 \\
\hline & $-0,45-0,95$ & $.0,295$ & 1,514 & Ds $=47,632 u^{2}+28,097 u-2,630$ & $\underline{0,89}$ \\
\hline \multirow[t]{2}{*}{ Sequeiro } & $0,00-0,45$ & 0,280 & 1,522 & $D s=70,759 u^{2}+39,636 u-4,028$ & 0,86 \\
\hline & $-0,45-0,95$ & $\underline{0,286}$ & 1,516 & Ds $=69,249 u^{2}+39,614 u-4,148$ & 0,85 \\
\hline \multirow[t]{2}{*}{ Irrigado } & $0,00-0,45$ & 0,284 & 1,499 & Ds $=27,779 u^{2}+15,815 u-0,756$ & 0,97 \\
\hline & $0,45-0,95$ & 0,293 & 1,515 & $D s=47,927 u^{2}+28,169 u-2,624$ & 0,88 \\
\hline
\end{tabular}

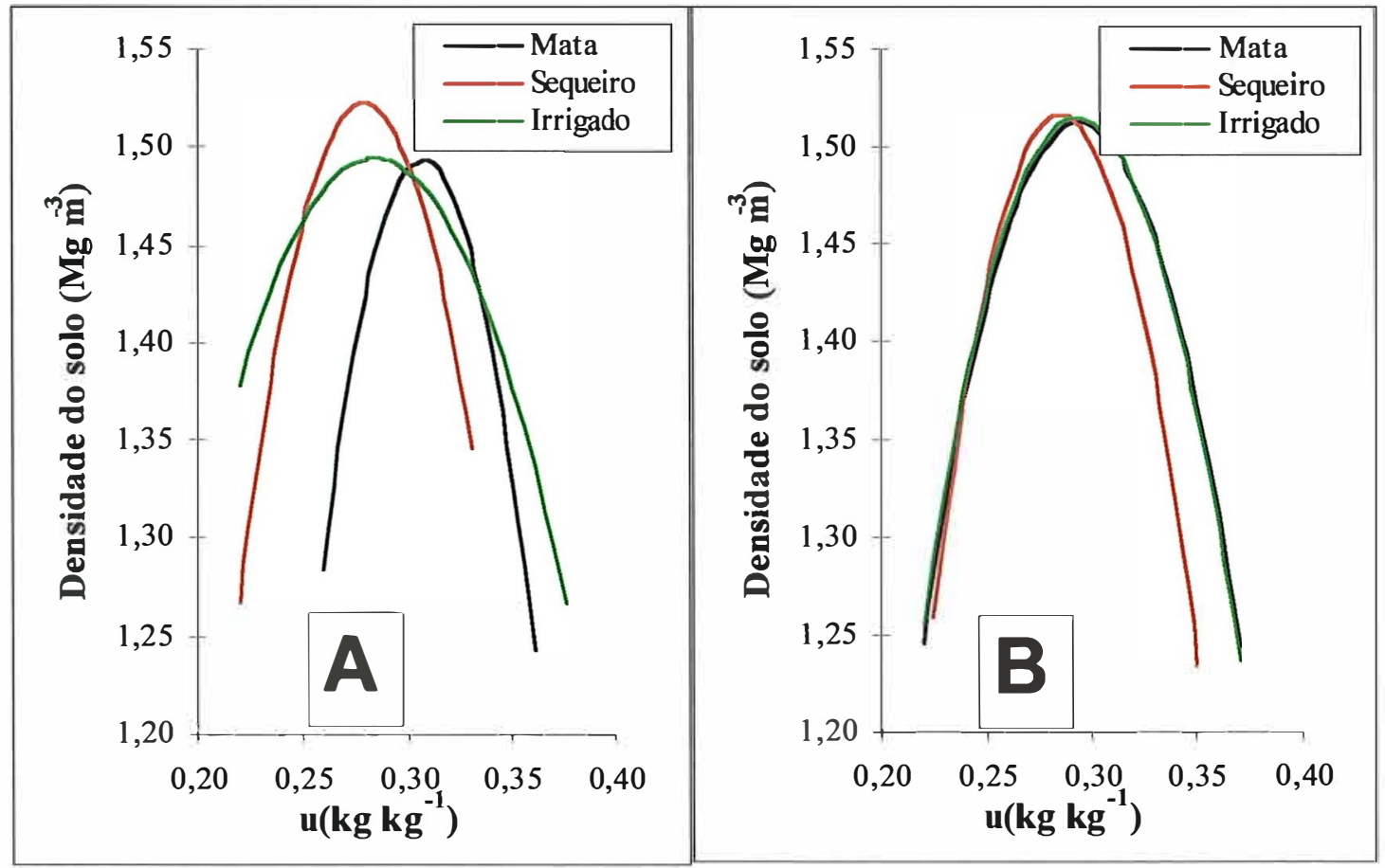

Figura 11 - Curvas de compactação do solo teste de Proctor(A) 0,00 - 0,45 m e (B) 0,45 - 0,95 $m$ de profundidade para os três manejos. 
$\mathrm{Na}$ camada de 0,00 - 0,45 $\mathrm{m}$ de profundidade observam-se diferenças nos valores de umidade ótima de compactação entre o solo de mata $\left(0,30 \mathrm{~kg} \mathrm{~kg}^{-1}\right)$ e os outros dois manejos $\left(0,28 \mathrm{~kg} \mathrm{~kg}^{-1}\right)$, sendo que a densidade máxima para mata $\left(1,492 \mathrm{Mg} \mathrm{m}^{-3}\right) \mathrm{e}$ irrigado(1,499 $\left.\mathrm{Mg} \mathrm{m}^{-3}\right)$ foi semelhante e inferior à do sequeiro $\left(1,522 \mathrm{Mg} \mathrm{m}^{-3}\right)$.

Para a camada 0,45 - 0,95 m, as curvas de compactação são muito semelhantes com uma pequena diferença na umidade ótima de compactação mas sem qualquer diferença nos valores de densidade máxima para os três manejos.

A umidade ótima para compactação do solo na camada de $0-0,45 \mathrm{~m}$ de profundidade para mata, sequeiro e irrigado é de 0,$307 ; 0,280$ e $0,284 \mathrm{~kg} \mathrm{~kg}^{-1}$ respectivamente, enquanto que umidade de capacidade de campo média para esta camada é de 0,$341 ; 0,345$ e $0,344 \mathrm{~kg} \mathrm{~kg}^{-1}$ respectivamente. Isto implica em dizer que a umidade ótima de compactação está situada na faixa de umidade na qual o solo está friável. Sendo que para mata esta umidade é igual a $90 \%$ do LP enquanto que para sequeiro e irrigado em torno de $80 \%$ do LP, Figueiredo et al. (1998) observaram condição semelhante para o mesmo tipo de solo.

Esta constatação de que a máxima compactação ocorre dentro da faixa de friabilidade do solo é preocupante do ponto de vista de manejo agrícola, uma vez que a recomendação é de que se efetue os preparos nesta condição de umidade. Por outro lado operações como a colheita por exemplo, desde que haja condições de trafegabilidade da colhedora o efeito negativo sobre a estrutura do solo será menor com o solo mais úmido.

A saturação relativa (poros saturados em relação a porosidade total) na condição de máxima compactação estão apresentados na tabela 6 .

Observa-se que a porosidade do solo após o teste praticamente não variou o mesmo não ocorrendo com a saturação relativa. Na camada de $0,45-0,95 \mathrm{~m}$, observa-se que a alteração na porosidade foi ocasionada pelas diferenças nos valores da densidade de partículas. Esta alteração incrementou em duas vezes a variação na $S r$. 
Tabela 6 - Saturação relativa $\left(\mathrm{Sr}-\mathrm{m}^{3} \mathrm{~m}^{-3}\right)$ e porosidade total $\left(\mathrm{Pt} \mathrm{m}^{3} \mathrm{~m}^{-3}\right)$ do solo na máxima densidade

\begin{tabular}{ccccccc}
\hline \hline \multirow{2}{*}{ Prof $(\boldsymbol{m})$} & \multicolumn{2}{c}{ Mata } & \multicolumn{2}{c}{ Sequeiro } & \multicolumn{2}{c}{ Irrigado } \\
\cline { 2 - 7 } & $\boldsymbol{S r}$ & $\boldsymbol{P t}$ & $\boldsymbol{S r}$ & $\boldsymbol{P t}$ & $\boldsymbol{S r}$ & $\boldsymbol{P t}$ \\
\hline $0,00-0,45$ & 0,711 & 0,432 & 0,625 & 0,448 & 0,672 & 0,423 \\
$0,45-0,95$ & 0,701 & 0,421 & 0,628 & 0,455 & 0,680 & 0,431 \\
\hline \hline
\end{tabular}

Como pode ser observado na análise da consistência deste solo, as diferenças ocorreram nas mais superficiais. Neste sentido para se ter maior precisão nestas determinações da compactabilidade do solo deveria ser feito um teste de Proctor para cada camada, pois certamente o comportamento será bastante distinto. Isto só não foi feito neste estudo por falta de material e tempo.

Outra questão que merece ser analisada, é que com o teste de Proctor é realizado com solo com estrutura alterada $(4,8 \mathrm{~mm})$, condição que não ocorre naturalmente no campo. Neste sentido a coleta de amostras com estrutura indeformada, submetidas a pressões de consolidação, como apresenta Hâkansson, (1990) é uma metodologia muito mais interessante e representativa das condições de campo.

\subsection{Resistência do solo à penetração}

Analisando as figuras 12a, 13a e 14a observa-se a grande variação, para os três manejos, nos valores de resistência do solo à penetração em função da condição de umidade. Por exemplo, na área irrigada, na camada superficial $(0,036 \mathrm{~m})$, para uma mesma densidade, esta resistência variou de 0,8 a 3,8 $\mathrm{MPa}$, enquanto a umidade volumétrica variou de 0,4 a $0,32 \mathrm{~m}^{3} \cdot \mathrm{m}^{-3}$. Resistências limitantes ao crescimento radicular das plantas, $2 \mathrm{MPa}$ ocorreram na tensão de $50 \mathrm{kPa}$ na área irrigada, $300 \mathrm{kPa}$ no sequeiro e na mata mesmo na tensão de $500 \mathrm{kPa}$ não ocorreu limitação. 
Portanto, a resistência à penetração, determinada sob condições de umidade controlada, assume papel muito importante, pois permitirá prever em que densidade e umidade do solo, ocorrerá impedimento ao crescimento do sistema radicular.

Este comportamento da resistência do solo à penetração em profundidade em função da umidade, principalmente em área de sequeiro sob plantio direto, indica os problemas que poderão ocorrer com a penetração das raízes, até a profundidade de $0,4 \mathrm{~m}$, em períodos de déficit hídrico. Neste sentido, Vieira (1985), destaca que a raiz principal da soja, em áreas sob plantio direto, via de regra apresenta uma curvatura, coincidindo com o fundo do sulco da semeadura, sendo que, após esta curvatura a mesma se divide em raizes primárias mais finas, crescendo em profundidade, o que sem dúvida nenhuma, pode indicar uma adaptação da planta a estas condições, que não é detectada pelo cone do penetrômetro.

Para a área irrigada sob plantio direto, embora apresente os maiores valores de densidade e resistência limitante já na tensão de $50 \mathrm{kPa}$, se a irrigação for manejada corretamente, irrigando-se sempre que o potencial mátrico atingir valor de $60 \mathrm{kPa}$ conforme recomendam Saad \& Libardi (1994) para um Latossolo Roxo, não haveria maiores problemas com a resistência mecânica à penetração das raízes das plantas. De qualquer maneira estes dados mostram que no futuro só o manejo da irrigação talvez não resolva o problema e outras práticas, como escarificação ou subsolagem, precisem ser adotadas.

Analisando-se o efeito dos manejos nas propriedades fisico-hídricas do solo, observa-se que a intensidade de manejo associada a maiores valores de umidade do solo, situação que ocorre na área irrigada, acarreta um incremento significativo na densidade até a profundidade de $0,4 \mathrm{~m}$ (Figuras 12c, 13c e 14c) com, conseqüente, incremento na resistência do solo à penetração. Estes resultados de densidade estão de acordo com os relatados por Tognon (1991), Curmi et al. (1994) e Kertzmann (1996) em trabalhos realizados no mesmo tipo de solo e região (Guaira - SP). 


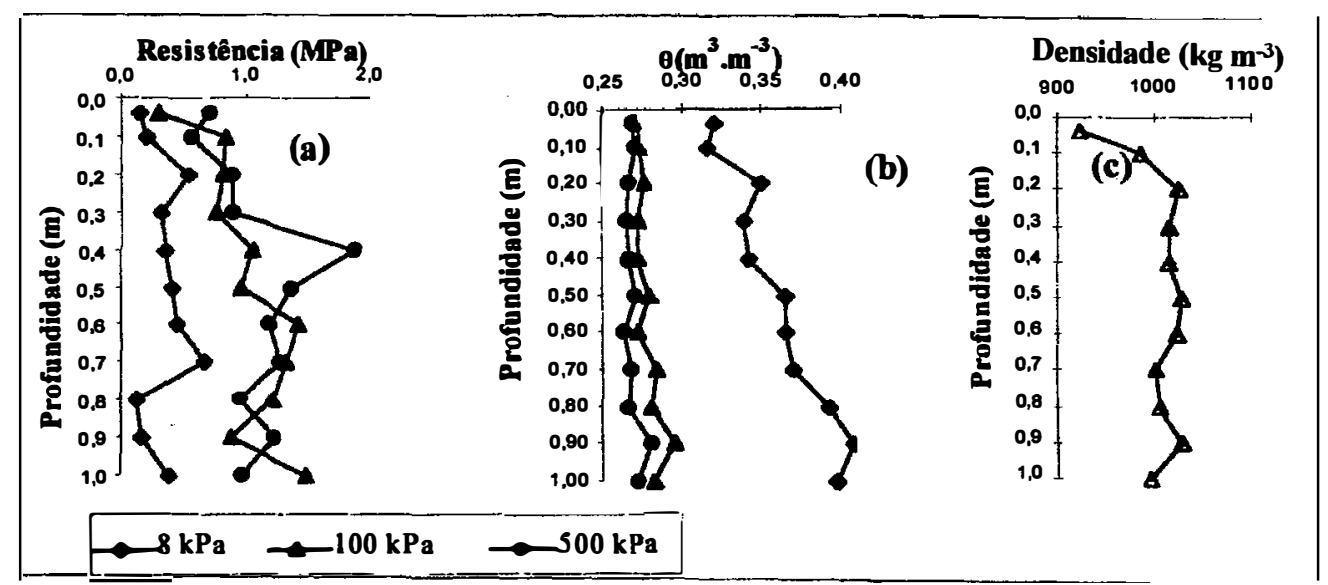

Figura 12 - (a) Resistência à penetração, (b) umidade volumétrica (c) e densidade do solo em área de mata.

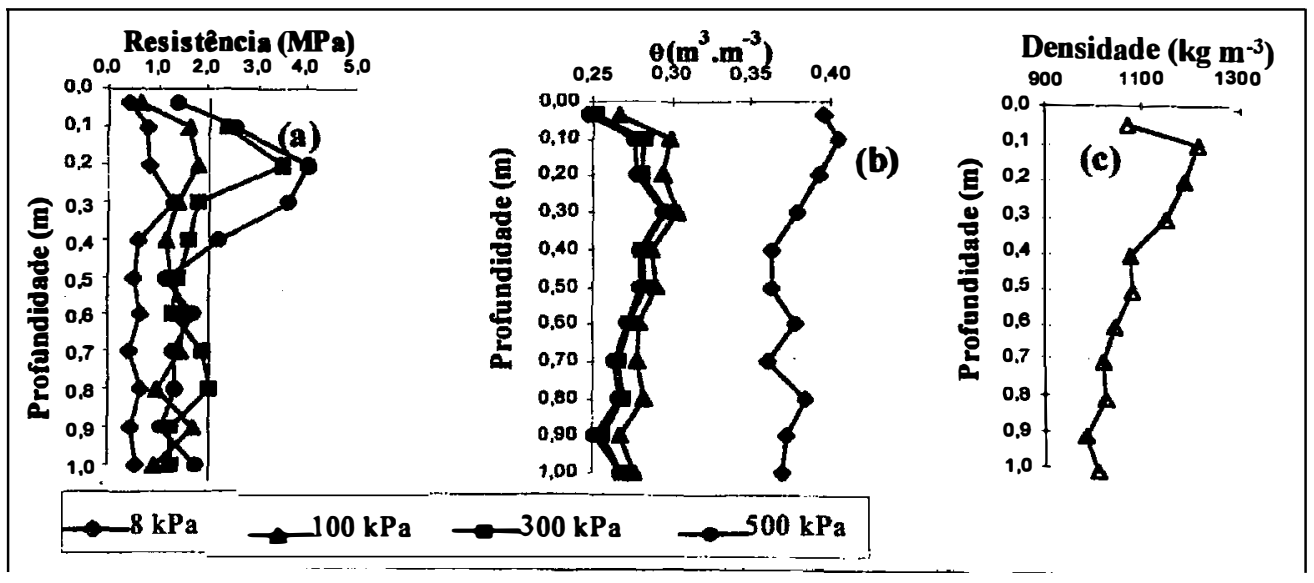

Figura 13 - (a) Resistência à penetração, (b) umidade volumétrica (c) e densidade do solo em área de sequeiro sob sistema plantio direto.

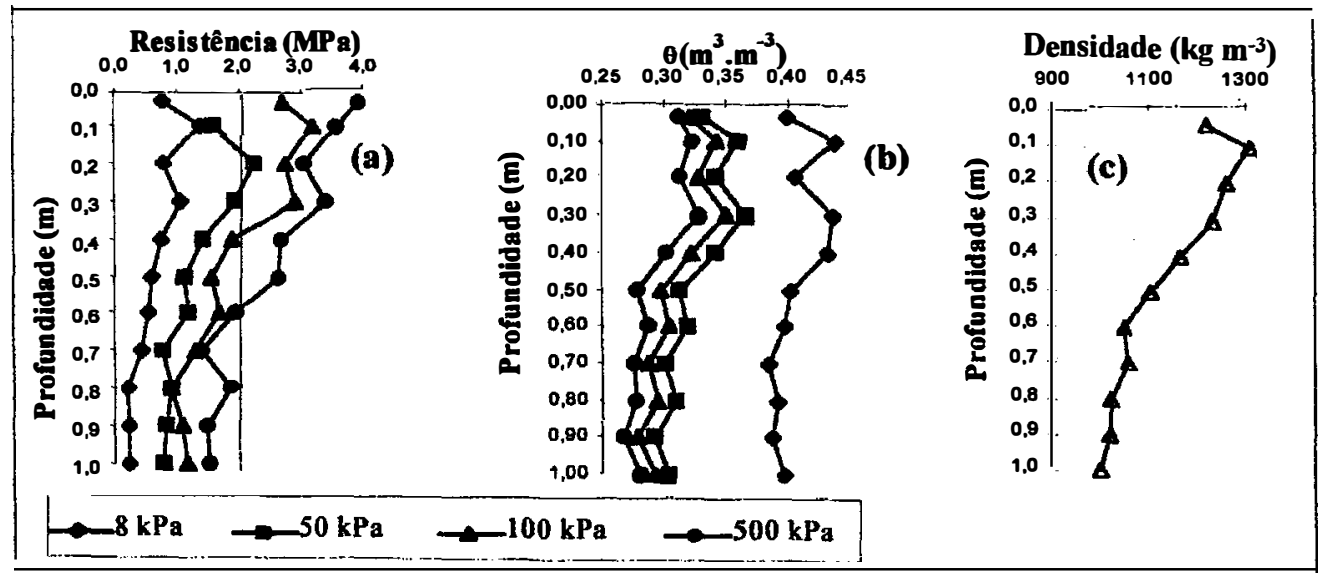

Figura 14 - (a) Resistência à penetraçāo, (b) umidade volumétrica (c) e densidade do solo em área irrigada sob sistema plantio direto. 
Em relação à recomendação de se efetuar a determinação no campo, próximo a capacidade de campo a qual, para este solo, corresponde a umidade na tensão de $8 \mathrm{kPa}$, os valores de resistência não são limitantes ao crescimento do sistema radicular em todos os manejos. A variação nos valores de resistência à penetração, apesar de acompanharem a variação da densidade do solo, é muito menor do que nas outras condições de umidade, como bem destaca Perini et al. (1998) que afirmam que quando se determina a resistência com o solo muito úmido, regiões compactadas não são detectadas. Isso pode ser observado, analisando-se os valores de resistência da figura 13a e os valores de umidade na figura $14 \mathrm{~b}$ para a profundidade $0,2 \mathrm{~m}$. Observa-se que na tensão de $8 \mathrm{kPa}$, capacidade de campo, a camada adensada não foi detectada enquanto nas tensões maiores, os valores de resistência superaram a resistência limitante de $2 \mathrm{MPa}$.

Em uma situação de campo, a condição de umidade na capacidade de campo é mantida apenas por um curto período de tempo, de modo que a resistência aumenta com a secagem do solo. Destaca-se que, na capacidade de campo, a utilização da resistência do solo à penetração, para comparar efeitos de sistemas de manejo, não é uma boa indicadora das condições para o crescimento radicular.

Analisando-se os valores de resistência da figura 13a e os valores de umidade na figura 14b para a profundidade $0,2 \mathrm{~m}$, por exemplo, onde na tensão de $8 \mathrm{kPa}$, capacidade de campo, a camada adensada não foi detectada enquanto nas tensões maiores, os valores de resistência superaram em muito a resistência limitante de $2 \mathrm{MPa}$.

- O ajuste por regressão múltipla dos valores da resistência à penetração em função da densidade e umidade volumétrica do solo foi altamente significativa, verificando-se, conforme pode ser observado na figura 15 , que $76 \%$ da variação observada na resistência à penetração podem ser atribuída a variação da densidade $\mathrm{e}$ umidade volumétrica do solo. Petter (1990) obteve resultados semelhantes, com $\mathrm{r}^{2}$ de 0,86, trabalhando, no entanto, com núcleos compactados, situação em que a variabilidade espacial desta propriedade é muito menor do que aquela encontrada em condições de campo. 
Correchel et al. (1997) estudando a resistência de um Latossolo Roxo à penetração, em dois sistemas de manejo (plantio direto e convencional), observaram que o plantio direto apresentou os maiores valores de resistência e que o modelo que melhor ajustou os dados de resistência à penetração em função da densidade e umidade não foi linear, sendo semelhante ao obtido neste trabalho (figura 15).

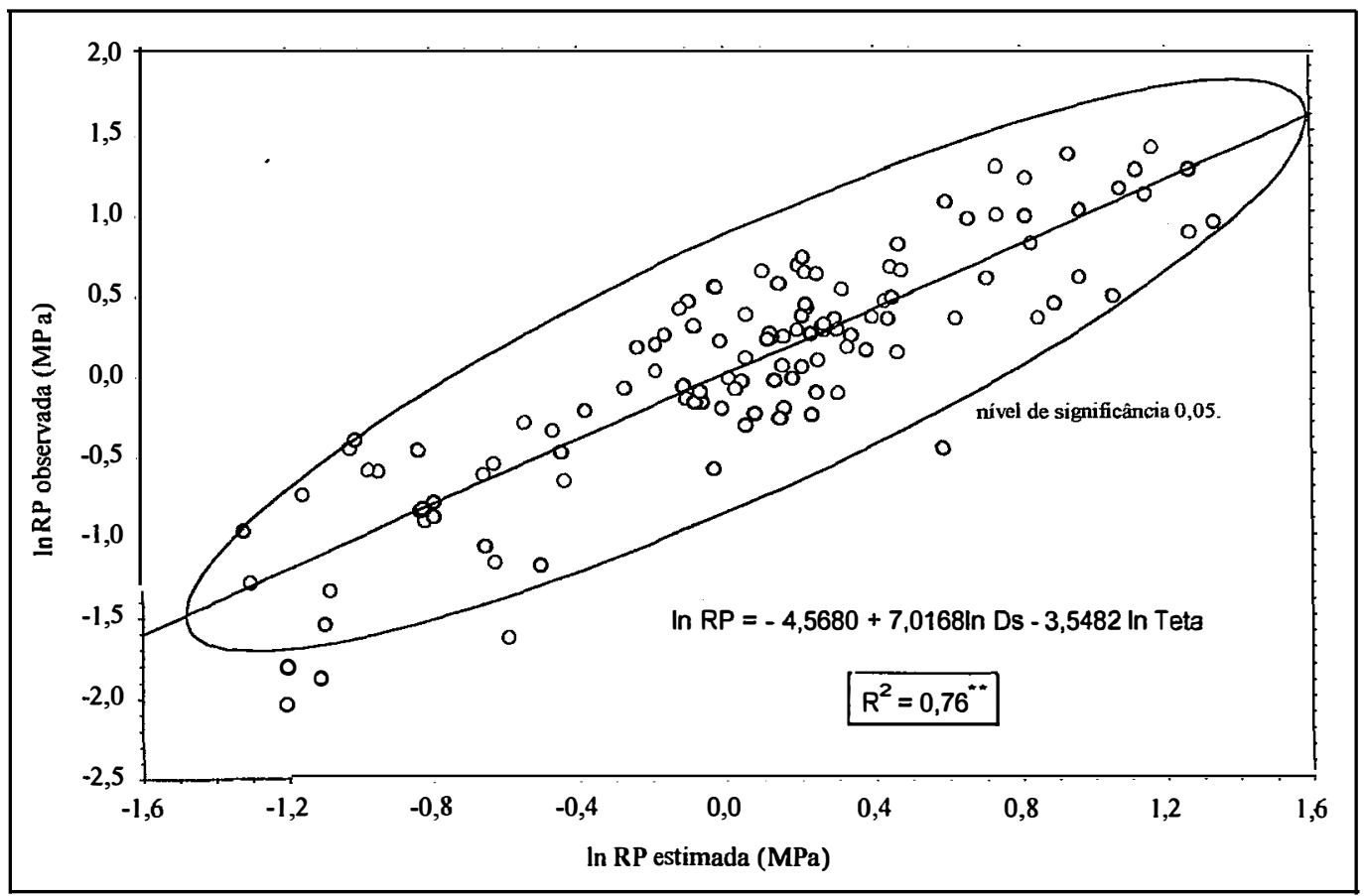

Figura 15 -Ajuste da equação da resistência à penetração do solo em função da densidade e umidade volumétrica do solo.

\subsection{Curvas de retenção da água no solo com estrutura preservada}

As curvas de dessorção de água do solo, para os 3 manejos e 13 profundidades, estão apresentadas na figura 16 e os parâmetros empíricos de ajuste dos pontos experimentais à equação de Van Genuchten (1980) no apêndice 3.1.

É importante ressaltar que cada ponto experimental da curva é oriundo de amostra distinta, explicando com isto uma certa dispersão dos pontos experimentais em relação a linha de ajuste, mas é sem dúvida uma técnica muito interessante para 
minimizar o efeito da variabilidade espacial desta propriedade fisico-hídrica do solo, bem estudada e comprovada por Fietz (1998).

- Constata-se que o uso e manejo do solo alterou consideravelmente o tracado das curvas em função da redução na porosidade e alteração na distribuịção do diâmetro dos poros. Estas alterações são mais acentuadas na área irrigada, coincidindo com a camada até $0,4 \mathrm{~m}$ de profundidade onde ocorreram os maiores valores de densidade, sendo que após esta profundidade as curvas são muito similares.

As alterações na densidade promoveram uma menor umidade do solo na saturação e maior no ponto de murcha permanente. Estas diferenças, podem no entanto interferir muito pouco na disponibilidade de água as plantas, pois maiores valores de umidade próximos a saturação significam água facilmente drenável. Sendo que as diferenças importantes estão nos valores de umidade próximo ao ponto de murcha permanente, pois maiores valores significam mais água indisponível.

Observa-se também que estes solos possuem um comportamento muito semelhante ao solo arenoso, com um rápido declínio da umidade quando da aplicação de baixas tensões e variando muito pouco com a aplicação de tensões acima de $10 \mathrm{kPa}$. Estas curvas são muito semelhantes as obtidas por Saad (1991) e Espirito Santo (1998) trabalhando neste solo naquela região, bem como com os resultados apresentados por Penna Medina \& Grohmann (1966) em trabalho pioneiro em solos de cerrado.

- Na camada em que ocorreu a maior alteração na densidade do solo em relação a mata, foi na profundidade de $0,10 \mathrm{~m}$ no sistema irrigado. Analisando as curvas de retenção, nesta camada, observa-se que na condição de solo saturado a umidade é $0,15 \mathrm{~m}^{3} \mathrm{~m}^{-3}$ maior na mata, enquanto que na tensão de $8 \mathrm{kPa}$ e no PMP a umidade é $0,09 \mathrm{~m}^{3} \mathrm{~m}^{-3}$ e $0,05 \mathrm{~m}^{3} \mathrm{~m}^{-3}$, respectivamente, superior no irrigado. Isto indica que as alterações na porosidade provocadas pelo aumento da densidade foram mais acentuadas na porosidade relacionada ao movimento rápido da água no solo do que em relação a retenção de água, que inclusive aumentou. 


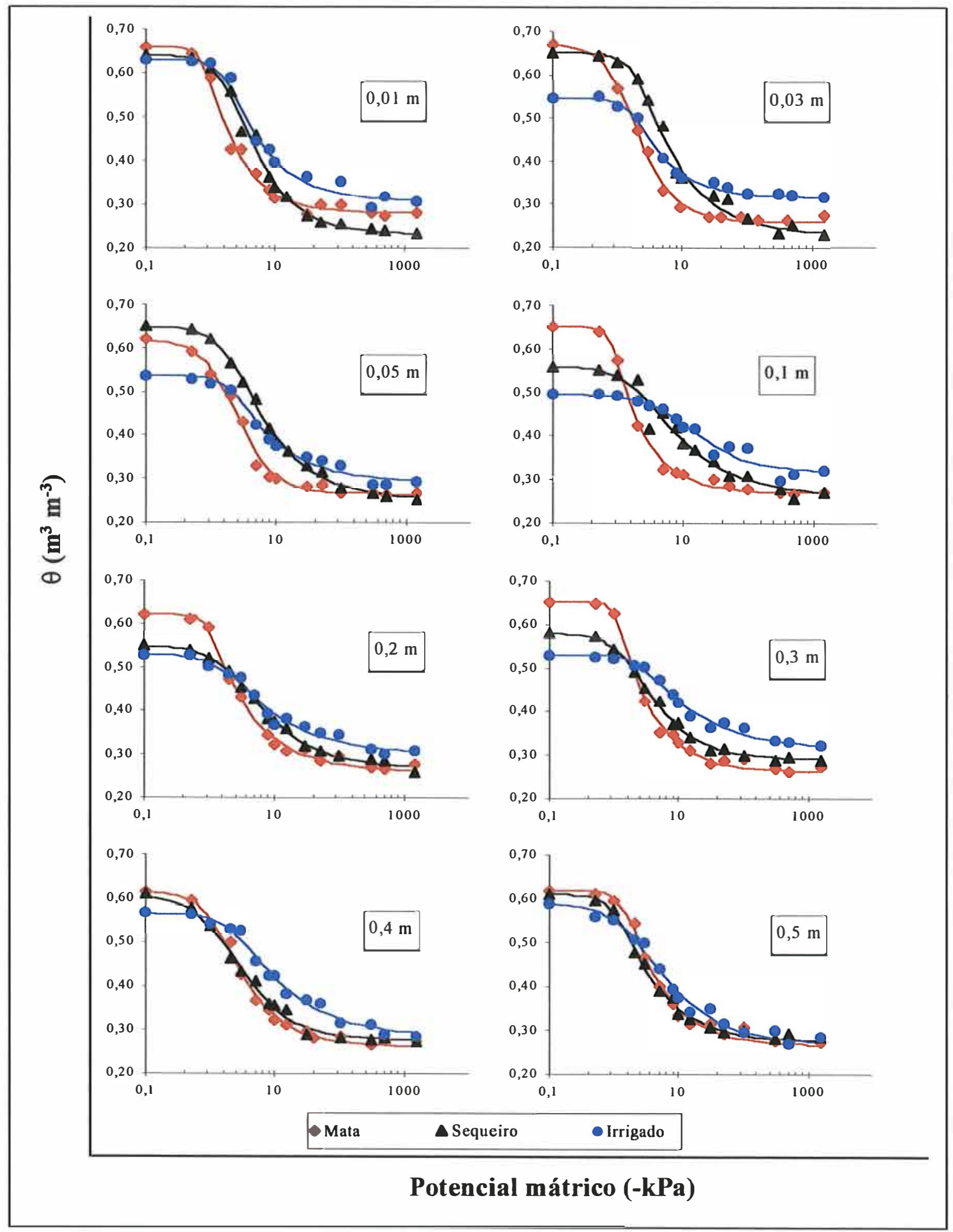

continua na próxima página... 


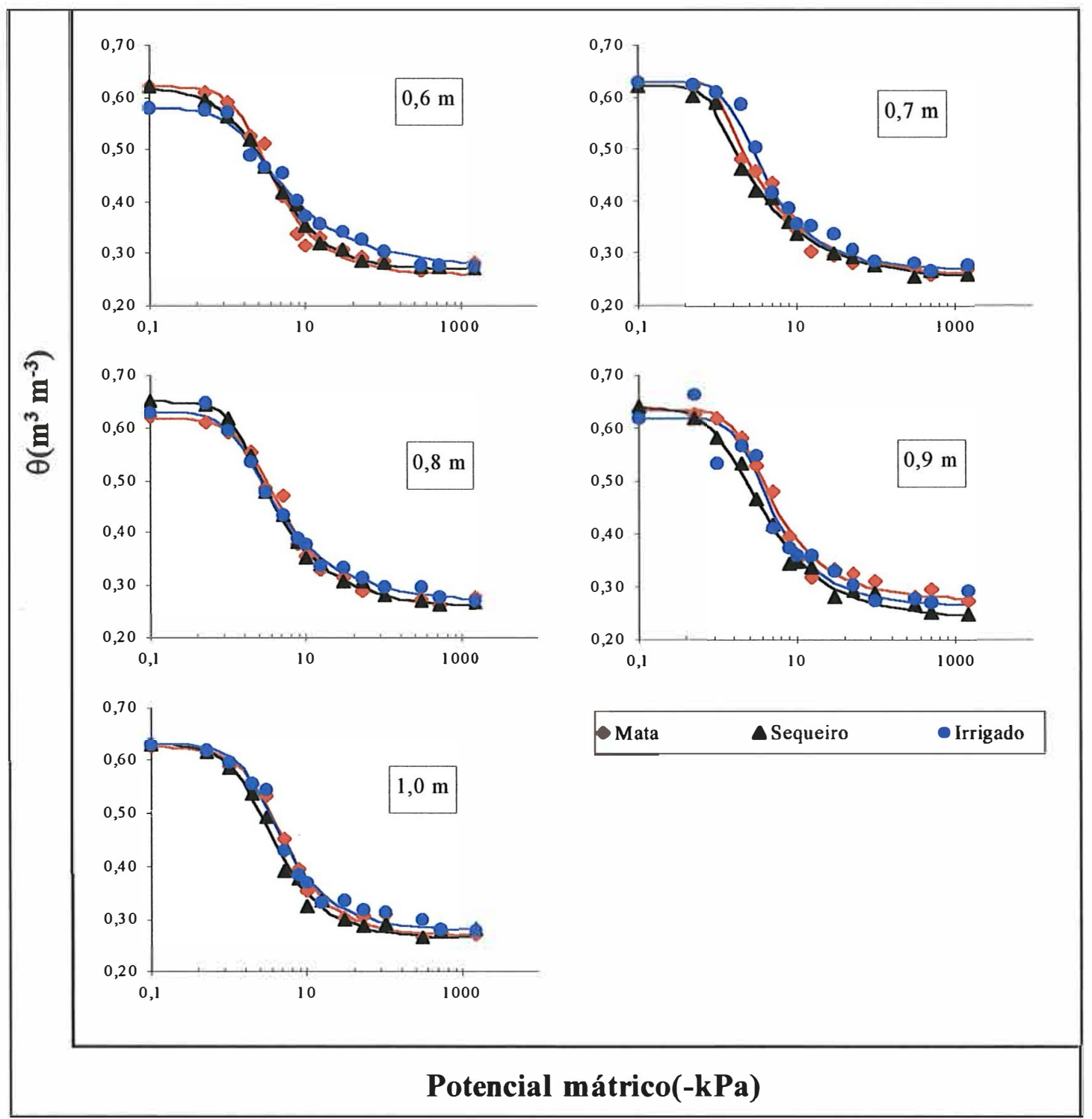

Figura 16 -Curva de retenção de água no solo para os manejos e profundidades, cada ponto experimental é oriundo de uma sub-amostra.

\subsection{Curvas de retenção da água no solo com estrutura alterada}

Trabalhos, como o de Castro (1995), têm sido apresentados ressaltando que a estrutura do solo pouco influencia no teor de água do solo em altas tensões (acima de $500 \mathrm{kPa}$ ). Portanto as determinações de retenção de água nestas tensões poderiam ser feitas em solo com estrutura alterada. Por outro lado, Sidiras et al. (1984) em um trabalho comparando sistemas de manejo, concluíram que as curvas de retenção de água 
em amostras com estrutura alterada superestimaram a água disponível e as de estrutura indeformada devem ser preferidas por simularem melhor as condições de campo. Julgamos que as análises devem sempre ser feitas em amostras de solo que representam a condição de campo. $O$ assunto é polêmico e foi o que motivou a determinação da retenção de água em amostras de solo com estrutura alterada (tfsa).

Na figura 17 estão apresentadas as curvas de retenção da água no solo com estrutura alterada, para as 13 profundidades e 3 manejos. Os parâmetros de ajuste dos dados experimentais a equação de Van Genuchten (1980) estão no apêndice 3.2.

Observa-se que as diferenças entre as curvas entre manejos quando realizadas com estrutura preservada foram bastante reduzidas especificamente a partir de tensões de $100 \mathrm{kPa}$, demonstrando que a realização de curvas de retenção com os pontos de alta tensão ( 500 e $1500 \mathrm{kPa}$ ) com amostras com estrutura alterada não é indicada, pois o fato de as curvas terem ficado parecidas indica que as diferenças originais, realmente devemse as diferenças na estrutura. Neste sentido, as curvas de retenção com estrutura alterada superestimam a água disponível concordando com Sidiras et al. (1984), por superestimar a umidade a baixas tensões e subestimar a altas tensões.

Até a profundidade de $0,1 \mathrm{~m}$ o solo da mata apresenta um comportamento diferente do sequeiro e do irrigado, indicando uma maior agregação, o que originou a formação de poros com maior diâmetro e mais uniformes, pois ao se atingir a tensão em torno de $6 \mathrm{kPa}$ (macroporos) rapidamente todos se esvaziaram, estabilizando após em níveis de umidade em torno de $25 \%$, que é a água retida dentro dos poros intraagregados (criptoporos). Esta constatação concorda com Kiehl (1979) que apresenta uma relação positiva entre diâmetro dos agregados e volume de macroporos do solo. 


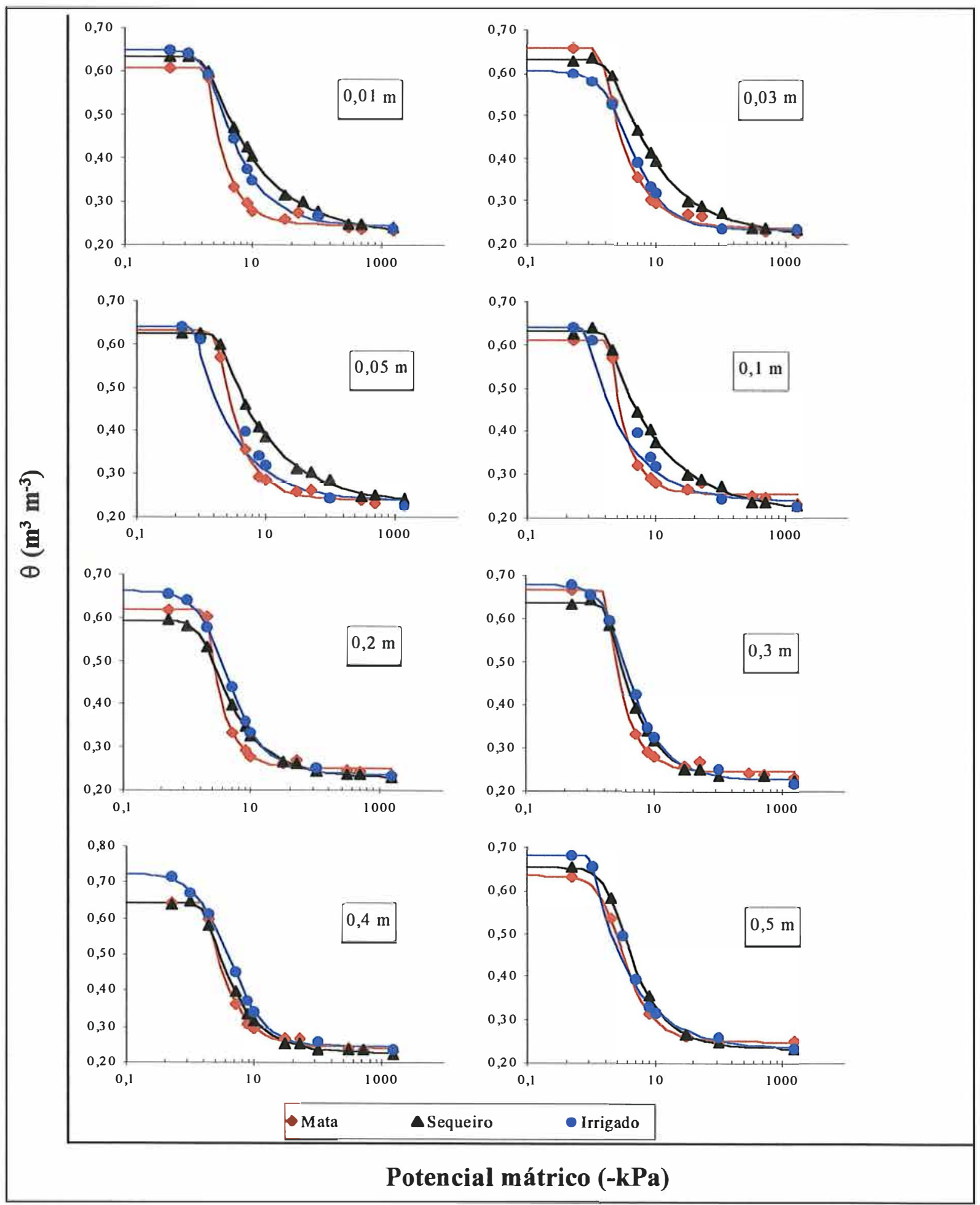

continua na próxima página... 


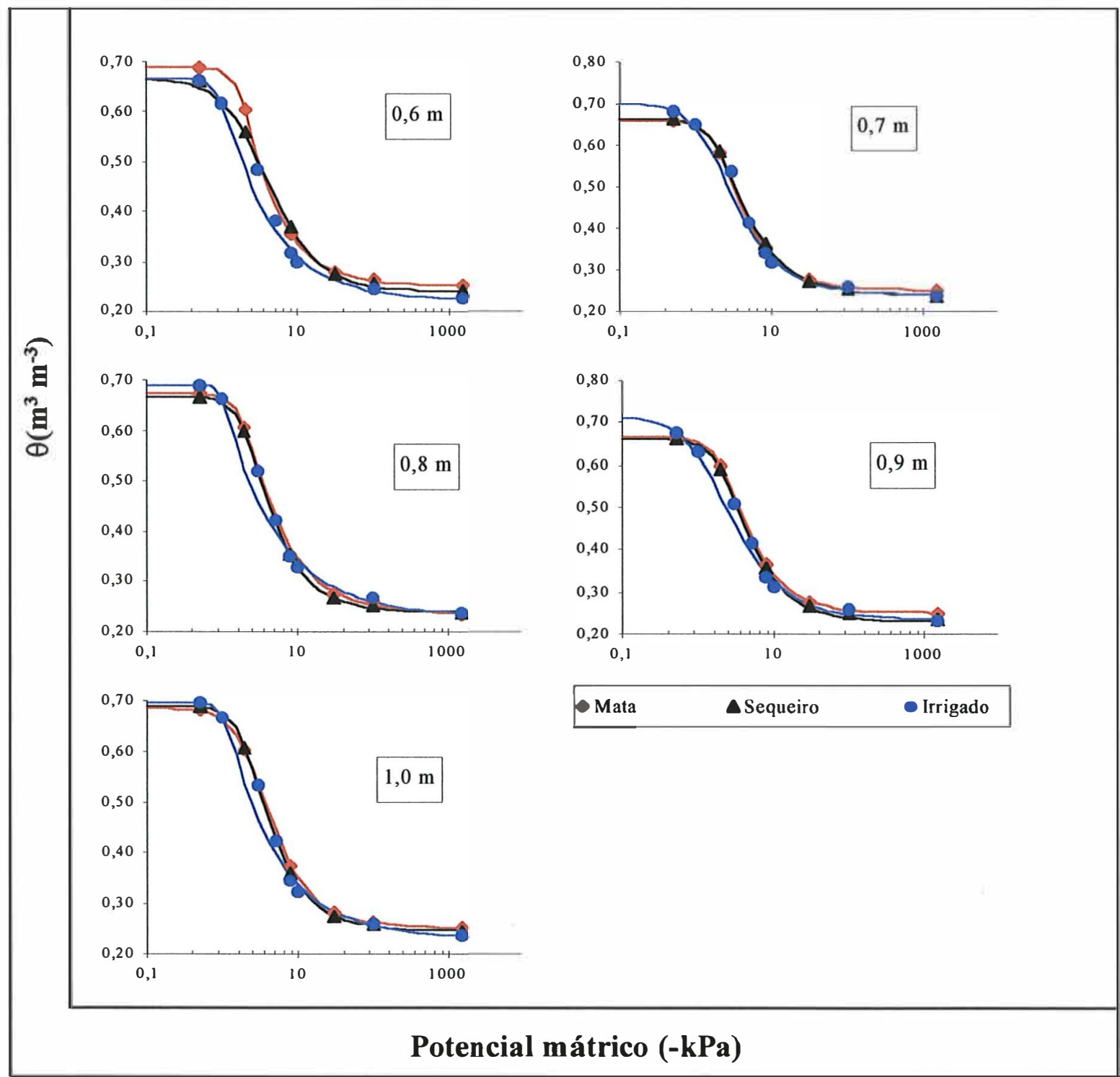

Figura 17-Curvas de retenção de água no solo com estrutura alterada em profundidades para os diferentes manejos.

\subsection{Porosidade do solo}

A partir das curvas de retenção da água no solo com estrutura preservada (figura 16) é possível estudar a distribuição dos diâmetros dos poros do solo através da derivação das equações em relação ao potencial mátrico, como está apresentado, para algumas profundidades, na figura 18. 


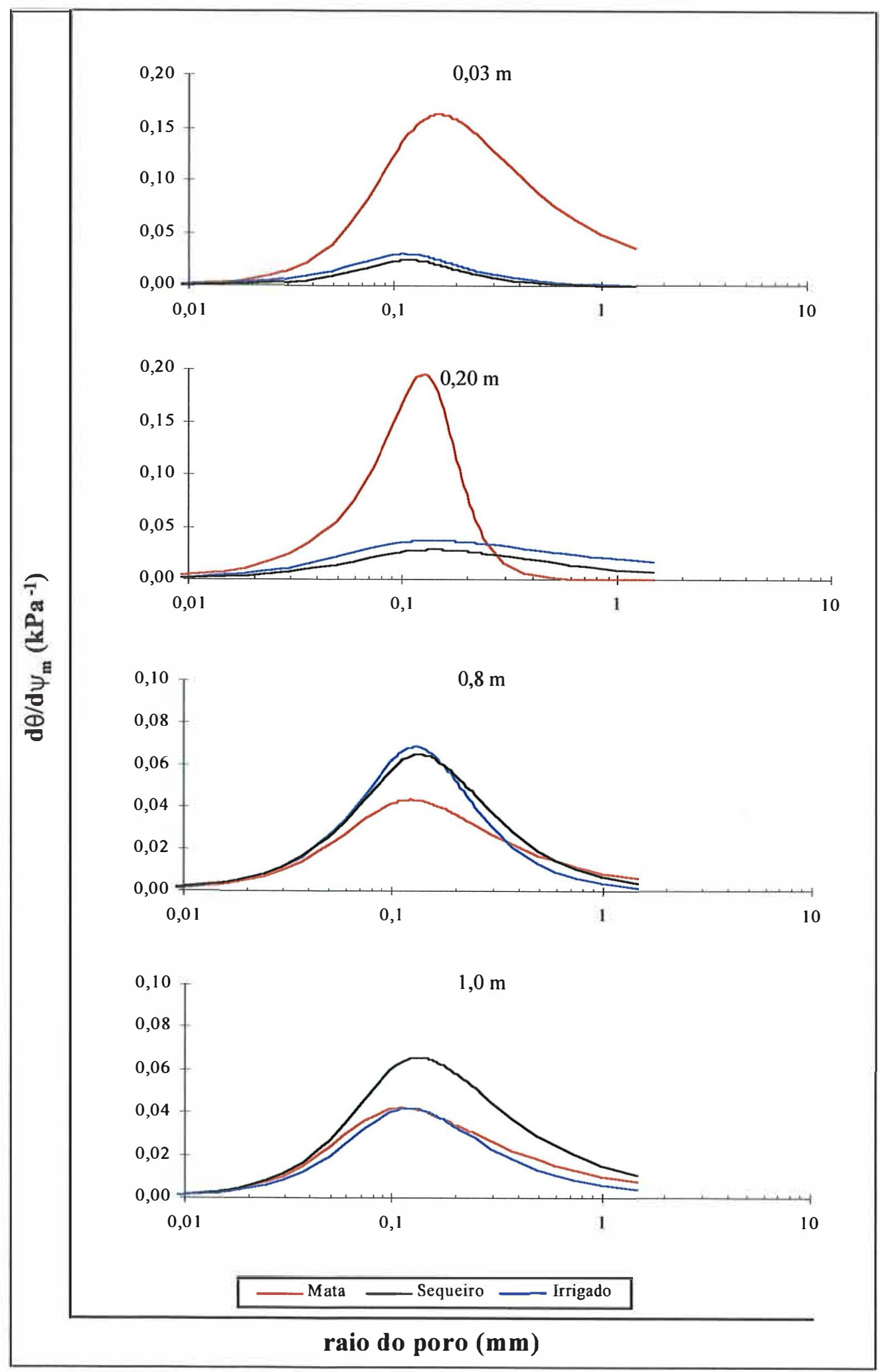

Figura 18 -Distribuição do diâmetro dos poros em solo com estrutura preservada. 
Pode-se constatar um pequeno deslocamento do máximo da curva, o que significa que o manejo alterou o raio dos poros predominantes. Em profundidade maior estas diferenças foram muito pequenas e os máximos das curvas coincidentes, o que demonstra que houve uma pequena redução no volume total dos poros, sem afetar a distribuição do diâmetro dos poros no solo.

Neste sentido Tognon (1991) estudando a porosidade do solo através da porosimetria por injeção de mercúrio detectou que a distribuição de poros é bimodal, com um primeiro máximo entre 0,005 e $0,2 \mathrm{~mm}$ de diâmetro, correspondendo aos poros interagregados e um outro entre 0,00001 a 0,0001 mm denominados de poros intra-agregados. Como neste estudo a distribuição do diâmetro dos poros foi feito utilizando somente a curva de retenção de água no solo, pode-se observar apenas o primeiro máximo, pois o menor diâmetro de poro que pode ser estudado pela curva de retenção na tensão de $1500 \mathrm{kPa}$ é $0,0002 \mathrm{~mm}$.

A análise da distribuição do tamanho dos poros no solo, em classes, para os três manejos está apresentada na figura 19, e as alterações no volume de sólidos e classes de poros dos manejos em relação à mata na tabela 7. Observa-se que no solo da mata a porosidade total praticamente não variou em profundidade, o mesmo ocorrendo com os criptoporos. Os macro e microporos apresentaram alterações, sendo que os primeiros apresentaram uma tendência de diminuição em profundidade e em conseqüência disso os microporos um aumento.

Estes dados confimam afirmações feitas por Tognon (1991) e Kertzmann (1996) que os poros com diâmetro menor que $0,0002 \mathrm{~mm}$, neste trabalho denominados de criptoporos, seriam os poros intra-agregados. Como nesta situação não ocorreu alteração da densidade e portanto do volume de sólidos, o volume de agregados não foi alterado. Disso se conclui que as alterações no volume de micro e macroporos são conseqüência do arranjo destes agregados e da atividade biológica nesta camada mais superficial. 
* Para o sistema de manejo de sequeiro observa-se uma pequena redução na porosidade total na camada superficial, isto é, até $0,05 \mathrm{~m}$ de profundidade, sendo importante destacar que nesta área, antes da implantação da cultura do milho (safninha março 1997) foi efetuado um preparo reduzido com a utilização de grade leve de discos, para eliminação das invasoras, a qual mobilizou o solo até esta profundidade, estando o solo, no momento da coleta, pulverizado e friável. Esta mobilização não afetou a porosidade total, alterando, no entanto, a distribuição dos diâmetro dos poros, diminuindo macro e criptoporos e aumentando microporos. Esta diminuição dos criptoporos, leva a crer, que o manejo adotado nesta área com a utilização de grades, ainda que de forma esporádica, afeta a estrutura dos microagregados, desestruturando-os. Na camada de 0,05 a $0,15 \mathrm{~m}$ de profundidade, ocorreu uma diminuição da porosidade total em torno de $9 \%$, enquanto que os macroporos diminuíram em $24 \%$, comprovando o que afirmarn autores como Grohmann \& Queiroz Neto (1966) e Silva et al. (1986) que , no processo de compactação, ocorre a transformação de macro em microporos. Em relação aos criptoporos, destaca-se que ocorreu um incremento em torno de $6 \%$, em decorrência do aumento do volume de agregados por volume de solo.

$\mathrm{Na}$ área irrigada, onde, em função do plantio direto, não existe preparo do solo e um tráfego intenso de maquinaria agrícola, ocorreram as maiores alterações na porosidade do solo, sendo que estas atingiram a profundidade de 0,4 . Na camada de 0,15 à 0,35 , observa-se alteração menor na alteração da porosidade total, diminuição em torno de $3 \%$, permanecendo no entanto a tendência na distribuição do tamanho dos poros, com diminuição de macro e aumento de micro e criptoporos. Na camada superficial, em função do não revolvimento do solo, ocorreu a maior redução na porosidade, diminuindo em cerca de $20 \%$ o volume de poros em relação a mata, sendo que a redução mais crítica no volume de macroporos ocorreu na camada de $0,1 \mathrm{~m}$. 


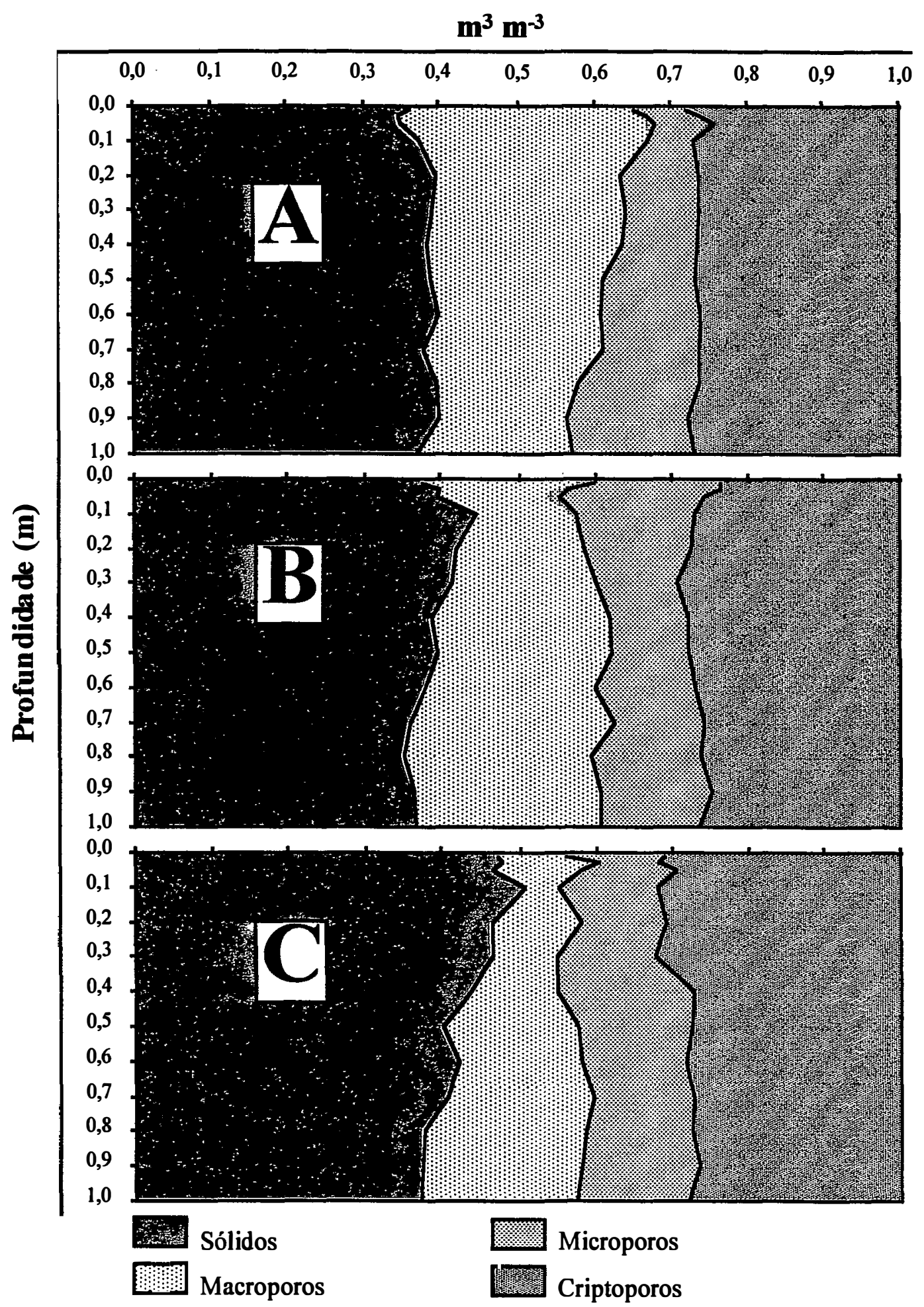

Figura 19- Distribuição das classes de poros no perfil do solo sob mata(A), de sequeiro (B) e irrigado (C) 
Tabela 7 - Alterações no volume de sólidos, de poros e na distribuição do diâmetro dos poros do solo nos sistemas de manejo de sequeiro e irrigado em relação a mata

\begin{tabular}{|c|c|c|c|c|c|}
\hline \multirow{3}{*}{ Prof. (m) } & Sólidos & Porosidade & macroporos & microporos & criptoporos \\
\hline & $-m$ & -3 solo- & \multicolumn{3}{|c|}{$m^{3} m^{-3} d a$ porosidade total.- } \\
\hline & \multicolumn{4}{|c|}{ Sequeiro em relação a mata } & \\
\hline 0,01 & 3,884 & $-2,207$ & $-0,099$ & 0,164 & $-0,065$ \\
\hline 0,03 & 15,180 & $-8,033$ & $-0,216$ & 0,221 & $-0,005$ \\
\hline 0,05 & 13,439 & $-7,123$ & $-0,213$ & 0,193 & 0,020 \\
\hline 0,1 & 19,941 & $-11,873$ & $-0,240$ & 0,182 & 0,058 \\
\hline 0,2 & 5,476 & $-3,604$ & $-0,102$ & 0,067 & 0,035 \\
\hline 0,3 & 5,983 & $-3,837$ & $-0,090$ & 0,023 & 0,067 \\
\hline 0,4 & 1,689 & $-1,051$ & $-0,036$ & 0,008 & 0,028 \\
\hline 0,5 & 2,351 & $-1,492$ & 0,004 & $-0,025$ & 0,022 \\
\hline 0,6 & $-5,240$ & 3,477 & 0,004 & $-0,006$ & 0,001 \\
\hline 0,7 & $-5,675$ & 3.478 & 0,041 & $-0,019$ & $-0,022$ \\
\hline 0,8 & $-11,404$ & 7,474 & 0,072 & $-0,040$ & $-0,032$ \\
\hline 0,9 & $-8,833$ & 5,886 & 0,107 & $-0,032$ & $-0,075$ \\
\hline 1,0 & $-0,451$ & 0,262 & 0,057 & $-0,048$ & $-0,009$ \\
\hline \multicolumn{6}{|c|}{ Irrigado em relação a mata } \\
\hline 0,01 & 30,288 & $-17,205$ & $-0,286$ & 0,139 & 0,146 \\
\hline 0,03 & 37,875 & $-20,044$ & $-0,252$ & 0,041 & 0,211 \\
\hline 0,05 & 32,948 & $-17,683$ & $-0,253$ & 0,108 & 0,145 \\
\hline 0,1 & 35,223 & $-20,972$ & $-0,380$ & 0,164 & 0,217 \\
\hline 0,2 & 17,019 & $-11,201$ & $-0,176$ & 0,039 & 0,137 \\
\hline 0,3 & 18,857 & $-12,094$ & $-0,257$ & 0,083 & 0,173 \\
\hline 0,4 & 13,878 & $-8,637$ & $-0,215$ & 0,159 & 0,056 \\
\hline 0,5 & 3,676 & $-2,333$ & $-0,074$ & 0,052 & 0,022 \\
\hline 0,6 & 5,691 & $-3,776$ & $-0,072$ & 0,019 & 0,053 \\
\hline 0,7 & 7,205 & $-4,416$ & $-0,053$ & 0,018 & 0,035 \\
\hline 0,8 & $-5,003$ & 3,279 & 0,033 & $-0,039$ & 0,005 \\
\hline 0,9 & $-6,426$ & 4,281 & 0,059 & $-0,020$ & $-0,038$ \\
\hline 1,0 & 0,905 & $-0,526$ & 0,001 & $-0,018$ & 0,017 \\
\hline
\end{tabular}




\subsubsection{Porosidade de aeração}

As alterações na porosidade total e na distribuição do diâmetro dos poros afeta de forma direta a porosidade de aeração. Considerando-se apenas o fato de que é principalmente nos macroporos que ocorre a circulação de ar. Observa-se que para a mata esta macroporosidade ficou sempre em torno de $0,20 \mathrm{~m}^{3} \mathrm{~m}^{-3}$ do volume do solo, enquanto que para o sequeiro o valor mínimo na camada mais compacta ficou em torno de $0,12 \mathrm{~m}^{3} \mathrm{~m}^{-3}$. Já no sistema irrigado na profundidade com maior densidade, este valor foi $0,045 \mathrm{~m}^{3} \mathrm{~m}^{-3}$, metade do que preconiza Erickson (1982) que cita ser $0,10 \mathrm{~m}^{3} \mathrm{~m}^{-3} \mathrm{a}$ necessidade mínima de poros de aeração para a maioria das culturas.

Na tabela 8 pode-se observar o comportamento da água no solo durante o processo de redistribuição, tanto no solo de mata como no de sequeiro após 12 horas de saturação (inundação), situação que dificilmente ocorre naturalmente neste sistema agrícola, a porosidade livre de água em todo o perfil era maior do que $0,15 \mathrm{~m}^{3} \mathrm{~m}^{-3}, \mathrm{o}$ mesmo não ocorrendo com a área irrigada, que mesmo após 96 horas de drenagem, os valores de espaço poroso livre de água, até a profundidade de $0,3 \mathrm{~m}$ ainda eram inferiores a $0,15 \mathrm{~m}^{3} \mathrm{~m}^{-3}$, o que poderá ocasionar problemas de deficiência de aeração ao sistema radicular das plantas. 
Tabela 8 - Porosidade de aeração $\left(\mathrm{m}^{3} \mathrm{~m}^{-3}\right)$ de solo em diferentes tempos de redistribuição água no solo.

\begin{tabular}{|c|c|c|c|c|c|c|}
\hline Prof. (m) & mata & sequeiro & irrigado & mata & sequeiro & irrigado \\
\hline & \multicolumn{3}{|c|}{12 horas } & \multicolumn{3}{|c|}{24 horas } \\
\hline 0,01 & $0, \overline{28} \overline{1}$ & 0,177 & $\overline{0}, \overline{178}$ & $\overline{0,300}$ & $0,19 \overline{7}$ & 0,200 \\
\hline 0,03 & 0,295 & 0,134 & 0,139 & 0,321 & 0,155 & 0,154 \\
\hline 0,05 & 0,232 & 0,150 & 0,107 & 0,259 & 0,168 & 0,124 \\
\hline 0,1 & 0,290 & 0,147 & 0,040 & 0,308 & 0,160 & 0,049 \\
\hline 0,2 & 0,229 & 0,145 & 0,105 & 0,245 & 0,157 & 0,118 \\
\hline 0,3 & 0,266 & 0,189 & 0,073 & 0,284 & 0,200 & 0,086 \\
\hline 0,4 & 0,227 & 0,233 & 0,106 & 0,244 & 0,244 & 0,122 \\
\hline 0,5 & 0,200 & 0,233 & 0,160 & 0,223 & 0,243 & 0,178 \\
\hline 0,6 & 0,202 & 0,217 & 0,156 & 0,229 & 0,233 & 0,170 \\
\hline 0,7 & 0,230 & 0,240 & 0,215 & 0,247 & 0,251 & 0,233 \\
\hline 0,8 & 0,176 & 0,235 & 0,202 & 0,205 & 0,252 & 0,220 \\
\hline 0,9 & 0,181 & 0,239 & 0,181 & 0,205 & 0,257 & 0,209 \\
\hline \multirow[t]{2}{*}{1} & 0,169 & 0,226 & 0,175 & 0,200 & 0,243 & 0,200 \\
\hline & \multicolumn{3}{|c|}{48 horas } & \multicolumn{3}{|c|}{96 horas } \\
\hline 0,01 & $\overline{0,314}$ & $0, \frac{1}{12}$ & $0, \overline{2} 16$ & $0,3 \overline{25}$ & 0,225 & $0, \overline{2} 2 \overline{9}$ \\
\hline 0,03 & 0,341 & 0,171 & 0,166 & 0,355 & 0,185 & 0,175 \\
\hline 0,05 & 0,281 & 0,184 & 0,138 & 0,297 & 0,196 & 0,149 \\
\hline 0,1 & 0,322 & 0,171 & 0,057 & 0,332 & 0,180 & 0,065 \\
\hline 0,2 & 0,257 & 0,169 & 0,127 & 0,270 & 0,179 & 0,136 \\
\hline 0,3 & 0,299 & 0,211 & 0,096 & 0,311 & 0,219 & 0,105 \\
\hline 0,4 & 0,259 & 0,255 & 0,134 & 0,273 & 0,263 & 0,146 \\
\hline 0,5 & 0,246 & 0,253 & 0,188 & 0,262 & 0,261 & 0,199 \\
\hline 0,6 & 0,252 & 0,248 & 0,182 & 0,268 & 0,260 & 0,192 \\
\hline 0,7 & 0,260 & 0,262 & 0,248 & 0,273 & 0,270 & 0,261 \\
\hline 0,8 & 0,226 & 0,268 & 0,232 & 0,242 & 0,281 & 0,244 \\
\hline 0,9 & 0,223 & 0,270 & 0,224 & 0,241 & 0,282 & 0,238 \\
\hline \multirow[t]{2}{*}{1} & 0,226 & 0,259 & 0,220 & 0,245 & 0,272 & 0,236 \\
\hline & \multicolumn{3}{|c|}{192 horas } & \multicolumn{3}{|c|}{720 horas } \\
\hline 0,01 & $\overline{0,33} \overline{5}$ & 0,240 & $0, \overline{2} 41$ & $\overline{0,35} \overline{3}$ & 0,265 & $\overline{0,261}$ \\
\hline 0,03 & 0,368 & 0,201 & 0,183 & 0,389 & 0,229 & 0,196 \\
\hline 0,05 & 0,312 & 0,212 & 0,159 & 0,335 & 0,238 & 0,177 \\
\hline 0,1 & 0,341 & 0,191 & 0,074 & 0,358 & 0,212 & 0,093 \\
\hline 0,2 & 0,282 & 0,190 & 0,143 & 0,308 & 0,210 & 0,159 \\
\hline 0,3 & 0,324 & 0,229 & 0,114 & 0,349 & 0,244 & 0,130 \\
\hline 0,4 & 0,288 & 0,274 & 0,157 & 0,311 & 0,291 & 0,179 \\
\hline 0,5 & 0,276 & 0,270 & 0,211 & 0,300 & 0,286 & 0,233 \\
\hline 0,6 & 0,284 & 0,274 & 0,202 & 0,310 & 0,297 & 0,220 \\
\hline 0,7 & 0,284 & 0,281 & 0,273 & 0,304 & 0,299 & 0,295 \\
\hline 0,8 & 0,259 & 0,294 & 0,255 & 0,289 & 0,317 & 0,277 \\
\hline 0,9 & 0,261 & 0,296 & 0,254 & 0,288 & 0,318 & 0,279 \\
\hline 1 & 0,265 & 0,285 & 0,251 & 0,294 & 0,310 & 0,277 \\
\hline
\end{tabular}




\subsection{Infiltração da água no solo}

Os resultados da capacidade de infiltração da água no solo feitas no campo em três profundidades para os manejos de sequeiro e irrigado foram ajustados à equação de Kostiakov, sendo importante destacar, que os pontos experimentais, apresentados nos gráficos, são oriundos de três determinações (repetições). A variação nestes resultados esta de acordo com a grande variabilidade espacial ( > $100 \%$ ) encontrada por Warrick \& Nielsen (1980) para a condutividade hidráulica do solo saturado, parâmetro que influencia diretamente na capacidade de infiltração. Outros autores como Vieira et al. (1981) e Gurovich \& Stern (1983) fizeram um estudo utilizando a geoestatística para avaliar a variabilidade espacial desta propriedade do solo encontrando também alta variabilidade espacial.

Observa-se que os valores da taxa constante de infiltração para a profundidade de $0,5 \mathrm{~m}$, para os dois sistemas de manejo, foram bem superiores aos das demais profundidades estudadas, evidenciando o efeito negativo do manejo do solo sobre a infiltração da água nas camadas superficiais, coincidindo com aquelas de menor densidade (figuras 20 e 21).

Não foram feitas determinações na mata, por problemas operacionais. Além disso, já se dispunha de resultados neste tipo de solo na região e até mesmo nesta fazenda, apresentados por Tognon (1991); Saad (1991) e Kertzmann (1996) que acharam valores da taxa constante de infiltração na superfície do solo, acima de $1000 \mathrm{~mm} \mathrm{~h}^{-1}$, valores bastante altos, o que demonstra a característica dos Latossolos de elevada permeabilidade em função da sua microagregação, já destacada por Vargas (1978).

O tempo para estabilização da taxa de infiltração foi menor na área irrigada em função da maior umidade inicial do solo, pelo fato de terem sido efetuadas irrigações no período que antecedeu as determinações. 


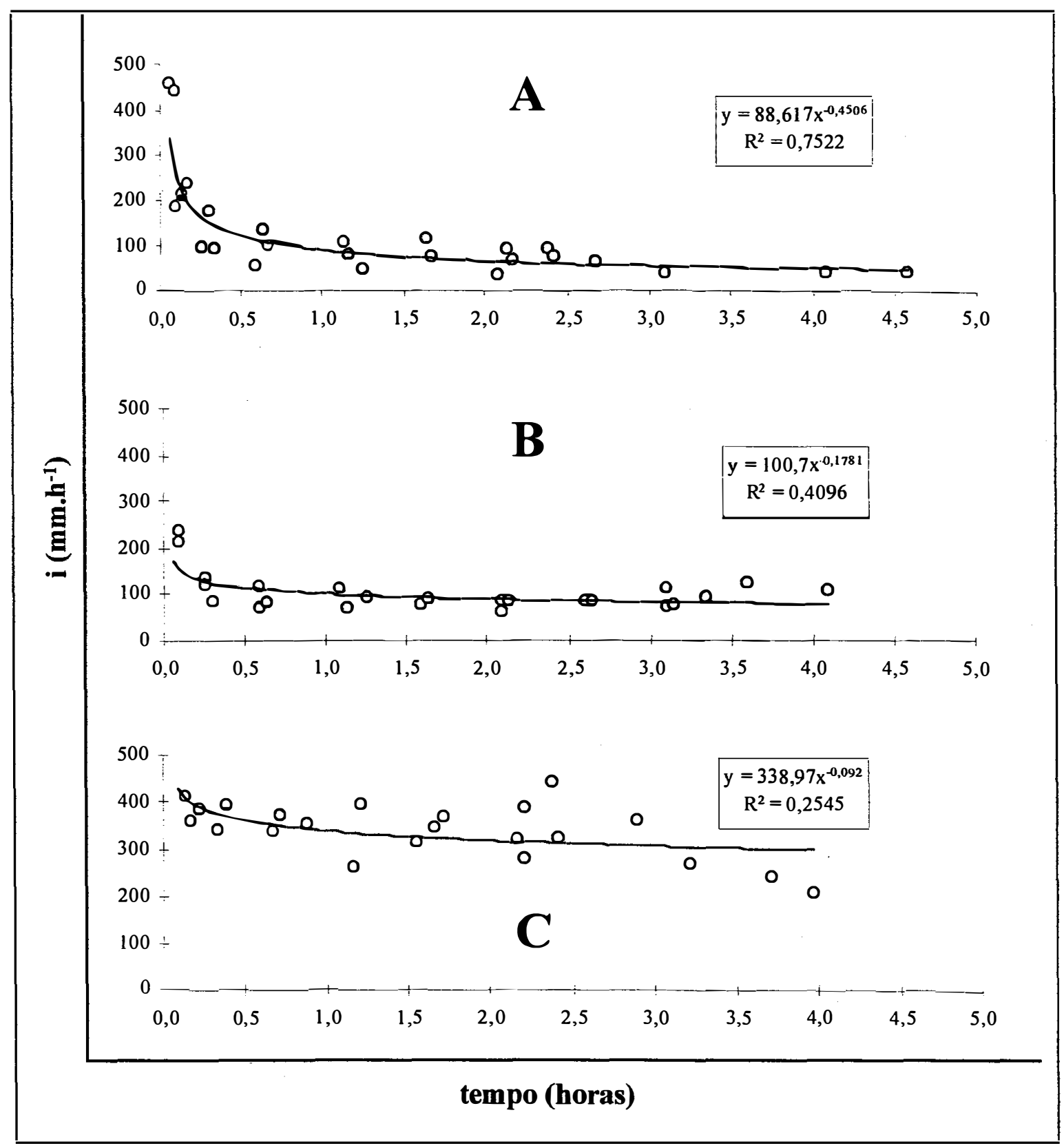

Figura 20 -Taxa de infiltração de água no solo para o sistema sequeiro (A) superficie, (B) 0,2 $m e$ (C) 0,5 $m$ de profundidade. 


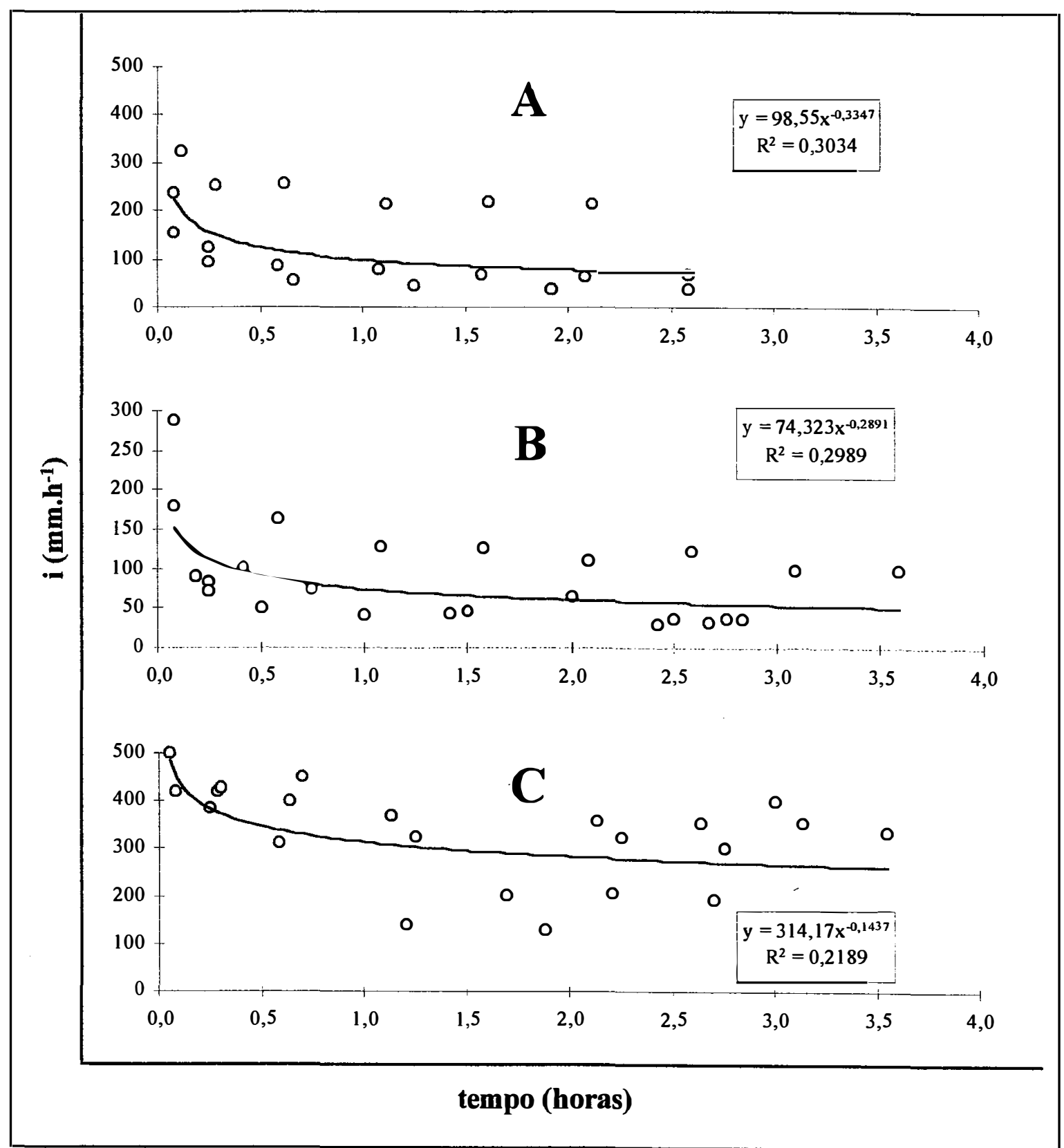

Figura 21 - Taxa de infiltração de água no solo para o sistema irrigado (A) superfície, (B) 0,2 $\mathrm{m} e$ (C) 0,5 $\mathrm{m}$ de profundidade. 
Considerando-se a taxa constante de infiltração de água no solo, ajustada para as três repetições os valores para a área de sequeiro foram: superficie $\left(45 \mathrm{~mm} \mathrm{~h}^{-1}\right)$, 0,2 $\mathrm{m}\left(79 \mathrm{~mm} \mathrm{~h}^{-1}\right)$ e $0,5 \mathrm{~m}\left(299 \mathrm{~mm} \mathrm{~h}^{-1}\right)$, enquanto no irrigado os valores foram: superficie $\left(73 \mathrm{~mm} \mathrm{~h}^{-1}\right), 0,2 \mathrm{~m}\left(52 \mathrm{~mm} \mathrm{~h}^{-1}\right)$ e $0,5 \mathrm{~m}\left(263 \mathrm{~mm} \mathrm{~h}^{-1}\right)$. A menor taxa de infiltração na profundidade $0,2 \mathrm{~m}$ da área irrigada em relação a superficie pode ser explicada por provável fluxo lateral de água proporcionado ou por canais ou pelo impedimento ao fluxo da camada compactada situado nesta profundidade.

A redução na taxa de infiltração da água no solo dos dois sistemas de manejo em relação à mata é muito grande, o que indica o efeito sobre esta propriedade da redução da macroporosidade do solo, efeito do tráfego da maquinaria agrícola, uma vez que o cultivo nestas áreas é plantio direto.

A permeabilidade do solo apesar de ter sido reduzida consideravelmente, ainda é alta, considerando-se precipitações médias e lâminas de água aplicadas por irrigação. Em função desta permeabilidade associado a irrigações feitas sem muito critério técnico, adubações e calagens pesadas, acarretou uma lixiviação significativa de nutrientes em profundidade, especificamente na área irrigada, como pode ser observado nos resultados dos atributos químicos do apêndice 2.1 a 2.9.

Analisando apenas os valores do $\mathrm{r}^{2}$ do ajuste da equação de Kostiakov, estes são menores para o sistema irrigado, indicando uma maior variabilidade espacial desta propriedade neste sistema, o que pode ser explicado pela intenso cultivo nesta área com 2,5 cultivos por ano, ocasionando assim grande retorno de material orgânico e intensa atividade biológica no solo, que podem formar canais conectados com a superfície do solo, aumentando a infiltração (Ehlers, 1975).

\subsection{Condutividade hidráulica do solo saturado}

A condutividade hidraúlica do solo saturado determinada em amostras com estrutura indeformada foi altamente influenciada pelos sistemas de manejo, (tabela 9), 
sendo que na profundidade mais crítica de $0,1 \mathrm{~m}$ a redução neste parâmetro do solo da área irrigada em relação a mata, foi da ordem de $94 \%$, permanecendo este valor para área irrigada em $54,2 \mathrm{~mm} \mathrm{~h}^{-1}$.

Comparando-se os manejos observa-se uma tendência de comportamento inverso da condutividade em relação a densidade do solo, sendo que abaixo da camada de 0,4 m não mais se observou diferenças entre os tratamentos.

Observa-se também um maior coeficiente de variação entre os valores nas áreas de sequeiro e irrigado, o que pode ser atribuído a ação antrópica, atividade biológica e aos canais deixados pela decomposição das raízes das culturas colhidas.

Tabela 9 - Condutividade do solo saturado, em profundidade, para diferentes manejos

\begin{tabular}{|c|c|c|c|c|c|c|c|c|c|}
\hline \multirow{3}{*}{$\begin{array}{c}\text { Prof. (m) } \\
0,01\end{array}$} & \multirow{2}{*}{\multicolumn{3}{|c|}{ Mata }} & \multirow{2}{*}{\multicolumn{3}{|c|}{$\frac{\text { Sequeiro }}{m m h^{-1}}$}} & \multicolumn{3}{|c|}{ Irrigado } \\
\hline & & & & & & & & & \\
\hline & $\bar{A}$ & 1008,5 & $a$ & B & 242,6 & $a b$ & B & 150,8 & bcd \\
\hline 0,10 & A & 820,2 & $a b c$ & B & 134,5 & b & B & 54,2 & d \\
\hline 0,20 & A & 963,6 & $a b$ & B & 275,5 & $a b$ & B & 100,7 & cd \\
\hline 0,30 & A & 877,9 & $a b c$ & B & 378,8 & $a b$ & B & 118,2 & bcd \\
\hline 0,40 & A & 722,2 & $a b c$ & $\mathrm{AB}$ & 407,3 & $a b$ & B & 185,7 & abcd \\
\hline 0,50 & A & 697,5 & $a b c$ & A & 393,1 & $a b$ & A & 335,3 & $a b c$ \\
\hline 0,60 & A & 670,3 & $a b c$ & A & 549,6 & a & A & 329,4 & abc \\
\hline 0,70 & A & 518,8 & bc & A & 417,4 & $a b$ & A & 359,4 & $a b$ \\
\hline 0,80 & A & 576,3 & $a b c$ & A & 414,6 & $a b$ & A & 311,0 & abc \\
\hline 0,90 & A & 488,8 & c & A & 428,9 & $a b$ & A & 421,9 & $\mathbf{a}$ \\
\hline 1,00 & A & 451,4 & c & A & 337,7 & $a b$ & A & 333,2 & $a b c$ \\
\hline Média & A & 708,69 & & B & 362,73 & & C & 245,44 & \\
\hline $\begin{array}{l}\text { CV(\%) tratan } \\
C V(\%) \text { geral }\end{array}$ & & $\begin{array}{l}33,57 \\
37,31\end{array}$ & & & 55,08 & & & 52,77 & \\
\hline
\end{tabular}

Médias seguidas pelas mesmas letras minúsculas, nas colunas, e antecedidas pelas mesmas letras maiúsculas, nas linhas não diferem significativamente entre si, ao nível de $5 \%$, pelo teste de Duncan. 
É importante considerar que a elevada variabilidade espacial deste parâmetro, evidenciada pelos elevados coeficientes de variação obtidos, também destacada por Ellies et al. (1997), pode proporcionar uma importante condição de maior infiltração, ou condução de água no solo, pois dentro do micro-relevo da superfície do solo, a água tende a se mover para parte mais baixa podendo encontrar condições de maior infiltrabilidade.

Para analisar a influência da distribuição dos diâmetros dos poros no solo sobre o comportamento da condutividade hidráulica do solo não saturado, representou-se na figura 22, os valores de Ko versus a macroporosidade relativa definida como o quociente entre macroporosidade e porosidade total do solo. São estes os poros responsáveis pela condução da água. A sua diminuição como se pode observar na figura 22, reduz a condutividade hidráulica do solo saturado. Em trabalho semelhante, Ellies et al. (1997) obtiveram boa correlação entre o volume de poros maiores que $0,05 \mathrm{~mm}$ e a condutividade hidráulica do solo saturado.

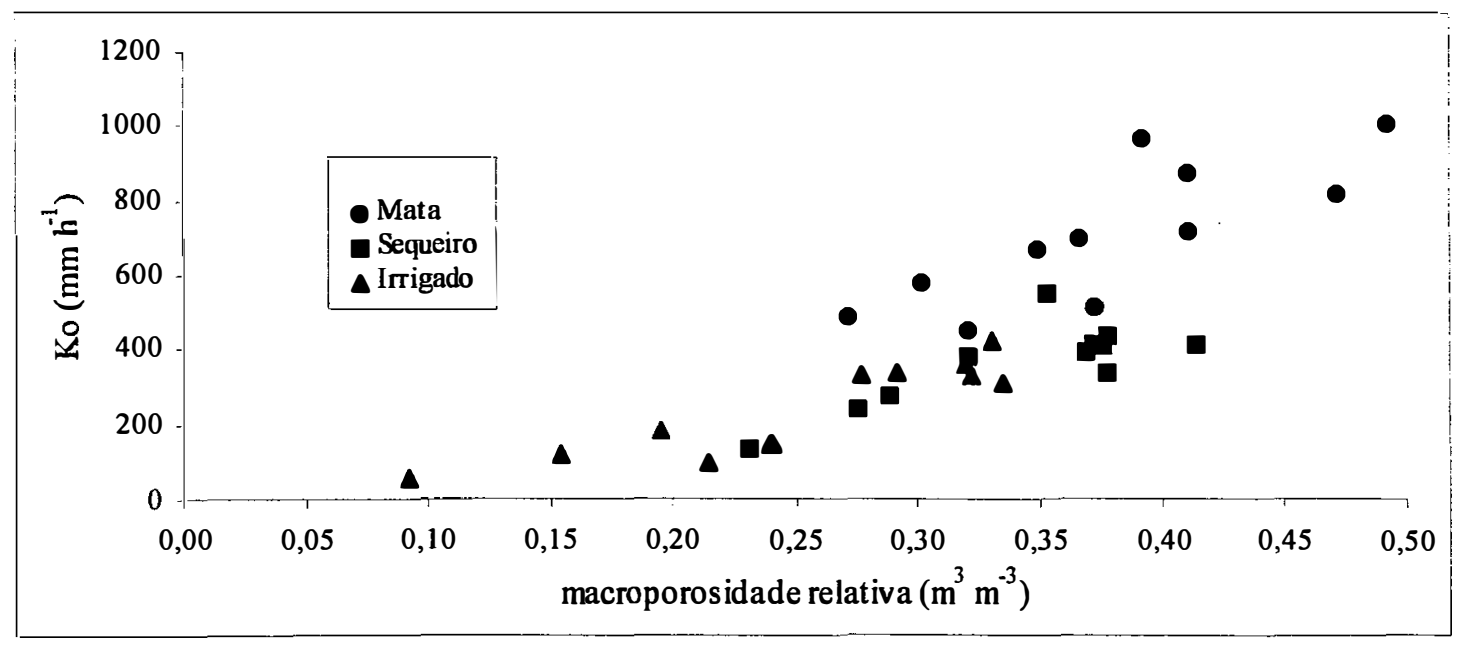

Figura 22 -Condutividade hidráulica do solo saturado em função da fração de macroporos do solo 


\subsection{Redistribuição da água no solo}

A energia da água no solo durante o processo de redistribuição, acompanhada através das leituras nos manômetros dos tensiômetros, está apresentada na forma de potencial total nos apêndices 3.5, 3.6 e 3.7, para mata, sequeiro e irrigado respectivamente, onde se observa que, mesmo 700 horas após a saturação, ainda ocorria fluxo descendente de água no perfil do solo.

* $\mathrm{O}$ gradiente de potencial total de água no solo, durante o processo de redistribuição (apêndice 3.8) indica que para o sequeiro e irrigado o gradiente de potencial foi menor e com menor variabilidade do que na mata, o que de certa forma concorda com Hillel et al. (1972) que afinna que gradiente hidráulico menor que 0,6 indicariam camadas de impedimento ao fluxo de água no perfil do solo.

$\mathrm{Na}$ figura 23 estão representados os perfis de umidade do solo em vários tempos durante o processo de redistribuição. Observa-se que no caso da mata, a água se movia da camada de menor umidade para a de maior, obviamente em função dos diferentes níveis de energia em que esta se encontrava.

Na camada superficial, a mais importante em termos agrícolas, tanto no sequeiro como irrigado a umidade do solo foi superior ao da mata o que, no entanto, não indica mais água disponível as plantas, pois esta maior retenção ocorreu em função das alterações na porosidade, com maior volume de microporos. 


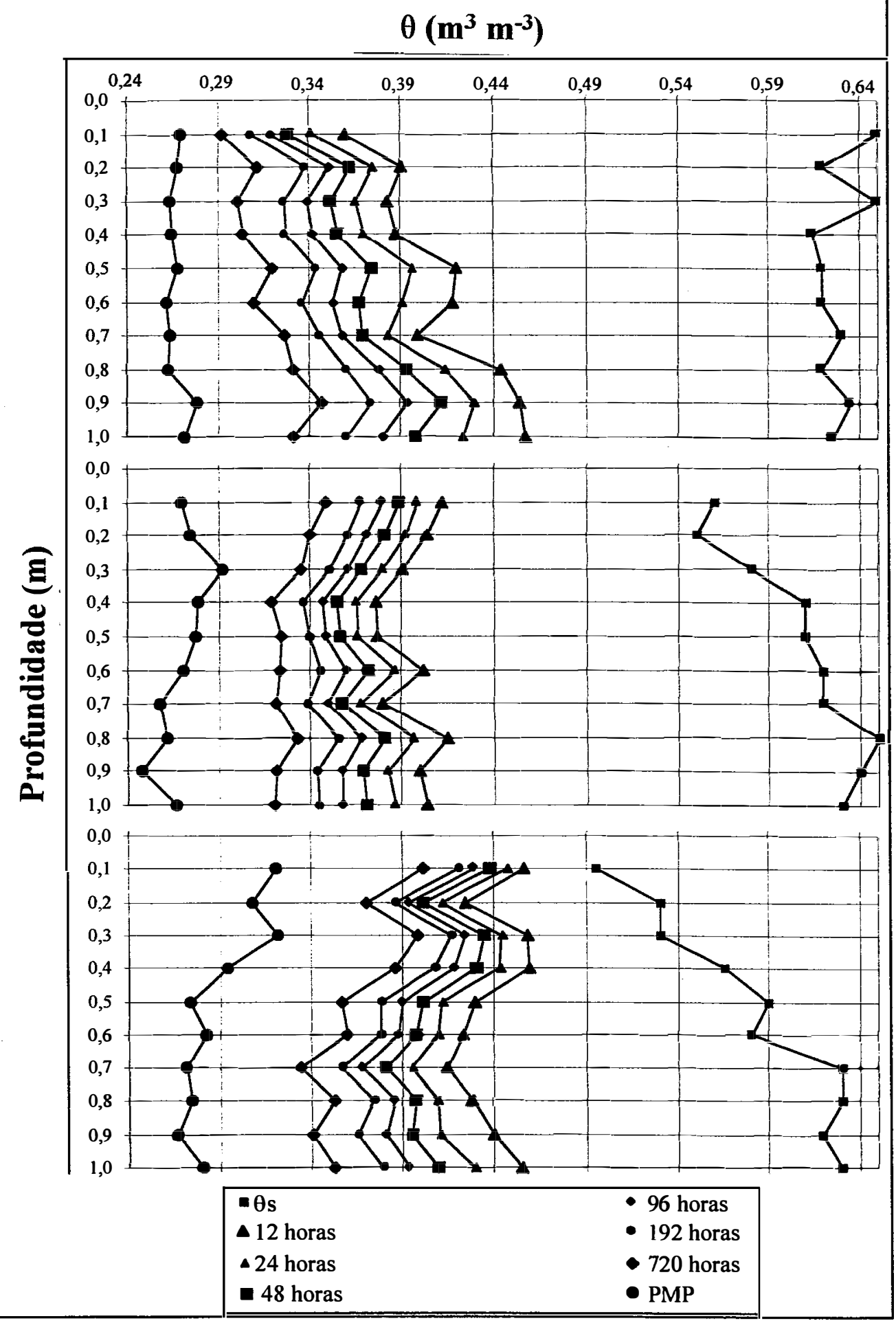

Figura 23 - Perfis de umidade do solo, durante a redistribuição da água no solo sob mata(A), de sequeiro (B) e Irrigado (C) 


\subsection{Condutividade hidráulica do solo não saturado}

\subsubsection{Determinação no campo}

Analisando-se os parâmetros empíricos de ajuste dos dados experimentais a equação 4 e seus respectivos coeficientes de determinação $\left(\mathrm{r}^{2}\right)$ (tabela 10) para as repetições, profundidades e manejos constata-se o bom ajuste dos dados à equação, com valores de $\mathrm{r}^{2}$ sempre maiores que 0,90 e na vasta maioria dos casos, maiores que 0,99 . A similaridade nos parâmetros empíricos entre as repetições demonstra a uniformidade de comportamento da água no solo dentro de cada manejo.

y Para o fluxo de água no solo (q) nas diferentes profundidades e tempos, calculado pela equação 5, observa-se uma maior depleção de água na camada superficial para o solo da mata no tempo inicial (até 48 horas) em comparação aos outros dois manejos (tabela 11). Em termos de manejo da irrigação isto é considerado um fator negativo, pois nesta condição natural, em função da pouca capacidade de retenção, irrigaçõ̃es mais freqüentes e com menor lâmina deveriam ser aplicadas.

Com o gradiente de potencial total (grad $\phi \mathrm{t}$ ) calculado pela equação 6 e apresentado no apêndice 3.8 , calculou-se a condutividade hidráulica $(\mathrm{K})$ através da equação 7 (tabela 12).

Do ajuste de $\mathrm{K}$ em função de $\theta$ obtiveram-se os parâmetros empíricos da equação 8 que estão apresentados na tabela 13 . 
Tabela 10 - Parâmetros empíricos da equação 4: ajuste da variação da armazenagem de água no solo até a profundidade $\mathrm{z}(\mathrm{m})$ em função do tempo $(\mathrm{h})$

\begin{tabular}{|c|c|c|c|c|c|c|c|c|c|}
\hline \multicolumn{10}{|c|}{ Mata } \\
\hline & \multicolumn{3}{|c|}{ Trincheira 1} & \multicolumn{3}{|c|}{ Trincheira 2} & \multicolumn{3}{|c|}{ Trincheira 3} \\
\hline$z(\boldsymbol{m})$ & $a\left(m m h^{-b}\right)$ & b & $r^{2}$ & $a\left(m m h^{-b}\right)$ & $\boldsymbol{b}$ & $r^{2}$ & $a\left(m m h^{-b}\right)$ & b & $r^{2}$ \\
\hline 0,2 & 0,0904 & $-0,0537$ & 0,99 & 0,0907 & $-0,0542$ & 0,99 & 0,0846 & $-0,0463$ & 0,99 \\
\hline 0,3 & 0,1378 & $-0,0586$ & 0,99 & 0,1328 & $-0,0545$ & 0,99 & 0,1274 & $-0,0498$ & 0,99 \\
\hline 0,4 & 0,1866 & $-0,0629$ & 0,99 & 0,1718 & $-0,0529$ & 0,99 & 0,1657 & $-0,0481$ & 0,99 \\
\hline 0,5 & 0,2429 & $-0,0657$ & 0,99 & 0,2267 & $-0,0571$ & 0,99 & 0,2111 & $-0,0470$ & 0,97 \\
\hline 0,6 & 0,3183 & $-0,0813$ & 0,99 & 0,2897 & $-0,0652$ & 0,99 & 0,2709 & $-0,0565$ & 0,98 \\
\hline 0,7 & 0,3522 & $-0,0722$ & 0,98 & 0,3340 & $-0,0616$ & 0,99 & 0,3183 & $-0,0568$ & 0,99 \\
\hline 0,8 & 0,4104 & $-0,0692$ & 0,99 & 0,3955 & $-0,0616$ & 0,99 & 0,3722 & $-0,0544$ & 0,99 \\
\hline 0,9 & 0,5085 & $-0,0799$ & 0,99 & 0,4740 & $-0,0659$ & 0,99 & 0,4381 & $-0,0551$ & 0,99 \\
\hline \multicolumn{10}{|c|}{ Sequeiro } \\
\hline & \multicolumn{3}{|c|}{ Trincheira 4} & \multicolumn{3}{|c|}{ Trincheira 5} & \multicolumn{3}{|c|}{ Trincheira 6} \\
\hline 0,2 & 0,0979 & $-0,0571$ & 0,98 & 0,0932 & $-0,0463$ & 0,99 & 0,1014 & $-0,0658$ & 0,92 \\
\hline 0,3 & 0,1419 & $-0,0529$ & 0,98 & 0,1359 & $-0,0435$ & 0,99 & 0,1496 & $-0,0646$ & 0,91 \\
\hline 0,4 & 0,1781 & $-0,0482$ & 0,99 & 0,1760 & $-0,0445$ & 0,99 & 0,1825 & $-0,0545$ & 0,93 \\
\hline 0,5 & 0,2183 & $-0,0476$ & 0,99 & 0,2177 & $-0,0457$ & 0,99 & 0,2100 & $-0,0424$ & 0,98 \\
\hline 0,6 & 0,2765 & $-0,0545$ & 0,99 & 0,2743 & $-0,0523$ & 0,99 & 0,2797 & $-0,0592$ & 0,95 \\
\hline 0,7 & 0,3237 & $-0,0557$ & 0,99 & 0,3252 & $-0,0554$ & 0,99 & 0,3331 & $-0,0633$ & 0,95 \\
\hline 0,8 & 0,3742 & $-0,0554$ & 0,99 & 0,3782 & $-0,0558$ & 0,99 & 0,3671 & $-0,0534$ & 0,98 \\
\hline 0,9 & 0,4382 & $-0,0615$ & 0,99 & 0,4359 & $-0,0588$ & 0,99 & 0,4399 & $-0,0636$ & 0,98 \\
\hline \multicolumn{10}{|c|}{ Irrigado } \\
\hline & \multicolumn{3}{|c|}{ Trincheira 7} & \multicolumn{3}{|c|}{ Trincheira 8} & \multicolumn{3}{|c|}{ Trincheira 9} \\
\hline 0,2 & 0,0921 & $-0,0336$ & 0,99 & 0,0949 & $-0,0392$ & 0,96 & 0,0945 & $-0,0381$ & 0,97 \\
\hline 0,3 & 0,1439 & $-0,0342$ & 0,99 & 0,1462 & $-0,0371$ & 0,97 & 0,1473 & $-0,0379$ & 0,98 \\
\hline 0,4 & 0,2043 & $-0,0407$ & 0,99 & 0,2009 & $-0,0378$ & 0,99 & 0,2021 & $-0,0388$ & 0,99 \\
\hline 0,5 & 0,2526 & $-0,0469$ & 0,99 & 0,2457 & $-0,0423$ & 0,99 & 0,2429 & $-0,0412$ & 0,99 \\
\hline 0,6 & 0,2869 & $-0,0440$ & 0,99 & 0,2839 & $-0,0421$ & 0,99 & 0,2841 & $-0,0434$ & 0,99 \\
\hline 0,7 & 0,3298 & $-0,0473$ & 0,99 & 0,3516 & $-0,0589$ & 0,95 & 0,3376 & $-0,0517$ & 0,99 \\
\hline 0,8 & 0,3816 & $-0,0505$ & 0,99 & 0,4211 & $-0,0688$ & 0,93 & 0,3879 & $-0,0537$ & 0,99 \\
\hline 0,9 & 0,4511 & $-0,0569$ & 0,99 & 0,4666 & $-0,0625$ & 0,98 & 0,4462 & $-0,0570$ & 0,98 \\
\hline
\end{tabular}


Tabela 11 - Fluxo da água no solo no sentido descendente $\left(\mathrm{mm} \mathrm{dia}{ }^{-1}\right)$, durante a redistribuição da água no solo, para os três manejos em profundidade

\begin{tabular}{|c|c|c|c|c|c|c|c|c|}
\hline \multirow[b]{3}{*}{ temnn(h) } & \multicolumn{8}{|c|}{ Profundidade (m) } \\
\hline & 0,2 & 0,3 & 0,4 & 0,5 & 0,6 & 0,7 & 0,8 & 0,9 \\
\hline & \multicolumn{8}{|c|}{ Mata_ } \\
\hline 12 & 8.399 & 13.053 & 17,121 & 39,816 & 29,328 & 29,583 & 34.734 & 31,777 \\
\hline 24 & 3,546 & 4,856 & 7,014 & 13,824 & 11,909 & 14,260 & 12,537 & 13,423 \\
\hline 48 & 1,673 & 2,361 & 3,773 & 5,232 & 5,026 & 6,792 & 5,651 & 7,686 \\
\hline 96 & 0,842 & 1,195 & 2,023 & 2,422 & 3,004 & 3,723 & 3,236 & 4,131 \\
\hline 192 & 0,434 & 0,693 & 0,905 & 1,237 & 1,840 & 1,952 & 2,207 & 2,257 \\
\hline 240 & 0,338 & 0,628 & 0,751 & 0,905 & 1,431 & 1,561 & 2,095 & 1,848 \\
\hline 480 & 0,204 & 0,273 & 0,341 & 0,400 & 0,720 & 1,362 & 1,435 & 0,993 \\
\hline \multirow[t]{2}{*}{720} & 0,133 & 0,124 & $\underline{0}, \underline{084}$ & $\underline{0}, 2323$ & 0,652 & 0,599 & 0,939 & 0,651 \\
\hline & \multicolumn{8}{|c|}{ Seaueiro } \\
\hline 12 & 5.344 & 4.050 & 8.824 & 8.450 & 11,863 & 12,687 & 20,546 & 26,773 \\
\hline 24 & 3,026 & 2,102 & 5,065 & 4,700 & 6,189 & 7,180 & 11,002 & 13,175 \\
\hline 48 & 2,130 & 1,080 & 2,538 & 2,678 & 3,545 & 4,493 & 5,340 & 6,770 \\
\hline 96 & 1,414 & 0,609 & 1,611 & 1,800 & 2,068 & 3,104 & 3,332 & 4,031 \\
\hline 192 & 0,753 & 0,353 & 0,784 & 0,914 & 1,325 & 1,867 & 1,898 & 1,979 \\
\hline 240 & 0,555 & 0,310 & 0,672 & 0,851 & 1,204 & 1,223 & 1,481 & 1,742 \\
\hline 480 & 0,236 & 0,156 & 0,431 & 0,388 & 0,696 & 0,980 & 0,977 & 1,292 \\
\hline \multirow[t]{2}{*}{720} & $0_{2}, 038$ & 0,118 & $\underline{0}, 278$ & 0,256 & 0,466 & 0,699 & 0,608 & $\underline{0}, \underline{784}$ \\
\hline & \multicolumn{8}{|c|}{ Lrigado } \\
\hline 12 & 4,686 & 9,279 & 15,524 & 19,166 & 27,761 & 22,305 & 20,986 & 33,614 \\
\hline 24 & 2,189 & 3,362 & 7,128 & 6,973 & 9,901 & 10,972 & 11,123 & 11,824 \\
\hline 48 & 1,199 & 1,576 & 3,366 & 5,668 & 5,168 & 5,158 & 6,179 & 7,610 \\
\hline 96 & 0,687 & 0,737 & 1,830 & 2,973 & 2,735 & 2,848 & 3,556 & 4,456 \\
\hline 192 & 0,410 & 0,381 & 1,012 & 1,220 & 1,359 & 1,556 & 2,247 & 2,548 \\
\hline 240 & 0,326 & 0,284 & 0,878 & 0,906 & 0,974 & 1,440 & 2,011 & 1,971 \\
\hline 480 & 0,168 & 0,131 & 0,407 & 0,419 & 0,550 & 0,899 & 1,111 & 1,331 \\
\hline 720 & 0,142 & 0,073 & 0,252 & 0,281 & 0,432 & 0,695 & 0,747 & 0,970 \\
\hline
\end{tabular}


Tabela 12 - Condutividade hidráulica do solo não saturado ( $\left.\mathrm{mm} \mathrm{dia}{ }^{-1}\right)$, durante a redistribuição da água no solo, para os três manejos em profundidade

\begin{tabular}{|c|c|c|c|c|c|c|c|c|}
\hline \multirow[b]{3}{*}{ tempo(h) } & \multicolumn{8}{|c|}{ Profundidade (m) } \\
\hline & 0,2 & 0,3 & 0,4 & 0,5 & 0,6 & 0,7 & 0,8 & 0,9 \\
\hline & \multicolumn{8}{|c|}{ Mata } \\
\hline 12 & 6,454 & 12.385 & 18.204 & 35,618 & 20.913 & 27,229 & 34,048 & 33,420 \\
\hline 24 & 2,780 & 4,620 & 7,183 & 10,738 & 8,006 & 11,930 & 12,747 & 14,653 \\
\hline 48 & 1,408 & 2,146 & 3,161 & 3,414 & 3,524 & 6,078 & 6,407 & 7,787 \\
\hline 96 & 0,732 & 1,073 & 1,536 & 1,501 & 2,048 & 3,336 & 3,744 & 4,077 \\
\hline 192 & 0,378 & 0,537 & 0,686 & 0,743 & 1,149 & 1,872 & 2,121 & 2,032 \\
\hline 240 & 0,308 & 0,435 & 0,520 & 0,561 & 0,962 & 1,581 & 1,783 & 1,635 \\
\hline 480 & 0,157 & 0,220 & 0,293 & 0,304 & 0,676 & 1,084 & 1,117 & 1,107 \\
\hline 720 & 0,093 & 0,138 & 0,188 & 0,211 & 0,458 & 0,714 & 0,786 & 0,768 \\
\hline \multirow[t]{2}{*}{ PMP } & $\mathbf{0}_{2}, 007$ & $\underline{0}_{2} \underline{017}$ & $\underline{0}_{2} \underline{022}$ & 0,015 & 0,082 & 0,033 & 0,080 & $\underline{0}, 068$ \\
\hline & \multicolumn{8}{|c|}{ Sequeiro } \\
\hline 12 & 6,930 & 4.715 & 10.763 & 10.922 & 15.500 & 16.541 & 21,608 & 27,552 \\
\hline 24 & 4,745 & 2,781 & 6,457 & 5,855 & 8,449 & 9,526 & 10,770 & 14,202 \\
\hline 48 & 3,282 & 1,644 & 3,883 & 3,347 & 4,783 & 5,567 & 5,433 & 8,342 \\
\hline 96 & 2,445 & 1,091 & 2,611 & 2,143 & 2,992 & 3,748 & 3,242 & 5,343 \\
\hline 192 & 1,736 & 0,651 & 1,583 & 1,279 & 1,813 & 2,232 & 1,906 & 3,163 \\
\hline 240 & 1,570 & 0,559 & 1,366 & 1,082 & 1,492 & 1,847 & 1,664 & 2,704 \\
\hline 480 & 1,165 & 0,381 & 0,943 & 0,715 & 1,057 & 1,292 & 1,104 & 1,855 \\
\hline 720 & 0,927 & 0,278 & 0,694 & 0,509 & 0,747 & 0,924 & 0,757 & 1,332 \\
\hline \multirow[t]{2}{*}{ PMP } & $0_{2}, 012$ & $0_{2}, 038$ & $0_{2}, 010$ & 0,035 & 0,010 & 0,040 & 0,040 & 0,077 \\
\hline & \multicolumn{8}{|c|}{ Irrigado } \\
\hline 12 & 3.970 & 9.000 & 16,644 & 20,070 & 29.671 & 26.970 & 24.294 & 44.975 \\
\hline 24 & 1,821 & 3,547 & 7,767 & 8,074 & 12,974 & 12,787 & 10,996 & 16,617 \\
\hline 48 & 1,062 & 1,783 & 4,424 & 6,307 & 6,307 & 7,030 & 6,513 & 9,692 \\
\hline 96 & 0,640 & 0,925 & 2,585 & 3,513 & 3,513 & 4,080 & 3,957 & 5,731 \\
\hline 192 & 0,412 & 0,489 & 1,535 & 1,429 & 1,921 & 2,471 & 2,413 & 3,325 \\
\hline 240 & 0,347 & 0,392 & 1,282 & 1,132 & 1,613 & 2,117 & 2,022 & 2,748 \\
\hline 480 & 0,217 & 0,203 & 0,747 & 0,642 & 0,933 & 1,313 & 1,268 & 1,763 \\
\hline 720 & 0,164 & 0,139 & 0,547 & 0,464 & 0,666 & 0,994 & 0,954 & 1,353 \\
\hline PMP & 0,004 & $\underline{0}_{2}, 001$ & $0_{2}, 007$ & 0,006 & $0_{2}, 006$ & 0,075 & 0,032 & 0,095 \\
\hline
\end{tabular}


Tabela 13 - Parâmetros empíricos para cálculo da condutividade hidráulica do solo não saturado em função dos manejos

\begin{tabular}{lccccccccc}
\hline \multirow{2}{*}{$(\boldsymbol{m})$} & \multicolumn{3}{c}{ Mata } & \multicolumn{3}{c}{ Sequeiro } & \multicolumn{3}{c}{ Irrigado } \\
\cline { 2 - 10 } & $\boldsymbol{a}$ & $\boldsymbol{b}$ & $\boldsymbol{r}^{2}$ & $\boldsymbol{a}$ & $\boldsymbol{b}$ & $\boldsymbol{r}^{2}$ & $\boldsymbol{a}$ & $\boldsymbol{b}$ & $\boldsymbol{r}^{2}$ \\
\hline 0,2 & 53,47 & $-22,22$ & 0,85 & 30,95 & $-13,78$ & 0,79 & 59,56 & $-27,10$ & 0,94 \\
0,3 & 54,61 & $-21,61$ & 0,97 & 48,84 & $-20,02$ & 0,75 & 57,76 & $-27,47$ & 0,95 \\
0,4 & 54,30 & $-21,33$ & 0,91 & 47,26 & $-18,60$ & 0,94 & 46,99 & $-22,05$ & 0,93 \\
0,5 & 50,86 & $-20,98$ & 0,92 & 57,32 & $-22,42$ & 0,93 & 52,08 & $-22,56$ & 0,97 \\
0,6 & 35,32 & $-14,91$ & 0,88 & 37,92 & $-15,71$ & 0,91 & 59,33 & $-24,96$ & 0,93 \\
0,7 & 49,08 & $-19,52$ & 0,95 & 49,46 & $-19,16$ & 0,91 & 41,17 & $-16,96$ & 0,97 \\
0,8 & 33,38 & $-14,47$ & 0,92 & 40,87 & $-17,08$ & 0,96 & 43,16 & $-18,48$ & 0,89 \\
0,9 & 35,27 & $-15,65$ & 0,98 & 38,35 & $-15,23$ & 0,93 & 35,58 & $-15,00$ & 0,94 \\
\hline \hline
\end{tabular}

Ajustou-se uma única equação aos dados experimentais para as três repetições por profundidade. Observa-se que o ajuste foi bastante satisfatório indicando não haver para esta propriedade do solo uma variabilidade espacial muito grande ao contrário do que constataram Reichardt et al. (1993) para uma Terra Roxa estruturada em Piracicaba (SP) o que talvez possa ser atribuído a maior variabilidade espacial deste solo e ao instrumento de medida de umidade do solo utilizado, que neste trabalho foi a sonda de nêutrons.

t Analisando-se a figura 24 pode-se constatar uma menor condutividade para o irrigado até a profundidade de $0,5 \mathrm{~m}$, coincidindo com a camada em que ocorreram as maiores alterações na porosidade total e na distribuição do tamanho dos poros em função da compactação do solo, concordando com Roth et al. (1988) que também encontraram influência negativa sobre o $\mathrm{K}(\theta)$ em função de manejos e cultivos sucessivos.

É importante destacar que a faixa de umidade na qual se determinou a condutividade hidráulica do solo não saturado no campo é relativamente estreita, devido à rápida drenagem da água no início da determinação e da elevada capacidade de retenção de água que este solo possui. No caso da mata, rapidamente a maior parte da 


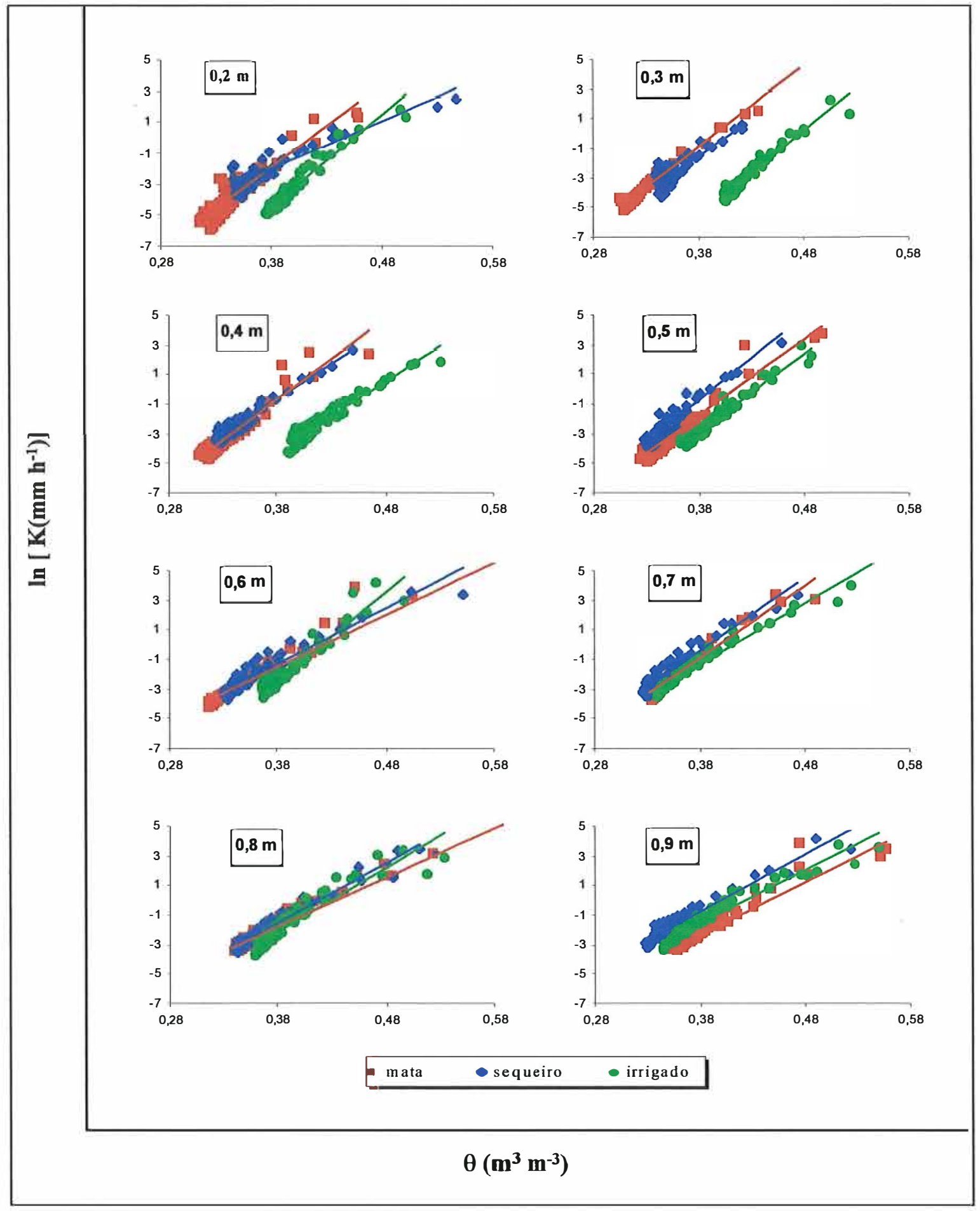

Figura 24 -Condutividade hidráulica do solo não saturado em função da umidade para os três manejos. 
água drenou, dificultando medidas iniciais, ou por falta de precisão dos manômetros de mercúrio ou demora no tempo de resposta dos tensiômetros. Enquanto no irrigado a umidade estabilizou em valores bem mais altos drenando menor quantidade de água.

$+{ }^{\prime}$ Para o tempo de 12 horas e profundidade de $0,2 \mathrm{~m}$ na mata a $\mathrm{K}(0,391)$ era de $6,45 \mathrm{~mm} \mathrm{dia}^{-1}$, enquanto para o irrigado, a $\mathrm{K}(0,425)$ era de $3,97 \mathrm{~mm} \mathrm{dia}^{-1}$, obtidas a partir da equação 8. Isto evidencia que, no sistema irrigado, mesmo mantendo a umidade do solo mais elevada a condutividade hidráulica do solo não saturado é menor. A constatação de que a condutividade hidráulica do solo não saturado é afetada pelo aumento da densidade em função da diminuição da porosidade e alteração na distribuição dos poros é muito importante e deve ser considerada em termos de manejo da água no solo, conforme também enfatizam Horton el al. (1994).

Para correlacionar a condutividade hidráulica do solo não saturado com a distribuição dos poros do solo, atribuiu-se o valor de $3 \mathrm{~mm} \mathrm{dia}^{-1}$ para a condutividade e assumiu-se gradiente unitário. Comparou-se esta com as frações de volume ocupado pelas diferentes classes de poros, constatando-se a boa correlação com o somatório da micro e criptoporosidade (figura 25), o inverso do que ocorreu com a Ko que se correlacionou positivamente com a macroporosidade (figura 22).

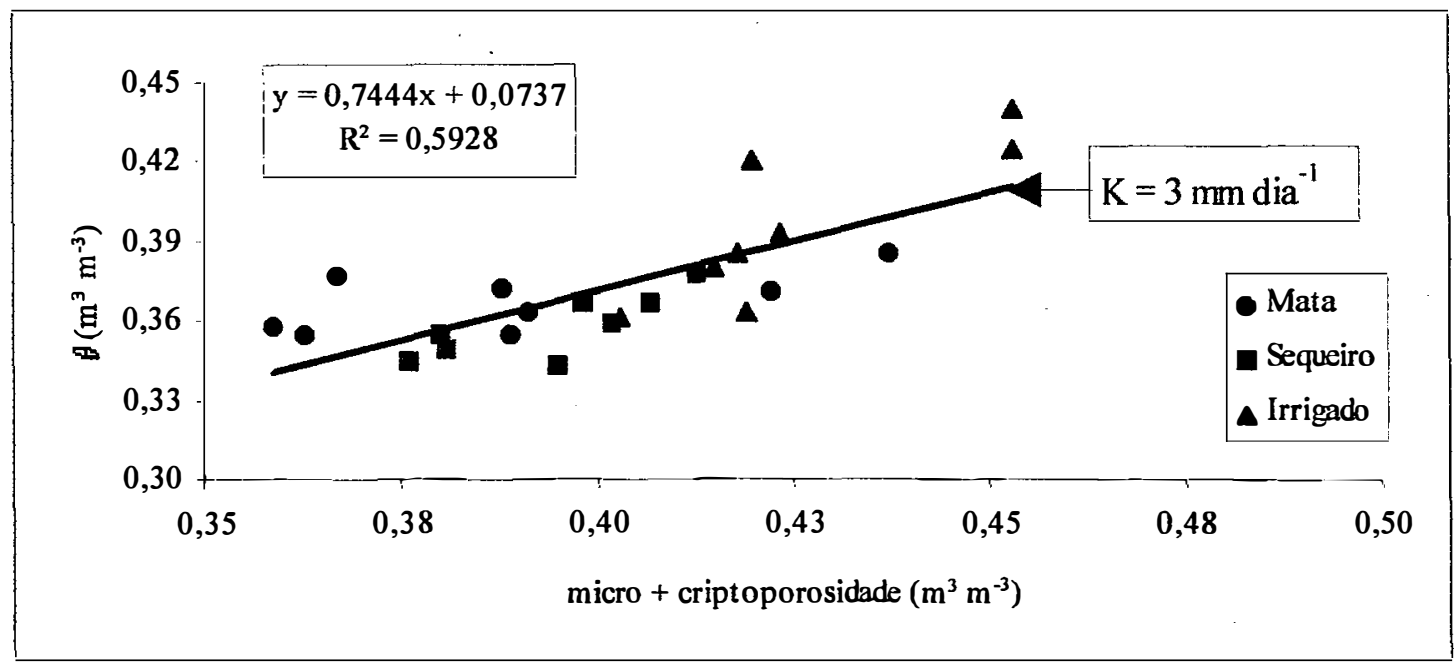

Figura 25 -Condutividade hidráulica do solo não saturado, em função da umidade e do somatório de micro e criptoporosidade do solo. 
Com a equação $8 \mathrm{e}$ os parâmetros empíricos da tabela 13 determinou-se $\mathrm{o}$ valor de $\mathrm{K}\left(\mathrm{mm} \mathrm{h}^{-1}\right)$ para o solo saturado $(\theta=\theta \mathrm{s})$ (tabela 14). Observa-se uma grande discrepância entre os valores de Ko medidos nas amostras de solo em laboratório (3 repetições) e os valores obtidos a partir da equação, o que indica não ser possível uma extrapolação da equação para fora da faixa de umidade para qual foi feito o ajuste, sendo que na maioria dos casos há uma superestimativa do Ko.

Tabela 14 - Comparação entre condutividade hidráulica do solo saturado determinada em laboratório e aquela estimada pela equação 8

\begin{tabular}{|c|c|c|c|c|c|c|c|c|}
\hline & \multicolumn{8}{|c|}{ Profundidade } \\
\hline & 0,2 & 0,3 & 0,4 & 0,5 & 0,6 & 0,7 & 0,8 & 0,9 \\
\hline & \multicolumn{8}{|c|}{$K o\left(m m h^{-1}\right)$ determinada em laboratório } \\
\hline Mata & 963,6 & 877,9 & 722,2 & 697,5 & 670,2 & 518,8 & 576,2 & 488,7 \\
\hline Sequeiro & 275,5 & 378,8 & 407,3 & 393,1 & 549,6 & 417,4 & 414,6 & 438,9 \\
\hline Irrigado & 100,7 & 118,2 & 185,7 & 335,3 & 329,3 & 359,3 & 311,0 & 421,8 \\
\hline \multicolumn{9}{|c|}{$K o\left(m m h^{-1}\right)$ estimada por extrapolação } \\
\hline Mata & 22530 & 116081 & 186287 & 25009 & 556,4 & 54911 & 297,7 & 241,6 \\
\hline Sequeiro & 67,5 & 5419 & 27725 & 183628 & 2616 & 289907 & 12747 & 9305 \\
\hline Irrigado & 121,1 & 31,69 & 82,57 & 5188 & 11591 & 1708 & 4668 & 1426,4 \\
\hline
\end{tabular}

\subsubsection{Determinação em laboratório}

A determinação da $\mathrm{K}(\theta)$ em amostras com estrutura indeformada coletadas no campo se mostrou uma metodologia simples, rápida de ser executada e com resultados muito interessantes, permitindo determinações em uma faixa de umidade diferente daquela obtida no campo, faixa próxima a saturação do solo, muito importante para a boa compreensão do processo de infiltração da água no solo.

Um ponto importante que precisa ser discutido é se a estrutura do solo permaneceu realmente indeformada dentro das colunas. Para isto se apresenta na 
tabela 15 a comparação entre os valores de densidade do solo, coletado no campo e dentro da coluna após feitas as determinações.

Tabela 15 - Densidade do solo das amostras coletadas a campo e aquelas coletadas dentro da coluna de solo no laboratório, média de três repetições

\begin{tabular}{|c|c|c|c|c|c|c|}
\hline \multirow[t]{3}{*}{ Prof. (m) } & \multicolumn{2}{|c|}{ Mata } & \multicolumn{2}{|c|}{ Sequeiro } & \multicolumn{2}{|c|}{ Irrigado } \\
\hline & campo & coluna & campo & coluna & campo & coluna \\
\hline & \multicolumn{6}{|c|}{ Densidade do solo $\left(\mathrm{Mg} \mathrm{m}^{-3}\right)$} \\
\hline 0,025 & 0,924 & 0,823 & 1,068 & 1,092 & 1,213 & 1,012 \\
\hline 0,1 & 0,986 & 0,960 & 1,212 & 1,205 & 1,299 & 1,261 \\
\hline 0,2 & 1,025 & 1,001 & 1,185 & 1,227 & 1,255 & 1,342 \\
\hline 0,3 & 1,014 & 1,050 & 1,146 & 1,272 & 1,228 & 1,337 \\
\hline 0,4 & 1,016 & 1,053 & 1,076 & 1,167 & 1,161 & 1,270 \\
\hline 0,5 & 1,027 & 1,052 & 1,077 & 1,118 & 1,104 & 1,184 \\
\hline 0,6 & 1,023 & 0,986 & 1,039 & 1,107 & 1,051 & 1,167 \\
\hline 0,7 & 1,002 & 1,038 & 1,014 & 1,089 & 1,058 & 1,102 \\
\hline 0,8 & 1,007 & 1,053 & 1,018 & 1,035 & 1,022 & 1,084 \\
\hline 0,9 & 1,027 & 1,123 & 0,983 & 1,027 & 1,019 & 1,080 \\
\hline
\end{tabular}

A análise estatística comparativa (teste t) entre a densidade do solo obtida no campo e aquela em laboratório, para a mata não apresentaram diferença significativa $(\mathrm{p}<0,05)$ em todas as profundidades. No entanto para o solo do sequeiro apresentou diferenças nas profundidades 0,$4 ; 0,5$ e 0,9 e o irrigado nas profundidades 0,$025 ; 0,3$ e 04. Atribui-se estas diferenças a problemas que ocorreram durante a coleta das amostras de dentro da coluna, sendo que estas foram coletadas com o solo ainda bastante úmido e com anéis com volume menor do que aqueles utilizados no campo ou a variabilidade espacial que esta propriedade apresenta no campo.

A partir dos valores do fluxo da água estabilizado através da coluna e o gradiente de potencial total, calculou-se a $\mathrm{K}$. Através de regressão linear de ln $\mathrm{K}$ versus $\theta$, apresentados na figura 26 , obteve-se os parâmetros empíricos que estão apresentados na tabela 16. 


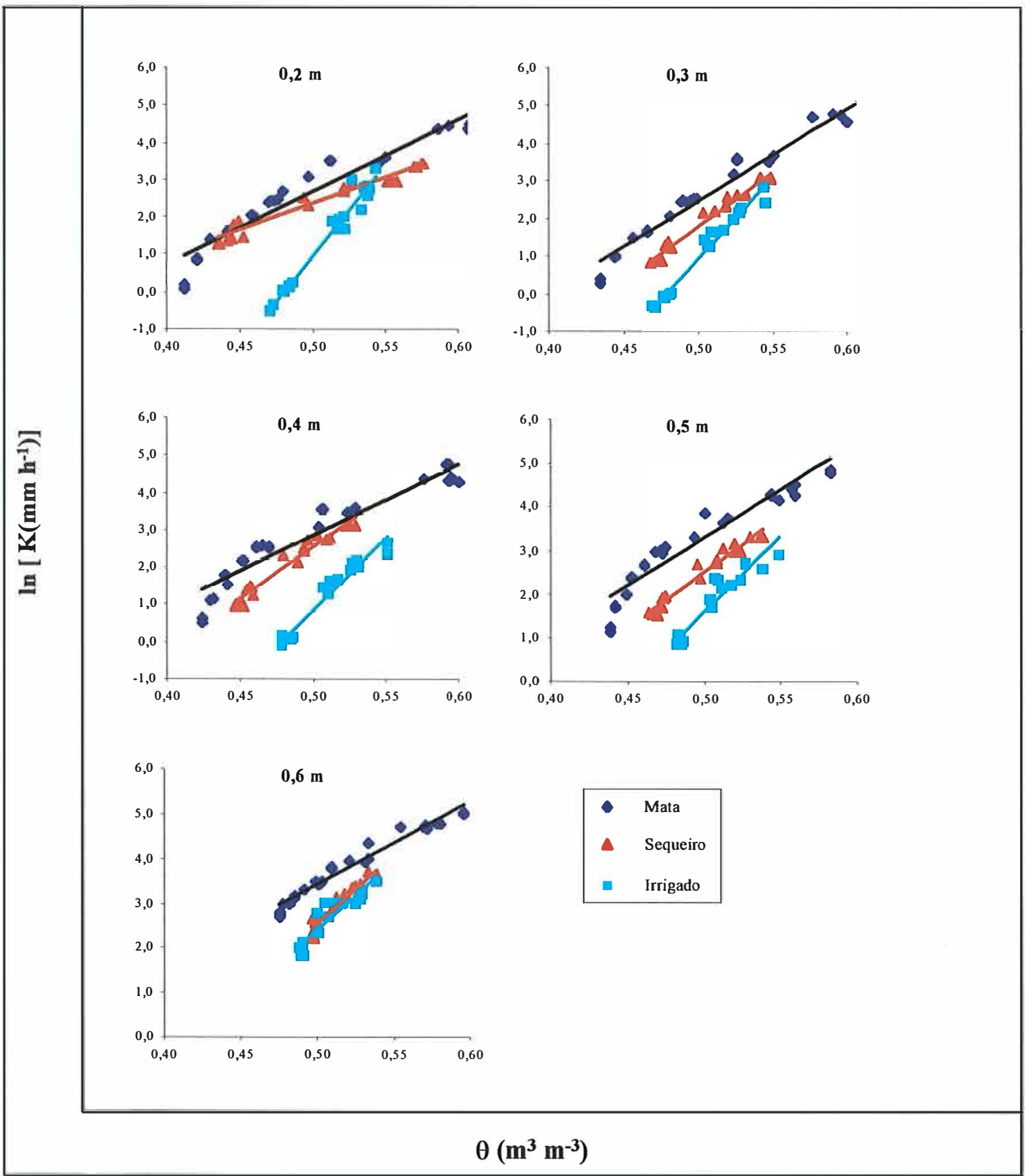

Figura 26- Relação umidade-condutividade hidráulica do solo não saturado determinada nas colunas de solo indeformada em laboratório para os três manejos considerados. 
Tabela 16 - Parâmetros empíricos da equação 8, obtidos em laboratório para os três manejos considerados

\begin{tabular}{lccccccccc}
\hline \hline Prof(m) & \multicolumn{3}{c}{ Mata } & \multicolumn{3}{c}{ Sequeiro } & \multicolumn{3}{c}{ Irrigado } \\
\cline { 2 - 10 } & $\boldsymbol{a}$ & $\boldsymbol{b}$ & $\boldsymbol{r}^{2}$ & $\boldsymbol{a}$ & $\boldsymbol{b}$ & $\boldsymbol{r}^{2}$ & $\boldsymbol{a}$ & $\boldsymbol{b}$ & $\boldsymbol{r}^{2}$ \\
\hline 0,2 & 19,287 & 6,9752 & 0,930 & 14,112 & 4,7126 & 0,955 & 48,961 & 23,533 & 0,965 \\
0,3 & 24,604 & 9,8196 & 0,961 & 28,326 & 12,349 & 0,968 & 43,059 & 20,562 & 0,973 \\
0,4 & 19,125 & 6,7106 & 0,908 & 27,577 & 11,264 & 0,945 & 39,146 & 18,717 & 0,953 \\
0,5 & 21,998 & 7,6871 & 0,896 & 25,348 & 10,162 & 0,950 & 34,811 & 15,813 & 0,907 \\
0,6 & 18,538 & 5,8439 & 0,961 & 30,525 & 12,715 & 0,924 & 31,53 & 13,381 & 0,864 \\
\hline \hline
\end{tabular}

Destaca-se que só foi possível determinar a $\mathrm{K}(\theta)$ em 5 profundidades, pois a primeira $0,1 \mathrm{~m}$ foi utilizada para o cálculo do grad $\phi \mathrm{t}$ em $0,2(0,1-0,3 \mathrm{~m})$, enquanto que os tensiômetros instalados nas profundidades 0,8 e 0,9 m não saíram da faixa (quase) saturada por estarem muito próximos ao nivel de água.

* Observou-se também, com esta metodologia, diferenças no comportamento da condutividade para os diferentes manejos e profundidades, com a mesma tendência observada na determinação do campo, tendo o sistema irrigado menores valores até a profundidade $0,5 \mathrm{~m}$.

Com a equação $K(\theta)$ extrapolou-se esta até porosidade total $(\theta s)$ para prever a Ko (tabela 17). Observa-se que, ao contrário da determinação de campo, esta subestimou a Ko. 
Tabela 17 - Comparação entre condutividade hidráulica do solo saturado determinada em laboratório e aquela estimada pela equação 8

\begin{tabular}{|c|c|c|c|c|c|}
\hline & \multicolumn{5}{|c|}{ Profundidade } \\
\hline & 0,2 & 0,3 & 0,4 & 0,5 & 0,6 \\
\hline & \multicolumn{5}{|c|}{ Ko $\left(m m h^{-1}\right)$ determinada em laboratório } \\
\hline Mata & 963,6 & 877,9 & 722,2 & 697,5 & 670,2 \\
\hline Sequeiro & 275,5 & 378,8 & 407,3 & 393,1 & 549,6 \\
\hline \multirow[t]{2}{*}{ Irrigado } & 100,7 & 118,2 & 185,7 & 335,3 & 329,3 \\
\hline & \multicolumn{5}{|c|}{ Ko $\left(m m h^{-1}\right)$ estimada em colunas grandes no laboratório } \\
\hline Mata & 145,87 & 479,62 & 156,22 & 384,39 & 284,19 \\
\hline Sequeiro & 21,09 & 59,15 & 259,30 & 200,39 & 497,95 \\
\hline Irrigado & 11,20 & 9,58 & 29,98 & 112,79 & 135,15 \\
\hline
\end{tabular}

\subsubsection{Análise conjunta de $K(\theta)$ realizada no campo e em laboratório}

Observando-se os parâmetros de ajuste a e b da equação 8 nota-se as diferenças entre os valores obtidos no campo e em laboratório, o que é confirmado pela análise das figuras 27,28 e 29.

* Ficou claro e evidente neste trabalho a diferença no comportamento da condutividade hidráulica próxima à saturação em relação à outra fase onde o potencial mátrico governa o movimento. Estes dados corroboram com as afirmações de Radulovich et al (1992) e Chen et al. (1993) que descrevem bem este fenômeno.

Observa-se que esta diferença no comportamento foi diminuindo, a medida que, em função da compactação do solo, houve redução da macroporosidade. Na figura 27 observa-se como este efeito é acentuado no solo da mata, onde existe uma uniformidade de macroporos em grande volume em todo o perfil, enquanto que no irrigado (figura 29), na camada até $0,4 \mathrm{~m}$ de profundidade, praticamente não se observa este efeito. 


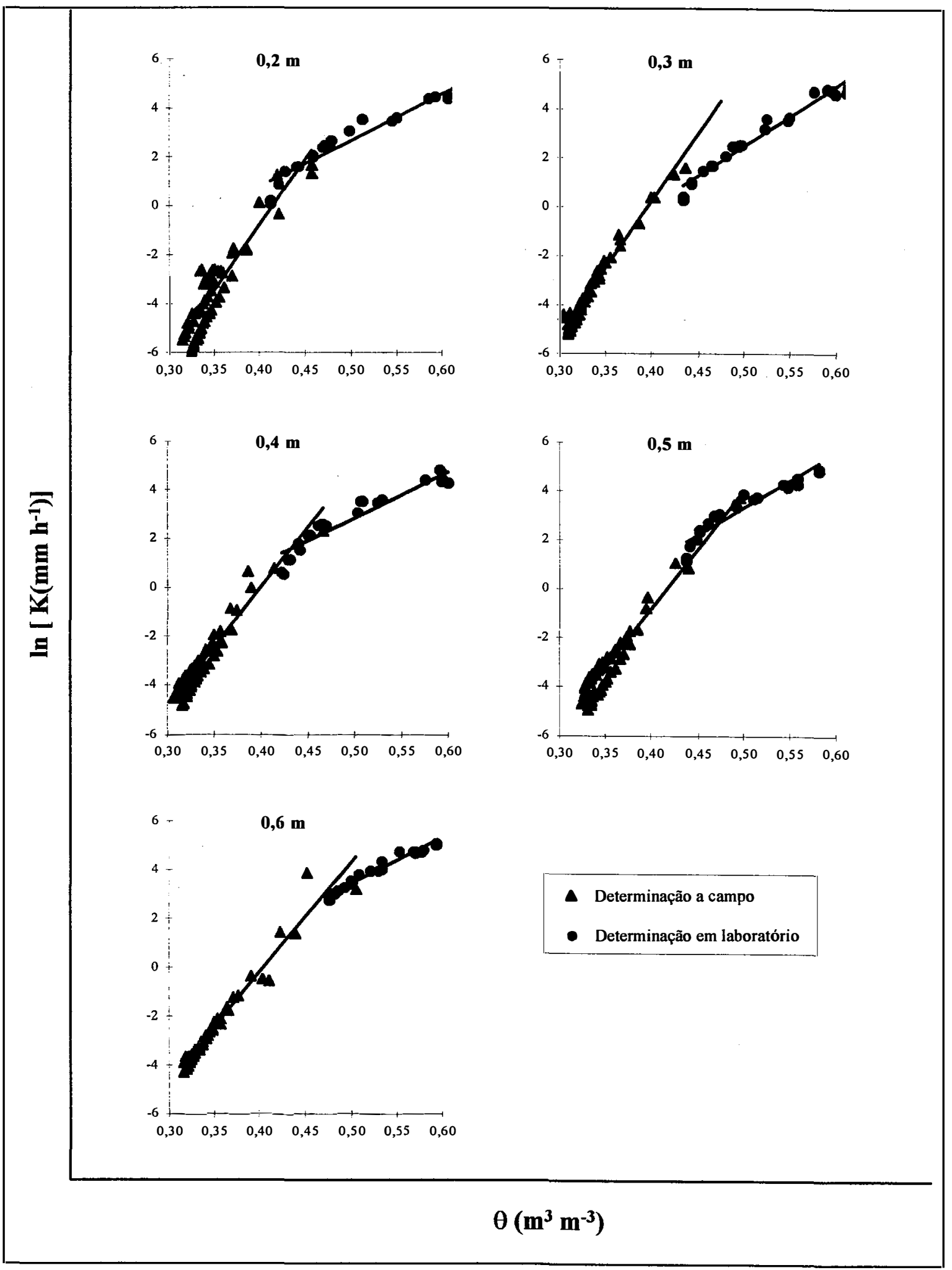

Figura 27 - Relação $\theta$ versus $K$ da área com mata determinado no campo e em laboratório. 


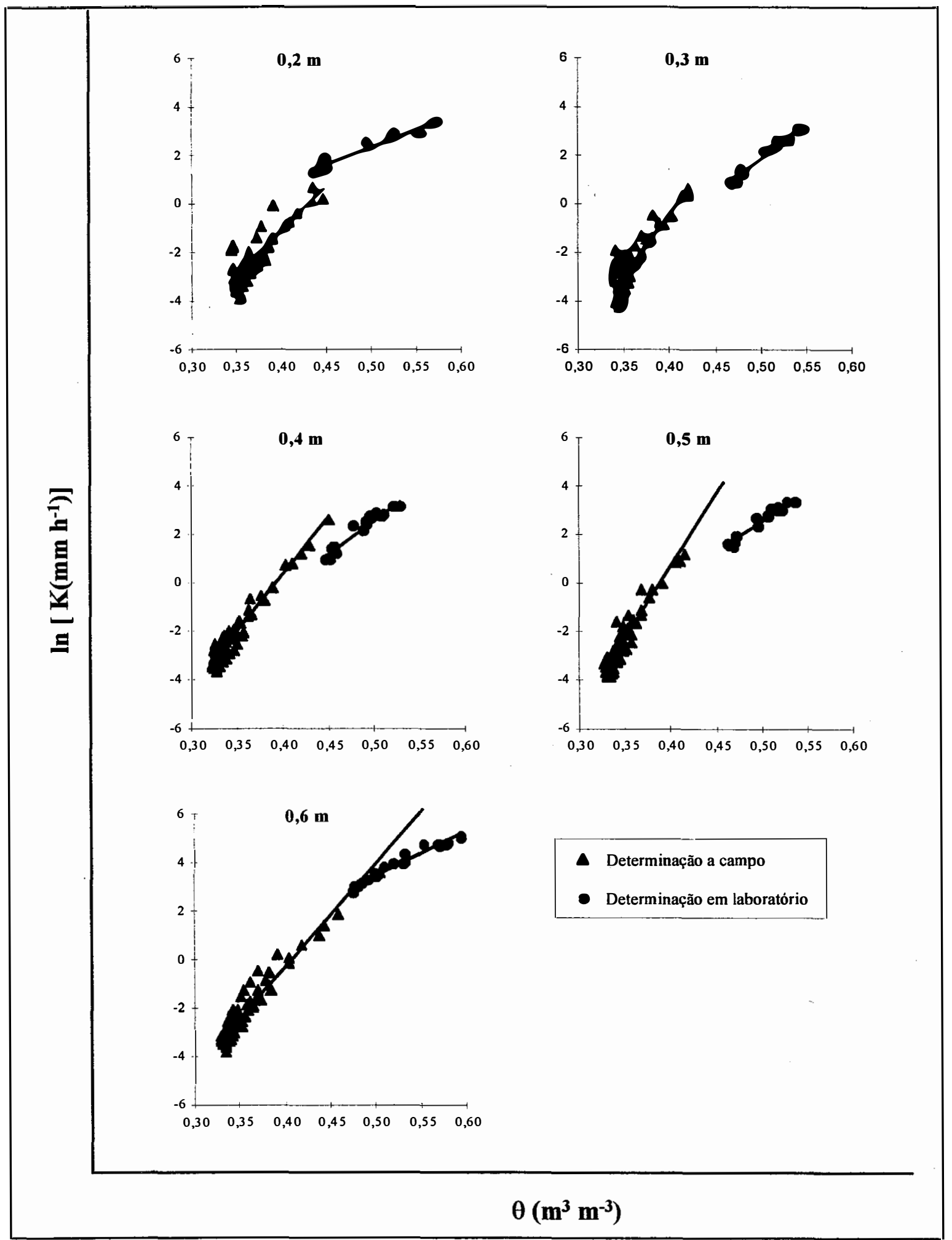

Figura 28 - Relação $\theta$ versus $K$ da área com cultivo de sequeiro determinado no campo e em laboratório. 


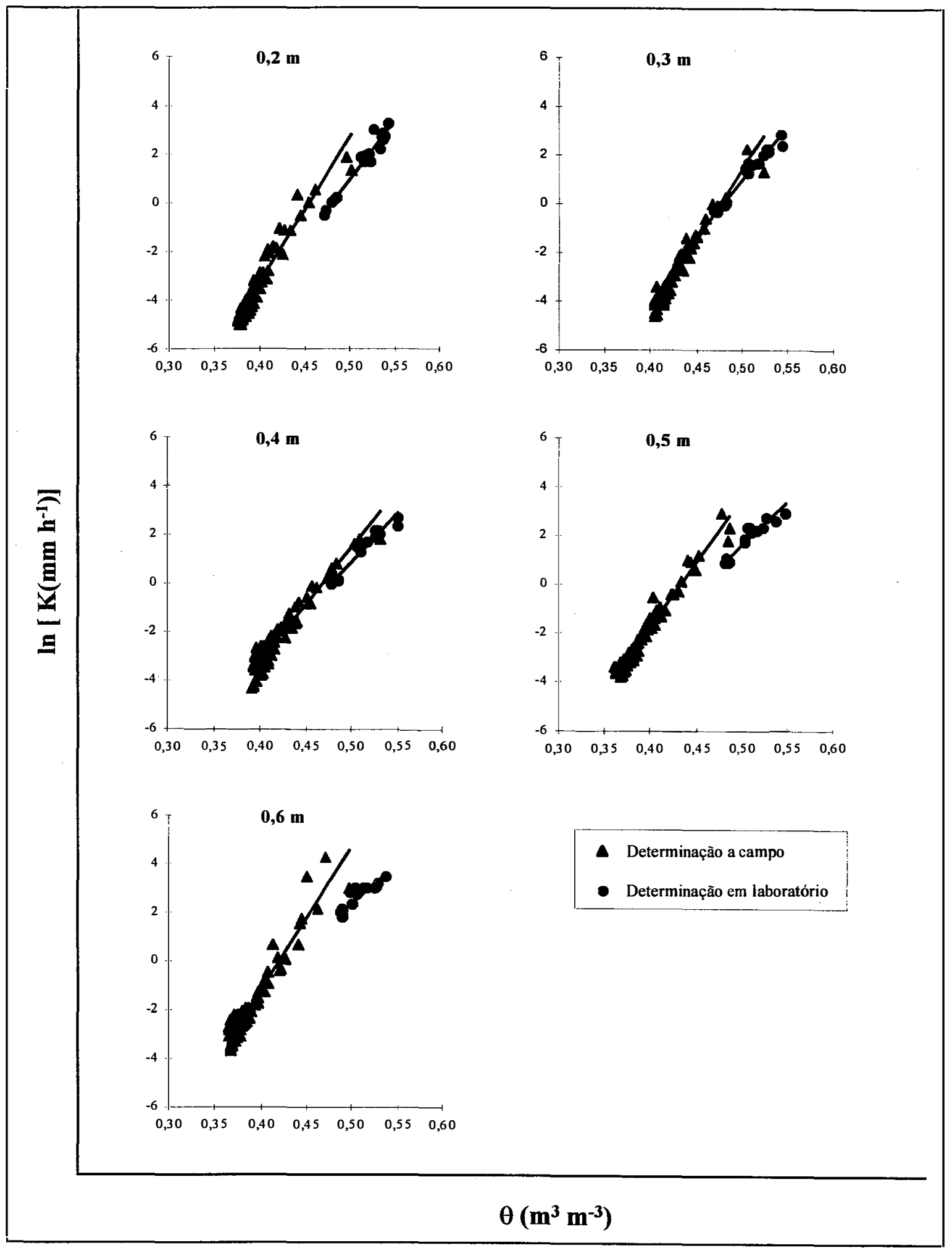

Figura 29 -Relação $\theta$ versus $K$ da área irrigada determinado no campo e em laboratório. 
A descontinuidade não pode ser atribuída a utilização de diferentes metodologias, pois em várias profundidades observa-se que os pontos obtidos em laboratório acompanham a tendência daqueles obtidos no campo.

Analisando o valor da umidade volumétrica em que ocorre esta descontinuidade, em torno de $0,45 \mathrm{~m}^{3} \mathrm{~m}^{-3}$ para todos os manejos, relacionando com a curva de retenção da água no solo, para obter potencial mátrico equivalente, calculou-se o tamanho aproximado do poro desta descontinuidade. O diâmetro situou-se em torno de 0,1 mm concordando com Luxmoore (1981)que sugere ser este o menor diâmetro dos poros para serem classificados como macroporos, responsáveis portanto pelo fluxo rápido da água no solo.

Isto sugere que a metodologia de determinação da condutividade hidráulica do solo não saturado no campo e em laboratório podera ser utilizada para definir o limite do diâmetro dos poros no qual a ação da capilaridade (potencial mátrico) começa a interferir no movimento da água no solo.

\subsection{Armazenagem de água no solo e disponibilidade as culturas}

\subsubsection{Capacidade de campo}

A decisão de qual potencial mátrico ou tempo de drenagem deveria ser utilizado para a definição da umidade de capacidade de campo é difícil e complexa. Como esta apresentado na figura 30, ocorre um rápido decréscimo do potencial mátrico até $-8 \mathrm{kPa}$, ocorrendo em torno deste ponto uma descontinuidade da curva, com declínio lento e gradual. 


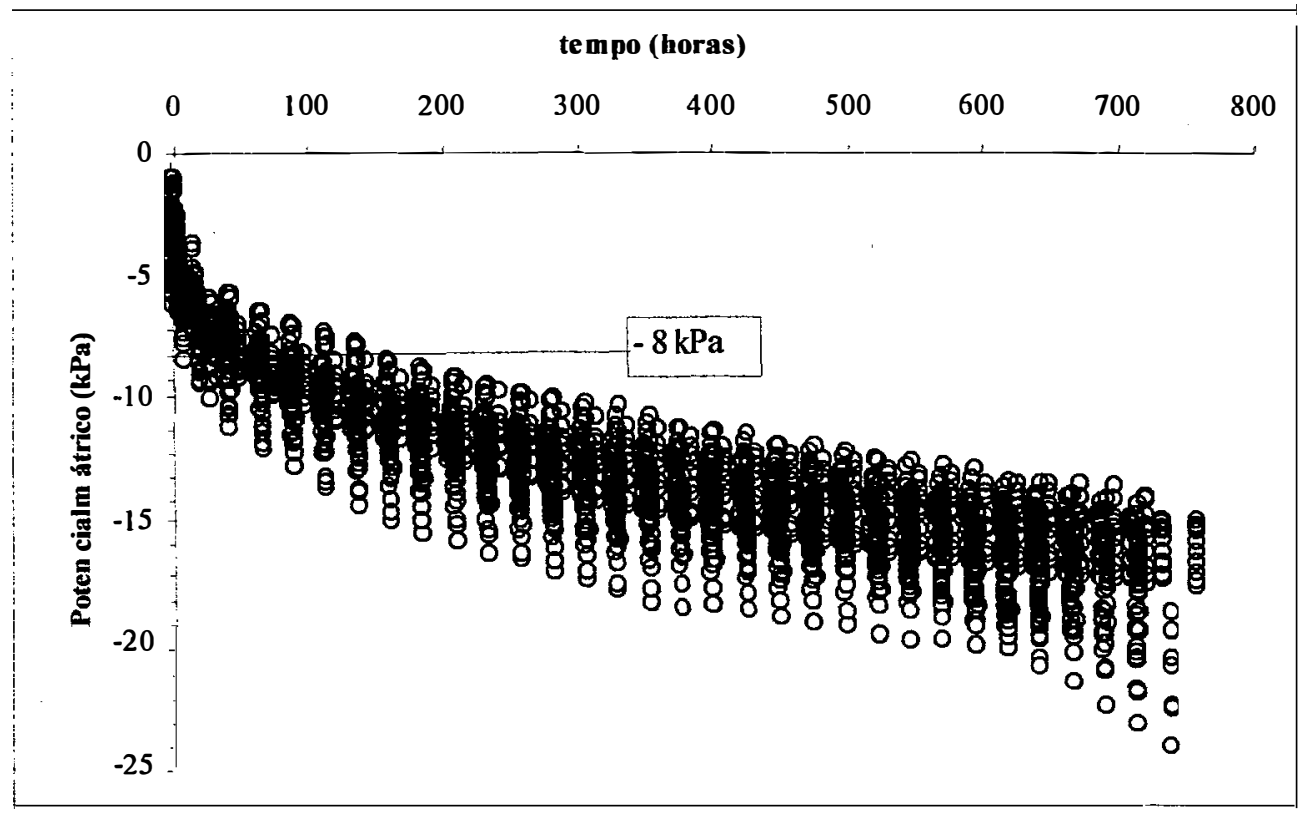

Figura 30 - Potencial mátrico em função do tempo de drenagem.

Na figura 31 estão os valores da umidade volumétrica do solo 48 horas após a inundação e a umidade na tensão de $8 \mathrm{kPa}$ (curva de retenção), considerada por Sidiras et al. (1984), Faria \& Caramori (1986) e Saad \& Libardi (1994) como a condição de umidade na qual este solo se encontra na capacidade de campo. Os dados obtidos neste trabalho, confirmam este resultado. Veihmeyer \& Hendrickson (1949) ressaltam que em torno de 48 horas de drenagem um solo franco-arenoso normalmente tem seu fluxo reduzido significativamente. O Latossolo Roxo, apesar do seu elevado teor de argila, em função da sua microagregação apresenta um comportamento semelhante a de um franco-arenoso.

No entanto, como o objetivo é avaliar a capacidade do solo de reter água e de tomá-la disponível as plantas, utilizar o conceito de capacidade de campo, definindo qualquer tempo de drenagem também será discutível, pois se houver uma cultura implantada, desde o período inicial de drenagem, se não houver deficiência de aeração, esta já estará extraindo água do solo água que não mais irá drenar." 


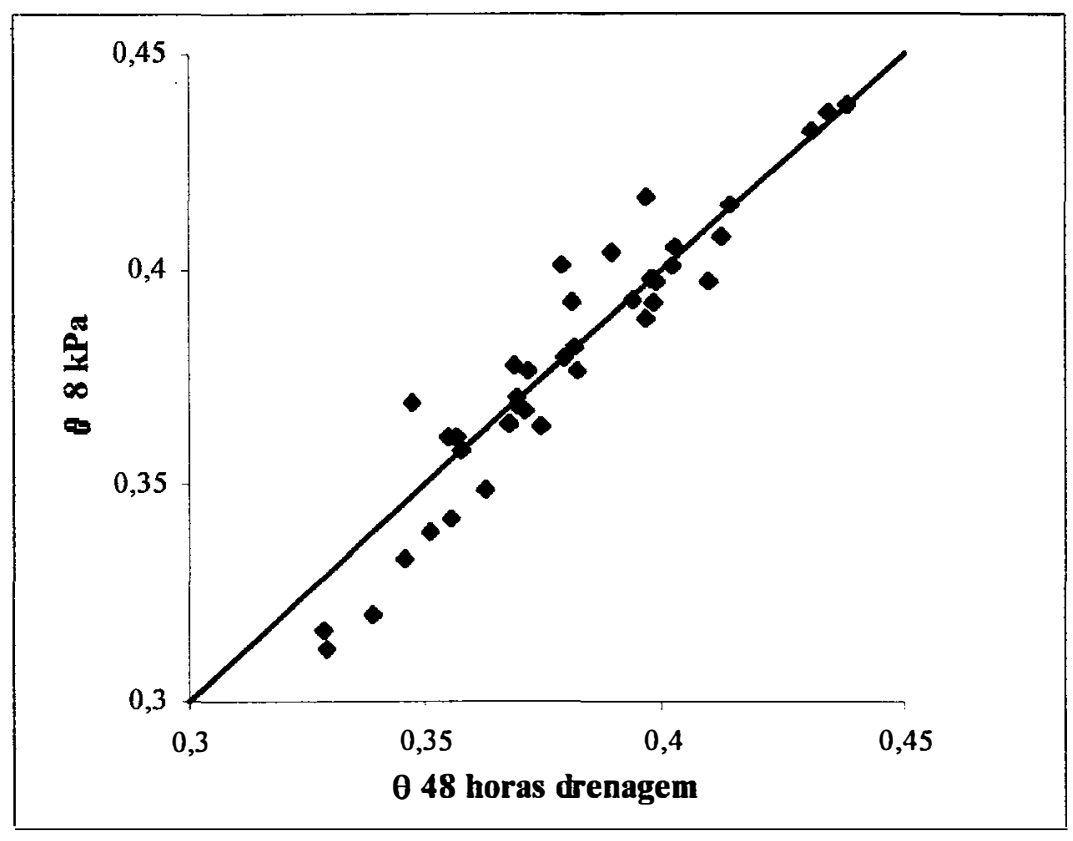

Figura 31 -Umidade do solo na tensão de $8 \mathrm{kPa}$ e 48 horas de drenagem.

No apêndice 3.3 observa-se a grande drenagem ocorrida no solo de mata passando de uma porosidade total, máxima saturação, em torno de $0,65 \mathrm{~m}^{3} \mathrm{~m}^{-3}$ para 0,35 $\mathrm{m}^{3} \mathrm{~m}^{-3}$. Transcorridas 12 horas, enquanto para a área irrigada, na camada superficial, esta variação de umidade foi muito menor. Neste caso, transcorridas 12 horas. Na camada de 0,05 a $0,15 \mathrm{~m}$ a variação foi inferior a $5 \%$, demonstrando, que este solo possui capacidade muito maior de retenção de água quando comparado com o da mata, em função da sua maior microporosidade.

Em função disto calculou-se a variação de armazenagem de água no solo, umidade volumétrica do solo e o ponto de murcha permanente nos diferentes tempos de drenagem considerando-se diferentes profundidades (figura 32).

Quando se considerou a camada de solo até a profundidade de $1,0 \mathrm{~m}$ (apêndice 3.4) os valores de umidade no irrigado foram sempre superiores aos do sequeiro e da mata. Em tempos maiores que 48 horas estas diferenças do irrigado em 
relação à mata foram sempre da ordem de $20 \mathrm{~mm}$. Considerando-se uma taxa de evapotranspiração de uma cultura qualquer de $3 \mathrm{~mm} \mathrm{dia}^{-1}$, haveria disponibilidade de água às plantas por um período aproximado de 7 dias, o que poderá decisivo na estabilidade da produção em culturas anuais em épocas de veranico.

$\mathrm{Na}$ agricultura a camada do solo de maior importância é aquela onde se concentra a maior parte do sistema radicular, a qual normalmente é considerada até 0,25 $\mathrm{m}$ de profundidade. Merten \& Mielniczuk (1991) estudando o sistema radicular de várias culturas em diferentes sistemas de manejo, concluíram que $70 \%$ das raízes estão concentradas na profundidade de $0-0,1 \mathrm{~m}$ e é onde são colocados os fertilizantes e insumos necessários para o crescimento das plantas. Neste sentido é importante observar as mudanças na capacidade de armazenamento de água nesta camada, pois para as condições deste estudo é nesta camada que estão concentrados os nutrientes, principalmente o fósforo (apêndice 2.4).

Considerando-se apenas a armazenagem de água no solo na camada até $0,25 \mathrm{~m}$, o solo da área de sequeiro reteve sempre mais água do que o solo da mata e irrigado, sendo a maior variação entre a mata e os outros dois sistemas de manejo. No tempo de 48 horas a variação entre mata e sequeiro foi de $10,3 \mathrm{~mm}$, água suficiente para manter uma cultura por mais alguns 4 dias.

Considerando-se a camada de 0,0 a $0,2 \mathrm{~m}$, profundidade na qual a resistência é limitante a $50 \mathrm{kPa}$ e onde, normalmente, a maior parte do sistema radicular das culturas anuais, está concentrada, a disponibilidade de água às plantas é $9 \%$ superior no sistema plantio direto irrigado em relação à mata.

Portanto, o manejo do solo sob plantio direto, embora aumente a densidade do solo, bem como a resistência à penetração das raízes, aumenta o volume de água armazenada em relação a mata (figura 33). 


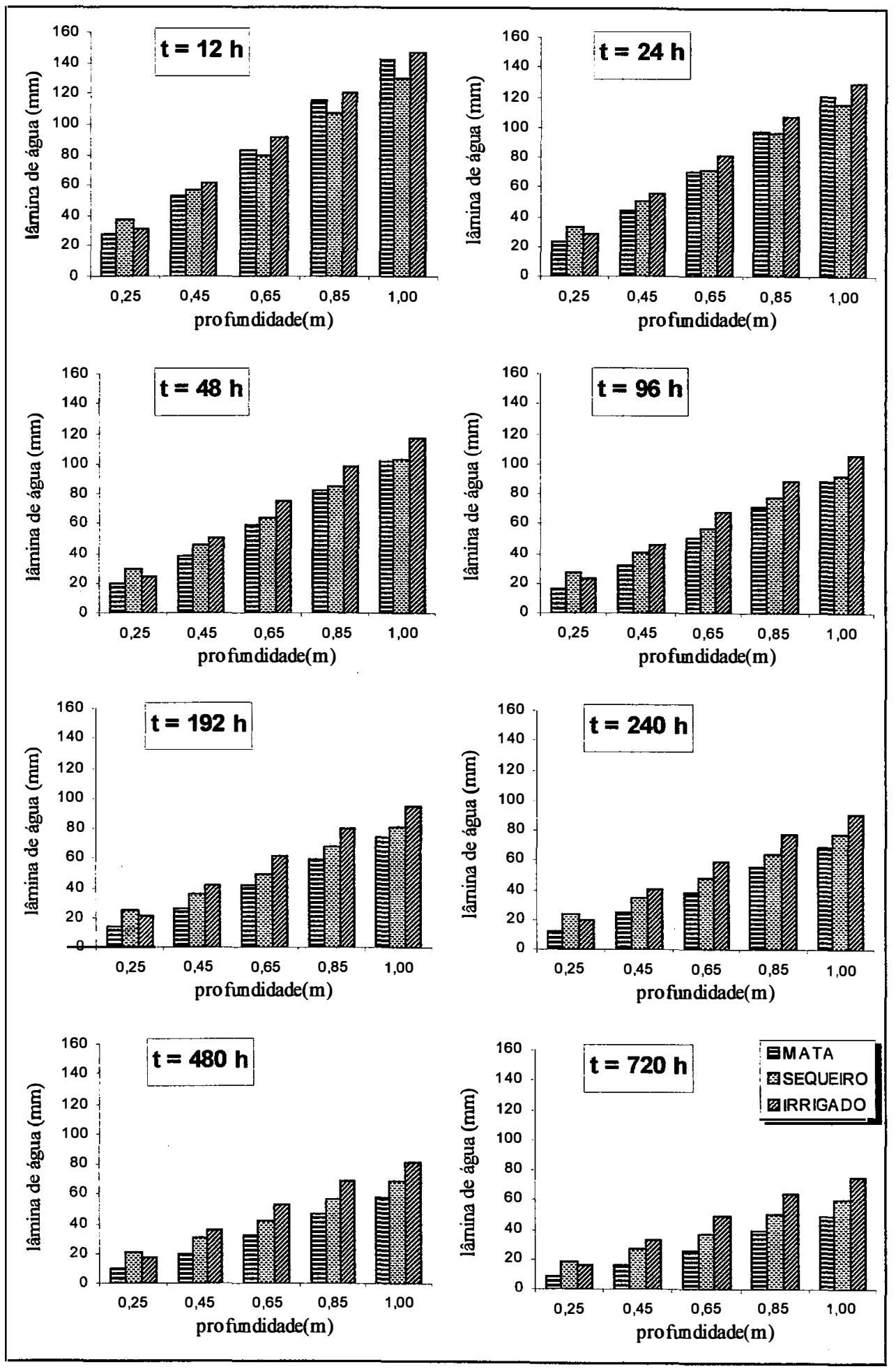

Figura 32 - Variação da armazenagem de água no solo para os três manejos, entre a umidade atual e o PMP, para oito diferentes tempos de drenagem e cinco profundidades. 


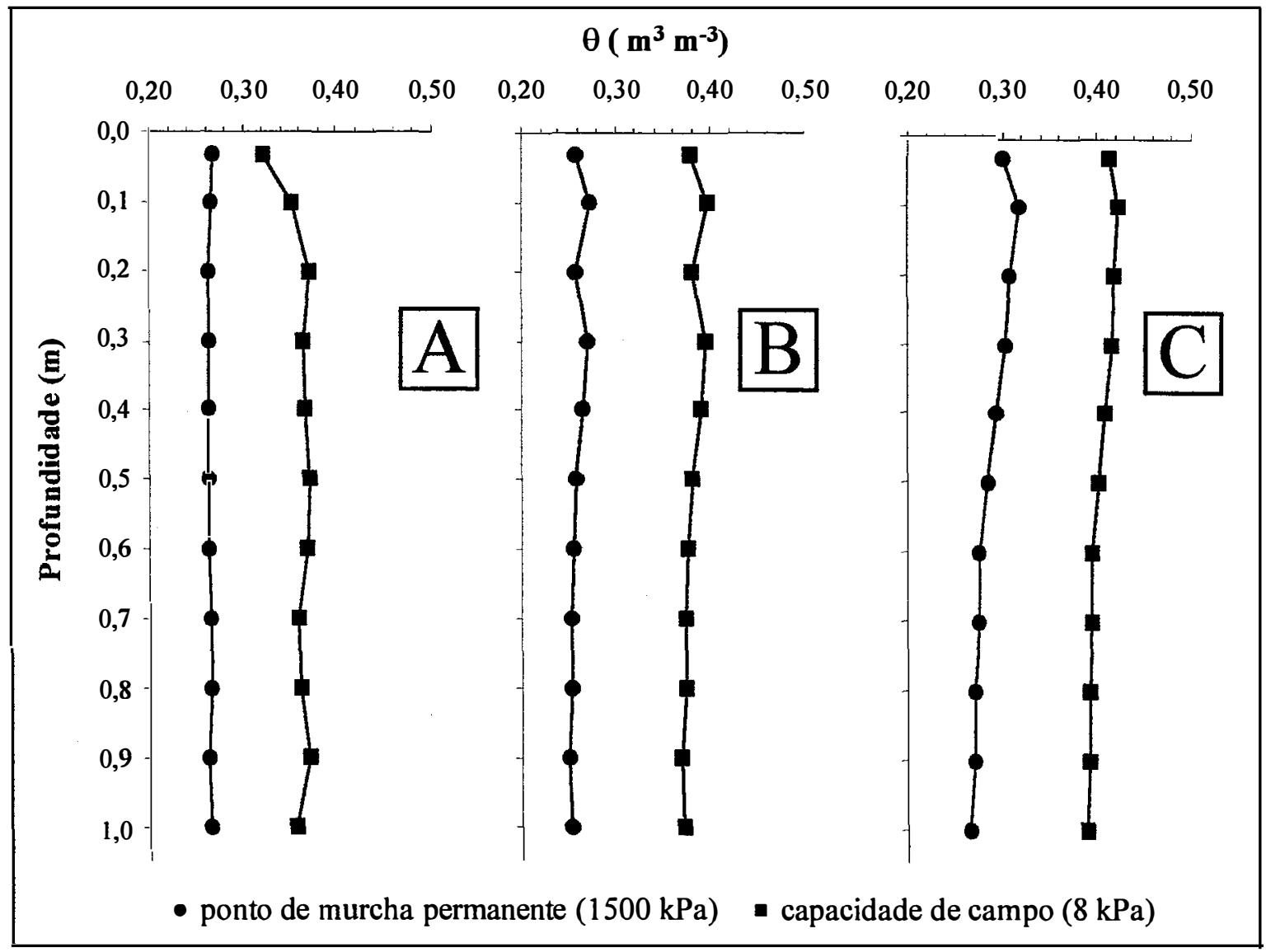

Figura 33 -Armazenagem de água no solo entre capacidade de campo e ponto de murcha permanente em profundidade para mata $(A)$, sequeiro (B) $e$ irrigado $(C)$

\subsubsection{Intervalo hídrico ótimo}

O intervalo hídrico ótimo (IHO), é a faixa de umidade do solo na qual as limitações ao desenvolvimento das plantas são minimas., isto é, nesta faixa de umidade do solo de ótima disponibilidade de água às plantas, sem limitações de energia de retenção, sem excesso de resistência à penetração nem problemas de aeração. É um importante indicador das condições fisico-hídricas do solo.

Para o solo da mata (figura 34a), observa-se que em nenhum momento a resistência à penetração ou a porosidade de aeração foram limitantes e o IHO variou 
positivamente com o aumento da densidade do solo de 0,0467 a $0,1121 \mathrm{~m}^{3} \mathrm{~m}^{-3}$ enquanto a densidade variou de 0,91 a $1,03 \mathrm{Mg} \mathrm{m}^{-3}$.

No solo de sequeiro (figura 34b), o IHO foi afetado no seu limite inferior pela resistência à penetração a partir da densidade de $1,11 \mathrm{Mg} \mathrm{m}^{-3}$, enquanto que a porosidade de aeração em nenhum momento foi limitante. O IHO variou de 0,1172 a $0,0897 \mathrm{~m}^{3} \mathrm{~m}^{-3}$ enquanto a densidade variou de 0,98 a $1,21 \mathrm{Mg} \mathrm{m}^{-3}$.

$\mathrm{Na}$ área irrigada (figura 34c) houve limitação tanto da resistência a penetração como da porosidade de aeração sobre o IHO. A resistência passou a ser limitante a partir da densidade do solo de $1,06 \mathrm{Mg} \mathrm{m}^{-3}$, enquanto que a porosidade de aeração a partir de $1,27 \mathrm{Mg} \mathrm{m}^{-3}$. O IHO variou de 0,123 a $0,0276 \mathrm{~m}^{3} \mathrm{~m}^{-3}$ enquanto a densidade variou de 1,0 a $1,3 \mathrm{Mg} \mathrm{m}^{-3}$.

Analisando os três manejos em conjunto observa-se que no irrigado se obteve a maior variação nos valores de IHO $\left(\Delta \mathrm{IHO}=0,0954 \mathrm{~m}^{3} \mathrm{~m}^{-3}\right)$, enquanto no sequeiro a menor variação $\left(\Delta \mathrm{IHO}=0,0275 \mathrm{~m}^{3} \mathrm{~m}^{-3}\right)$. Na área de mata $\left(\Delta \mathrm{IHO}=0,0654 \mathrm{~m}^{3} \mathrm{~m}^{-3}\right) \mathrm{o}$ valor máximo de IHO foi menor do que no sequeiro e irrigado. 


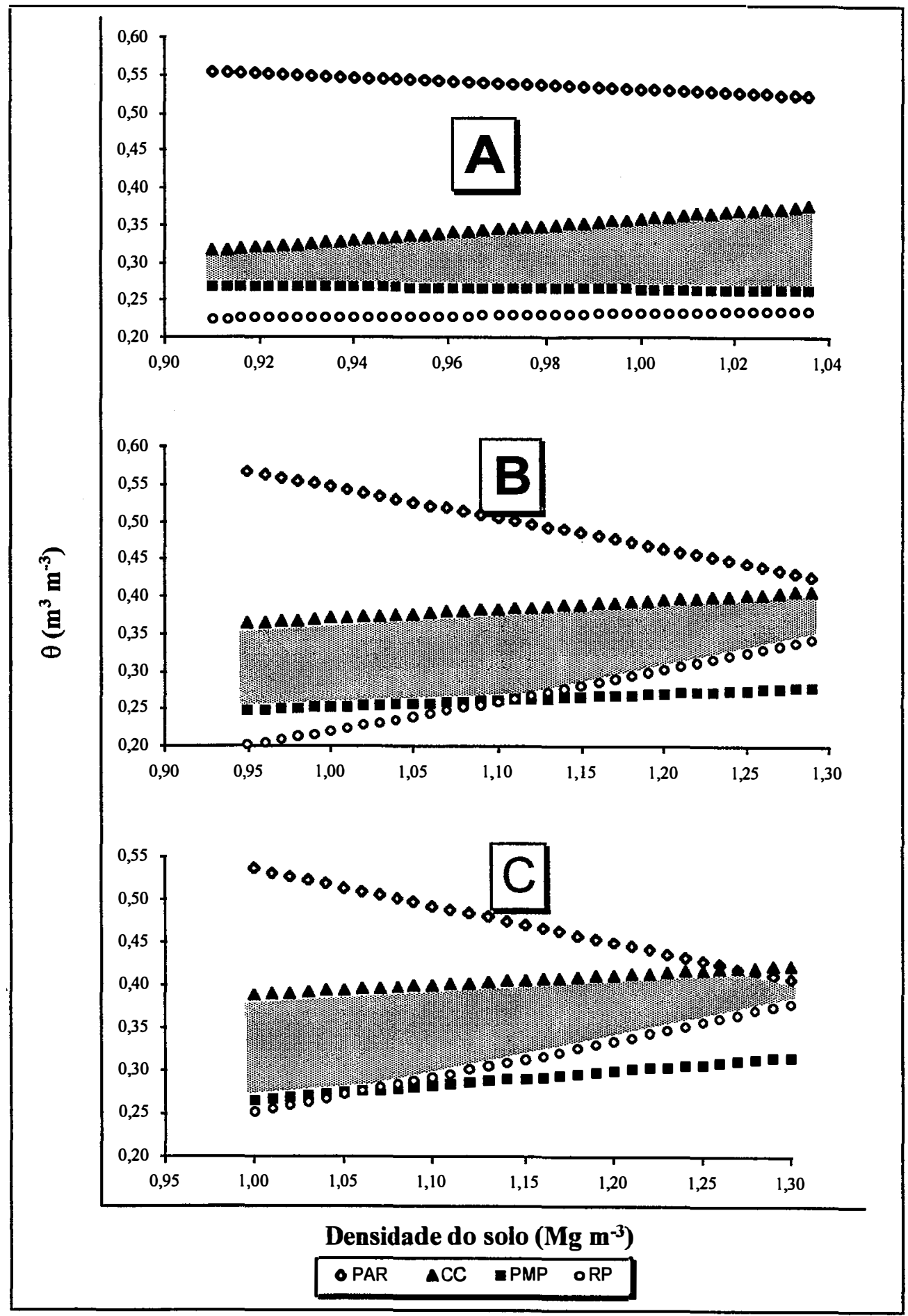

Figura 34 - Variação da umidade do solo em relação a densidade nos niveis críticos da porosidade de aeração(PAR), capacidade de campo(CC), ponto de murcha permanente $(P M P)$ e restência à penetração $(R P)$ para mata $(A)$, sequeiro (B) e irrigado (C) , área hachureada IHO. 
Para a área de sequeiro sob plantio direto o valor da densidade na qual a resistência do solo a penetração passou a ser limitante, $1,11 \mathrm{Mg} \mathrm{m}^{-3}$, foi praticamente igual a encontrada por Tormena et al. (1998b), trabalhando no mesmo tipo de solo, também sob plantio direto na região de Guaira. Estes resultados comprovam a influência do manejo e a repetibilidade dos resultados, afirmando esta metodologia, como bom indicador das condições físico-hídricas do solo.

A diferença nos valores de densidade do solo, entre os manejos de sequeiro $\left(1,11 \mathrm{Mg} \mathrm{m}^{-3}\right)$ e irrigado $\left(1,06 \mathrm{Mg} \mathrm{m}^{-3}\right)$, na qual a resistência à penetração se tornou limitante, sugere haver algum outro fator que afeta a resistência que não só a densidade, ou que só a densidade não consiga descrever as características da estrutura do solo que afetam a resistência à penetração.

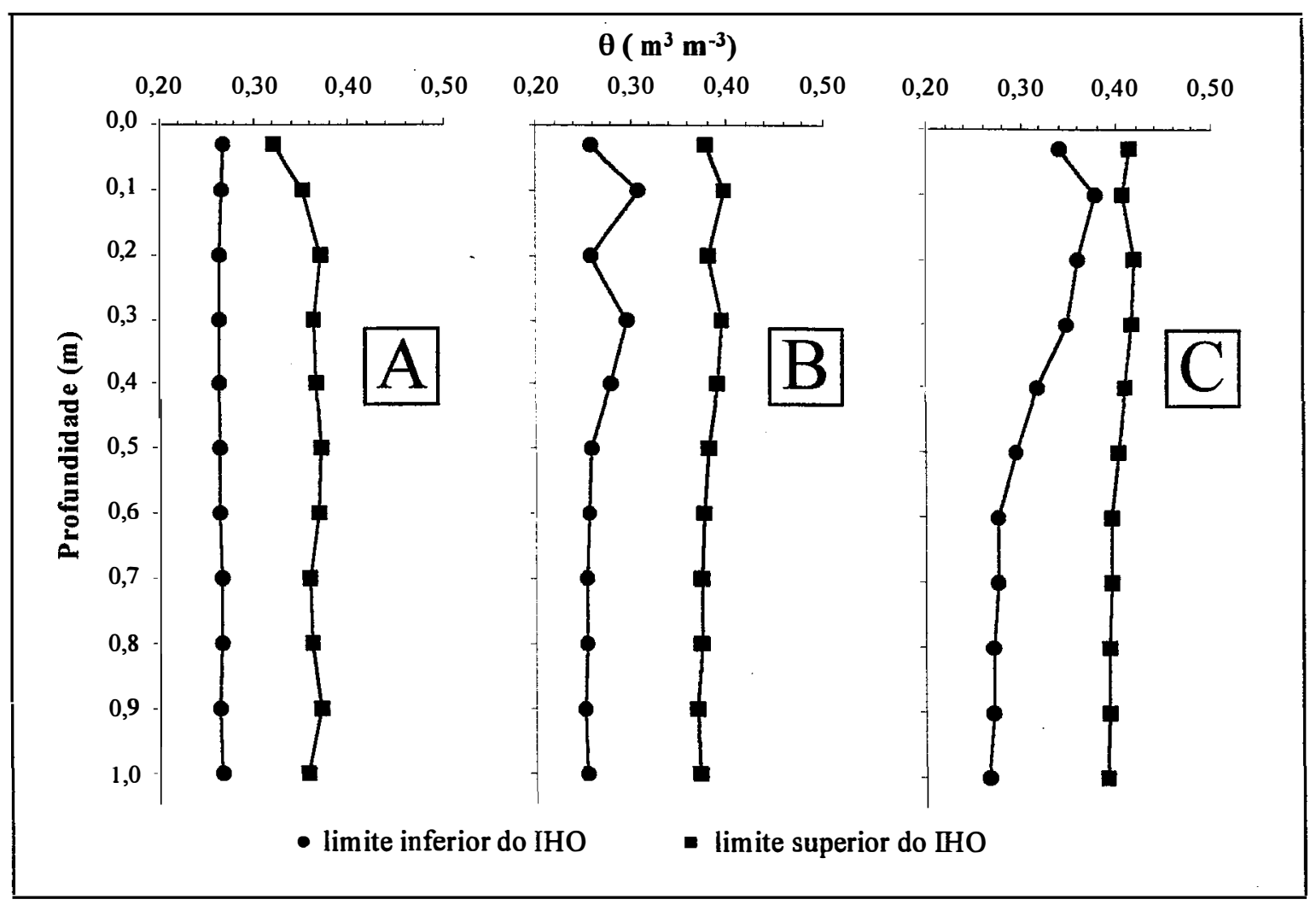

Figura 35 -Variação do IHO em profundidade para mata (A), sequeiro (B) $e$ irrigado $(C)$. 
Analisando a figura 35 na qual se apresenta os limites inferior (ponto de murcha permanente ou resistência à penetração) e superior (capacidade de campo ou porosidade de aeração) do intervalo hídrico ótimo observa-se as diferenças que existem entre os manejos, em profundidade, embora se reconheça que estes limites são apenas referências relativas, uma vez que a variabilidade espacial e temporal destes é muito grande e será decisiva na limitação ou não do crescimento radicular.

Neste sentido, Correchel et al. (1997) estudaram a variabilidade espacial da resistência do solo a penetração, de um Latossolo roxo sob plantio direto, na camada de 0 - 0,07 m e observaram que de 96 amostras somente 37,5\%, apresentou valores de RP superiores a $2 \mathrm{MPa}$, na tensão de $30 \mathrm{kPa}$, o que poderá ou não afetar o crescimento das raízes, por estas possuírem grande capacidade de adaptação, buscando sempre a região de menor resistência.

O solo da mata, apresenta valores de densidade do solo menores na superfície (tabela 4), isto, de acordo com a figura 34a, é negativo para a armazenagem da água bem como para o IHO, como pode ser observado na figura 35 , pois em função da elevada macroporosidade retém pouca água.

Com o aumento da densidade, até um limite, aumenta-se o IHO do solo em estudo, como é o caso do solo de sequeiro, que apresenta uma densidade intermediária entre a mata e o irrigado apresentando conseqüentemente um maior IHO e menor variação.

$\mathrm{O}$ solo da área irrigada, especificamente na camada de $0,1 \mathrm{~m}$ apresenta problemas tanto de resistência limitante quanto de porosidade de aeração, sendo importante destacar que esta limitação na porosidade de aeração poderá comprometer a aeração de todo o perfil, pois a difusão de gases deverá se dar junto a superfície e , havendo uma camada de impedimento, esta poderá ser limitante.

O estudo da variação temporal do IHO para a área irrigada, que a princípio é a área mais problemática, em função da variação da umidade, em função do tempo de drenagem, está apresentado na figura 36. Observa-se que em relação a porosidade de 
aeração esta continuou limitante, menor que $0,10 \mathrm{~m}^{3} \mathrm{~m}^{-3}$, após 48 horas, somente para densidade superior a $1,25 \mathrm{Mg} \mathrm{m}^{-3}$.

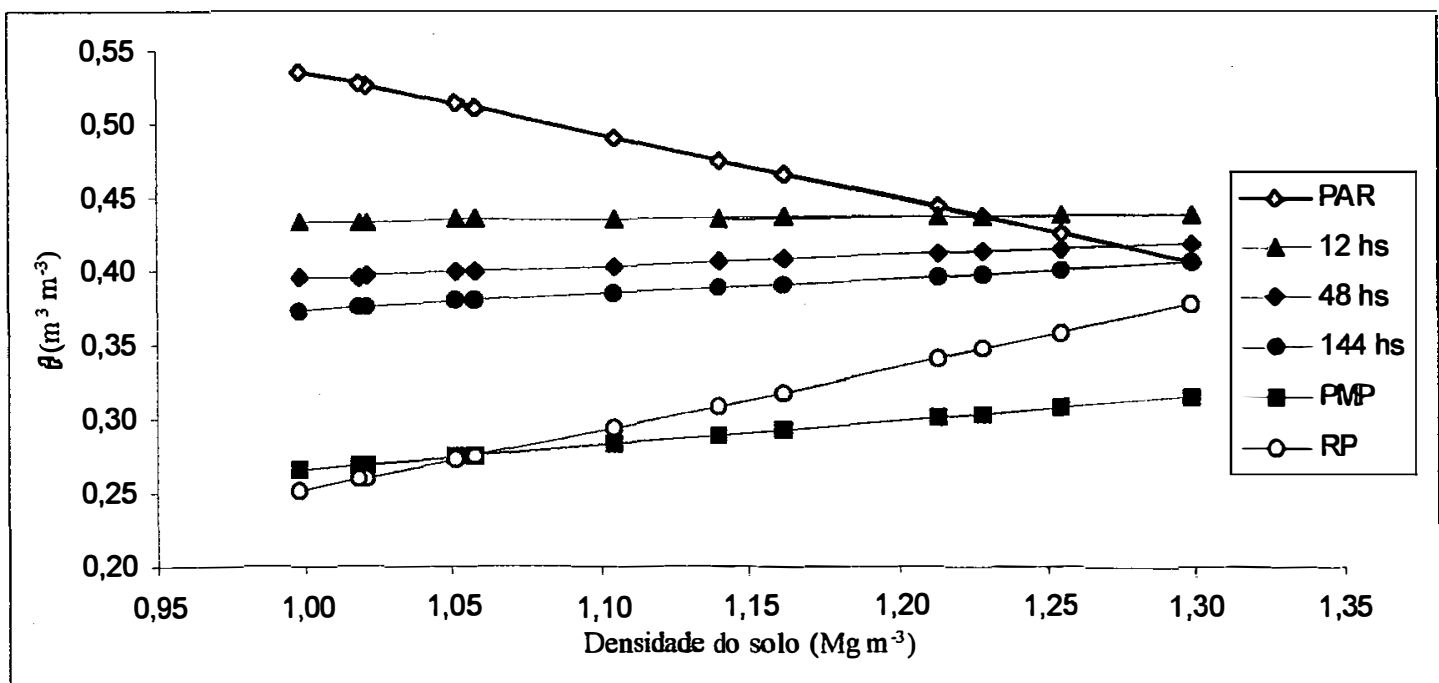

Figura 36 -Variação do IHO em função do tempo de drenagem para área de plantio direto irrigada.

Plotando-se o IHO em função da densidade do solo, conforme figura 37 , é possível definir um valor ou uma faixa de densidade como ideal, em função da maior disponibilidade de água as plantas, concordando o que autores como Swan et al. (1987) afirmam de que um nível de compactação intermediária é benéfico para a produção das culturas, por aumentar a disponibilidade de água as plantas. Neste sentido para este solo estudado pode-se afirmar que uma densidade entre 1 a $1,1 \mathrm{Mg} \mathrm{m}^{-3}$, seria o ideal pois nesta condição o IHO seria o máximo, em torno de $0,12 \mathrm{~m}^{3} \mathrm{~m}^{-3}$, condição em que a água disponível as plantas é $20 \%$ superior do que aquela apresentada por Van Wambeke citado por Cerri (1986), o qual afirma que para oxissóis existe uma razão de $1 \mathrm{~mm}$ de lâmina de água disponível por centímetro de profundidade.

Sidiras \& Vieira (1984) também observaram que uma certa compactação do solo, ocasionada pelo tráfego de um trator, proporcionou incrementos na retenção de água no solo, no crescimento e rendimento das culturas de trigo, soja e nabo forrageiro. 


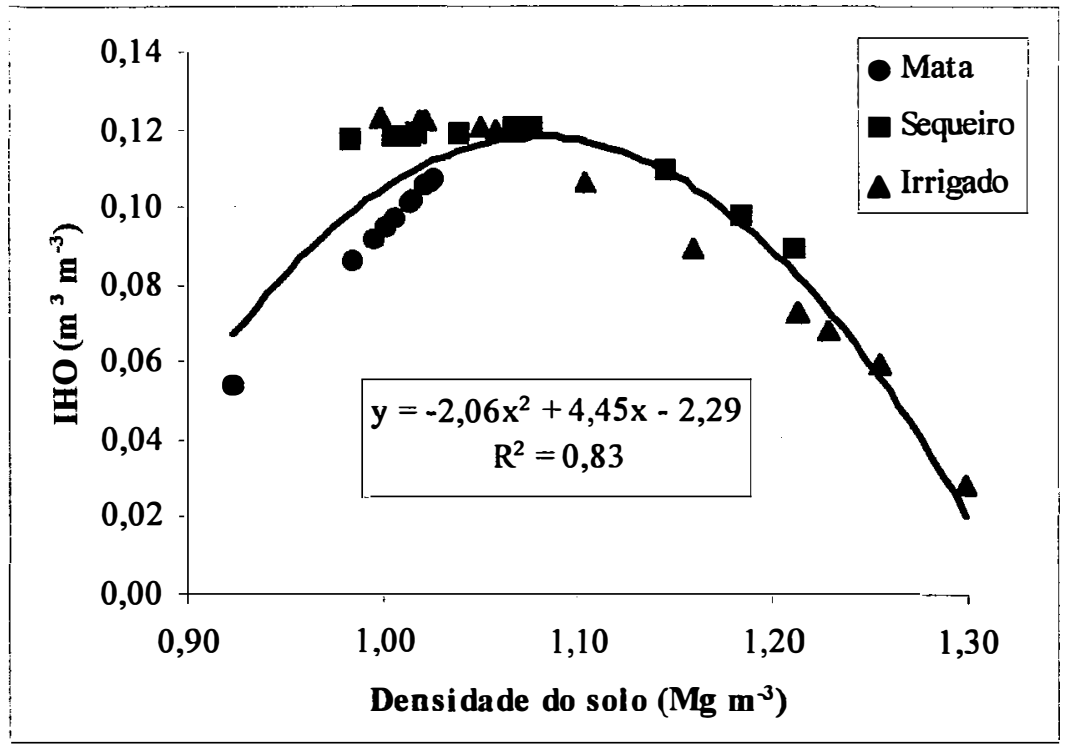

Figura 37 -IHO em função da densidade do solo 


\section{CONCLUSÕES}

A hipótese levantada foi comprovada, demonstrando-se com este trabalho que o plantio direto provoca alterações significativas nas propriedades fisico-hídricomecânicas de um Latossolo Roxo em relação a condição natural (mata) permitindo concluir que:

1 - O manejo do solo sob plantio direto aumenta a densidade até a profundidade de $0,4 \mathrm{~m}$, com conseqüente o aumento na resistência à penetração. Esta é altamente influenciada pela condição de umidade do solo e a sua determinação, apenas quando o solo se encontra próximo à capacidade de campo, não é recomendável, pois, grandes variações de densidade poderão não ser detectadas. Além disso o manejo do solo diminui a porosidade total e altera a distribuição do diâmetro dos poros diminuindo o volume de macroporos e aumentando o de micro e criptoporos, sendo que em densidades superiores a 1,2 $\mathrm{Mg} \mathrm{m}^{-3}$ a porosidade de aeração passou a ser limitante $\left(<0,10 \mathrm{~m}^{3} \mathrm{~m}^{-3}\right)$.

2 - Os manejos reduzem a condutividade hidráulica do solo saturado e não saturado nas profundidades em que a densidade foi alterada. As equações de $K(\theta)$ obtidos no campo, não podem ser extrapolados para fora da faixa de umidade em que foram obtidas, especificamente para aquela próxima a saturação conforme determinação em colunas de solo com estrutura preservada, que permitiu obter as equações de $K(\theta)$ na faixa de umidade próxima a saturação. 
3 - As curvas de retenção de água no solo com estrutura alterada apresentaram comportamento distinto daquelas com estrutura preservada, superestimando a umidade nas baixas tensões e subestimando nas altas tensões.

4 - As alterações na densidade provocaram uma menor umidade do solo próximo a saturação e maior no ponto de murcha permanente aumentando no entanto o volume de água armazenada e o intervalo hídrico ótimo até o limite de $1,10 \mathrm{Mg} \mathrm{m}^{-3}$

5 - O manejo do solo diminuiu o índice de plasticidade, aumentou a umidade do limite plástico e diminuiu a umidade do limite líquido e limite de pegajosidade do solo. 


\section{REFERÊNCIAS BIBLIOGRÁFICAS}

AKRAM, M. ; KEMPER, W.D. Infiltration of soils as affected by pressure and water content at the time of compaction. Soil Science Society of America Journal, v.3, p.1080-1086, 1979.

ARRUDA, F.B.; ZULLO Jr. J. ; OLIVEIRA, J.B. de. Parâmetros de solo para o cálculo da água disponível com base na textura do solo. Revista Brasileira de Ciência do Solo, v.11, p.11-15, 1987.

ASHBURNER, J.E.; SIMS, B.G. Elementos de diseño del tractor y herramientas de labranza. San José: IICA, 1984. 474p.

AZOOZ, R.H.; ARSHAD, M.A. Soil infiltration and hydraulic conductivity under longterm no-tillage and conventional tillage systems. Canadian Journal of Soil Science, v.76, p.143-152, 1996.

BALASTREIRE, L.A. Máquinas agrícolas. São Paulo: Manole, 1987. 310p.

BALL, B.C.; CHESHIRE, M.V.; ROBERTSON, E.A.G. ; HUNTER, E.A. Carbohydrate composition in relation to structural stability, compactibility and plasticity of two soils in a long-term experiment. Soil \& Tillagé Research, v.39, p.143-160, 1996.

BARYEH, E.A. Tillage effects on growth, yield of maize and some soil properties : an experience at Dschang, Cameroon. Agricultural Engineer, v. 41, p.38-42, 1986. 
BAUDER, J.W.; RANDAL, G.W. ; SWANN, J.B. Effect of four continuous system on mechanical impedance of a clay loam soil. Soil Science Society of America Journal, v. 45, p.802-806, 1981.

BAUMER, K. ; BAKERMANS, W.A.P. Zero- tillage. Advances in Agronomy, v.25, p.77-125, 1973.

BAVER, L.D.; GARDNER, W.H. ; GARDNER, W.R. Soil physics. New York: John Wiley, 1972. 498p.

BELTRAME, L.F.S. ; TAYLOR, J.C. Causas e efeitos da compactação do solo. Lavoura Arrozeira, v. 33, p.59-62, 1980 .

BENGHOUGH, A.G. ; MULLINS, C.E. Mechanical impedance to root growth: a review of experimental techniques and root growth responses. Journal of Soil Science, v. 41, p.341-358, 1990.

BEVEN, K.; GERMANN, P. Water flow in soil macropores: 2. A combined flow model. Journal of Soil Science, v.32, p.15-39, 1981.

BLEVINS, R.L.; SMITH, M.S.; THOMAS, G.W. Changes in soil properties under notillage. In: PHILLIPS, R.E.; PHILLIPS, S.H. (Ed.) No-tillage agriculture: principles and practices. New York, VNR, 1984. cap 9. p.190-230.

BOUMA, J. Influence of soil macroporosity on environmental quality. Advances in Agronomy, v. 46, p.2-36, 1991.

BOUMA, J.; JONGERIUS, A.; BOHSUMA, O.; LEGER, A.; SCTROONDERBEER, D. The function of different types of macroporos during saturated flow through four swelling soil horizons. Soil Science Society of America Journal, v. 41, p. 945-950, 1977.

BOUMER, H. Intake rate: cylinder infiltrometer. In: KLUTE, A. (Ed.) Methods of soil analysis: physical, chemical and mineralogical methods. Madison: American Society of Agronomy, 1986. cap.19, p.825-844. 
BRADFORD, J.M. Penetrability. In: KLUTE, A. (Ed.) Methods of soil analysis: physical, chemical and mineralogical methods. Madison: American Society of Agronomy, 1986. cap.19, p.463-478.

BREWER, R.; SLEEMAN, J.R. Soil structure : attempts at its quantitative characterization. Journal of Soil Science, v.11, p.172-185, 1960.

BRUCE, R.R. An instrument for the determination of soil compactibility. Soil Science Society of America Proceedings, v.19, p.253-257, 1955.

BUENO, B.S. ; VILAR, O.M. Mecânica dos solos. São Carlos: USP, EESC, 1998, v. $1,131 \mathrm{p}$.

CAMARGO, O. Compactação do solo e desenvolvimento de plantas. Campinas: Fundação Cargill, 1983. 44p.

CAMPOS, D. A.F. de Micropedologia. Piracicaba: ESALQ, 1971. 39p.

CASSEL, D.K. Subsoiling. Crops and soils magazine, v.32, p.7-10, 1979.

CASSEL, D.K. Tillage effects on soil bulk density and mechanical impedance. In. ANNUAL MEETING OF THE AMERICAN SOCIETY OF AGRONOMY AND SOIL SCIENCE SOCIETY OF AMERICA, Detroit, 1980. Predicting tillage effects on soil physical properties and processes. Madison: ASA; SSSA, 1982. cap. 4, p. 45-67. (ASA. Special Publication, 44)

CASSEL, D.K. ; KLUTE, A. Water Potential: Tensiometry. In: KLUTE, A. (Ed.) Methods of soil analysis: physical, chemical and mineralogical methods. Madison: American Society of Agronomy, 1986. cap. 23, p.563-596.

CASSEL, D.K.; BOWEN, H.D.; NELSON, L. A. An evaluation of mechanical impedance for three tillage treatments on Norfolk Sandy Loam. Soil Science Society of America Journal, v. 42, p.116-120, 1978.

CASTRO, O.M. Preparo do solo para a cultura do milho. Campinas: Fundação Cargill, 1989. 41p. 
CASTRO, O. M. Comportamento fisico e químico de um Latossolo Roxo em função do seu preparo na cultura do milho ( Zea mays L.) Piracicaba, 1995. 174p. Tese (Doutorado)- Escola Superior de Agricultura "Luiz de Queiroz", Universidade de São Paulo.

CERRI, C. C. Dinâmica da matéria orgânica do solo no agrossistema cana-de-acúcar. Piracicaba, 1986. 197p. Tese (Livre- Docência)- Escola Superior de Agricultura Luiz de Queiroz, Universidade de São Paulo.

CHANCELLOR, W.J. Compaction of soil by agricultural equipment. Berkeley: University of California, Division of Agricultural Sciences, 1977. 53p. (Bulletin, 1881)

CHEN, C.; THOMAS, D.M.; GREEN, R.E.; WAGENET, R.J. Two-Domain estimation of hydraulic properties in macropore soils. Soil Science Society of America Journal, v.57, p.680-686, 1993.

CORRECHEL, V.; SILVA, A.P. da; TORMENA, C.A. ; SANCHEZ, A.C. Resistência de um Latossolo Roxo ao penetrômetro em dois sistemas de preparo do solo(compact disc). In: CONGRESSO BRASILEIRO DE CIÊNCIA DO SOLO, 26., Rio de Janeiro, 1997. Anais, Rio de Janeiro: SBCS;EMBRAPA, 1997.

CURMI, P.; KERTZMANN, F.F.; QUEIROZ NETO, J.P. Degradation of structure and hydraulic properties in an Oxisol under cultivation (Brazil). In: INTERNATIONAL WORKING MEETING ON SOIL MICROMORPHOLOGY, 9.,Townswillw, Soil micromorphology: studies in management and genesis. Amsterdam: Elsevier, 1994. p.569-579. (Developments in Soil Science, 22)

DALLA ROSA, A. Uso, manejo e conservação do solo : um grito de alerta. Santo Ângelo: COTRISA, 1981. 32p.

DERPSCH, R.; SIDIRAS, N.; ROTH, C.H. Results of studies made from 1977 to 1984 to control erosion by cover crops and no-tillage techniques in Paraná, Brazil. Soil \& Tillage Research, v.8, p.253-263, 1986. 
DONEEN, L.D.; HENDERSON, D.W.; FERRY, G.V. Soil compaction by tractors. California Agriculture, v.6, p. 7-8, 1952.

DOURADO NETO, D.; JONG VAN LIER, Q. de; BOTREL, T. A.; LIBARDI, P.L. Programa para confeç̧ão da curva de retenção de água no solo utilizando o modelo de Genuchten. Engenharia Rural, v.1, p.92-102, 1990.

EARL, R. Prediction of trafficability and workability using tensiometers. Journal of Agricultural Engineering Research, v.63, p.27-34, 1996.

EDWARDS, W.M. Predicting tillage effects on infiltration. In. ANNUAL MEETING OF THE AMERICAN SOCIETY OF AGRONOMY AND SOIL SCIENCE SOCIETY OF AMERICA, Detroit, 1980. Predicting tillage effects on soil physical properties and processes. Madison: ASA; SSSA, 1982. cap. 7, p. 105-115. (ASA. Special Publication, 44)

EHLERS, W. Observations on earthworm channels and infiltration on tilled and untilled loess soil. Soil Science, v. 119, p. 242-249, 1975.

EL-SWAIFY, S. A. Physical and mechanical properties of oxisols. In. THENG, B.K. (Ed.) Soils with variable charge. Palmerstoon North: New Zealand, Society of Soil Science, 1980. cap.15, p.303-322.

ELA, S.D.; GUPTA, S.C.; RAWLS, W.J. Macropore and surface seal interactions affecting water infiltration into soil. Soil Science Society of America Journal, v.56, p.714-721, 1992.

ELLIES, A. ; GAYOSO, J. Die Bestimmung der Konsistenzgrenzen in einigen Vulkanaschenböden aus Südchile. Zeitschrift für Pflanzenernährung und Bobenkunde, v.149, p.1-8, 1986.

ELLIES, A. ; MAC DONALD, R. Evaluacion de la consistencia de los principales suelos de las provincias de valdivia y osorno. Agro Sur, v.13, p.77-83, 1985. 
ELLIES, A.; GREZ, R.; RAMIREZ, C. La conductividad hidráulica en fase saturada como herramienta par el diagnostico de la estructura del suelo. Agro Sur, v. 5, p 51-56, 1997.

ELLIES, A.; RAMIREZ, C.; MAC DONALD, R. Cambios em la porosidad de um suelo por efecto de uso. Turrialba, v.43, p.72-76, 1993.

EMERSON, W.W. The plastic limit of silty, surface soils in relation to their content of polysaccharide gel. Australian Journal of Soil Research, v. 33, p.1-9, 1995.

EMPRESA BRASILEIRA DE PESQUISA AGROPECUÁRIA. Centro Nacional de Pesquisa de Solos. Manual de métodos de análise de solo. 2.ed. Rio de Janeiro: 1997. 212p.

ERICKSON, A.E. Tillage Effects on Soil Aeration. Predicting tillage effects on infiltration. In. ANNUAL MEETING OF THE AMERICAN SOCIETY OF AGRONOMY AND SOIL SCIENCE SOCIETY OF AMERICA, Detroit, 1980. Predicting tillage effects on soil physical properties and processes. Madison: ASA; SSSA, 1982. cap. 6, p. 91-104. (ASA. Special Publication, 44)

ESPIRITO DO SANTO, F.R Retenção e transmissão de água em um Latossolo Roxo sob diferentes sistemas de cultivo. Piracicaba, 1998. 105p. Tese(Doutorado) Escola Superior de Agricultura "Luiz de Queiroz", Universidade de São Paulo.

ESTADOS UNIDOS. Department of Agriculture. Soil Conservation Service. Soil Survey Laboratory. Methods and procedures for collecting soil samples: soil survey investigations. Washington, 1972. (Report, 1) 73p.

FARIA, R.T. de; CARAMORI, P.H. Caracterização fisico-hídrica de um latossolo roxo distrófico do município de Londrina, PR. Pesquisa Agropecuária Brasileira, v.21, p.1303-1311, 1986.

FIETZ, C.R. Variabilidade espacial do armazenamento de água no solo visando o manejo da irrigação por aspersão. Piracicaba， 1998. 97p. Tese (Doutorado)- Escola Superior de Agricultura "Luiz de Queiroz", Universidade de São Paulo. 
FIGUEIREDO, L.H.A.; DIAS JUNIOR, M.S.; SANTOS, G. A.; BUENO FILHO, J.S.S. Efeitos dos manejos do solo na densidade do solo máxima e umidade ótima de um Latossolo Roxo. In: REUNIÃO BRASILEIRA DE MANEJO E CONSERVAÇÃo DO SOLO E DA ÁGUA. 12., Fortaleza, Anais. Fortaleza: SBCS;UFCE, 1998, p.294-295.

FORSYTHE, W. Física de suelos. manual de laboratório. San José: IICA, 1975. 212p.

FRANCIS, G.S.; CAMERON, K.C.; KEMP, R. A. A comparison of soil porosity and solute leaching after six years of direct drilling or conventional cultivation. Australian Journal of Soil Research, v.26, p.637-649, 1988.

FREIRE, J.C. Condutividade hidráulica e capacidade de campo de latossolo roxo distrófico não saturado. Revista Brasileira de Ciência do Solo, v.3, p.73-77, 1979.

GEE, G.W.; BAUDER, J.W. Particle size analysis. In.. KLUTE, A. (Ed.) Methods of soil analysis: physical, chemical and mineralogical methods. Madison: American Society of Agronomy, 1986. cap. 15, p.383-411.

GREENLAND, D.J. Soil management and soil degradation. Journal of Soil Science, v. 32, p. 301-322, 1981 .

GROHMANN, F. ; QUEIROZ NETO, J.P. Efeito da compactação artificial de dois solos limo-argilosos sobre a penetração de raízes de arroz. Bragantina, v.25, p 421-431, 1966.

GUERIF, J. L'analyse de la porosité: Application à l'étude du compactage des sols. In. MONIER, G. ; GROSS, M.J. (Ed.) Soil compaction and regeneration. Rotterdam: AAB, 1987, p. 122-131.

GUPTA, S.C. ; LARSON, W.E. Modeling soil mechanical behavior during tillage. In. ANNUAL MEETING OF THE AMERICAN SOCIETY OF AGRONOMY AND SOIL SCIENCE SOCIETY OF AMERICA, Detroit, 1980. Predicting tillage effects on soil physical properties and processes. Madison: ASA; SSSA, 1982. cap. 10, p. 151-178. (ASA. Special Publication, 44) 
GUROVICH, L.A. ; STERN , J. Variabilidad espacial de la velocidad de infiltración en el suelo. II. Análisis geostadístico y estructura espacial. Ciencia e Investigación Agraria, v. 10, p.271-278, 1983.

HÂKANSSON, I. A method for characterizing the state of compactness of the plough

- layer. Soil \& Tillage Research, v.16, p.105-120, 1990.

HENDERSON, C.W.L. Using a penetrometer to predict the effects of soil compaction on the growth and yield of wheat on uniform, sandy soils. Australian Journal of Agricultural Research, v. 40, p.497-508, 1989.

HILLEL, D. Solo e água: fenômenos e princípios fisicos. Porto Alegre: UFRGS, 1970. $231 \mathrm{p}$.

HILLEL, D. Fundamentals of soil physics. New York: Academic Press, 1980. 413p.

HILLEL, D.; KRENTOS, V.D.; STYLIANOU, Y. Procedure and test of an internal drainage method for measuring soil hydraulic characteristics in situ. Soil Science, v.114, p.395-400, 1972.

HORTON, R.; ANKENY, M.D.; ALLMARAS, R.R. Effects of compaction on soil hydraulic properties. In: SOANE, B.D.; VAN OUWERKERK, C. (Ed.), Soil compaction in crop production. Amsterdam: Elsevier, 1994. cap. 7, p.141-165.

HULUGALLE, N.R.; WILLATT, S.T. The role of soil resistance in determining water uptake by plant toot systems. Australian Journal of Soil Research, v.21, p.571$574,1983$.

INSTITUTO DE PESQUISAS TECNOLÓGICAS DO ESTADO DE SÃO PAULO. Análises granulométricas e mineralógicas de um Latossolo Roxo de Guaira. São Paulo, 1994. 19p. ( IPT. Relatório Técnico, 818 363). 
INSTITUTO DE PESQUISAS TECNOLÓGICAS DO ESTADO DE SÃO PAULO. Áreas de conflito de uso das terras do município de Guaira - SP. São Paulo, 1995. 60p. (IPT. Relatório Técnico, 33 042).

JONG VAN LIER, Q. de; LIBARDI, P.L. Extraction of soil water by plants: development and validation of a model. Revista Brasileira de Ciência do Solo, v.212, p.535-542, 1997.

KERTZMANN, F.F. Modificações na estrutura e no comportamento de um latossolo roxo provocadas pela compactação. São Paulo, 1996. 153p. Tese (Doutorado)Faculdade de Filosofia, Letras e Ciências Humanas, Universidade de São Paulo.

KIEHL, E.J. Manual de edafologia: relações solo-planta. São Paulo: Ceres, 1979. 262p.

KLADIVKO, E.J., MACKAY, A.D. ; BRADFORD, J.M. Earthworms as a factor in the reduction of soil crusting. Soil Science Society of America Journal, v. 50, p. 191-196, 1986.

KLEIN, V.A. ; BOLLER, W. Avaliação de diferentes métodos de manejos de solo e métodos de semeadura em área sob sistema plantio direto. Ciência Rural, v.25, p.395-398, 1995.

KLUTE, A. ; DIRKSEN. C; Hidraulic conductivity and diffusivity: laboratory methods. In: KLUTE, A. (Ed.) Methods of soil analysis: physical, chemical and mineralogical methods. Madison: American Society of Agronomy, 1986. cap. 28, p.687-734.

KOOLEN, A.J. ; KUIPERS, H. Agricultural soil mechanics. Berlin: Springer-Verlag, 1983. 241p.

KOOREVAAR, P.; MENELIK, G. ; KIRKSEN, C. Elements of soil physics. Amsterdam: Elsevier, 1983. 228p. (Developments in Soil Science 13). 
LAL, R. Mechanized tillage system effects on properties of a tropical alfisol in watersheds cropped to maize. Soil \& Tillage Research, v.6, p.149-161, 1955.

LARSON, W.E. Soil parameters for evaluating tillage needs and operations. Soil Science Society of America Proceedings, v.28, p.118-122, 1964.

LEMOS, R.C. de; SANTOS, R.D. dos. Manual de descrição e coleta de solo no campo. Campinas: SBCS; SNLCS, 1984. 46p.

LETEY, J. Relationship between soil physical properties and crop productions. Advances in Soil Science, v.1, p.277-294, 1985.

LIBARDI, P.L. Condutividade hidráulica do solo em condições de campo. 1978. 113p. Tese (Doutorado)- Escola Superior de Agricultura "Luiz de Queiroz", Universidade de São Paulo.

LIBARDI, P.L. Dinâmica da água no solo. Piracicaba: O autor, 1995. 497p.

LIBARDI, P.L. Determinação da condutância hidráulica e da pressão de borbulhamento de cápsulas porosas para tensiômetros. Piracicaba: ESALQ, 1997. 10p.

LUXMOORE, R.J. Micro-,meso-, and microporosity of soil. Soil Science Society of America Journal, v.45. p.671-672, 1981.

MATA, J. D.V. da. Relações entre características fisicas e os níveis de compactação de alguns latossolos paranaenses. Curitiba, 1988. 105p. Dissertação (Mestrado)Universidade Federal do Paraná.

MATERECHERA, S.A.; DEXTER, A.R.; ALSTON, A.M. Penetration of very strong soils by seedling of different plant species. Plant and Soil, v.135, p.31-41, 1991.

MERTEN, G.H. ; MIELNICZUK, J. Distribuição do sistema radicular e dos nutrientes em Latossolo Roxo, sob dois sistemas de preparo do solo. Revista Brasileira de Ciência do Solo, v.15, p.369-374, 1991. 
MOURA FILHO, W.; BUOL, S.W. Studies of a Latossol Roxo (Eutrustox) in Brazil: Clay mineralogy. Experientiae, v.13, p.218-234, 1972.

MUKTAR, S.; BAKER, J.L.; HORTON, R. ; ERBACH, D.C. Soil water infiltration as affected by the use of the paraplow. Transactions of the ASAE, v. 28, p.1811$1816,1985$.

NESMITH, D.S. Soil compaction in double cropped wheat and soybean on Ultissol Soil Science Society of America Journal, v.51, p.183-186, 1987.

NOGUEIRA, J.B. Mecânica dos solos: ensaios de laboratório. São Carlos: USP, EESC, 1998. 248p.

NOVAK, L.R.; MANTOVANI, E.C.; MARTYN, P.J.; FERNANDES, B. Efeito do tráfego de trator e da pressão de contato pneu/solo na compactação de um latossolo vermelho-escuro álico, em dois níveis de umidade. Pesquisa Agropecuária Brasileira, v.27, p.1587-1595, 1992.

ORELLANA, J.A. de; PILATTI, M.A.; GRENÓN, D.A. Soil quality: an approach to physical state assessment. Journal of Sustainable Agriculture, v.9, p.91-108, 1997.

OTHMER, H.; DIEKKRUGER, B.; KUTILEK, M. Bimodal porosity and unsaturated hydraulic conductivity. Soil Science, v.52, p.139-150, 1991.

- PAULETTO, E.A. Determinação da condutividade hidráulica de solos a partir da curva de retenção de água. . Piracicaba, 1986. 133p. Tese (Doutorado)- Escola Superior de Agricultura "Luiz de Queiroz", Universidade de São Paulo.

PENNA MEDINA, H.; GROHMANN, F. Disponibilidade de água em alguns solos sob cerrado. Bragantia, v.25, p.65-75, 1966.

PERINI, M.,; MEDEIROS, G.A.; LUCARELLI,J.R.F.; FERREIRA, J.C.; DANIEL, L.A. Efeito da compactação do solo sobre o desenvolvimento radicular da soja(Glycine max, L.) In: CONGRESSO BRASILEIRO DE ENGENHARIA 
AGRÍCOLA, 27., Poços de Caldas, 1998. Anais. Lavras: UFLA; SBEA, 1998. p.319-321.

PERROUX, K.M.; WHITE, I. Designs for disc permeameters. Soil Science Society of America Journal, v.52, p.1205-1215, 1988.

PETTER, R.L. Desenvolvimento radicular da soja em função da compactação do solo, conteúdo de água e fertilidade em Latossolo. Santa Maria, 1990. 144p. Dissertação(Mestrado) - Universidade Federal de Santa Maria.

RADULOVICH, R.; SOLLINS, P.; BAVEYE, P.; SOLÓRZANO, E. Bypass water flow through unsaturated microaggregated tropical soils. Soil Science Society of America Journal, v.56, p.721-726, 1992.

RAGHAVAN, G.S.V.; ALVO, P.; MCKYES, E. Soil compaction in Agriculture: A view toward managing the problem. Advances in Soil Science, v.11, p.1-35, 1990.

RAGHAVAN, G.S.V.; MCKYES, E.; BEAULIEU, B. Prediction of clay soil compaction. Journal of Terramechanics, v.14, p. 31-38, 1977 a.

RAGHAVAN, G.S.V.; MCKYES, E.; CHASSÉ, M. Effect of wheel slip on soil compaction. Journal Agricultural Engineering Research, v.22, p.79-83, 1977 b.

REICHARDT, K. A água em sistemas agrícolas. São Paulo: Manole. 1987. 188p.

REICHARDT, K. Capacidade de campo. Revista Brasileira de Ciência do Solo, v.12, p.211-216, 1988.

REICHARDT, K. ; BACCHI, O.O.S.; VILLAGRA, M.M.; TURATTI, A.L.; PEDROSA, Z.O. Hydraulic variability in space and time in a dark red latosol on the tropics. Geoderma, v.60, p.159-168, 1993.

REZENDE, J.O. Compactação e adensamento do solo, metodologia para avaliação e práticas agrícolas recomendadas (compact disc). In: CONGRESSO BRASILEIRO DE CIÊNCIA DO SOLO, 26., Rio de Janeiro, 1997. Anais. Rio de Janeiro: SBCS;EMBRAPA, 1997. 
RICHARDS, L. A. Physical conditions of water in soil. In: BLACK, C.A. (Ed.) Methods of soil analysis. Madison, American Society for Testing and Materials. 1965. p. 128-152. (Agronomy 9, Part 1)

ROTH, C.H.; MEYER, B.; FREDE, H.G.; DERPSCH, R. Effect of mulch rates and tillage systems on infiltrability and other soil physical properties of an oxisol in Paraná, Brazil. Soil \& Tillage Research, v.11, p.81-91, 1988.

SAAD, A.M. Uso do tensiômetro no controle da irrigação por pivô central em cultura do feijoeiro. Piracicaba, 1993. 144p. Dissertação (Mestrado) - Escola Superior de Agricultura "Luiz de Queiroz", Universidade de São Paulo.

SAAD, A.M.; LIBARDI, P.L. Qualidade da irrigação controlada por tensiômetros em pivô central. Scientia Agricola, v.51, p.549-555, 1994.

SALIRE, E.V. ; WOODHEAD, T. Soil friability. In. WOPEREIS, M.; BOUMA, K.J.; WIJK, A.V. ; WOODHEAD, T. (Ed.) Soil physical properties. measurement and use in rice-based cropping systems.. Manila: IRRI, 1994. p.70-71.

SANCHEZ, P. A. Soil organic matter. In: SANCHEZ, P.A. (Ed.) Properties and management of soils in the tropies. New York: John Wiley, 1976. cap. 6, p.162183.

SAUER, T.J. ; CLOTHIER, B.E. ; DANIEL, T.C. Surface Measurements of the Hydraulic Properties of a Tilled and Untilled Soil. Soil \& Tillage Research, v. 15, p. 359-369, 1990.

SCHAFFER, R.L.; REAVES, C. A. ; YOUNG, D.F. An interpretation of distortion in the similitude of certain soil-machines systems. Transaction of the ASAE, v.12, p.145-149,1969.

SETZER, J. Contribuição para o estudo do clima do estado de São Paulo. São Paulo: Escolas Profissionais Salesianas, 1946. 239p. 
SHARMA, M.L.; UEHARA, G. Influence of soil structure on water relations in low Humic Latosols: II. Water movement. Soil Science Society of America Proceedings, v.32, p.770-774, 1968.

SIDIRAS, N.; VIEIRA, M.J. Comportamento de um Latossolo roxo distrófico compactado pelas rodas do trator na semeadura, rendimento de três culturas. Pesquisa Agropecuária Brasileira, v.19, p.1285-1293, 1984.

SIDIRAS, N.; VIEIRA, S.R. ; ROTH, C.H. Determinação de algumas características fisicas de um Latossolo roxo distrófico sob plantio direto e preparo convencional. Revista Brasileira de Ciência do Solo, v.8, p.265-268, 1984.

SILVA, A.P. da ; KAY, B.D. The sensitivity of shoot growth of corn to the least limiting water range of soils. Plant and Soil, v.184, p.323-329, 1996.

SILVA, A.P. da ; KAY, B.D. Estimating the least limiting water range of soil from properties and management. Soil Science Society of America Journal, v.61, p.877883, 1997.

SILVA, A.P. da ; LIBARDI, P.L. ; CAMARGO O.A. Influência da compactação nas propriedades físicas de dois latossolos. Revista Brasileira de Ciência do Solo, v.10, p. 91-95, 1986.

SILVA, V.R.; RUBIM, R.B.; REINERT, D.J.; REICHERT, J.M.; SOUTO,J. Compressibilidade de dois solos em função do estado inicial de compactação do solo. In: REUNIÃO BRASILEIRA DE MANEJO E CONSERVAÇÃO DO SOLO E DA ÁGUA, 12., Fortaleza, 1998. Anais. Fortaleza: UFCE; SBCS, 1998. p.236237.

SILVEIRA, G.M. O preparo do solo: implementos corretos. São Paulo: Ed. Globo. $1988,243 p$.

SILVEIRA, M.S.; SILVA, J.G.; STONE, L.F.; ZIMMERMANN, F.J.P. Efeito do sistema de preparo na densidade do solo (compact disc). In: CONGRESSO 
BRASILEIRO DE CIÊNCIA DO SOLO, 26. Rio de Janeiro, 1997. Anais. Rio de Janeiro: EMBRAPA, SBCS, 1997.

SOANE, B.D.; CAMPBELL, D.J.; HERKES, S.M. The characterization of some Scottish arable topsoil's by agricultural and engineering methods. Journal of Soil Science, v. 23, p.93-104, 1972.

SOJKA, R.E. Stomatal closure in oxygen-stressed plants. Soil Science, v.154, p.269280, 1992.

SOWERS, G.G. Consistency. In: BLACK, C.A. (Ed.) Methods of soil analysis. Madison: American Society for Testing and Materials, 1965. cap. 31, p.391-399. (Agronomy 9, Part 1)

SWAN, J.B.; MONCRIEF, J.F.; VOORHEES, W.B. Soil compaction: causes, effects and control. Minneapolis: Minesota Extension Service. 1987. 11p. (Bulletin, 3115),

SYKES, D.J. Reconsideração do conceito da umidade de murchamento permanente. Turrialba, v.19, p.525-530, 1969.

STIRZAKER, R.J.; PASSIOURA, J.B.; WILMS,Y. Soil structure and plant growth: Impact of bulk density and biopores. Plant and Soil, v.185, p.151-162, 1996.

STOLZY, L.H. ; BARLEY, K.P. Mechanical resistance encountered by root entering compacted soils. Soil Science, v.105, p.297-301, 1968.

TAYLOR, H.M. ; GARDNER, H.R. Penetration of cotton seedlings taproots as influenced by bulk density, moisture content and strength soil. Soil Science, v.96, p.153-156, 1963.

TAYLOR, H.M.; ROBERTSON, G.M. ; PARKER, J.J. Soil strength root penetration relations for medium to coarse textured soil materials. Soil Science, v.102, p.18-22, 1966.

$\rightarrow$ TAYLOR, J.H.; GILL, W.R. Soil compaction: state-of-the-art report. Journal of Terramechanics, v.21, p.195-213, 1984. 
TOGNON, A.A. Propriedades fisico-hídricas do Latossolo Roxo da região de Guaira-SP sob diferentes sistemas de cultivo. Piracicaba , 1991. 85p. Dissertação (Mestrado) Escola Superior de Agricultura "Luiz de Queiroz", Universidade de São Paulo.

TORMENA, C. A. ; ROLOFF, G. Dinâmica da resistência à penetração de um solo sob plantio direto. Revista Brasileira de Ciência do Solo, v.20, p.333-339, 1996.

TORMENA, C.A.; ROLOFF, G.; SÁ, J.C.M. Propriedades fisicas do solo sob plantio direto influenciadas por calagem, preparo inicial e tráfego. Revista Brasileira de Ciência do Solo, v.22, p.301-309, 1998a.

TORMENA, C. A., SILVA, A.P. da ; LIBARDI, P.L. Caracterização do intervalo hídrico ótimo de um latossolo roxo sob plantio direto. In: REUNIÃO BRASILEIRA DE MANEJO E CONSERVAÇÃO DO SOLO E DA ÁGUA, 12., Fortaleza, 1998. Resumos expandidos. Fortaleza: SBCS;UFCE, 1998b. p.179-180.

TROJAN, M.D.; LINDEN, D.R. Microrelief and rainfall effects on water and solute movement in earthworm burrows. Soil Science Society of America Journal, v.56, p.727-733, 1992.

VAN GENUCHTEN, M.TH. A Closed-Form equation for predicting the hydraulic conductivity of unsaturated soils. Soil Science Society of America Journal. v.44, p.892-897, 1980.

VARGAS, M. Introdução à mecânica dos solos. São Paulo: McGraw-Hill, 1978. 508 .

VEIHMEYER, V.J.; HENDRICKSON, A.H. Methods of measuring field capacity and wilting percentage of soils. Soil Science, v.68, p.75-94, 1949.

VIEIRA, M.J. Comportamento fisico do solo em plantio direto. In: FANCELLI, A.L.; TORRADO, P.V.; MACHADO, J. Atualização em plantio direto. Campinas: Fundação Cargill, 1985. p. 163-179. 
VIEIRA, S.R.; NIELSEN, D.R.; BIGGAR, J.W. Spatial Variability of Field-Measured Infiltration Rate. Soil Science Society of America Journal,. v. 45, p.1040-1048, 1981.

WARRICK, A.W. ; NIELSEN, D.R. Spatial variability of soil physical properties in the field. In: HILLEL, D. (Ed.) Application of soil physics. New York: Academic Press, 1980. p. 319-344.

WEAICH, K.; BRISTOW, K.L.; CASS, A. Preemergent shoot growth of maize under different drying conditions. Soil Science Society of America Journal, v.56, p. 1272-1278, 1992.

WOORHEES, W.B. ; LINDSTROM, M.J. Soil compaction on conservation tillage in the northern corn belt. Journal of Soil and Water Conservation, v. 38, p.307-311, 1983.

WÜNSCHE, W. ; DENARDIN, J.E. Conservação e manejo dos solos. Passo Fundo: EMBRAPA, CNPTrigo, 1980. 20p. (Circular Técnica, 2).

ZANETTE, A.; SILVA,V.R.; REINERT, D.J.; REICHERT, J.M.; RUBIM, R.B.; SOUTO, J. Pressão crítica de pré-adensamento e índice de compressão em função do grau de saturação. In: REUNIÃO BRASILEIRA DE MANEJO E CONSERVA ÇÃO DO SOLO E DA ÁGUA, 12, Fortaleza, 1998. Anais. Fortaleza: SBCS; UFCE, 1998. p.250-251. 


\section{APÊNDICE 1}

Resultados da análise granulométrica do solo 
Apêndice 1.1 - Argila do solo dispersa em água para os três manejos em profundidade(média de 3 repetições)

\begin{tabular}{|c|c|c|c|c|c|c|c|c|c|}
\hline Prof(m) & & Mata & & & Sequeir & & & rrigado & \\
\hline & & & & & $\left(g g^{-1}\right)$ & & & & \\
\hline 0,01 & $\bar{A}$ & 0,323 & a & $\mathrm{C}$ & 0,048 & $a b$ & B & 0,191 & b \\
\hline 0,03 & A & 0,342 & $\mathbf{a}$ & $\mathrm{C}$ & 0,088 & $\mathbf{a}$ & B & 0,218 & b \\
\hline 0,05 & A & 0,366 & $\mathbf{a}$ & $\mathrm{C}$ & 0,095 & $\mathbf{a}$ & B & 0,260 & $\mathbf{a}$ \\
\hline 0,1 & A & 0,325 & $\mathbf{a}$ & $\mathrm{C}$ & 0,068 & $a b$ & B & 0,219 & b \\
\hline 0,2 & A & 0,105 & b & A & 0,013 & b & A & 0,037 & c \\
\hline 0,3 & A & 0,074 & b & B & 0,006 & b & B & 0,013 & c \\
\hline 0,4 & A & 0,020 & b & A & 0,006 & b & A & 0,013 & c \\
\hline 0,5 & A & 0,020 & b & A & 0,013 & b & A & 0,013 & c \\
\hline 0,6 & A & 0,021 & b & A & 0,007 & b & A & 0,010 & c \\
\hline 0,7 & A & 0,029 & b & B & 0,000 & b & B & 0,013 & c \\
\hline 0,8 & A & 0,022 & b & $\mathrm{A}$ & 0,020 & b & $\mathrm{A}$ & 0,010 & c \\
\hline 0,9 & A & 0,021 & b & A & 0,034 & $a b$ & A & 0,010 & c \\
\hline 1,0 & $\mathrm{~A}$ & 0,056 & b & $\mathrm{A}$ & 0,041 & $a b$ & $\mathrm{~A}$ & 0,010 & c \\
\hline Média & $\bar{A}$ & 0,133 & & $\mathrm{C}$ & 0,034 & & B & 0,078 & \\
\hline$C V(\%)$ trat. & & 33,61 & & & 103,10 & & & 23,91 & \\
\hline$C V(\%)$ geral & & 42,58 & & & & & & & \\
\hline
\end{tabular}

Médias seguidas pelas mesmas letras minúsculas, nas colunas, e antecedidas pelas mesmas letras maiúsculas, nas linhas não diferem significativamente entre si, ao nível de $5 \%$, pelo teste de Duncan.

Apêndice 1.2 - Fração areia do solo para os três manejos de solo em profundidade(média de 3 repetições)

\begin{tabular}{|c|c|c|c|c|c|c|c|c|c|}
\hline \multirow[t]{2}{*}{$\operatorname{Prof}(m)$} & \multicolumn{3}{|c|}{ Mata } & \multicolumn{3}{|c|}{ Sequeiro } & \multicolumn{3}{|c|}{ Irrigado } \\
\hline & & & & & $\left(g g^{-1}\right)$ & & & & \\
\hline 0,01 & $\mathrm{C}$ & 0,219 & $a b c$ & B & 0,319 & $a b c$ & A & 0,417 & a \\
\hline 0,03 & $\mathrm{C}$ & 0,231 & $a b$ & B & 0,344 & $\mathbf{a}$ & A & 0,415 & $\mathbf{a}$ \\
\hline 0,05 & B & 0,228 & $a b$ & A & 0,315 & abc & A & 0,363 & abc \\
\hline 0,1 & $\mathrm{C}$ & 0,242 & $\mathbf{a}$ & B & 0,324 & $a b$ & A & 0,376 & $a b$ \\
\hline 0,2 & B & 0,218 & $a b c$ & $\mathrm{~A}$ & 0,303 & abcd & A & 0,346 & bcd \\
\hline 0,3 & A & 0,243 & $\mathbf{a}$ & A & 0,283 & bcde & A & 0,282 & ef \\
\hline 0,4 & B & 0,206 & $a b c$ & $\mathrm{AB}$ & 0,247 & ef & A & 0,296 & def \\
\hline 0,5 & $\mathrm{C}$ & 0,191 & abc & B & 0,273 & cdef & A & 0,315 & cdef \\
\hline 0,6 & A & 0,217 & $a b c$ & A & 0,244 & ef & A & 0,297 & def \\
\hline 0,7 & B & 0,171 & bc & A & 0,256 & def & A & 0,277 & ef \\
\hline 0,8 & B & 0,168 & bc & A & 0,298 & abcd & A & 0,253 & $\mathrm{f}$ \\
\hline 0,9 & $\mathrm{C}$ & 0,166 & bc & B & 0,226 & f & A & 0,333 & bcde \\
\hline 1,0 & B & 0,160 & c & A & 0,292 & bcde & $\mathrm{A}$ & 0,292 & def \\
\hline Média & $\mathrm{C}$ & 0,205 & & $\mathrm{~B}$ & 0,287 & & $\mathrm{~A}$ & 0,328 & \\
\hline$C V(\%)$ trat & & 16,12 & & & 9,11 & & & 9,960 & \\
\hline $\mathrm{CV}(\%)$ gera & & 11,80 & & & & & & & \\
\hline
\end{tabular}

Médias seguidas pelas mesmas letras minúsculas, nas colunas, e antecedidas pelas mesmas letras maiúsculas, nas linhas não diferem significativamente entre si, ao nível de $5 \%$, pelo teste de Duncan. 
Apêndice 1.3 - Fração argila do solo para os três manejos de solo em profundidade (média de 3 repetições)

\begin{tabular}{|c|c|c|c|c|c|c|c|c|c|}
\hline Prof(m) & \multicolumn{3}{|c|}{ Mata } & \multicolumn{3}{|c|}{ Sequeiro } & \multicolumn{3}{|c|}{ Irrigado } \\
\hline & & & & & $\left(g g^{-1}\right)$ & & & & \\
\hline 0,01 & $\mathrm{~A}$ & 0,685 & $\mathrm{~cd}$ & B & 0,566 & de & $\mathrm{C}$ & 0,459 & $\mathrm{e}$ \\
\hline 0,03 & A & 0,682 & cd & B & 0,540 & $\mathrm{e}$ & $\mathrm{C}$ & 0,474 & de \\
\hline 0,05 & A & 0,704 & abcd & B & 0,574 & de & $\mathrm{C}$ & 0,517 & d \\
\hline 0,1 & A & 0,663 & d & B & 0,572 & de & $\mathrm{C}$ & 0,491 & de \\
\hline 0,2 & A & 0,717 & abcd & B & 0,599 & cd & B & 0,563 & c \\
\hline 0,3 & A & 0,698 & bcd & B & 0,640 & bc & B & 0,619 & $a b$ \\
\hline 0,4 & A & 0,727 & $a b c$ & B & 0,668 & $a b$ & B & 0,620 & $a b$ \\
\hline 0,5 & A & 0,736 & $a b c$ & B & 0,658 & $a b$ & $\mathrm{C}$ & 0,615 & b \\
\hline 0,6 & A & 0,723 & abcd & $\mathrm{AB}$ & 0,686 & $a b$ & B & 0,612 & b \\
\hline 0,7 & A & 0,760 & $a b$ & B & 0,666 & $a b$ & B & 0,646 & $a b$ \\
\hline 0,8 & A & 0,763 & $\mathbf{a}$ & B & 0,650 & $a b$ & B & 0,662 & $\mathbf{a}$ \\
\hline 0,9 & A & 0,757 & $a b$ & B & 0,696 & $\mathbf{a}$ & $\mathrm{C}$ & 0,611 & b \\
\hline 1,0 & A & 0,753 & $a b$ & B & 0,639 & bc & B & 0,638 & $a b$ \\
\hline Média & $\mathrm{A}$ & 0,721 & & B & 0,627 & & $\mathrm{C}$ & 0,579 & \\
\hline$C V(\%)$ trat. & & 4,48 & & & 4,34 & & & 4,30 & \\
\hline CV(\%) geral & & 4,25 & & & & & & & \\
\hline
\end{tabular}

Médias seguidas pelas mesmas letras minúsculas, nas colunas, e antecedidas pelas mesmas letras maiúsculas, nas linhas não diferem significativamente entre si, ao nível de 5\%, pelo teste de Duncan.

Apêndice 1.4 - Fração silte do solo para os três manejos de solo em profundidade(média de 3 repetições

\begin{tabular}{|c|c|c|c|c|c|c|c|c|c|}
\hline \multirow[t]{2}{*}{$\operatorname{Prof}(m)$} & \multicolumn{3}{|c|}{ Mata } & \multicolumn{3}{|c|}{ Sequeiro } & \multicolumn{3}{|c|}{ Irrigado } \\
\hline & & & & & $\left(g g^{-1}\right)$ & & & & \\
\hline 0,01 & A & 0,094 & a & $\mathrm{A}$ & 0,113 & a & A & 0,123 & $a b$ \\
\hline 0,03 & B & 0,086 & $a b$ & $\mathrm{AB}$ & 0,114 & $\mathbf{a}$ & A & 0,110 & $a b c$ \\
\hline 0,05 & B & 0,066 & $a b$ & A & 0,110 & $\mathrm{ab}$ & A & 0,119 & $a b$ \\
\hline 0,1 & A & 0,093 & $\mathbf{a}$ & A & 0,103 & abc & A & 0,131 & $\mathbf{a}$ \\
\hline 0,2 & A & 0,063 & $a b$ & A & 0,097 & $a b c$ & A & 0,089 & bcde \\
\hline 0,3 & A & 0,058 & b & A & 0,076 & bcd & A & 0,098 & abcd \\
\hline 0,4 & A & 0,065 & $a b$ & A & 0,083 & abcd & A & 0,084 & bcde \\
\hline 0,5 & A & 0,072 & $a b$ & A & 0,068 & cd & A & 0,069 & cde \\
\hline 0,6 & B & 0,058 & b & $\mathrm{AB}$ & 0,069 & cd & A & 0,090 & bcde \\
\hline 0,7 & $\mathrm{AB}$ & 0,068 & $a b$ & A & 0,076 & bcd & A & 0,076 & cde \\
\hline 0,8 & $\mathrm{AB}$ & 0,068 & $a b$ & B & 0,051 & d & A & 0,084 & bcde \\
\hline 0,9 & A & 0,076 & $a b$ & A & 0,077 & bcd & A & 0,055 & e \\
\hline 1,0 & A & 0,086 & $a b$ & A & 0,068 & cd & A & 0,068 & de \\
\hline Média & $\mathrm{B}$ & 0,073 & & $\mathrm{~A}$ & 0,085 & & A & 0,092 & \\
\hline$C V(\%)$ trat & & 21,60 & & & 22,29 & & & 23,09 & \\
\hline$C V(\%)$ ger & & 20,69 & & & & & & & \\
\hline
\end{tabular}

$\overline{\text { Médias seguidas pelas mesmas letras minúsculas, nas colunas, e antecedidas pelas mesmas letras }}$ maiúsculas, nas linhas não diferem significativamente entre si, ao nível de $5 \%$, pelo teste de Duncan. 
Apêndice 1.5 - Fração da areia muito grossa e grossa da areia total do solo para os três manejos de solo em profundidade (média de 3 repetições)

\begin{tabular}{|c|c|c|c|c|c|c|c|c|c|}
\hline \multirow{3}{*}{$\begin{array}{c}\text { Prof }(m) \\
0,01\end{array}$} & \multicolumn{3}{|c|}{ Mata } & \multicolumn{3}{|c|}{ Sequeiro } & \multicolumn{3}{|c|}{ Irrigado } \\
\hline & \multicolumn{9}{|c|}{$\left(g g^{-1}\right)$} \\
\hline & $A B$ & 0,088 & $\mathrm{a}$ & $A$ & 0,076 & $\bar{b}$ & $A$ & 0,099 & $a b c$ \\
\hline 0,03 & A & 0,081 & $a b$ & A & 0,081 & $a b$ & A & 0,083 & abc \\
\hline 0,05 & A & 0,068 & abc & A & 0,079 & $a b$ & A & 0,073 & bc \\
\hline 0,1 & A & 0,069 & $a b c$ & A & 0,074 & b & A & 0,068 & c \\
\hline 0,2 & B & 0,054 & c & A & 0,081 & $a b$ & A & 0,086 & $a b c$ \\
\hline 0,3 & A & 0,077 & $a b c$ & A & 0,097 & $a b$ & A & 0,082 & abc \\
\hline 0,4 & B & 0,060 & bc & A & 0,091 & $a b$ & A & 0,088 & $a b c$ \\
\hline 0,5 & B & 0,071 & $a b c$ & $\mathrm{AB}$ & 0,093 & $a b$ & A & 0,112 & a \\
\hline 0,6 & A & 0,075 & abc & A & 0,104 & $a b$ & A & 0,104 & abc \\
\hline 0,7 & B & 0,057 & bc & A & 0,095 & $a b$ & A & 0,096 & abc \\
\hline 0,8 & B & 0,068 & abc & A & 0,095 & $a b$ & A & 0,090 & abc \\
\hline 0,9 & A & 0,068 & $a b c$ & A & 0,107 & $\mathbf{a}$ & A & 0,108 & $a b$ \\
\hline 1,0 & A & 0,064 & abc & A & 0,104 & $a b$ & A & 0,112 & $\mathbf{a}$ \\
\hline Média & $\mathrm{B}$ & 0,069 & & $\mathrm{~A}$ & 0,091 & & $\mathrm{~A}$ & 0,092 & \\
\hline$C V(\%)$ trat & & 17,38 & & & 16,99 & & & 20,36 & \\
\hline$C V(\%)$ gera & & 16,46 & & & & & & & \\
\hline
\end{tabular}

Médias seguidas pelas mesmas letras minúsculas, nas colunas, e antecedidas pelas mesmas letras maiúsculas, nas linhas não diferem significativamente entre si, ao nível de 5\%, pelo teste de Duncan.

Apêndice 1.6 - Fração da areia média da areia total do solo para os três manejos de solo em profundidade (média de 3 repetições)

\begin{tabular}{|c|c|c|c|c|c|c|c|c|c|}
\hline Prof(m) & \multicolumn{3}{|c|}{ Mata } & \multicolumn{3}{|c|}{ Sequeiro } & \multicolumn{3}{|c|}{ Irrigado } \\
\hline & & & & & $\left(g g^{-1}\right)$ & & & & \\
\hline 0,01 & B & 0,273 & $\mathbf{a}$ & A & 0,451 & a & $A B$ & 0,379 & $a b$ \\
\hline 0,03 & A & 0,291 & a & A & 0,442 & a & A & 0,475 & $a b$ \\
\hline 0,05 & B & 0,268 & $a b$ & A & 0,434 & $\mathbf{a}$ & $\mathrm{AB}$ & 0,357 & $a b$ \\
\hline 0,1 & B & 0,252 & abc & A & 0,404 & a & A & 0,398 & $a b$ \\
\hline 0,2 & A & 0,246 & abc & A & 0,379 & a & A & 0,468 & $a b$ \\
\hline 0,3 & B & 0,254 & abc & A & 0,389 & a & $\mathrm{AB}$ & 0,340 & $a b$ \\
\hline 0,4 & B & 0,224 & bcd & A & 0,352 & a & A & 0,407 & $a b$ \\
\hline 0,5 & B & 0,246 & $a b c$ & A & 0,393 & a & B & 0,291 & b \\
\hline 0,6 & B & 0,220 & cd & AB & 0,346 & a & A & 0,432 & $a b$ \\
\hline 0,7 & B & 0,217 & cd & $\mathrm{AB}$ & 0,328 & a & A & 0,571 & $\mathbf{a}$ \\
\hline 0,8 & B & 0,198 & d & $\mathrm{AB}$ & 0,303 & a & A & 0,427 & $a b$ \\
\hline 0,9 & A & 0,196 & d & A & 0,426 & a & A & 0,360 & $a b$ \\
\hline 1,0 & B & 0,188 & $d$ & A & 0,364 & $\mathbf{a}$ & $\mathrm{AB}$ & 0,331 & $\mathrm{ab}$ \\
\hline Média & $\mathrm{B}$ & 0,236 & & A & 0,385 & & $\mathrm{~A}$ & 0,403 & \\
\hline$C V(\%)$ trat & & 10,36 & & & 22,71 & & & 31,61 & \\
\hline$C V(\%)$ geral & & 26,02 & & & & & & & \\
\hline
\end{tabular}

Médias seguidas pelas mesmas letras minúsculas, nas colunas, e antecedidas pelas mesmas letras maiúsculas, nas linhas não diferem significativamente entre si, ao nível de $5 \%$, pelo teste de Duncan. 
Apêndice 1.7 - Fração da areia fina da areia total do solo para os três manejos de solo em profundidade (média de 3 repetições)

\begin{tabular}{|c|c|c|c|c|c|c|c|c|c|}
\hline \multirow{3}{*}{$\begin{array}{c}\text { Prof.(m) } \\
0,01\end{array}$} & \multicolumn{3}{|c|}{ Mata } & \multicolumn{3}{|c|}{ Sequeiro } & \multicolumn{3}{|c|}{ Irrigado } \\
\hline & \multicolumn{9}{|c|}{$\left(\mathrm{g} \mathrm{g}^{-1}\right)$} \\
\hline & A & 0,514 & $\mathrm{e}$ & B & 0,391 & a & $\mathrm{AB}$ & 0,433 & a \\
\hline 0,03 & A & 0,510 & e & A & 0,385 & a & A & 0,355 & $\mathbf{a}$ \\
\hline 0,05 & A & 0,528 & cde & B & 0,399 & a & $\mathrm{AB}$ & 0,447 & a \\
\hline 0,1 & A & 0,549 & abcd & B & 0,418 & $\mathbf{a}$ & $\mathrm{AB}$ & 0,444 & a \\
\hline 0,2 & A & 0,561 & $a b$ & $\mathrm{AB}$ & 0,436 & a & B & 0,376 & a \\
\hline 0,3 & A & 0,525 & de & B & 0,411 & a & $\mathrm{AB}$ & 0,455 & a \\
\hline 0,4 & A & 0,564 & $\mathbf{a}$ & B & 0,442 & $\mathbf{a}$ & B & 0,409 & $\mathbf{a}$ \\
\hline 0,5 & A & 0,541 & abcd & B & 0,415 & a & B & 0,458 & $\mathbf{a}$ \\
\hline 0,6 & A & 0,535 & bcde & $\mathrm{AB}$ & 0,435 & a & B & 0,381 & a \\
\hline 0,7 & A & 0,550 & abcd & $\mathrm{AB}$ & 0,444 & $\mathbf{a}$ & B & 0,267 & $\mathbf{a}$ \\
\hline 0,8 & A & 0,556 & $a b c$ & A & 0,452 & a & A & 0,381 & $\mathbf{a}$ \\
\hline 0,9 & A & 0,544 & abcd & A & 0,366 & a & A & 0,416 & a \\
\hline 1,0 & A & 0,543 & abcd & B & 0,427 & a & B & 0,409 & $\mathrm{a}$ \\
\hline Média & $\mathrm{A}$ & 0,540 & & $\mathrm{~B}$ & 0,417 & & $\mathrm{~B}$ & 0,403 & \\
\hline$C V(\%)$ trat. & & 2,71 & & & 16,12 & & & 26,15 & \\
\hline$C V(\%)$ gera & & 15,74 & & & & & & & \\
\hline
\end{tabular}

Médias seguidas pelas mesmas letras minúsculas, nas colunas, e antecedidas pelas mesmas letras maiúsculas, nas linhas não diferem significativamente entre si, ao nível de $5 \%$, pelo teste de Duncan.

Apêndice 1.8 - Fração da areia muito fina da areia total do solo para os três manejos de solo em profundidade(média de 3 repetições)

\begin{tabular}{|c|c|c|c|c|c|c|c|c|c|}
\hline \multirow[t]{2}{*}{ Prof. (m) } & \multicolumn{3}{|c|}{ Mata } & \multicolumn{3}{|c|}{ Sequeiro } & \multicolumn{3}{|c|}{ Irrigado } \\
\hline & & & & & $\left(g g^{-1}\right.$ & & & & \\
\hline 0,01 & A & 0,124 & ef & B & 0,080 & b & B & 0,088 & $\mathrm{abc}$ \\
\hline 0,03 & A & 0,116 & f & A & 0,089 & b & A & 0,085 & abc \\
\hline 0,05 & A & 0,134 & ef & A & 0,085 & b & A & 0,121 & $a b c$ \\
\hline 0,1 & A & 0,129 & $f$ & $\mathrm{AB}$ & 0,103 & $a b$ & B & 0,087 & abc \\
\hline 0,2 & A & 0,137 & ef & $\mathrm{AB}$ & 0,102 & $a b$ & B & 0,067 & c \\
\hline 0,3 & A & 0,142 & def & A & 0,101 & $a b$ & A & 0,121 & $a b c$ \\
\hline 0,4 & A & 0,151 & def & $\mathrm{AB}$ & 0,113 & $a b$ & B & 0,093 & $a b c$ \\
\hline 0,5 & A & 0,140 & cde & B & 0,097 & $a b$ & A & 0,137 & $a b$ \\
\hline 0,6 & A & 0,168 & bcd & $\mathrm{AB}$ & 0,113 & $a b$ & B & 0,082 & bc \\
\hline 0,7 & A & 0,174 & $a b c$ & $\mathrm{AB}$ & 0,131 & $a b$ & B & 0,064 & c \\
\hline 0,8 & A & 0,178 & abc & $\mathbf{A}$ & 0,148 & $\mathbf{a}$ & B & 0,100 & abc \\
\hline 0,9 & A & 0,190 & $a b$ & B & 0,099 & $a b$ & $\mathrm{AB}$ & 0,115 & abc \\
\hline 1,0 & A & 0,203 & $\mathbf{a}$ & $\mathrm{C}$ & 0,103 & $a b$ & B & 0,147 & $\mathbf{a}$ \\
\hline Média & $\mathrm{A}$ & 0,153 & & $\mathrm{~B}$ & 0,105 & & $\mathrm{~B}$ & 0,100 & \\
\hline$C V(\%)$ trat. & & 10,91 & & & 26,64 & & & 32,13 & \\
\hline$C V(\%)$ gera & & 21,85 & & & & & & & \\
\hline
\end{tabular}

Médias seguidas pelas mesmas letras minúsculas, nas colunas, e antecedidas pelas mesmas letras maiúsculas, nas linhas não diferem significativamente entre si, ao nível de 5\%, pelo teste de Duncan. 


\section{APÊNDICE 2}

Resultados da análise dos atributos químicos do solo 
Apêndice 2.1 - Saturação por bases a pH 7, em profundidade para diferentes manejos (média de 3 repetições)

\begin{tabular}{|c|c|c|c|c|c|c|c|c|c|}
\hline \multirow{3}{*}{$\begin{array}{c}\text { Prof. }(m) \\
0,01\end{array}$} & \multicolumn{3}{|c|}{ Mata } & \multirow{2}{*}{\multicolumn{3}{|c|}{$\frac{\text { Sequeiro }}{V \%)}$}} & \multicolumn{3}{|c|}{ Irrigado } \\
\hline & & & & & & & & & \\
\hline & $\mathrm{C}$ & 49,33 & a & B & 63,33 & $\mathrm{a}$ & A & 89,67 & $\mathrm{a}$ \\
\hline 0,03 & $\mathrm{C}$ & 43,33 & $\mathbf{a}$ & B & 68,33 & a & A & 83,67 & $a b$ \\
\hline 0,05 & B & 29,00 & $\mathrm{~b}$ & A & 65,00 & $\mathbf{a}$ & A & 74,00 & $\mathrm{~b}$ \\
\hline 0,1 & B & 20,33 & bc & A & 63,00 & $\mathbf{a}$ & A & 77,00 & b \\
\hline 0,2 & B & 11,33 & cd & A & 49,33 & b & A & 59,33 & c \\
\hline 0,3 & B & 11,33 & cd & A & 41,67 & bc & A & 41,67 & d \\
\hline 0,4 & B & 5,00 & d & A & 33,00 & cde & A & 36,33 & d \\
\hline 0,5 & B & 6,33 & d & A & 41,00 & bcd & A & 44,67 & d \\
\hline 0,6 & B & 8,67 & d & A & 36,67 & bcd & A & 35,67 & d \\
\hline 0,7 & $\mathrm{C}$ & 6,00 & d & A & 40,33 & bcd & A & 43,00 & d \\
\hline 0,8 & $\mathrm{C}$ & 7,67 & d & B & 23,00 & e & A & 43,00 & d \\
\hline 0,9 & B & 7,00 & d & A & 32,67 & de & A & 44,67 & d \\
\hline 1,0 & B & 9,67 & cd & A & 27,67 & cde & A & 39,67 & $\mathrm{~d}$ \\
\hline Média & $\mathrm{C}$ & 16,54 & & $\mathrm{~B}$ & 45,00 & & $\bar{A}$ & 54,79 & \\
\hline$C V(\%)$ trat. & & 37,90 & & & 16,19 & & & 10,58 & \\
\hline$C V(\%)$ gera & & 15,79 & & & & & & & \\
\hline
\end{tabular}

Médias seguidas pelas mesmas letras minúsculas, nas colunas, e antecedidas pelas mesmas letras maiúsculas, nas linhas não diferem significativamente entre si, ao nível de $5 \%$, pelo teste de Duncan

Apêndice 2.2 - Soma de bases em profundidade para diferentes manejos (média de 3 repetições)

\begin{tabular}{|c|c|c|c|c|c|c|c|c|c|}
\hline \multirow{2}{*}{ Prof: (m) } & \multicolumn{3}{|c|}{ Mata } & \multicolumn{3}{|c|}{ Sequeiro } & \multicolumn{3}{|c|}{ Irrigado } \\
\hline & & & & & $\mathrm{mmol}_{c}$ & & & & \\
\hline 0,01 & $\bar{B}$ & $47, \overline{3}$ & a & B & 57,90 & a & A & 204,23 & a \\
\hline 0,03 & B & 34,80 & b & B & 65,77 & a & A & 123.53 & b \\
\hline 0,05 & B & 24,43 & c & A & 61,27 & $\mathbf{a}$ & A & 87.33 & c \\
\hline 0,1 & $\mathrm{C}$ & 14,40 & d & B & 49,37 & $a b$ & A & 79,77 & c \\
\hline 0,2 & B & 7,97 & de & A & 34,97 & bc & A & 46,90 & d \\
\hline 0,3 & B & 6,20 & de & A & 19,73 & cd & A & 22,20 & e \\
\hline 0,4 & B & 2,50 & e & A & 15,90 & cd & A & 19,53 & $\mathrm{e}$ \\
\hline 0,5 & B & 2,77 & e & A & 17,00 & cd & A & 20,87 & e \\
\hline 0,6 & B & 3,73 & e & A & 15,80 & cd & A & 18,53 & e \\
\hline 0,7 & B & 2,33 & e & A & 14,13 & d & A & 17,67 & e \\
\hline 0,8 & $\mathrm{C}$ & 2,70 & e & B & 6,63 & d & $\mathrm{A}$ & 22,00 & e \\
\hline 0,9 & B & 2,40 & e & $\mathrm{AB}$ & 10,93 & d & A & 16,67 & e \\
\hline 1,0 & A & 2,67 & e & B & 8,23 & d & A & 16,53 & e \\
\hline Média & $\mathrm{C}$ & 11,86 & & $\mathrm{~B}$ & 29,04 & & $\mathrm{~A}$ & 53,52 & \\
\hline$C V(\%)$ trat. & & 39,74 & & & 37,14 & & & 22,18 & \\
\hline$C V(\%)$ gera & & 28,71 & & & & & & & \\
\hline
\end{tabular}

Médias seguidas pelas mesmas letras minúsculas, nas colunas, e antecedidas pelas mesmas letras maiúsculas, nas linhas não diferem significativamente entre si, ao nível de $5 \%$, pelo teste de Duncan 
Apêndice $2.3-\mathrm{pH}\left(\mathrm{CaCl}_{2}\right)$, em profundidade para diferentes manejos (média de 3 repetições)

\begin{tabular}{|c|c|c|c|c|c|c|c|c|c|}
\hline \multirow[t]{2}{*}{ Prof: $(m)$} & \multicolumn{3}{|c|}{ Mata } & \multirow{2}{*}{\multicolumn{3}{|c|}{$\begin{array}{l}\text { Sequeiro } \\
\left.(\mathrm{pH} \text { CaCl})_{2}\right)\end{array}$}} & \multicolumn{3}{|c|}{ Irrigado } \\
\hline & & & & & & & & & \\
\hline 0,01 & $\mathrm{C}$ & 4,73 & bcde & B & 5,17 & $\mathrm{~ns}$ & A & 5,87 & abcd \\
\hline 0,03 & C & 4,83 & $a b c$ & B & 5,27 & & A & 5,90 & $a b c$ \\
\hline 0,05 & B & 4,57 & cdefg & A & 5,33 & & A & 5,63 & cde \\
\hline 0,1 & $\mathrm{C}$ & 4,57 & cdefg & B & 5,33 & & A & 6,03 & a \\
\hline 0,2 & $\mathrm{C}$ & 4,40 & fg & B & 5,27 & & A & 5,67 & bcde \\
\hline 0,3 & B & 4,53 & edfg & A & 5,50 & & A & 5,83 & abcde \\
\hline 0,4 & $\mathrm{C}$ & 4,30 & g & B & 5,33 & & A & 5,53 & e \\
\hline 0,5 & $\mathrm{C}$ & 4,47 & efg & B & 5,47 & & A & 5,83 & abcde \\
\hline 0,6 & B & 4,67 & bcdef & A & 5,47 & & A & 5,57 & de \\
\hline 0,7 & B & 4,63 & bcdef & A & 5,60 & & A & 5,87 & abcd \\
\hline 0,8 & B & 4,90 & $\mathrm{ab}$ & A & 5,60 & & A & 5,63 & cde \\
\hline 0,9 & $\mathrm{C}$ & 4,77 & bcd & B & 5,63 & & A & 5,97 & $a b$ \\
\hline 1,0 & B & 5,07 & a & $\mathrm{AB}$ & 5,47 & & A & 5,70 & bcde \\
\hline Média & $\mathrm{C}$ & 4,64 & & B & 5,41 & & $\mathrm{~A}$ & 5,77 & \\
\hline$C V(\%)$ trat. & & 3,28 & & & 4,50 & & & 2,83 & \\
\hline$C V(\%)$ geral & & 3,47 & & & & & & & \\
\hline
\end{tabular}

Médias seguidas pelas mesmas letras minúsculas, nas colunas, e antecedidas pelas mesmas letras maiúsculas, nas linhas não diferem significativamente entre si, ao nível de 5\%, pelo teste de Duncan

Apêndice 2.4 - Teor de $\mathrm{P}$ em profundidade para diferentes manejos (média de 3 repetições)

\begin{tabular}{|c|c|c|c|c|c|c|c|c|c|}
\hline Prof. (m) & & Mata & & & Sequei & & & rrigado & \\
\hline & & & & & nmole a & & & & \\
\hline 0,01 & $\bar{B}$ & 16,67 & a & $\mathrm{B}$ & 26,67 & $a$ & $\mathrm{~A}$ & 59,67 & $a b$ \\
\hline 0,03 & B & 14,67 & $a b$ & B & 20,67 & $\mathbf{a}$ & A & 48,00 & b \\
\hline 0,05 & B & 11,33 & b & B & 22,67 & a & A & 61,33 & $\mathbf{a}$ \\
\hline 0,1 & B & 7,00 & c & B & 21,00 & a & A & 71,00 & a \\
\hline 0,2 & A & 3,00 & d & A & 7,00 & b & A & 9,67 & c \\
\hline 0,3 & A & 4,00 & cd & A & 2,33 & b & A & 3,00 & c \\
\hline 0,4 & A & 3,33 & cd & A & 2,67 & b & A & 2,67 & c \\
\hline 0,5 & A & 3,67 & cd & $\mathrm{AB}$ & 2,67 & b & A & 2,33 & c \\
\hline 0,6 & A & 3,67 & cd & A & 2,67 & b & A & 3,00 & c \\
\hline 0,7 & A & 3,67 & cd & A & 2,33 & b & A & 2,00 & c \\
\hline 0,8 & A & 4,33 & cd & $\mathrm{AB}$ & 3,00 & b & A & 2,00 & c \\
\hline 0,9 & A & 3,00 & d & A & 3,33 & b & A & 2,67 & c \\
\hline 1,0 & A & 3,00 & d & A & 2,67 & b & A & 2,67 & c \\
\hline Média & $\mathrm{C}$ & 6,25 & & B & 9,20 & & $\bar{A}$ & 20,77 & \\
\hline$C V(\%)$ trat. & & 32,47 & & & 44,52 & & & 34,49 & \\
\hline$C V(\%)$ geral & & 41,08 & & & & & & & \\
\hline
\end{tabular}

Médias seguidas pelas mesmas letras minúsculas, nas colunas, e antecedidas pelas mesmas letras maiúsculas, nas linhas não diferem significativamente entre si, ao nível de $5 \%$, pelo teste de Duncan 
Apêndice 2.5 - Teor de K, em profundidade para diferentes manejos (média de 3 repetições)

\begin{tabular}{|c|c|c|c|c|c|c|c|c|c|}
\hline \multirow{2}{*}{ Prof. (m) } & \multirow{2}{*}{\multicolumn{3}{|c|}{ Mata }} & \multirow{2}{*}{\multicolumn{3}{|c|}{$\begin{array}{l}\text { Sequeiro } \\
\left(\text { mmolc } d^{-3}\right)^{-3}\end{array}$}} & \multicolumn{3}{|c|}{ Irrigado } \\
\hline & & & & & & & & & \\
\hline 0,01 & B & 1,00 & $a$ & $\overline{\mathrm{A}}$ & 4,23 & a & A & 4,90 & $\mathrm{a}$ \\
\hline 0,03 & B & 0,80 & $a b$ & $\mathrm{AB}$ & 2,77 & b & A & 5,20 & $a b$ \\
\hline 0,05 & B & 0,77 & $a b c$ & $\mathrm{AB}$ & 2,27 & bc & A & 4,00 & abc \\
\hline 0,1 & $\mathrm{C}$ & 0,73 & abcd & B & 1,70 & cd & A & 3,10 & abcd \\
\hline 0,2 & B & 0,97 & a & $\mathrm{AB}$ & 1,97 & bc & A & 2,90 & bcd \\
\hline 0,3 & B & 0,53 & bcde & A & 1,40 & cde & A & 1,53 & d \\
\hline 0,4 & $\mathrm{C}$ & 0,50 & bcde & B & 0,90 & def & A & 1,53 & d \\
\hline 0,5 & B & 0,43 & bcde & B & 0,67 & def & A & 1,53 & d \\
\hline 0,6 & B & 0,40 & cde & B & 0,47 & ef & $\mathrm{A}$ & 1,87 & cd \\
\hline 0,7 & B & 0,33 & e & B & 0,47 & ef & A & 1,00 & $\mathrm{~d}$ \\
\hline 0,8 & B & 0,37 & de & B & 0,30 & f & A & 1,33 & d \\
\hline 0,9 & B & 0,40 & cde & B & 0,27 & f & A & 1,00 & d \\
\hline 1,0 & B & 0,33 & e & B & 0,23 & $\mathrm{f}$ & $\mathrm{A}$ & 1,87 & cd \\
\hline Média & $\mathrm{C}$ & 0,58 & & $\mathrm{~B}$ & 1,35 & & $\mathrm{~A}$ & 2,44 & \\
\hline$C V(\%)$ trat. & & 34,25 & & & 42,98 & & & 50,35 & \\
\hline$C V(\%)$ gera & & 54,24 & & & & & & & \\
\hline
\end{tabular}

Médias seguidas pelas mesmas letras minúsculas, nas colunas, e antecedidas pelas mesmas letras maiúsculas, nas linhas não diferem significativamente entre si, ao nivel de $5 \%$, pelo teste de Duncan

Apêndice 2.6 - Teor de $\mathrm{Ca}$ em profundidade para diferentes manejos (média de 3 repetições)

\begin{tabular}{|c|c|c|c|c|c|c|c|c|c|}
\hline \multirow[t]{2}{*}{ Prof. (m) } & \multicolumn{3}{|c|}{ Mata } & \multicolumn{3}{|c|}{ Sequeiro } & \multicolumn{3}{|c|}{ Irrigado } \\
\hline & & & & & nmole a & & & & \\
\hline 0,01 & B & 31,00 & a & B & 33,67 & $a b$ & A & 104,00 & $\mathbf{a}$ \\
\hline 0,03 & B & 22,67 & b & B & 42,33 & $\mathbf{a}$ & A & 74,00 & b \\
\hline 0,05 & B & 15,33 & c & A & 40,33 & $\mathbf{a}$ & A & 54,67 & c \\
\hline 0,1 & $\mathrm{C}$ & 8,33 & d & B & 35,33 & $a b$ & A & 54,33 & c \\
\hline 0,2 & B & 3,67 & de & A & 24,33 & bc & A & 31,67 & d \\
\hline 0,3 & B & 3,00 & de & A & 13,33 & cd & A & 15,00 & e \\
\hline 0,4 & B & 1,00 & e & A & 10,67 & d & $\mathrm{A}$ & 12,67 & e \\
\hline 0,5 & B & 1,33 & e & A & 11,33 & d & A & 13,67 & e \\
\hline 0,6 & B & 2,33 & de & A & 11,00 & d & A & 11,67 & e \\
\hline 0,7 & B & 1,00 & e & A & 9,00 & d & A & 11,67 & e \\
\hline 0,8 & $\mathrm{C}$ & 1,00 & e & B & 3,67 & d & A & 14,00 & e \\
\hline 0,9 & B & 1,00 & e & A & 8,00 & d & A & 11,67 & e \\
\hline 1,0 & $\mathrm{C}$ & 1,00 & e & $\mathrm{B}$ & 5,67 & $\mathrm{~d}$ & $\mathrm{~A}$ & 11,00 & e \\
\hline Média & $\mathrm{C}$ & 7,13 & & B & 19,13 & & $\mathrm{~A}$ & 32,30 & \\
\hline$C V(\%)$ trat. & & 51,76 & & & 35,31 & & & 20,47 & \\
\hline$C V(\%)$ gera & & 28,21 & & & & & & & \\
\hline
\end{tabular}

Médias seguidas pelas mesmas letras minúsculas, nas colunas, e antecedidas pelas mesmas letras maiúsculas, nas linhas não diferem significativamente entre si, ao nível de $5 \%$, pelo teste de Duncan 
Apêndice 2.7 - Teor de $\mathrm{Mg}$, em profundidade para diferentes manejos (média de 3 repetições)

\begin{tabular}{|c|c|c|c|c|c|c|c|c|c|}
\hline \multirow{3}{*}{$\begin{array}{c}\text { Prof. }(\boldsymbol{m}) \\
0,01\end{array}$} & \multicolumn{3}{|c|}{ Mata } & \multicolumn{3}{|c|}{ Sequeiro } & \multicolumn{3}{|c|}{ Irrigado } \\
\hline & \multicolumn{9}{|c|}{$\left(\right.$ mmolc $\left.\mathrm{dm}^{-3}\right)$} \\
\hline & $\mathrm{B}$ & $15, \overline{33}$ & a & B & 20,00 & a & A & 95,33 & a \\
\hline 0,03 & B & 11,33 & b & B & 20,67 & $\mathbf{a}$ & A & 44,33 & b \\
\hline 0,05 & B & 8,33 & c & $\mathrm{AB}$ & 18,67 & $\mathbf{a}$ & $\mathrm{A}$ & 28,67 & c \\
\hline 0,1 & B & 5,33 & d & B & 12,33 & $a b$ & A & 22,33 & c \\
\hline 0,2 & B & 3,33 & de & $\mathrm{AB}$ & 8,67 & bc & A & 12,33 & d \\
\hline 0,3 & $\mathrm{~A}$ & 2,67 & e & A & 5,00 & bc & A & 5,67 & d \\
\hline 0,4 & B & 1,00 & e & A & 4,33 & bc & A & 5,33 & d \\
\hline 0,5 & B & 1,00 & e & A & 5,00 & bc & A & 5,67 & d \\
\hline 0,6 & B & 1,00 & e & A & 4,33 & bc & A & 5,00 & d \\
\hline 0,7 & A & 1,00 & e & A & 4,67 & bc & A & 5,00 & d \\
\hline 0,8 & B & 1,33 & e & B & 2,67 & c & $\mathrm{A}$ & 6,67 & d \\
\hline 0,9 & B & 1,00 & e & $\mathrm{AB}$ & 2,67 & c & A & 4,00 & d \\
\hline 1,0 & A & 1,33 & e & A & 2,33 & c & A & 3,67 & d \\
\hline Média & $\mathrm{C}$ & 4,15 & & $\mathrm{~B}$ & 8,56 & & $\mathrm{~A}$ & 18,77 & \\
\hline$C V(\%)$ trat. & & 39,87 & & & 53,93 & & & 31,67 & \\
\hline$C V(\%)$ gera & & 40,07 & & & & & & & \\
\hline
\end{tabular}

Médias seguidas pelas mesmas letras minúsculas, nas colunas, e antecedidas pelas mesmas letras maiúsculas, nas linhas não diferem significativamente entre si, ao nível de 5\%, pelo teste de Duncan

Apêndice 2.8 - Teor de $\mathrm{H}+\mathrm{Al}$ em profundidade para diferentes manejos (média de 3 repetições)

\begin{tabular}{|c|c|c|c|c|c|c|c|c|c|}
\hline \multirow[t]{2}{*}{ Prof. (m) } & \multicolumn{3}{|c|}{ Mata } & \multicolumn{3}{|c|}{ Sequeiro } & \multicolumn{3}{|c|}{ Irrigado } \\
\hline & & & & & molc dm & & & & \\
\hline 0,01 & A & 49,33 & abcde & B & 33,00 & $a b$ & B & 23,00 & $\mathrm{~cd}$ \\
\hline 0,03 & A & 45,67 & bcde & B & 28,00 & bcde & B & 24,00 & cd \\
\hline 0,05 & A & 61,00 & a & B & 32,00 & $a b c$ & B & 30,00 & $a b c$ \\
\hline 0,1 & A & 52,33 & $a b c$ & B & 29,00 & abcd & B & 23,33 & cd \\
\hline 0,2 & $\mathrm{~A}$ & 56,00 & $a b$ & B & 34,33 & $\mathbf{a}$ & B & 31,00 & $a b c$ \\
\hline 0,3 & A & 47,33 & bcde & $\mathrm{AB}$ & 27,00 & cdef & B & 32,33 & $a b$ \\
\hline 0,4 & A & 50,33 & abcd & B & 32,00 & $a b c$ & B & 34,00 & $\mathbf{a}$ \\
\hline 0,5 & A & 42,00 & cdef & B & 24,00 & defg & B & 26,00 & abcd \\
\hline 0,6 & $\mathrm{~A}$ & 39,33 & edf & B & 27,00 & cdef & B & 33,00 & $a b$ \\
\hline 0,7 & A & 38,00 & ef & B & 20,67 & g & B & 23,00 & cd \\
\hline 0,8 & A & 32,00 & fg & B & 22,67 & efg & A & 29,00 & $a b c$ \\
\hline 0,9 & A & 33,00 & fg & B & 21,67 & $\mathrm{fg}$ & B & 20,00 & $\mathrm{~d}$ \\
\hline 1,0 & A & 25,00 & g & A & 22,00 & fg & A & 25,00 & bcd \\
\hline Média & $\mathrm{C}$ & 4,15 & & $\mathrm{~B}$ & 27,20 & & $\mathrm{~B}$ & 27,18 & \\
\hline$C V(\%)$ trat. & & 39,87 & & & 10,91 & & & 15,48 & \\
\hline$C V(\%)$ geral & & 40,07 & & & & & & & \\
\hline
\end{tabular}

Médias seguidas pelas mesmas letras minúsculas, nas colunas, e antecedidas pelas mesmas letras maiúsculas, nas linhas não diferem significativamente entre si, ao nível de $5 \%$, pelo teste de Duncan 
Apêndice 2.9 - CTC a pH 7, em profundidade para diferentes manejos (média de 3 repetições)

\begin{tabular}{|c|c|c|c|c|c|c|c|c|c|}
\hline \multirow[t]{2}{*}{ Prof. (m) } & \multirow{2}{*}{\multicolumn{3}{|c|}{ Mata }} & \multicolumn{3}{|c|}{ Sequeiro } & \multicolumn{3}{|c|}{ Irrigado } \\
\hline & & & & \multicolumn{3}{|c|}{$T\left(\right.$ mmolc $\left.\mathrm{dm}^{-3}\right)$} & & & \\
\hline 0,01 & B & 96,67 & a & B & 90,90 & $\bar{a}$ & $\mathrm{~A}$ & 227,23 & a \\
\hline 0,03 & B & 80,47 & b & B & 93,77 & $\mathbf{a}$ & $\mathrm{A}$ & $147, .23$ & b \\
\hline 0,05 & A & 85,43 & $a b$ & A & 93,27 & $\mathbf{a}$ & A & 117,33 & c \\
\hline 0,1 & B & 66,73 & c & $A B$ & 78,37 & $a b$ & A & 103.10 & c \\
\hline 0,2 & A & 63,97 & c & A & 69,30 & b & A & 77,90 & d \\
\hline 0,3 & A & 53,53 & cd & A & 46,73 & c & A & 54,53 & $\mathrm{e}$ \\
\hline 0,4 & $\mathrm{AB}$ & 52,83 & cd & B & 47,90 & c & A & 53,53 & e \\
\hline 0,5 & A & 44,77 & de & A & 41,00 & c & A & 46,87 & e \\
\hline 0,6 & B & 43,07 & de & B & 42,80 & c & A & 51,53 & $\mathrm{e}$ \\
\hline 0,7 & A & 40,33 & def & A & 37,80 & c & A & 40,67 & e \\
\hline 0,8 & B & 34,70 & ef & B & 29,30 & c & A & 51,00 & e \\
\hline 0,9 & A & 35,40 & ef & A & 32,60 & c & A & 36,67 & $\mathrm{e}$ \\
\hline 1,0 & B & 26,67 & $\mathrm{f}$ & B & 30,23 & c & A & 41,53 & e \\
\hline Média & $\mathrm{B}$ & 55,81 & & $\mathrm{~B}$ & 56,23 & & $\mathrm{~A}$ & 80,75 & \\
\hline$C V(\%)$ trat. & & 13,97 & & & 17,50 & & & 15,34 & \\
\hline$C V(\%)$ gera & & 14,30 & & & & & & & \\
\hline
\end{tabular}

Médias seguidas pelas mesmas letras minúsculas, nas colunas, e antecedidas pelas mesmas letras maiúsculas, nas linhas não diferem significativamente entre si, ao nível de $5 \%$, pelo teste de Duncan 


\section{APÊNDICE 3}

Resultados da análise físico-hídrica do solo 
Apêndice 3.1 - Parâmetros do ajuste dos pontos experimentais da curva de retenção de água no solo com estrutura preservada à equação de Van Genhuchten

\begin{tabular}{|c|c|c|c|c|c|}
\hline Prof (m) & $\alpha(1 / k P a)$ & $\mathbf{m}$ & $n$ & $\theta r\left(m^{3} m^{-3}\right)$ & $\theta s\left(m^{3} m^{-3}\right)$ \\
\hline \multicolumn{6}{|c|}{ Mata } \\
\hline 0,01 & 1,227 & 0,2156 & 3,9946 & 0,280 & 0,660 \\
\hline 0,03 & 0,703 & 0,6330 & 1,8583 & 0,260 & 0,670 \\
\hline 0,05 & 0,443 & 0,8732 & 1,5835 & 0,265 & 0,620 \\
\hline 0,1 & 1,293 & 0,1540 & 5,7771 & 0,269 & 0,650 \\
\hline 0,2 & 1,089 & 0,1162 & 5,5598 & 0,260 & 0,620 \\
\hline 0,3 & 0,961 & 0,1283 & 6,1828 & 0,262 & 0,650 \\
\hline 0,4 & 0,738 & 0,4336 & 1,9140 & 0,263 & 0,615 \\
\hline 0,5 & 0,669 & 0,2357 & 3,2505 & 0,266 & 0,620 \\
\hline 0,6 & 0,535 & 0,3567 & 2,3688 & 0,260 & 0,620 \\
\hline 0,7 & 1,010 & 0,0993 & 5,8519 & 0,258 & 0,630 \\
\hline 0,8 & 0,454 & 0,3788 & 1,9822 & 0,260 & 0,620 \\
\hline 0,9 & 0,490 & 0,2583 & 2,8129 & 0,275 & 0,635 \\
\hline 1,0 & 0,343 & 0,5173 & 1,8144 & 0,270 & 0,625 \\
\hline \multicolumn{6}{|c|}{ Sequeiro } \\
\hline 0,01 & 0,460 & 0,4145 & 1,9718 & 0,232 & 0,642 \\
\hline 0,03 & 0,497 & 0,2311 & 2,7988 & 0,230 & 0,650 \\
\hline 0,05 & 0,475 & 0,3442 & 1,8568 & 0,252 & 0,650 \\
\hline 0,1 & 0,465 & 0,3406 & 1,5495 & 0,260 & 0,560 \\
\hline 0,2 & 0,372 & 0,4690 & 1,4417 & 0,270 & 0,550 \\
\hline 0,3 & 0,592 & 0,3968 & 1,9051 & 0,290 & 0,580 \\
\hline 0,4 & 0,492 & 0,7357 & 1,2414 & 0,277 & 0,610 \\
\hline 0,5 & 0,909 & 0,2402 & 2,8512 & 0,275 & 0,610 \\
\hline 0,6 & 0,342 & 0,7637 & 1,3151 & 0,270 & 0,620 \\
\hline 0,7 & 1,216 & 0,1161 & 4,6973 & 0,252 & 0,620 \\
\hline 0,8 & 0,756 & 0,2263 & 2,8073 & 0,257 & 0,650 \\
\hline 0,9 & 0,720 & 0,3411 & 1,8855 & 0,243 & 0,640 \\
\hline 1,0 & 0,518 & 0,4536 & 1,9253 & 0,265 & 0,630 \\
\hline \multicolumn{6}{|c|}{ Irrigado } \\
\hline 0,01 & 0,566 & 0,2487 & 2,9261 & 0,308 & 0,630 \\
\hline 0,03 & 0,566 & 0,2744 & 3,1066 & 0,317 & 0,545 \\
\hline 0,05 & 0,465 & 0,2428 & 2,5703 & 0,292 & 0,535 \\
\hline 0,1 & 0,089 & 0,7509 & 1,1852 & 0,318 & 0,495 \\
\hline 0,2 & 0,555 & 0,2915 & 1,7564 & 0,300 & 0,530 \\
\hline 0,3 & 0,412 & 0,1733 & 2,6419 & 0,310 & 0,530 \\
\hline 0,4 & 0,390 & 0,2836 & 1,8979 & 0,285 & 0,565 \\
\hline 0,5 & 0,464 & 0,4447 & 1,4030 & 0,268 & 0,590 \\
\hline 0,6 & 0,658 & 0,2598 & 2,0884 & 0,275 & 0,580 \\
\hline 0,7 & 0,605 & 0,2586 & 2,9761 & 0,270 & 0,630 \\
\hline 0,8 & 0,760 & 0,2435 & 2,4346 & 0,269 & 0,630 \\
\hline 0,9 & 0,483 & 0,2446 & 3,1637 & 0,264 & 0,620 \\
\hline 1 & 0,475 & 0,3638 & 2,1869 & 0,278 & 0,630 \\
\hline
\end{tabular}


Apêndice 3.2 - Parâmetros do ajuste dos pontos experimentais da curva de retenção de água no solo com amostras de estrutura alterada à equação de Van Genhuchten

\begin{tabular}{|c|c|c|c|c|c|}
\hline Prof (m) & $\alpha(1 / \mathrm{kPa})$ & $\mathbf{m}$ & $\mathrm{n}$ & $\theta \mathrm{r}\left(\mathrm{m}^{3} \mathrm{~m}^{-3}\right)$ & $\theta \mathrm{s}\left(\mathrm{m}^{3} \mathrm{~m}^{-3}\right)$ \\
\hline \multicolumn{6}{|c|}{ Mata } \\
\hline 0,01 & 0,513 & 0,0756 & 18,7331 & 0,245 & 0,608 \\
\hline 0,03 & 0,713 & 0,1176 & 8,4109 & 0,237 & 0,660 \\
\hline 0,05 & 0,560 & 0,1353 & 8,9462 & 0,240 & 0,632 \\
\hline 0,1 & 0,535 & 0,0868 & 18,4371 & 0,256 & 0,611 \\
\hline 0,2 & 0,495 & 0,0779 & 20,7801 & 0,252 & 0,619 \\
\hline 0,3 & 0,566 & 0,1030 & 14,4139 & 0,248 & 0,665 \\
\hline 0,4 & 0,550 & 0,0777 & 15,0967 & 0,242 & 0,644 \\
\hline 0,5 & 0,473 & 0,4956 & 2,6481 & 0,250 & 0,635 \\
\hline 0,6 & 0,568 & 0,2033 & 4,6473 & 0,252 & 0,686 \\
\hline 0,7 & 0,481 & 0,3267 & 3,1378 & 0,251 & 0,660 \\
\hline 0,8 & 0,527 & 0,2011 & 4,0952 & 0,236 & 0,672 \\
\hline 0,9 & 0,406 & 0,3989 & 2,7259 & 0,251 & 0,665 \\
\hline 1,0 & 0,392 & 0,4692 & 2,2603 & 0,253 & 0,684 \\
\hline \multicolumn{6}{|c|}{ Sequeiro } \\
\hline 0,01 & 0,506 & 0,1210 & 4,3918 & 0,225 & 0,635 \\
\hline 0,03 & 0,492 & 0,1390 & 3,9562 & 0,217 & 0,633 \\
\hline 0,05 & 0,546 & 0,0655 & 8,3318 & 0,233 & 0,626 \\
\hline 0,1 & 0,616 & 0,0395 & 12,968 & 0,215 & 0,632 \\
\hline 0,2 & 0,537 & 0,2256 & 3,4071 & 0,229 & 0,593 \\
\hline 0,3 & 0,542 & 0,1320 & 6,7525 & 0,227 & 0,638 \\
\hline 0,4 & 0,541 & 0,1728 & 5,2799 & 0,227 & 0,644 \\
\hline 0,5 & 0,475 & 0,3052 & 3,0540 & 0,234 & 0,654 \\
\hline 0,6 & 0,329 & 0,6988 & 1,5513 & 0,241 & 0,666 \\
\hline 0,7 & 0,464 & 0,3360 & 2,7853 & 0,239 & 0,665 \\
\hline 0,8 & 0,460 & 0,3145 & 3,2386 & 0,239 & 0,667 \\
\hline 0,9 & 0,425 & 0,3743 & 2,7281 & 0,235 & 0,661 \\
\hline 1,0 & 0,475 & 0,3290 & 3,0965 & 0,247 & 0,689 \\
\hline \multicolumn{6}{|c|}{ Irrigado } \\
\hline 0,01 & 0,441 & 0,2867 & 3,0494 & 0,242 & 0,648 \\
\hline 0,03 & 0,383 & 0,5326 & 2,1136 & 0,233 & 0,606 \\
\hline 0,05 & 1,297 & 0,5050 & 13,6982 & 0,239 & 0,641 \\
\hline 0,1 & 0,211 & 1,1129 & 1,6432 & 0,238 & 0,625 \\
\hline 0,2 & 0,323 & 0,6053 & 1,9628 & 0,238 & 0,662 \\
\hline 0,3 & 0,454 & 0,3612 & 2,7396 & 0,228 & 0,677 \\
\hline 0,4 & 0.253 & 0,9538 & 1,5691 & 0,245 & 0,726 \\
\hline 0,5 & 1.092 & 0,0374 & 17,7792 & 0,233 & 0,682 \\
\hline 0,6 & 1.044 & 0,1496 & 4,6558 & 0,223 & 0,666 \\
\hline 0,7 & 0.573 & 0,4837 & 1,9832 & 0,241 & 0,701 \\
\hline 0,8 & 1.043 & 0.0683 & 8.9533 & 0.233 & 0.689 \\
\hline 0,9 & 0,618 & 0,5807 & 1,5727 & 0,235 & 0,716 \\
\hline 1 & 0,943 & 0,1232 & 5,3800 & 0,233 & 0,697 \\
\hline
\end{tabular}


Apêndice 3.3 - Umidade do solo nos diferentes tempos após a drenagem, para diferentes sistemas de manejo e profundidades

\begin{tabular}{|c|c|c|c|c|c|c|c|c|c|c|}
\hline \multirow{2}{*}{$\begin{array}{c}\text { Mata } \\
\text { (h) }\end{array}$} & \multicolumn{10}{|c|}{$\theta\left(m^{3} m^{-3}\right)$} \\
\hline & 0,1 & 0,2 & 0,3 & 0,4 & 0,5 & 0,6 & 0,7 & 0,8 & 0,9 & 1 \\
\hline$\theta$ & 0,650 & 0,620 & 0,650 & 0,615 & 0,620 & 0,620 & 0,630 & 0,620 & 0,635 & 0,625 \\
\hline 12 & 0,360 & 0,391 & 0,384 & 0,388 & 0,420 & 0,418 & 0,400 & 0,444 & 0,454 & 0,456 \\
\hline 24 & 0,342 & 0,375 & 0,366 & 0,371 & 0,397 & 0,391 & 0,383 & 0,415 & 0,430 & 0,425 \\
\hline 36 & 0,334 & 0,369 & 0,359 & 0,363 & 0,385 & 0,380 & 0,377 & 0,404 & 0,423 & 0,412 \\
\hline 48 & 0,328 & 0,363 & 0,351 & 0,356 & 0,374 & 0,368 & 0,370 & 0,394 & 0,412 & 0,399 \\
\hline 60 & 0,326 & 0,358 & 0,347 & 0,351 & 0,369 & 0,363 & 0,365 & 0,388 & 0,406 & 0,393 \\
\hline 72 & 0,322 & 0,355 & 0,343 & 0,348 & 0,364 & 0,358 & 0,362 & 0,383 & 0,400 & 0,387 \\
\hline 84 & 0,321 & 0,353 & 0,341 & 0,346 & 0,362 & 0,356 & 0,360 & 0,381 & 0,398 & 0,384 \\
\hline 96 & 0,318 & 0,350 & 0,339 & 0,342 & 0,358 & 0,352 & 0,357 & 0,378 & 0,394 & 0,380 \\
\hline 144 & 0,313 & 0,344 & 0,332 & 0,333 & 0,350 & 0,343 & 0,351 & 0,369 & 0,381 & 0,370 \\
\hline 192 & 0,309 & 0,338 & 0,326 & 0,327 & 0,344 & 0,336 & 0,346 & 0,361 & 0,374 & 0,360 \\
\hline 240 & 0,306 & 0,334 & 0,322 & 0,322 & 0,339 & 0,331 & 0,342 & 0,356 & 0,368 & 0,355 \\
\hline 360 & 0,301 & 0,326 & 0,315 & 0,317 & 0,332 & 0,324 & 0,337 & 0,348 & 0,363 & 0,349 \\
\hline 480 & 0,298 & 0,322 & 0,310 & 0,312 & 0,327 & 0,321 & 0,335 & 0,342 & 0,357 & 0,342 \\
\hline 720 & 0,292 & 0,312 & 0,301 & 0,304 & 0,320 & 0,310 & 0,326 & 0,331 & 0,347 & 0,331 \\
\hline PMP & 0,269 & 0,263 & 0,263 & 0,264 & 0.268 & 0,261 & 0,263 & 0,263 & 0,278 & 0,271 \\
\hline Sequeiro & \multicolumn{10}{|c|}{$\theta\left(m^{3} m^{3}\right)$} \\
\hline (h) & 0,1 & 0,2 & 0,3 & 0,4 & 0,5 & 0,6 & 0,7 & 0,8 & 0,9 & 1 \\
\hline As & 0,560 & 0,550 & 0,580 & 0,610 & 0,610 & 0,620 & 0,620 & 0,650 & 0,640 & 0,630 \\
\hline 12 & 0,413 & 0,405 & 0,391 & 0,377 & 0,377 & 0,403 & 0,380 & 0,415 & 0,401 & 0,404 \\
\hline 24 & 0,400 & 0,393 & 0,380 & 0,366 & 0,367 & 0,387 & 0,369 & 0,398 & 0,383 & 0,387 \\
\hline 36 & 0,395 & 0,387 & 0,375 & 0,360 & 0,362 & 0,379 & 0,364 & 0,390 & 0,376 & 0,379 \\
\hline 48 & 0,389 & 0,381 & 0,369 & 0,355 & 0,357 & 0,372 & 0,358 & 0,382 & 0,370 & 0,371 \\
\hline 60 & 0,386 & 0,379 & 0,366 & 0,352 & 0,354 & 0,368 & 0,355 & 0,377 & 0,366 & 0,367 \\
\hline 72 & 0,384 & 0,376 & 0,364 & 0,350 & 0,352 & 0,364 & 0,353 & 0,374 & 0,363 & 0,363 \\
\hline 84 & 0,383 & 0,374 & 0,363 & 0,348 & 0,350 & 0,362 & 0,351 & 0,372 & 0,361 & 0,360 \\
\hline 96 & 0,380 & 0,371 & 0,361 & 0,347 & 0,349 & 0,360 & 0,350 & 0,369 & 0,358 & 0,358 \\
\hline 144 & 0,373 & 0,365 & 0,355 & 0,340 & 0,343 & 0,352 & 0,343 & 0,362 & 0,350 & 0,350 \\
\hline 192 & 0,369 & 0,360 & 0,351 & 0,336 & 0,340 & 0,346 & 0,339 & 0,356 & 0,344 & 0,345 \\
\hline 240 & 0,365 & 0,357 & 0,349 & 0,333 & 0,337 & 0,341 & 0,335 & 0,353 & 0,340 & 0,341 \\
\hline 360 & 0,359 & 0,351 & 0,344 & 0,327 & 0,333 & 0,334 & 0,330 & 0,345 & 0,334 & 0,333 \\
\hline 480 & 0,356 & 0,348 & 0,341 & 0,325 & 0,330 & 0,332 & 0,328 & 0,343 & 0,330 & 0,329 \\
\hline 720 & 0,348 & 0,340 & 0,336 & 0,319 & 0,324 & 0,323 & 0,321 & 0,333 & 0,322 & 0,320 \\
\hline PMP & 0,269 & 0,274 & 0,292 & 0,278 & 0,277 & 0,271 & 0,258 & 0,262 & 0,247 & 0,266 \\
\hline \multirow{2}{*}{$\begin{array}{c}\text { Irrigado } \\
\text { (h) }\end{array}$} & \multicolumn{10}{|c|}{$\theta\left(m^{3} m^{-3}\right)$} \\
\hline & 0,1 & 0,2 & 0,3 & 0,4 & 0,5 & 0,6 & 0,7 & 0,8 & 0,9 & 1 \\
\hline$\theta s$ & 0,495 & 0,530 & 0,530 & 0,565 & 0,590 & 0,580 & 0,630 & 0,630 & 0,620 & 0,630 \\
\hline 12 & 0,455 & 0,425 & 0,457 & 0,459 & 0,430 & 0,424 & 0,415 & 0,428 & 0,439 & 0,455 \\
\hline 24 & 0,446 & 0,412 & 0,444 & 0,443 & 0,412 & 0,410 & 0,397 & 0,410 & 0,411 & 0,430 \\
\hline 36 & 0,442 & 0,406 & 0,439 & 0,436 & 0,408 & 0,404 & 0,388 & 0,404 & 0,402 & 0,419 \\
\hline 48 & 0,43̦8 & 0,403 & 0,434 & 0,431 & 0,402 & 0,398 & 0,382 & 0,398 & 0,396 & 0,410 \\
\hline 60 & 0,436 & 0,401 & 0,432 & 0,428 & 0,399 & 0,396 & 0,379 & 0,395 & 0,391 & 0,406 \\
\hline 72 & 0,434 & 0,397 & 0,429 & 0,424 & 0,395 & 0,393 & 0,374 & 0,391 & 0,387 & 0,402 \\
\hline 84 & 0,431 & 0,396 & 0,427 & 0,421 & 0,392 & 0,390 & 0,371 & 0,388 & 0,384 & 0,398 \\
\hline 96 & 0,430 & 0,394 & 0,425 & 0,419 & 0,391 & 0,388 & 0,369 & 0,386 & 0,382 & 0,394 \\
\hline 144 & 0,425 & 0,390 & 0,420 & 0,413 & 0,384 & 0,382 & 0,362 & 0,379 & 0,372 & 0,387 \\
\hline 192 & 0,421 & 0,387 & 0,416 & 0,408 & 0,379 & 0,378 & 0,357 & 0,375 & 0,366 & 0,379 \\
\hline 240 & 0,418 & 0,384 & 0,413 & 0,405 & 0,375 & 0,375 & 0,353 & 0,371 & 0,361 & 0,375 \\
\hline 360 & 0,411 & 0,379 & 0,408 & 0,397 & 0,368 & 0,369 & 0,345 & 0,364 & 0,353 & 0,366 \\
\hline 480 & 0,407 & 0,376 & 0,405 & 0,393 & 0,364 & 0,366 & 0,341 & 0,360 & 0,348 & 0,360 \\
\hline 720 & 0,402 & 0,371 & 0,400 & 0,386 & 0,357 & 0,360 & 0,335 & 0,353 & 0,341 & 0,353 \\
\hline PMP & 0,320 & 0,307 & 0,322 & 0,294 & 0,273 & 0,282 & 0,272 & 0,275 & 0,266 & 0,280 \\
\hline
\end{tabular}


Apêndice 3.4 -Variação da armazenagem da água $(\mathrm{mm})$ no solo sob três manejos considerando-se diferentes camadas(profundidades)

\begin{tabular}{|c|c|c|c|c|c|c|}
\hline Prof. & Mata & Sequeiro & Irrigado & Mata & Sequeiro & Irrigado \\
\hline$(m)$ & \multicolumn{3}{|c|}{12 horas } & \multicolumn{3}{|c|}{24 horas } \\
\hline 0.15 & $\overline{15.2}$ & 23,6 & $\overline{19,3}$ & $12, \overline{1}$ & $-\overline{21}, \overline{2}$ & $17, \overline{3}$ \\
\hline 0,25 & 28,0 & 36,8 & 31,1 & 23,3 & 33,1 & 27,8 \\
\hline 0,45 & 52,4 & 56,6 & 61,1 & 44,2 & 50,7 & 54,8 \\
\hline 0,65 & 83,3 & 79,8 & 91,0 & 70,1 & 71,3 & 81,5 \\
\hline 0,85 & 115,2 & 107,4 & 120,6 & 97,3 & 96,0 & 107,6 \\
\hline \multirow[t]{2}{*}{1,00} & 142,0 & 129,6 & 146,7 & 120,2 & 115,7 & 129,6 \\
\hline & \multicolumn{3}{|c|}{36 horas } & \multicolumn{3}{|c|}{48 horas } \\
\hline 0,15 & 10,6 & 20,3 & 16,4 & 9,7 & $\overline{19}, \overline{2}$ & $15, \overline{7}$ \\
\hline 0,25 & 21,3 & 31,6 & 26,3 & 19,6 & 29,9 & 25,2 \\
\hline 0,45 & 40,8 & 48,2 & 52,2 & 37,6 & 45,3 & 50,1 \\
\hline 0,65 & 64,3 & 67,5 & 77,8 & 58,9 & 63,4 & 74,6 \\
\hline 0,85 & 89,9 & 90,9 & 102,3 & 82,7 & 85,4 & 98,0 \\
\hline \multirow[t]{2}{*}{1,00} & 111,4 & 109,4 & 122,9 & 102,5 & 102,9 & 117,5 \\
\hline & \multicolumn{3}{|c|}{60 horas } & \multicolumn{3}{|c|}{ 는 horas } \\
\hline 0,15 & 9,2 & 18,7 & $15, \overline{3}$ & $\overline{8}, \overline{6}$ & 18,3 & $14, \overline{9}$ \\
\hline 0,25 & 18,7 & 29,2 & 24,6 & 17,7 & 28,5 & 23,9 \\
\hline 0,45 & 35,9 & 44,0 & 49,0 & 34,1 & 42,9 & 47,6 \\
\hline 0,65 & 56,1 & 61,4 & 72,9 & 53,4 & 59,8 & 70,8 \\
\hline 0,85 & 78,9 & 82,7 & 95,6 & 75,3 & 80,5 & 92,8 \\
\hline \multirow[t]{2}{*}{1,00} & 97,8 & 99,6 & 114,4 & 93,3 & 96,9 & 110,9 \\
\hline & \multicolumn{3}{|c|}{84 horas } & \multicolumn{3}{|c|}{96 horas } \\
\hline 0,15 & 8,3 & 18,0 & 14,5 & $7, \overline{8}$ & 17,6 & $1 \overline{4}, \overline{2}$ \\
\hline 0,25 & 17,3 & 28,0 & 23,3 & 16,6 & 27,3 & 22,9 \\
\hline 0,45 & 33,2 & 42,1 & 46,5 & 32,0 & 41,1 & 45,8 \\
\hline 0,65 & 52,1 & 58,6 & 69,2 & 50,1 & 57,2 & 68,1 \\
\hline 0,85 & 73,6 & 78,9 & 90,5 & 71,0 & 77,1 & 89,0 \\
\hline \multirow[t]{2}{*}{1,00} & 91,3 & 94,9 & 108,2 & 88,1 & 92,7 & 106,3 \\
\hline & \multicolumn{3}{|c|}{144 horas } & \multicolumn{3}{|c|}{192 horas } \\
\hline 0,15 & 6,9 & 16,2 & 13,4 & $6, \overline{2}$ & 15,5 & $12, \overline{8}$ \\
\hline 0,25 & 15,0 & 25,3 & 21,7 & 13,7 & 24,2 & 20,7 \\
\hline 0.45 & 28,8 & 37,9 & 43,4 & 26,3 & 36,0 & 41,7 \\
\hline 0,65 & 45,2 & 52,6 & 64,4 & 41,5 & 49,8 & 61,8 \\
\hline 0,85 & 64,6 & 71,2 & 83,9 & 59,5 & 67,3 & 80,3 \\
\hline \multirow[t]{2}{*}{1,00} & 79,9 & 85,6 & 99,8 & 73,6 & 81,0 & 95,3 \\
\hline & \multicolumn{3}{|c|}{240 horas } & \multicolumn{3}{|c|}{360 horas } \\
\hline 0,15 & 5,7 & 14,9 & 12,3 & $\overline{4}, \overline{9}$ & 13,9 & $11, \overline{3}$ \\
\hline 0,25 & 12,8 & 23,2 & 19,9 & 11,2 & 21,5 & 18,5 \\
\hline 0,45 & 24,5 & 34,4 & 40,2 & 21,6 & 31,7 & 37,4 \\
\hline 0,65 & 38,6 & 47,4 & 59,6 & 34,3 & 43,6 & 55,5 \\
\hline 0,85 & 55,8 & 64,3 & 77,3 & 50,2 & 59,2 & 71,8 \\
\hline \multirow[t]{2}{*}{1,00} & 69,0 & 77,3 & 91,5 & 62,6 & 71,2 & 84,8 \\
\hline & \multicolumn{3}{|c|}{480 horas } & \multicolumn{3}{|c|}{720 horas } \\
\hline 0,15 & 4,3 & 13,3 & 10,8 & $3, \overline{4}$ & 12,0 & $10, \overline{1}$ \\
\hline 0,25 & 10,2 & 20,7 & 17,7 & 8,3 & 18,7 & 16,5 \\
\hline 0,45 & 19,6 & 30,4 & 35,9 & 16,0 & 27,1 & 33,6 \\
\hline 0,65 & 31,5 & 41,8 & 53,3 & 26,1 & 37,0 & 49,8 \\
\hline 0,85 & 46,5 & 56,9 & 68,8 & 39,2 & 50,5 & 63,9 \\
\hline 1,00 & 58,0 & 68,4 & 81,0 & 49,1 & 60,7 & 75,0 \\
\hline
\end{tabular}




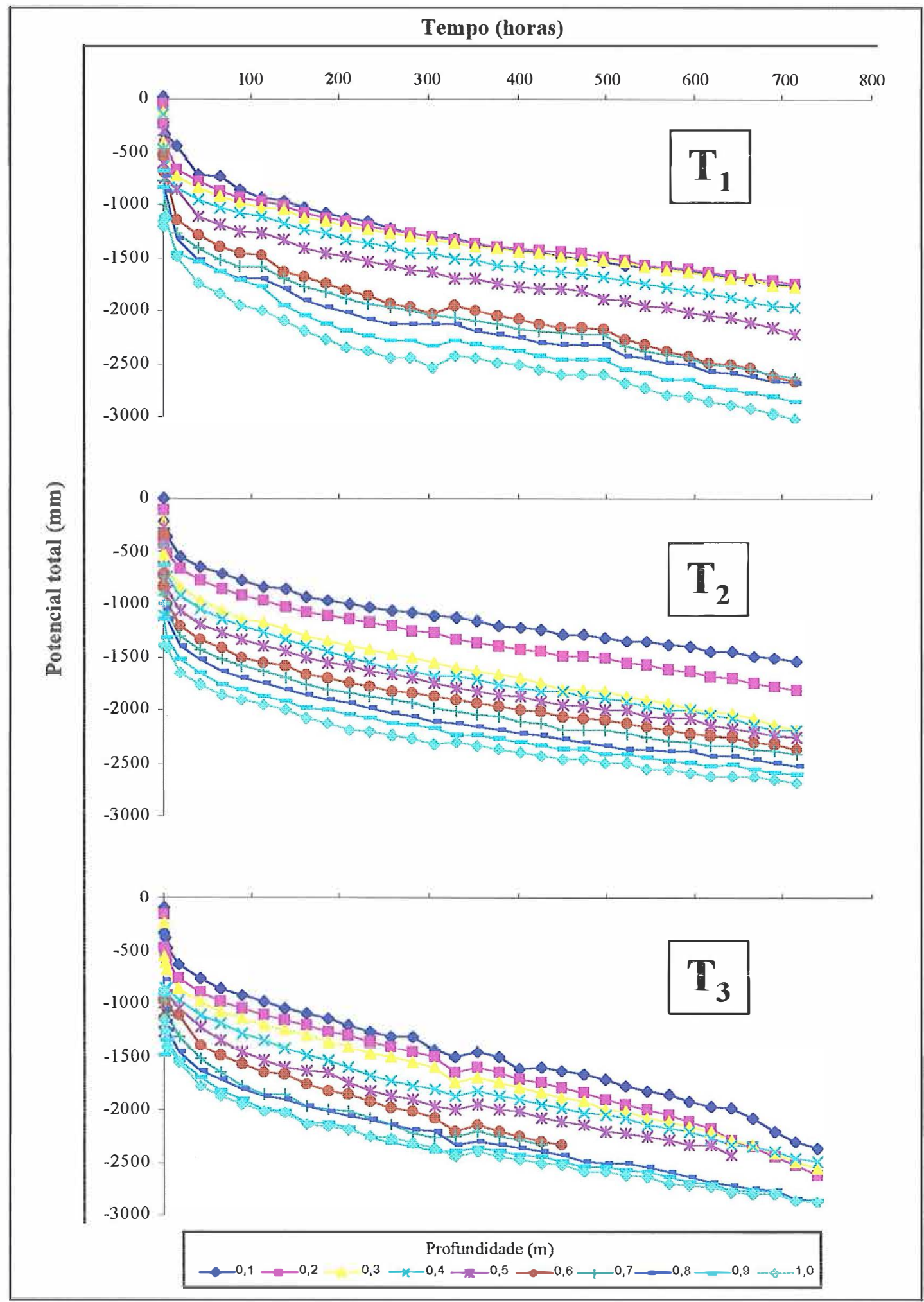

Apêndice 3.5 - Potencial total em função do tempo de drenagem da água no solo para as três repetições do solo da mata nas 10 profundidades. 


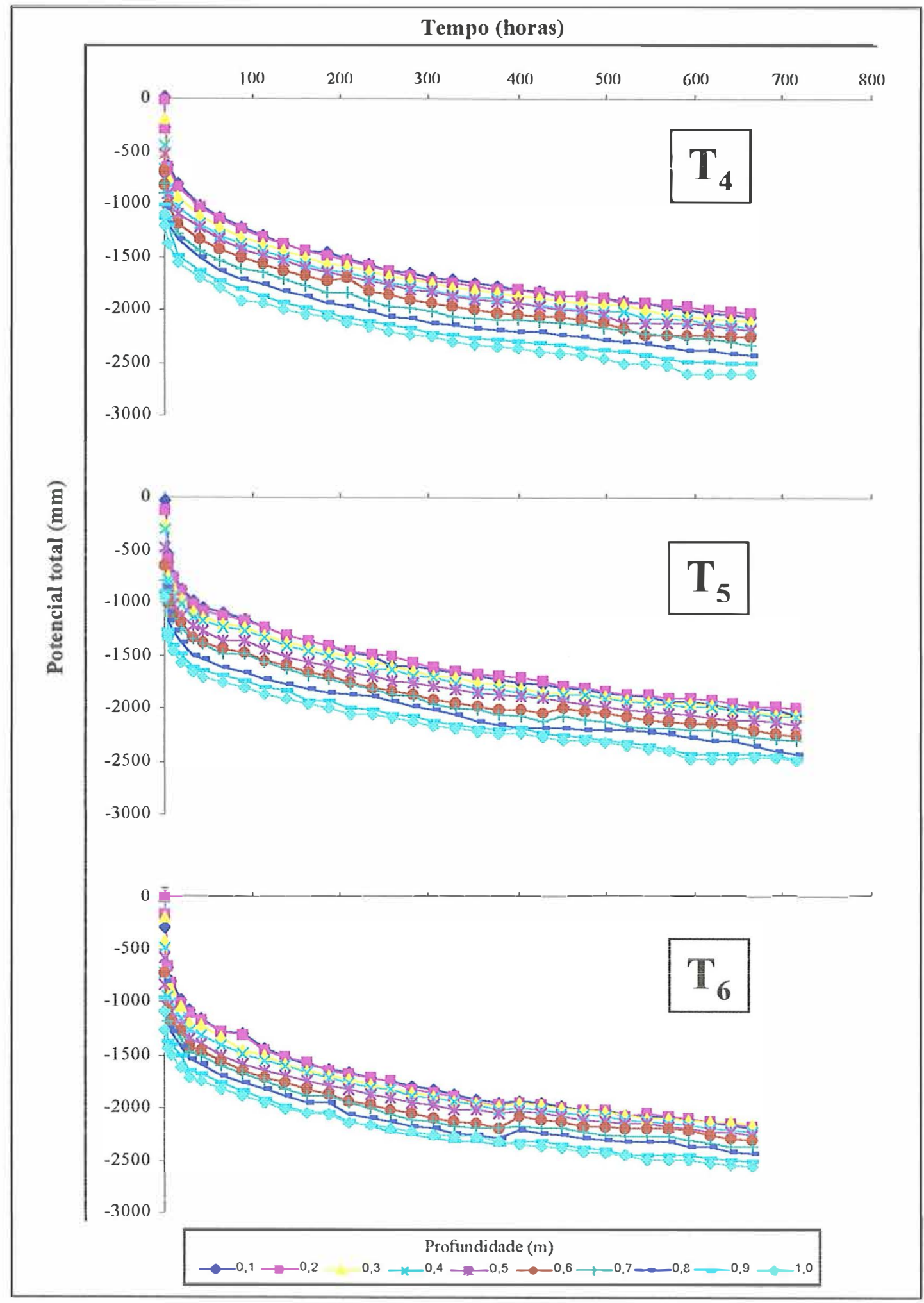

Apêndice 3.6 - Potencial total em função do tempo de drenagem da água no solo para as três repetições do solo da sequeiro nas 10 profundidades. 


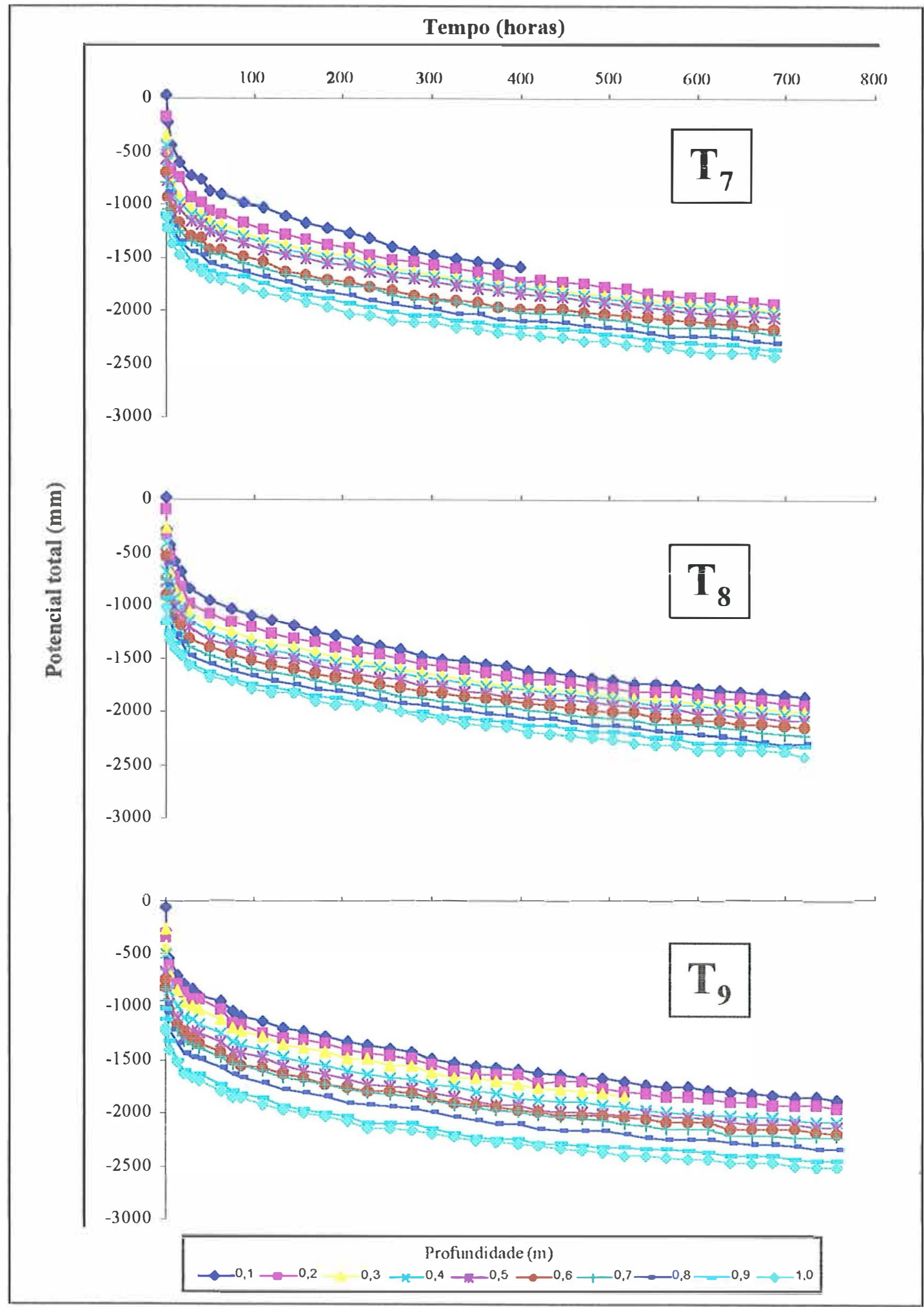

Apêndice 3.7 - Potencial total em função do tempo de drenagem da água no solo para as três repetições do solo da irrigado nas 10 profundidades. 

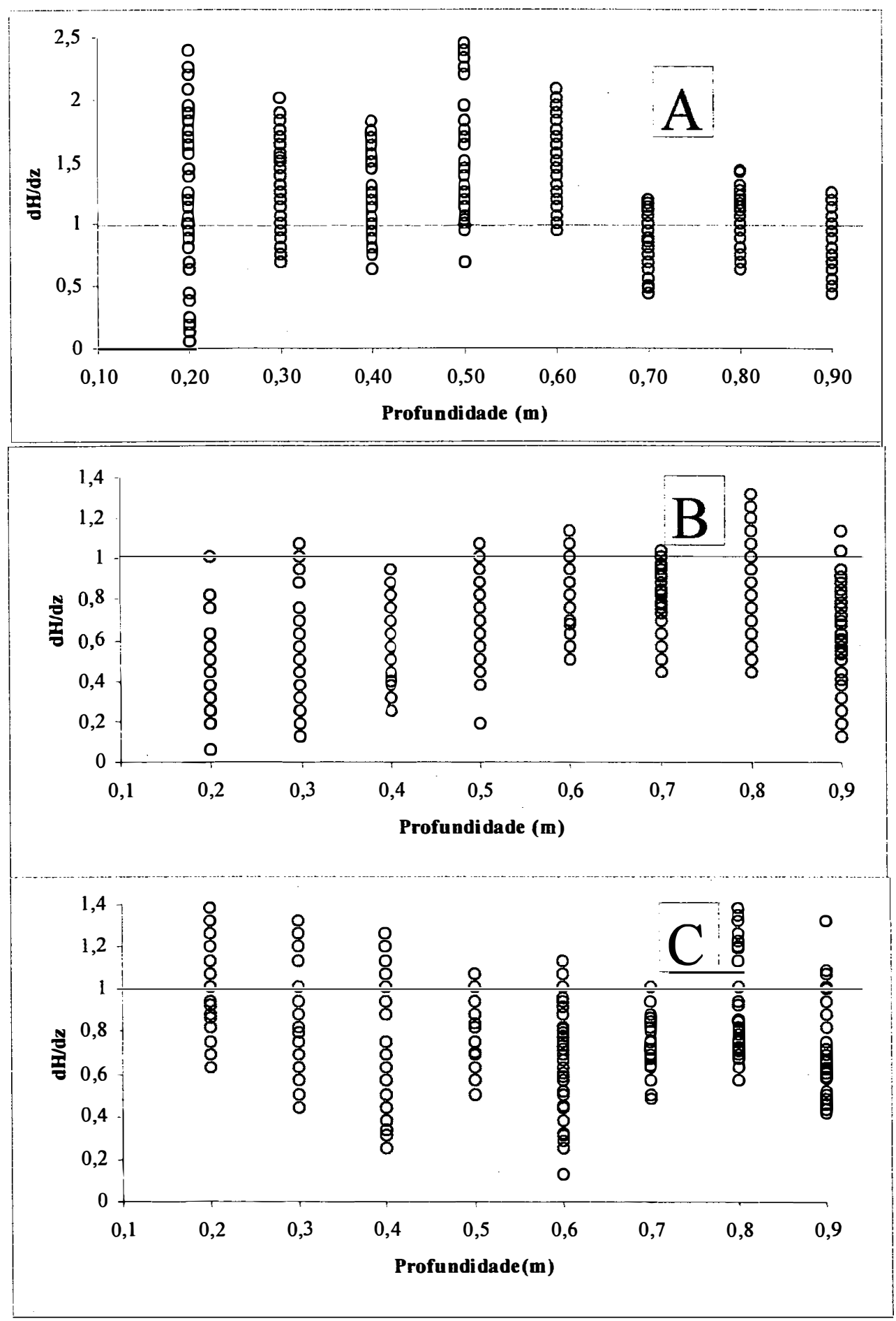

Apêndice 3.8 - Variação do gradiente de potencial total para as diferentes profundidades e manejos mata (A), sequeiro (B) e irrigado (C). 